Aus der Klinik für Mund-, Kiefer- und Gesichtschirurgie

(Prof. Dr. med. Dr. med. dent. H. Schliephake)

im Zentrum Zahn-, Mund- und Kieferheilkunde

der Medizinischen Fakultät der Universität Göttingen

\title{
Analyse der Genexpression \\ von humanen Stro-1-positiven Zahnkeim- und Beckenkammzellen in DME-Medium und osteogenem Differenzierungsmedium
}

\author{
INAUGURAL - DISSERTATION \\ zur Erlangung des Doktorgrades \\ für Zahnmedizin \\ der Medizinischen Fakultät der \\ Georg-August-Universität zu Göttingen
}

vorgelegt von

Charlotte Caroline Merten

aus

Göttingen

Göttingen 2019 
Dekan:

Referent/in:

Ko-Referent/in:

Drittreferent/in:

Datum der mündlichen Prüfung: $\quad$ 25.08.2020
Prof. Dr. med. W. Brück

Prof. Dr. med. Dr. med. dent. K. G. Wiese Prof. Dr. rer. nat. T. Beißbarth

Prof. Dr. med. M. Oppermann 
Hiermit erkläre ich, die Dissertation mit dem Titel „Analyse der Genexpression von humanen Stro-1-positiven Zahnkeim- und Beckenkammzellen in DME-Medium und osteogenem Differenzierungsmedium“ eigenständig angefertigt und keine anderen als die von mir angegebenen Quellen und Hilfsmittel verwendet zu haben.

Göttingen, den

(Unterschrift) 


\section{Inhaltsverzeichnis}

Abbildungsverzeichnis............................................................................................................ III

Tabellenverzeichnis ............................................................................................................ V

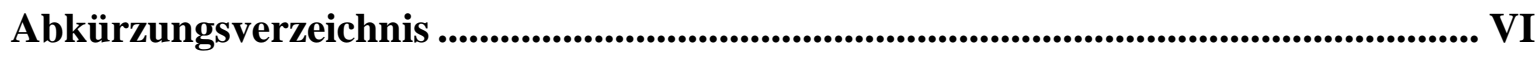

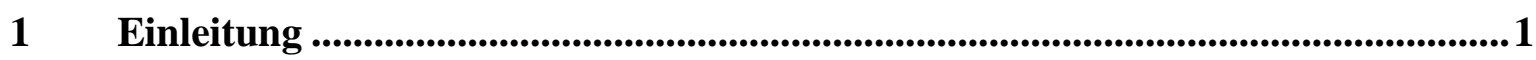

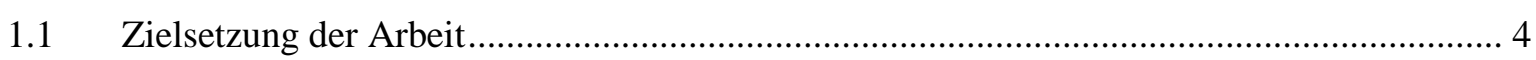

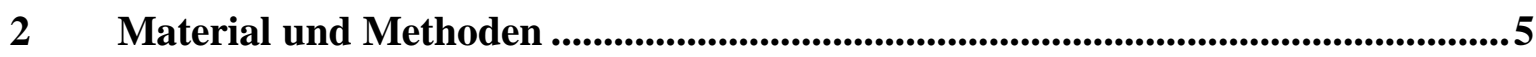

2.1 Entnahme der Proben und Anlegen der Zellkulturen...................................................... 5

2.2 Auszählung der Zellen und Sortierung mittels Magnet-Beads (MACS)............................... 7

2.3 RNA-Isolierung aus Stro-1-positiven Zahnkeim- und Beckenkammzellen.......................... 10

$2.4 \quad$ RNA-Amplifikation und Herstellung der Microarrays ........................................................ 11

2.5 Analyse der Microarray-Daten und statistische Auswertung............................................ 11

2.5.1 Vorgehensweise zur Identifikation differentieller Genexpressionen .................................. 13

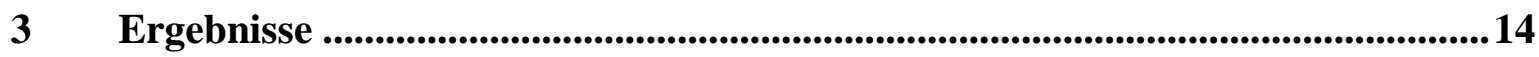

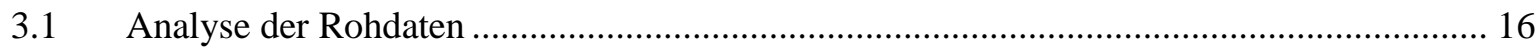

3.2 Der Einfluss der Medien auf die Genexpression.............................................................. 19

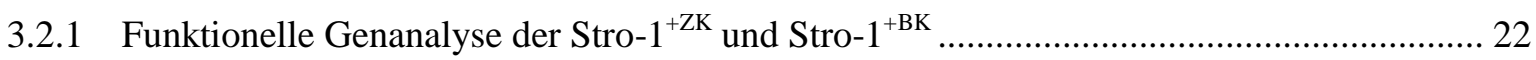

3.2.2 Genexpression der Stro- $1^{+Z K}$ im osteogenen und DME-Medium .................................... 25

3.2.3 Genexpression der Stro- $1^{+\mathrm{BK}}$ im osteogenen und DME-Medium ....................................... 26

3.3 Differentielle Genexpression der Stro- $1^{+\mathrm{ZK}}$ und Stro- $1^{+\mathrm{BK}}$ in den Medien......................... 27

3.3.1 Funktionelle Analyse der Gene mit einseitig signifikanten logFC-Werten ........................ 28

3.3.1.1 Gene mit signifikanten $\log \mathrm{FC}-$ Werten bei den Stro- $1^{+\mathrm{BK}}$ und nicht signifikanten logFC-

Werten bei den Stro- $1^{+\mathrm{ZK}}$

3.3.1.2 Gene mit signifikanten $\log \mathrm{FC}-$ Werten bei den Stro- ${ }^{+\mathrm{ZK}}$ und nicht signifikanten logFC-

Werten bei den Stro- $1^{+\mathrm{BK}}$

3.3.2 Funktionelle Analyse der Gene mit beidseitig signifikanten logFC-Werten

3.4 Funktionelle Unterschiede der Stro- $1^{+\mathrm{ZK}}$ und Stro- $1^{+\mathrm{BK}}$ im osteogenen Medium ................. 43 


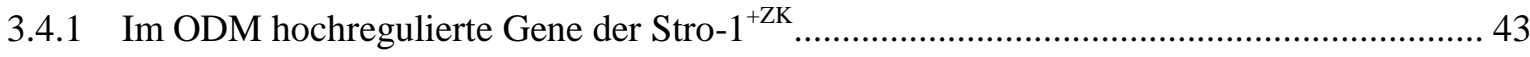

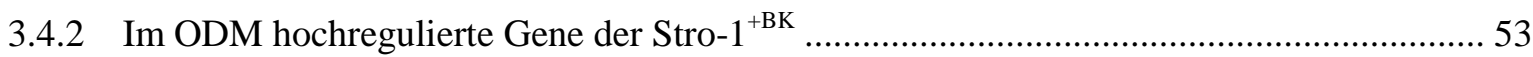

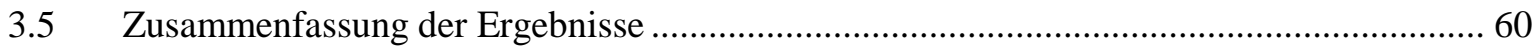

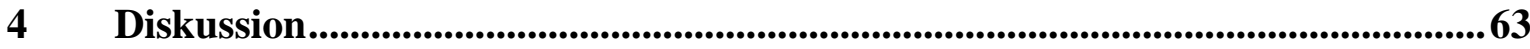

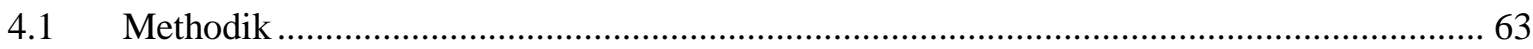

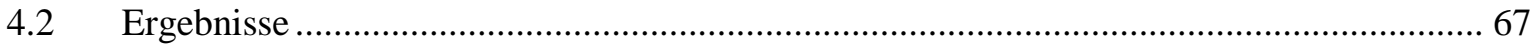

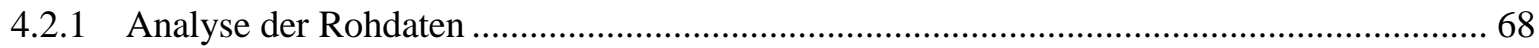

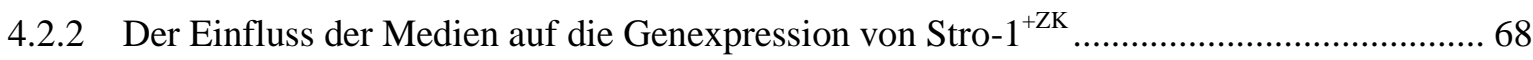

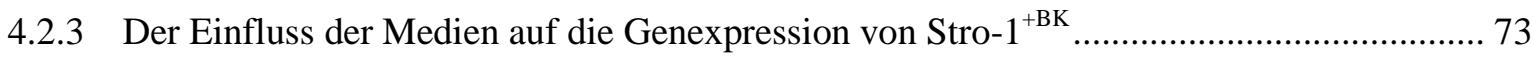

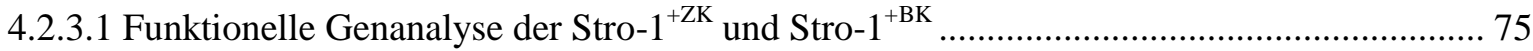

4.2.4 Differentielle Genexpression der Stro- $1^{+\mathrm{ZK}}$ und Stro- $1^{+\mathrm{BK}}$ in den Medien...................... 76

4.2.5 Differentialexpression der Gene von Stro- $1^{+\mathrm{ZK}}$ und Stro- $1^{+\mathrm{BK}}$ im osteogenen Medium und ihre biologisch-funktionellen Gruppen ........................................................... 78

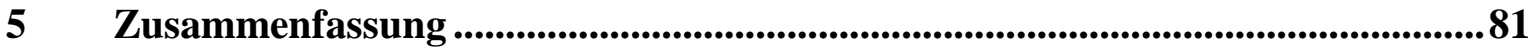

$6 \quad$ Anhang $6 . \ldots \ldots \ldots \ldots \ldots \ldots \ldots \ldots \ldots \ldots \ldots \ldots \ldots \ldots \ldots \ldots \ldots \ldots \ldots \ldots \ldots \ldots \ldots \ldots \ldots \ldots \ldots \ldots \ldots \ldots \ldots \ldots \ldots \ldots \ldots \ldots \ldots \ldots \ldots \ldots \ldots \ldots . \ldots . \ldots \ldots 4$

$7 \quad$ Literaturverzeichnis ...................................................................................................... 122 


\section{Abbildungsverzeichnis}

Abbildung 1: Schematische Darstellung des Versuchsablaufs zur Zellkultivierung 7

Abbildung 2: Funktionsweise des CASY Cell Counter ............................................................... 8

Abbildung 3: Schematische Darstellung der magnetischen Zellsortierung (MACS) ........................ 8

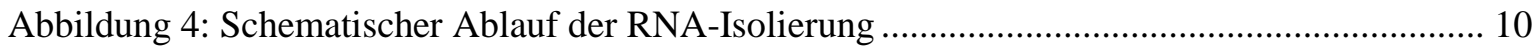

Abbildung 5: Schematische Darstellung der statistischen Auswertung der Array-Daten................ 12

Abbildung 6: Histologische Aufarbeitung der extrahierten Zahnkeime .......................................... 15

Abbildung 7: Histogramme der logFC-Intensitätsverteilung der Genexpression ............................ 18

Abbildung 8: Korrelation der $\log \mathrm{FC}-$ Werte identischer Gene der Stro- $1^{+\mathrm{ZK}}$ und Stro- $1^{+\mathrm{BK}} \ldots \ldots \ldots . . .27$

Abbildung 9: Korrelation der $\log \mathrm{FC}-$ Werte einseitig signifikanter Gene ......................................... 29

Abbildung 10: Heatmap der für die Angiogenese erkannten Gene der funktionellen Untergruppen

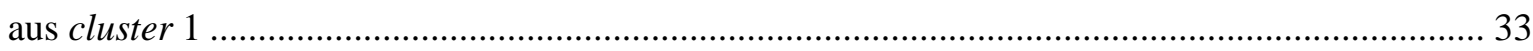

Abbildung 11: Korrelation der $\log \mathrm{FC}-$ Werte beidseitig signifikanter Gene .................................... 35

Abbildung 12: Heatmap der Gene der funktionellen Untergruppen aus cluster 1 der gleichsinnig signifikant heraufregulierten Gene von Stro- $1^{+\mathrm{ZK}}$ und Stro- $1^{+\mathrm{BK}}$

Abbildung 13: Heatmap der Gene der funktionellen Untergruppen aus cluster 2 der gleichsinnig signifikant heraufregulierten Gene von Stro- $1^{+\mathrm{ZK}}$ und Stro- $1^{+\mathrm{BK}}$

Abbildung 14: Heatmap der Gene der funktionellen Untergruppen aus cluster 15 der gleichsinnig signifikant heraufregulierten Gene von Stro- $1^{+\mathrm{ZK}}$ und Stro- $1^{+\mathrm{BK}}$

Abbildung 15: Heatmap der Gene der funktionellen Untergruppen aus cluster 1 der gleichsinnig signifikant herunterregulierten Gene von Stro- $1^{+\mathrm{ZK}}$ und Stro- $1^{+\mathrm{BK}}$

Abbildung 16: Heatmap der gegensinnig exprimierten Gene mit den zugehörigen funktionellen Untergruppen

Abbildung 17: Limitierte Darstellung einiger hochregulierter Gene aus cluster 1 der Stro- $1^{+Z K}$ im ODM

Abbildung 18: Limitierte Darstellung einiger hochregulierter Gene aus cluster 2 der Stro- ${ }^{+\mathrm{ZK}}$ im ODM

Abbildung 19: Heatmap der hochregulierten Gene aus cluster 3 der Stro- $1^{+Z K}$ im ODM 49

Abbildung 20: Darstellung einiger hochregulierter Gene aus cluster 126 der Stro- $1^{+Z K}$ im ODM.. 50 
Abbildung 21: Darstellung einiger hochregulierter Gene für Transkriptionsfaktoren aus cluster 54 der Stro-1 ${ }^{+Z K}$ im ODM

Abbildung 22: Darstellung einiger hochregulierter Gene aus cluster 85 der Stro- ${ }^{+Z K}$ im ODM.... 52

Abbildung 23: Limitierte Darstellung einiger hochregulierter Homeobox-Gene aus cluster 2 der Stro- $1^{+\mathrm{BK}}$ im ODM

Abbildung 24: Heatmap der hochregulierten Gene aus cluster 72 der Stro- $1^{+\mathrm{BK}}$ im ODM 57

Abbildung 25: Heatmap der hochregulierten Gene für Transkriptionsfaktoren aus cluster 163 der

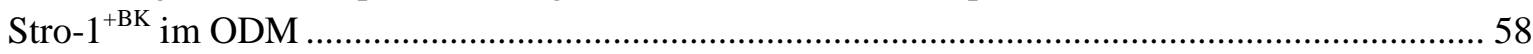

Abbildung 26: Heatmap der überexprimierten Gene des Zellzyklus aus cluster 174 der Stro- $1^{+\mathrm{BK}}$ im ODM 


\section{Tabellenverzeichnis}

Tabelle 1: Anzahl $\mathrm{n}$ der auf die FDR bezogenen statistisch signifikant exprimierten Gene 16

Tabelle 2: Anzahl $\mathrm{n}$ der hochregulierten und herunterregulierten Gene im ODM gegenüber dem DMEM je FDR-Wert

Tabelle 3: Darstellung der ersten zehn im ODM gegenüber dem DMEM höchst signifikant hochbzw. herunterregulierten Gene der Stro- $1^{+\mathrm{ZK}}$ und Stro- $1^{+\mathrm{BK}}$

Tabelle 4a: Die ersten zehn im ODM signifikant hochregulierten funktionellen Gruppen der Stro- $1^{+\mathrm{ZK}}$

Tabelle 4b: Die ersten zehn im ODM signifikant herunterregulierten funktionellen Gruppen der Stro- $1^{+\mathrm{ZK}}$

Tabelle 5a: Die ersten zehn im ODM signifikant hochregulierten funktionellen Gruppen der Stro- $1^{+\mathrm{BK}}$

Tabelle 5b: Die ersten zehn im ODM signifikant herunterregulierten funktionellen Gruppen der Stro- $1^{+\mathrm{BK}}$

Tabelle 6: Funktionelle Gruppen der Gene, die bei den Stro- ${ }^{+\mathrm{BK}}$ einseitig signifikant hochreguliert sind.

Tabelle 7: Funktionelle Gruppen der Gene, die bei den Stro- $1^{+\mathrm{BK}}$ einseitig signifikant herunterreguliert sind

Tabelle 8: Identische Gene, die in den Stro- $1^{+\mathrm{BK}}$ signifikant herauf- und in den Stro- $1^{+\mathrm{ZK}}$ herunterreguliert sind

Tabelle 9: Identische Gene, die in den Stro- $1^{+\mathrm{BK}}$ signifikant herunter- und in den Stro- ${ }^{+\mathrm{ZK}}$ heraufreguliert sind

Tabelle 10: Die ersten zehn im ODM bei den Stro- ${ }^{+Z K}$ signifikant hochregulierten funktionellen Gruppen.

Tabelle 11: Homeobox-Gene, die bei den Stro- $1^{+Z K}$ im ODM für den GO-term organ morphogenesis hochreguliert sind.

Tabelle 12: Die ersten fünf signifikant hochregulierten Gen-Cluster der Stro- $1^{+Z K}$ im ODM......... 46

Tabelle 13: Die ersten zehn im ODM bei den Stro- $1^{+\mathrm{BK}}$ signifikant hochregulierten funktionellen Gruppen....

Tabelle 14: Homeobox-Gene, die bei den Stro- $1^{+\mathrm{BK}}$ im ODM für den GO-term skeletal system development hochreguliert sind.

Tabelle 15: Die ersten drei signifikant hochregulierten Gen-Cluster der Stro- $1^{+\mathrm{BK}}$ im ODM 55 


\section{Abkürzungsverzeichnis}

\begin{tabular}{|c|c|}
\hline ALP & alkalische Phosphatase \\
\hline ANOVA & analysis of variance \\
\hline$A O X 1$ & aldehyde oxidase 1 \\
\hline $\mathrm{BK}$ & Stro-1-positive humane Knochenmarkstammzellen aus dem Beckenkamm \\
\hline BK1 & Stro-1-positive Beckenkammzellen im DME-Medium \\
\hline BK2 & Stro-1-positive Beckenkammzellen im osteogenen Differenzierungsmedium \\
\hline BMD & bone mineral density \\
\hline$B M P-1 / 2 / 4 / 6 / 7$ & bone morphogenetic protein $1 / 2 / 4 / 6 / 7$ \\
\hline BMSCs & bone marrow-derived mesenchymal stem cells \\
\hline $\mathrm{BP}$ & biological process \\
\hline $\mathrm{Ca}^{++}$ & ionisiertes Calcium \\
\hline cAMP & cyclisches Adenosinmonophosphat \\
\hline $\mathrm{CD}$ & cluster of differentiation \\
\hline cDNA & Copy-Desoxyribonukleinsäure \\
\hline COL4-A1/2/5 & Kollagen Typ IV alpha 1/2/5 \\
\hline COL6A2 & Kollagen Typ VI alpha 2 \\
\hline COL10A1 & Kollagen Typ X alpha 1 \\
\hline COL11A1 & Kollagen Typ XI alpha 1 \\
\hline COL12A1 & Kollagen Typ XII alpha 1 \\
\hline COL13A1 & Kollagen Typ XIII alpha 1 \\
\hline COL18A1 & Kollagen Typ XVIII alpha 1 \\
\hline CREB & cAMP response element-binding protein \\
\hline cRNA & Copy-Ribonukleinsäure \\
\hline CRP & C-reaktives Protein \\
\hline $\mathrm{Cy} 3$ & cyanine 3 \\
\hline DAVID & database for annotation, visualization and integrated discovery \\
\hline$D C N$ & decorin \\
\hline DDIT4 & DNA-damage-inducible transcript 4; syn. REDD1 \\
\hline DEPC & Diethylpyrocarbonat \\
\hline DFPCs & dental follicle progenitor cells \\
\hline$D L X 1$ & distal-less homeobox 1 \\
\hline DMEM & Dulbecco's Modified Eagle Medium \\
\hline DNA & Desoxyribonukleinsäure \\
\hline DNase & Desoxyribonuklease \\
\hline DPSCs & dental pulp stem cells \\
\hline
\end{tabular}


E. coli

EEF1A2

EGFR

EMT

ES

EZM

FACS

FDR

FGF-2

FK506

FKBP5

FKS

FLG

FOXF-1/2

FRZB

FST

G-Protein

GO

GPR68

GREMI

HOX-Gen

HOXB2

НОХВ3

HOXC8

$I G F-1 / 2$

IGFBP-2/3/5

IL-1 $\beta$

IL-6

IMPA2

IR

IVT

$\log \mathrm{FC}$

$\log _{2}$ (DMEM)

$\log _{2}(\mathrm{I})$

$\log _{2}(\mathrm{ODM})$

LPAR5

MACS
Escherichia coli

eukaryotic translation elongation factor 1 alpha 2

epidermal growth factor receptor

epithelial-mesenchymale Transition

enrichment score

extrazelluläre Matrix

fluorescence-activated cell-sorting

false discovery rate

fibroblast growth factor 2

Tacrolimus

FK506 binding protein 5

fetales Kälberserum

filaggrin

forkhead box F1 oder F2

frizzled-related protein

follistatin

Guanosintriphosphat-bindendes Protein

Gene Ontology

G protein-coupled receptor 68

gremlin 1

Homeobox-Gen

homeobox $B 2$

homeobox B3

homeobox $C 8$

insulin-like growth factor $1 / 2$

insulin-like growth factor-binding protein 2/3/5

interleukin-1 beta

interleukin-6

inositol(myo)-1(or4)-monophosphatase 2

Insulinrezeptor

In-vitro-Transkription

$\log _{2}$ fold change

logarithmierte Intensitätswerte für das DME-Medium

logarithmierte Intensitätswerte

logarithmierte Intensitätswerte für das osteogene Differenzierungsmedium

lysophosphatidic acid receptor 5

magnetic-activated cell-sorting 
MAO

$M A O-A / B$

METTL7A

$M M P-1 / 2 / 14$

mRNA

MSCs

MSX1

mTOR

$\mathrm{NF}-\kappa \mathrm{B}$

NFKBIA

$\mathrm{NH}$

OD

ODM

$P$. aeruginosa

PAR1

PAX9

PBS

PCA

PDLSCs

PEG3

$\mathrm{PGE}_{2}$

PKA

$P O X L$

PRRs

PTGER4

PTN

PTX3

RNA

RT-PCR

SAAI

SCAPs

SHEDs

SIX1

Stro- $1^{+}$

Stro- $1^{+B K}$

Stro- $1^{+\mathrm{ZK}}$

TGF- $\beta$
Monoaminoxidase

monoamine oxidase $A / B$

methyltransferase-like 7A

matrix metallopeptidase 1/2/14

Messenger-Ribonukleinsäure

mesenchymal stem cells

msh homeobox 1

mechanistic target of rapamycin

nuclear factor $\kappa B$

$N F-\kappa B$ inhibitor alpha

nonhematopoietic

optische Dichte

osteogenes Differenzierungsmedium bzw. osteogenes Medium

Pseudomonas aeruginosa

protease-activated receptor 1

paired box 9

phosphate-buffered saline

principal component analysis

periodontal ligament stem cells

paternally expressed gene 3

Prostaglandin $\mathrm{E}_{2}$

Proteinkinase A

podocalyxin-like

pattern recognition receptors

prostaglandin E receptor 4

pleiotrophin

pentraxin 3

Ribonukleinsäure

reverse transcription polymerase chain reaction

serum amyloid Al

stem cells from apical papilla

stem cells from exfoliated deciduous teeth

SIX homeobox 1

stromal cell surface marker 1 positive

Stro-1-positive humane Knochenmarkstammzellen aus dem Beckenkamm

Stro-1-positive humane pulpale Zahnkeimstammzellen

transforming growth factor beta 
TIFF

TIMP4

TNF- $\alpha$

tRNA

UMG

VEGFR2

VMOI

ZK

ZK1

ZK2 tagged image file format

tissue inhibitor of metalloproteinase 4

tumor necrosis factor- $\alpha$

Transfer-Ribonukleinsäure

Universitätsmedizin Göttingen

vascular endothelial growth factor receptor 2

vitelline membrane outer layer 1

Stro-1-positive humane pulpale Zahnkeimstammzellen

Stro-1-positive Zahnkeimzellen im DME-Medium

Stro-1-positive Zahnkeimzellen im osteogenen Differenzierungsmedium 


\section{$1 \quad$ Einleitung}

Der menschliche Organismus weist drei grundlegende Zelltypen auf, die in ihrer Gesamtheit für Entstehen und Fortbestehen jeglicher Lebensfunktion unerlässlich sind. Dabei handelt es sich um Keimzellen (germ cells), Körperzellen (somatic cells) sowie Stammzellen (stem cells). Als Stammzellen bezeichnet man eine Gruppe undifferenzierter Zellen, denen die Möglichkeit zur Differenzierung in spezialisierte Zelltypen gegeben ist (Becker et al. 1963, Siminovitch et al. 1963). In Abhängigkeit von ihrem Ursprungsort unterscheidet man embryonale Stammzellen von adulten Stammzellen. Erstere finden sich in Embryonen im Anfangsstadium in der sogenannten Blastozystenphase, letztere lassen sich in verschiedenen Gewebearten des menschlichen Organismus nach Abschluss der Embryonalentwicklung nachweisen. Während embryonale Stammzellen aufgrund ihrer Pluripotenz befähigt sind, sich in alle Keimblätter sowie deren Zelltypen differenzieren zu können, sind adulte Stammzellen nur multipotent und in ihrem Differenzierungsvermögen auf die Zellen des jeweiligen Keimblattes limitiert (Christophersen und Helin 2010, Takahashi und Yamanaka 2006, Thomson et al. 2011).

Die grundsätzliche Aufgabe von Stammzellen adulten Ursprungs besteht in der Aufrechterhaltung sowie Reparatur des Gewebetyps, in dem sie lokalisiert sind. Um diese Funktionen erfüllen zu können, reicht ein eingeschränktes Differenzierungspotential aus. Diese als Multipotenz bezeichnete Eigenschaft adulter Stammzellen ermöglicht die gezielte Erneuerung der entsprechenden Gewebearten. Eine Gruppe bilden hierbei die mesenchymalen Stammzellen (Pittenger et al. 1999, Bennett et al. 1991, Galotto et al. 1994, Kemp et al. 2005). Ihre Existenz konnte in einer Vielzahl von humanen Geweben nachgewiesen werden (Gronthos et al. 2001, Musina et al. 2006, Jiang et al. 2002), wobei der Hauptanteil auf das Knochenmark entfällt (Tuli et al. 2003). Es konnte gezeigt werden, dass mesenchymale Stammzellen nicht nur in der Lage sind, sich gewebsspezifisch zu differenzieren, sondern dass sie unter bestimmten Kultivierungsbedingungen auch Zellen anderer Gewebetypen generieren können (Pittenger et al. 1999).

Diese Eigenschaft hat adulte Stammzellen vermehrt in den Fokus der Stammzellforschung gerückt. Während außerhalb der Europäischen Union die wissenschaftliche Arbeit mit embryonalen Stammzellen vielfach zulässig ist, herrscht sowohl in Deutschland als auch anderen europäischen Ländern Uneinigkeit bezüglich der Forschung an Embryonen (Hepp et al. 2003, Dittrich et al. 2015, Faltus und Storz 2016). Als Quelle pränataler Stammzellen 
dienen der Wissenschaft einerseits überzählige Embryonen aus der künstlichen Befruchtung, andererseits besteht über das sogenannte therapeutische Klonen die Möglichkeit zur In-vitro-Züchtung embryonaler Stammzellen (Schöne-Seifert 2009). Aufgrund des Embryonenschutzgesetzes ist die Gewinnung embryonaler Stammzellen häufig kritisch zu bewerten (Deutsch 1992), während adulte Stammzellen mit Einverständnis des Spenders körpereigen gewonnen werden können. Auf der Suche nach geeigneten Spendergeweben haben in diesem Zusammenhang Stammzellen aus der menschlichen Zahnpulpa an Bedeutung gewonnen.

Die mesenchymalen Stammzellen des Knochenmarks (BMSCs) wurden bereits 1867 erstmals durch den Pathologen Cohnheim beschrieben. Seitdem sind sie Gegenstand zahlreicher Studien gewesen und gelten im Hinblick auf ihre Multipotenz als hinreichend untersucht. Neben dem Knochenmark scheinen auch Zähne ein natürliches Reservoir für adulte mesenchymale Stammzellen darzustellen. Im Zuge der Zahnentwicklung, die pränatal im zweiten Embryonalmonat beginnt, kommt es zum Einwachsen des ektodermalen Mundhöhlenepithels in das darunterliegende Mesenchym. Sowohl aus dem ektodermalen als auch dem mesenchymalen Keimblatt differenzieren sich nachfolgend Zellen, die verschiedene Bestandteile des Zahnes generieren. Der Zahnschmelz im Bereich der Zahnkrone wird von den Ameloblasten produziert, welche dem Ektoderm entstammen. Diese gehen nach Durchbruch des Zahnes verloren und stehen für eine posteruptive Schmelzbildung nicht mehr zur Verfügung. Aus dem mesenchymalen Anteil der Zahnanlage entwickeln sich dagegen Dentin, Zahnhalteapparat und Zahnpulpa. Die Odontoblasten, welche das Dentin bilden, verbleiben im Inneren der Pulpa und können über die gesamte Lebenszeit eines Zahnes Dentin nachbilden. Im Gegensatz zur schmelzummantelten Zahnkrone wird die Zahnwurzel von Wurzelzement umhüllt. Dieser wird von den Zementoblasten gebildet und verhält sich im Hinblick auf seine Regenerationsfähigkeit wie das Dentin (Schiebler und Korf 2007).

Während der Entstehung durchläuft ein Zahn somit verschiedene Stadien und entwickelt sich maßgeblich über Stammzellen zu einem dreidimensionalen Gebilde, die nach Wachstumsabschluss in bestimmten Gewebestrukturen verbleiben. Derartige multipotente Mesenchymzellen konnten in verschiedenen Studien bereits nachgewiesen werden. Neben den innerhalb der Zahnpulpa lokalisierten dental pulp stem cells (DPSCs) (Gronthos et al. 2000) und den aus Milchzahnpulpen extrahierten dental stem cells from exfoliated deciduous teeth (SHEDs) (Miura et al. 2003, Seo et al. 2008) fanden sich drei weitere Stammzelltypen. $\mathrm{Zu}$ diesen gehören die periodontal ligament stem cells (PDLSCs) (Seo et al. 
2004), die dental stem cells from apical papilla (SCAPs) (Sonoyama et al. 2008) sowie die dental follicle progenitor cells (DFPCs) (Morsczeck et al. 2005). Das Stammzellpotential dieser Zellen wurde dabei in unterschiedlichen Versuchen belegt. Einerseits erfolgte eine Detektion der unterschiedlichen Stammzellpopulationen über mesenchymale Stammzellmarker wie CD-(cluster of differentiation)-Moleküle und Stro-1-Antigene (Gronthos et al. 2003, Miura et al. 2004, Seo et al. 2004, Shi und Gronthos 2003). Andererseits konnte ihr Differenzierungsvermögen in vitro und in vivo verifiziert werden. Es zeigte sich, dass dentale Stammzellen die Fähigkeit besitzen, sich unabhängig von ihrem Ursprungsort in unterschiedliche Phänotypen zu differenzieren (Gronthos et al. 2000, Gronthos et al. 2002, D’Aquino et al. 2007, Morsczeck et al. 2005, Takeda et al. 2008, Gümmer 2011).

Als Ausgangsmaterial der oben aufgeführten Untersuchungen dienten hauptsächlich Zähne mit abgeschlossenem Wurzelwachstum. Die auf diese Weise isolierten Zellen dienen dem natürlichen Zahn in erster Linie als „Reservelager“ für etwaige Reparaturvorgänge. Durch entsprechende Zellkultivierung sowie Aufbereitung konnten allerdings bereits zahnähnliche Gebilde bei Mäusen herangezüchtet und erfolgreich implantiert werden (Ikeda et al. 2009, Oshima et al. 2011). Diese aus Stammzellen generierten Zähne waren in ihrem Grundaufbau mit natürlichen Zähnen vergleichbar, wiesen jedoch im Hinblick auf ihre äußere Form eher primitive Strukturen auf. Für das bioengineering anatomisch korrekter Zähne werden demnach mehr Informationen benötigt. Alleine das Vorhandensein von multipotenten dentalen Stammzellen ist nicht ausreichend, um in Zukunft beispielsweise eine dritte Zahngeneration zu generieren. Es werden zusätzlich umfassendere Einblicke in die molekularen Abläufe während der Zahnentwicklung benötigt.

In diesem Zusammenhang wäre eine spezifische Untersuchung von Zahnkeimen besonders sinnvoll. Hierbei handelt es sich um Zähne, bei denen die Ausbildung der Zahnwurzel noch nicht abgeschlossen wurde. Die Zahnentwicklung ist somit noch nicht gänzlich durchlaufen. In einer Studie von Takeda et al. (2008) konnten bereits Stammzellen aus der Pulpa von Zahnkeimen isoliert werden. Anhand der Oberflächenmarker Stro-1, CD271 und CD133 gelang unserer Arbeitsgruppe eine nähere Charakterisierung von Zahnkeimstammzellen (Gümmer 2011). Während das Differenzierungspotential auf zellulärer Ebene in verschiedenen Versuchen anhand der oben genannten Oberflächenepitope aufgezeigt wurde, fehlte bislang eine Charakterisierung der unterschiedlichen Zelltypen auf der Ebene ihrer Genexpressionen. So können z. B. Stro-1-positive Stammzellen aus unterschiedlichen Geweben isoliert werden, die dann das in ihrer Umgebung spezifische Gewebe regenerieren. Anhand von Stro-1-positiven aus Zahnkeimen und Beckenkamm isolierten Zellen 
konnten jüngst unterschiedliche Genexpressionen des gleichen Zelltyps in einer abgeschlossenen Dissertationsarbeit beschrieben werden (Oellerich 2016). Es stellt sich daher die Frage, welcher „Trigger“ Stro-1-positive Zellen veranlasst, unterschiedliche Gene zu exprimieren. Als ein möglicher Trigger könnte eine unterschiedliche Zusammensetzung des extrazellulären Milieus angesehen werden. In einer Zellkultur wäre dies dann ein anderes Kulturmedium.

\subsection{Zielsetzung der Arbeit}

Es war daher das Ziel dieser Arbeit, das Expressionsverhalten von Stro-1-positiven aus Zahnkeimen und Beckenkamm isolierten Zellen in unterschiedlichen Kulturmedien zu charakterisieren.

Es ergeben sich daraus folgende Fragestellungen:

1. Zeigen humane Stro-1-positive Stammzellen aus Zahnkeimen und dem Beckenkamm unterschiedliche Genexpressionsmuster in verschiedenen Kulturmedien (hier DME-Medium und osteogenes Differenzierungsmedium)?

2. Wenn ja, welche Gene werden in der Differentialexpression herauf- oder herunterreguliert? 


\section{Material und Methoden}

Die bei der vorliegenden Untersuchung verwendeten Stammzellen aus humanen Zahnkeimen und dem Beckenkamm wurden von der Abteilung für Mund-, Kiefer- und Gesichtschirurgie der Universitätsmedizin Göttingen (UMG) bereitgestellt.

Die Gewinnung der Zahnkeimstammzellen erfolgte dabei aus den Pulpae zuvor operativ entfernter Zahnkeime, die in retinierter Form oder als überzählige Zähne aus kieferorthopädischen Gründen entnommen werden mussten. Aufgrund ihres zum Zeitpunkt der Entfernung noch nicht abgeschlossenen Wurzelwachstums waren die hierbei anfallenden Germe besonders geeignet für die anschließende Stammzellisolierung. Für die Extraktion der Knochenmarkstammzellen wurden Überreste humaner Beckenkammpräparate verwendet. Diese fielen im Rahmen von Beckenkammtransplantationen im Bereich der rekonstruktiven Gesichtschirurgie an. Da es sich in allen Fällen um menschliche Körpermaterialien handelt, wurden die Patienten bzw. Erziehungsberechtigten im Rahmen einer schriftlichen Einverständniserklärung über die weitere Verwendung für Zwecke der medizinischen Forschung aufgeklärt. Die entsprechenden Dokumente liegen vor. Die Bewilligung der Studie durch die Ethikkommission der UMG erfolgte mit einem positiven Votum am 15/10/01 sowie $31 / 4 / 11$.

Die nachfolgend beschriebene Methodik in den Kapiteln 2.1 bis 2.5 folgt im Wesentlichen dem in der Dissertation von Gümmer (2011) beschriebenen Vorgehen.

\subsection{Entnahme der Proben und Anlegen der Zellkulturen}

Die Aufbereitung der entnommenen Zahnkeime und Beckenkammpräpate erfolgte ebenso wie die anschließende Kultivierung, Auszählung und Sortierung der Zellen in Zusammenarbeit mit dem Zelllabor der Abteilung für Mund-, Kiefer- und Gesichtschirurgie.

Um eine bakterielle und fungizide Verunreinigung der Proben auszuschließen, erfolgten regelmäßige mikroskopische Kontrollen (Mikroskop Carl Zeiss Vision GmbH, Hallbergmoos) vor jedem Wechsel der Nährmedien. Alle durchzuführenden Aufgaben im Zusammenhang mit den Zellkulturen sowie die Herstellung der genutzten Reagenzien wurden unter strikter Einhaltung der Asepsis durchgeführt (Sterilbank Biohazard Cleanair En12469, JA Woerden). Die Zellkultivierung fand unter Beobachtung bei einer konstanten 
Temperatur von $37{ }^{\circ} \mathrm{C}$, einem Kohlenstoffdioxidanteil von $5 \%$ und einer Luftfeuchtigkeit von $95 \%$ im Brutschrank statt (Sanyo Electric Biomedical CO., Ltd, Japan). Aus den gesammelten Zahnkeimen wurde zunächst das pulpale Weichgewebe in toto extrahiert und in kleinere Gewebeproben portioniert. Das Anlegen der Zellkultur erfolgte anschließend in einer mit 15 ml Nährmedium (DMEM, 10 \% FKS, $1 \%$ Penicillin-Streptomycin) gefüllten Petrischale $\left(58 \mathrm{~cm}^{2}\right.$, Sarstedt, Sarstedt AG \& CO, Nümbrecht). Die Aufbereitung der Beckenkammpräparate verlief nach identischem Muster. Nach Einsetzen der Zellproliferation und Ausbildung eines nahezu zusammenhängenden Zellrasens wurden die Gewebeproben auf weitere Petrischalen verteilt. Die in flacher Schicht am Boden der Wells zurückbleibenden Zellen der Primärkultur wurden nach Trypsinierung, Passagierung und Zellzählung auf Zellkulturflaschen von $75 \mathrm{~cm}^{2}$ Größe verteilt (Greiner, Bio-One GmbH, Solingen).

Vor jeder Passage wurde zunächst eine mikroskopische Begutachtung der Zellkulturen durchgeführt. Ein Ablösen der Zellen fand dabei stets bei Ausbildung eines nahezu konfluenten Zellrasens statt, um eine spontane Differenzierung der Zellen zu verhindern. In einem ersten Schritt wurde das alte Nährmedium unter Vakuum abgesaugt. Nach Waschung der Zellkultur mit auf $37^{\circ} \mathrm{C}$ vorgewärmtem PBS-Puffer erfolgte unter Zugabe von $2 \mathrm{ml}$ Trypsin $\left(37{ }^{\circ} \mathrm{C}\right)$ die Ablösung der Zellen. Es folgte eine fünfminütige Inkubation im Brutschrank. Durch vorsichtiges Klopfen auf den Flaschenboden wurden verbliebene adhärente Zellen losgelöst. Eine Aufhebung der enzymatischen Wirkung des Trypsins wurde durch die Zugabe von $8 \mathrm{ml}$ Nährmedium (DMEM) gewährleistet. Nachfolgend wurde die Zellsuspension in ein Zentrifugenröhrchen pipettiert und zur Zellzählung das Zellzählgerät CASY (Schärfe System/Innovatis, Reutlingen) verwendet. Nach fünfminütiger Zentrifugation bei $250 \mathrm{x}$ g sowie Verwerfen des Überstandes wurde das entstandene Zellpellet in einer zur ermittelten Zellzahl proportionalen Menge Nährmedium resuspendiert. Die anschließende Verteilung der Zellen auf die Zellkulturflaschen erfolgte mit einer maximalen Zellzahl von 700.000 Zellen pro Kulturgefäß. Die weitere Kultivierung wurde unter einheitlichen Bedingungen im Brutschrank nach mikroskopischer Prüfung fortgeführt. Eine Auffrischung des Nährmediums fand jeweils nach zwei bis drei Tagen statt.

Die oben beschriebenen Arbeitsschritte zum Anlegen der Zellkulturen finden sich zusammenfassend dargestellt in Abbildung 1 wieder. 


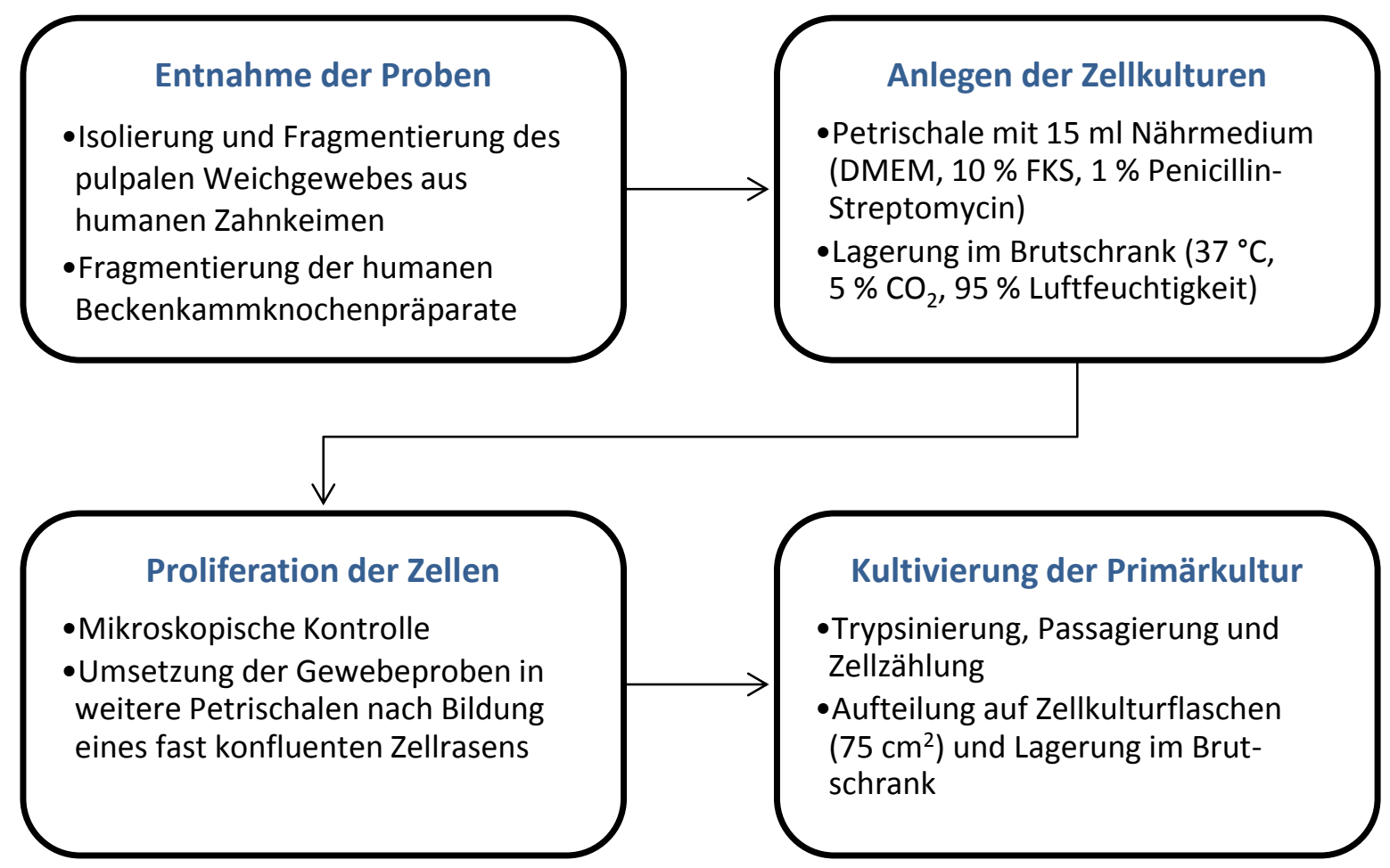

Abbildung 1: Schematische Darstellung des Versuchsablaufs zur Zellkultivierung.

\subsection{Auszählung der Zellen und Sortierung mittels Magnet-Beads (MACS)}

Nach jeder Passagierung der Zellen wurde eine Bestimmung der Zellzahl mithilfe des Zellzählgerätes CASY (Schärfe System/Innovatis, Reutlingen) vorgenommen. Aus den infolge der Trypsinierung entstandenen Zellsuspensionen erfolgte zu diesem Zweck eine Probenentnahme. Mithilfe einer gerätespezifischen Pufferlösung (CASYton) wurde die Probe anschließend im Verhältnis 1:100 verdünnt und zur Messung auf dem Probensockel des Zellzählgeräts positioniert.

Die Zellzählung mittels des CASY Cell Counter beruht dabei auf dem sogenannten Impedanzverfahren (,Widerstandsmessung“). Eine innerhalb des Geräts befindliche Messkapillare ist mit Pufferlösung gefüllt und stellt einen definierten elektrischen Widerstand dar. Bei Durchfluss der in Lösung befindlichen Zellen kommt es zu einer Verdrängung des Puffers. Die resultierende Widerstandsänderung löst einen elektrischen Impuls aus, welcher vom Gerät registriert wird. Somit lässt sich aus der Summe der auftretenden Signale letztlich die Zellzahl ermitteln (Abbildung 2). Zusätzlich kann eine Berechnung des Zellvolumens mithilfe der „Pulsflächenanalyse“ erfolgen. Für jede Zelle wird dabei eine Reihe von Einzelmessungen durchgeführt, aus denen sich entsprechend mehrere Impulse erge- 
ben. Durch Integration der Messwerte ergibt sich das jeweilige Volumen der Zelle. Auf diese Weise lassen sich neben der Größenverteilung in einer Zellkultur auch der Anteil vitaler und avitaler Zellen bestimmen.

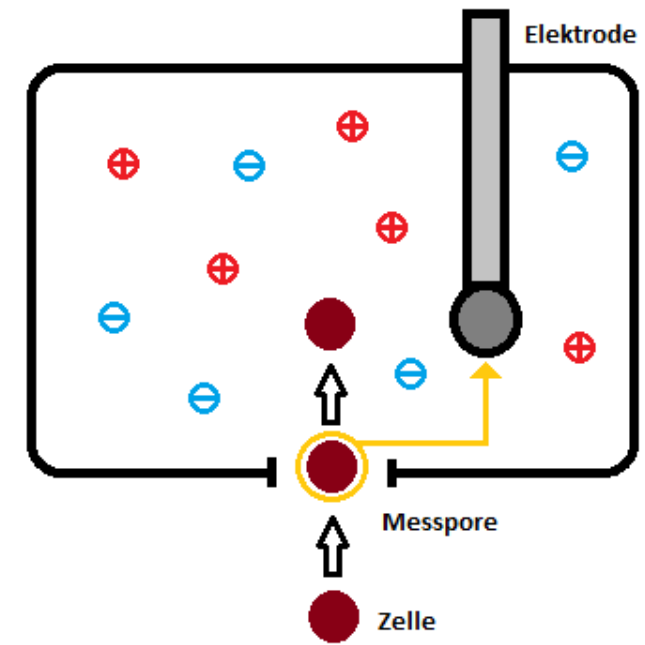

Abbildung 2: Funktionsweise des CASY Cell Counter (basierend auf RJM Sales, Inc.; www.rjmsales.com).

Die Sortierung der Zellen wurde mittels Magnetic Activated Cell Sorting (MACS) durchgeführt. Hierbei handelt es sich um ein Verfahren zur Zellselektion, welches auf magnetischen Wechselwirkungen beruht. Durch die Kopplung von kleinsten Magnetpartikeln (Microbeads) an spezifische Antikörper können Zellen mit entsprechenden Oberflächenantigenen gezielt markiert werden. Auf diese Weise lassen sich nach Durchfluss der Zellsuspension durch ein Magnetfeld bestimmte Zellpopulationen herausfiltern (Abbildung 3).

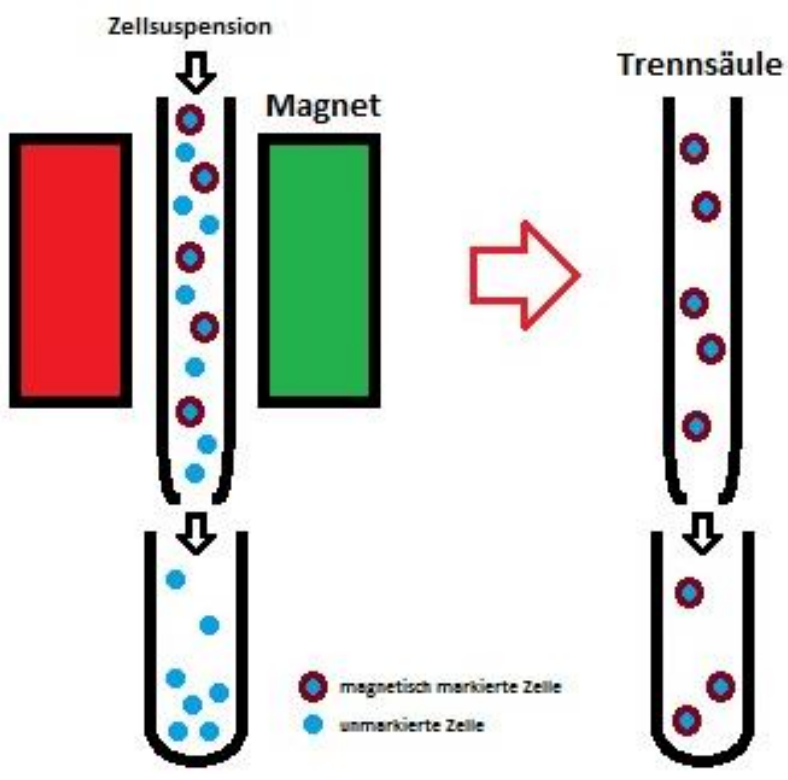

Abbildung 3: Schematische Darstellung der magnetischen Zellsortierung (MACS). 
In der vorliegenden Untersuchung wurden die Zellkulturen aus Zahnkeimen und Beckenkammpräparaten anhand des spezifischen Antikörpers Stro-1 einer positiven Selektion unterzogen. Nach Waschung der Zahnkeim- und Beckenkammzellen mit 2 ml PBS-Puffer sowie Trypsinierung erfolgte die Zellzählung im CASY. Anschließend fand eine Zentrifugation der Zellsuspension bei 250 x g statt. Der Überstand wurde verworfen und die verbliebenen Zellen erneut mit $2 \mathrm{ml}$ PBS-Puffer gewaschen. Es folgte eine weitere Zentrifugation mit Verwerfen des Überstandes. Unter Zugabe der Stro-1-Antikörper und Inkubation nach Herstellerprotokoll bildeten sich Zellpellets aus, die nachfolgend in MACS-Puffer resuspendiert wurden. In $500 \mu$ l MACS-Puffer wurden dabei maximal 2,5 Millionen Zellen gelöst.

Um die Zellsortierung einzuleiten, wurde die Magnetsäule (MS-Columns, Miltenyi Biotec $\mathrm{GmbH}$, Bergisch Gladbach) der Mini MACS-Separation Unit (Miltenyi Biotec GmbH, Bergisch Gladbach) mit $500 \mu 1$ MACS-Puffer gespült. Die in $500 \mu 1$ MACS-Puffer gelösten Zellen wurden auf die Trennsäule pipettiert, welche nachfolgend dreimal mit jeweils $500 \mu 1$ MACS-Puffer ausgewaschen wurde. Zellen, welche zuvor eine Bindung mit den magnetgekoppelten Stro-1-Antikörpern eingegangen waren, verblieben innerhalb der Trennsäule. Unmarkierte (negative) Zellen dagegen konnten nach ungehindertem Durchfluss und Spülung der Säule in einem Zentrifugenröhrchen aufgefangen werden. Nach Entfernung der Trennsäule aus dem Magnetfeld wurden die markierten (positiven) Zellen durch Ausspülen mit 1 ml MACS-Puffer in einem separaten Röhrchen gesammelt. Mittels des CASY wurde die Anzahl der positiven und negativen Zellen ermittelt.

Die isolierten Stro-1-positiven Zahnkeim- und Knochenmark-Stammzellpopulationen wurden anschließend jeweils in 6-Well-Platten zu je 50.000 Zellen pro Well in $3 \mathrm{ml} \mathrm{NH}-$ Medium (Stammzell-Expansionmedium der Fa. Miltenyi) fünf Tage lang im Brutschrank bei $7,5 \% \mathrm{CO}_{2}$ und $37{ }^{\circ} \mathrm{C}$ kultiviert. Nach zwei Tagen erfolgte der Wechsel mit frischem Medium der gleichen Art. An Tag fünf wurde die Hälfte aller Zellen auf ein Osteoblastendifferenzierungsmedium (ebenfalls Fa. Miltenyi) umgesetzt. An Tag sieben wurden diese Zellen erneut mit frischem OD-Medium versorgt, an Tag neun geerntet und für die Microarray-Analyse präpariert. Die andere Hälfte der Zellen wurde ab Tag fünf mit DMEM in der gleichen Zeitabfolge kultiviert. 


\subsection{RNA-Isolierung aus Stro-1-positiven Zahnkeim- und Becken- kammzellen}

Um die isolierten Stro-1-positiven Zellen aus Zahnkeimen und Beckenkammknochen auf die Microarray-Analyse vorzubereiten, wurde zunächst eine Isolierung der RNA durchgeführt. Diese erfolgte mithilfe des QIAGEN RNeasy Mini Kits (QIAGEN GmbH, Hilden) und ist vereinfacht in Abbildung 4 dargestellt.

Unter Beachtung des Herstellerprotokolls wurden die Zellproben zunächst lysiert und homogenisiert. Nach Zugabe von $10 \mu \mathrm{l} \beta$-Mercaptoethanol zu je $1 \mathrm{ml}$ Buffer RLT erfolgte hierzu die Vermischung der isolierten Zellen mit dem Lysispuffer. Zur Homogenisierung wurde das Lysat auf eine QIAshredder-Säule aufgetragen und für zwei Minuten bei 16.400 rpm zentrifugiert. Durch Hinzufügen von 70\%igem Ethanol wurde eine Bindung der RNA an die Silicagel-Membran der RNeasy-Zentrifugationsröhrchen vorbereitet. Die Probengemische wurden nachfolgend in diese überführt und erneut zentrifugiert. Eventuelle Verunreinigungen durch DNA-Moleküle wurden mithilfe des RNase-Free DNase Sets (QIAGEN GmbH, Hilden) eliminiert. Die abschließende Elution der isolierten RNA erfolgte mit DEPC-behandeltem Wasser. Um Kontaminationen der Eluate mit verbliebenen Proteinen auszuschließen, wurden Messungen im Photometer bei $280 \mathrm{~nm}$ durchgeführt. Gleichzeitig fand eine Bestimmung der Konzentration der RNA-Lösungen bei $260 \mathrm{~nm}$ für Nukleinsäuren statt. Aus dem Verhältnis der optischen Dichtemessungen bei $260 \mathrm{~nm}$ und $280 \mathrm{~nm}$ lässt sich die Reinheit der entsprechenden Probe ableiten. Ein Quotient von $\mathrm{OD}_{260} / \mathrm{OD}_{280}=2,0$ deutet in diesem Zusammenhang auf eine reine RNA-Isolierung hin.

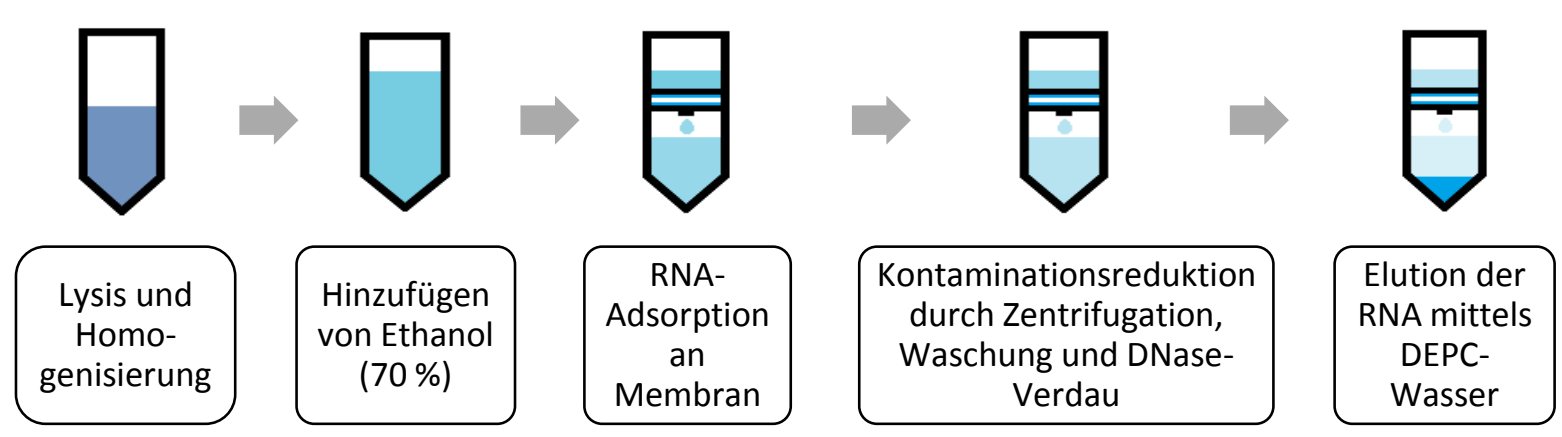

Abbildung 4: Schematischer Ablauf der RNA-Isolierung (basierend auf QIAGEN; www.qiagen.com). 


\subsection{RNA-Amplifikation und Herstellung der Microarrays}

Auf Grundlage der erfolgreichen RNA-Isolierung wurde vom Transkriptom-Analyselabor der UMG die Genexpressionsanalyse mithilfe der Microarray-Technik durchgeführt. Anhand der aus beiden Zelltypen isolierten RNA-Moleküle lassen sich Rückschlüsse auf die transkribierten Gene ziehen.

Um das gesamte menschliche Genom im Rahmen der Microarray-Analyse abzudecken, wurde das Whole Human Genome Microarray Kit 4 x 44 K (G4112F) von Agilent Technologies verwendet. Mittels des Low RNA Input Linear Amplification Kit Plus, One Color (Agilent Technologies, Inc. 2007; Cat $N^{\circ}$ : 5188-5339) wurde die gewonnene Menge an RNA durch In-vitro-Transkription (IVT) vermehrt und in fluoreszierende komplementäre RNA (cRNA) umgeschrieben. Entsprechend dem Standardprotokoll des Herstellers wurden hierzu 600 ng RNA als Ausgangsmaterial verwendet. Durch Hinzufügen der im Kit enthaltenen Komponenten erfolgte über die Synthese von cDNA die Herstellung Cy3markierter cRNA. Um den Versuchsablauf validieren zu können, wurde zusätzlich das Agilent One Color RNA Spike-In Kit (Agilent Technologies, Inc. 2007; Cat N: 5188-5282) als Positivkontrolle verwendet. Die aufgereinigte, amplifizierte cRNA wurde den Herstellerempfehlungen folgend mithilfe des NanoDrop ND-1000 UV-VIS Spectrophotometers (Version 3.2.1.) quantifiziert. Die Hybridisierung ( $17 \mathrm{~h}$ bei $10 \mathrm{rpm}$ und $65^{\circ} \mathrm{C}$ ) im Hybridisierungsofen (Agilent) sowie das Waschen und Färben der Microarrays wurden entsprechend dem One-Color Microarray-Based Gene Expression Analysis Protocol V5.7 durchgeführt.

Anschließend wurden die fertigen Microarray-Slides in den Agilent DNA Microarray Scanner (G2505B) eingelesen. Bei einer Auflösung von $5 \mu \mathrm{m}$ fand mittels one-color scanning eine Bestimmung der Cy3-Intensitäten statt. Die erstellten Scans wurden als TIFFBilddateien abgespeichert und der Analyse-Software zur weiteren Auswertung zugeführt.

\subsection{Analyse der Microarray-Daten und statistische Auswertung}

Die Microarray-Technologie ermöglicht einen umfassenden Blick auf die Genexpressionsprofile verschiedener Zelltypen. Ein einzelner Datenträger liefert dabei über die Messung von Fluoreszenzintensitätswerten Hinweise auf mehrere tausend Gene gleichzeitig. Zur Aufbereitung dieser umfangreichen Datenmengen empfiehlt es sich, einem standardisierten Verfahren zu folgen. Die statistische Auswertung der vorliegenden Untersuchung wurde 
daher nach dem in der Arbeit von Diana Oellerich (2016) beschriebenen Modell vorgenommen (Abbildung 5).

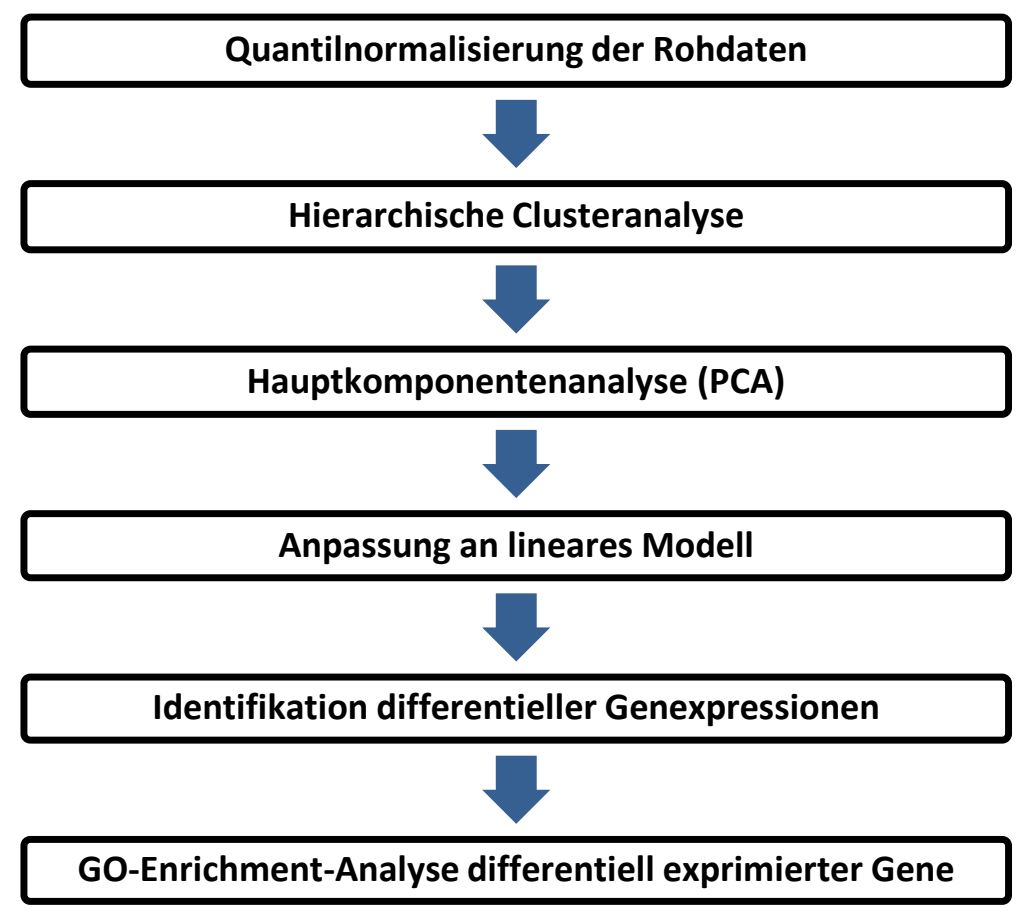

Abbildung 5: Schematische Darstellung der statistischen Auswertung der Array-Daten (nach Irizarry et al. 2003 und Opitz et al. 2010).

Die ersten vier Arbeitsschritte wurden vom Transkriptom-Analyselabor der UMG ausgeführt. Nach Umformung der detektierten Fluoreszenzintensitätswerte in $\log _{2}$-Werte wurde zunächst eine Quantilnormalisierung der Rohdaten durchgeführt. Unter der Annahme, dass zwischen den einzelnen Microarrays die globale Verteilung der Genexpressionwerte ungefähr gleich bleibt, erfolgt hierbei eine Angleichung der Daten. Schwankungen in den Messwerten, die auf systematische Fehler zurückzuführen sind, werden auf diese Weise herausgerechnet (Irizarry et al. 2003). Um in den Datensätzen Gene mit ähnlichen Expressionsmustern aufdecken zu können, kam eine hierarchische Clusteranalyse zur Anwendung. Nach dem „Bottom-up-Verfahren“ wurden sich ähnlich verhaltende Gene in entsprechenden Clustern zusammengefasst. Die Bildung der Cluster-Hierarchie gründete sich dabei auf den 1-Pearson's Korrelationskoeffizient als Distanzmaß sowie die AverageLinkage-Methode als Fusionierungsalgorithmus. Mittels der principal component analysis (PCA) wurden aus der Varianz aller Messdaten die wichtigsten Hauptkomponenten herausgefiltert (R Software princomp function). Es folgte die Ausarbeitung eines passenden linearen Modells, um verlässliche Aussagen über die statistische Signifikanz der Daten treffen zu können. Aus den drei parallelen Versuchsreihen für jedes Gen wurden die Mit- 
telwerte errechnet. Als Streumaß wurde die Standardabweichung ermittelt. Basierend auf dem linearen Modell wurde die empirische Bayes-Methode angewendet, um signifikant differentielle Genexpressionen zu detektieren (Smyth 2004). Zur weiteren Absicherung der Ergebnisse wurden über einen moderated t-Test die p-Werte erhoben. Mithilfe der false discovery rate (FDR) erfolgte eine Verschärfung der Signifikanzprüfung, indem eine Korrektur der p-Werte für multiples Testen vorgenommen wurde. Dieser Vorgang wird auch als Benjamini-Hochberg-Prozedur bezeichnet. Als cut-off für die Ablehnung der Nullhypothese, wurde eine FDR $<0,05$ verwendet. Unterhalb dieser Grenze können demnach die differentiellen Genexpressionen als statistisch signifikant bezeichnet werden. Mittels der GO-Enrichment-Analyse (R Software topGO package) wurden die Genlisten speziell nach überrepräsentierten Funktionen durchsucht. Die Einteilung der Gene in bestimmte Gruppen beruht dabei auf dem System von Gene Ontology (GO) (Beissbarth und Speed 2004). Eine Überprüfung der statistischen Signifikanz erfolgte durch Anwendung des Wilcoxon-MannWhitney-Test, wobei als cut-off p-Werte $<0,05$ nach Bonferroni-Korrektur gewählt wurden.

\subsubsection{Vorgehensweise zur Identifikation differentieller Genexpressionen}

Die Rohdaten der Microarray-Analyse wurden von der Klinik für Mund-, Kiefer- und Gesichtschirurgie zur weiteren Auswertung zur Verfügung gestellt. Diese wurden anhand festgelegter cut-offs für die ermittelten logFC- und FDR-Werte verschiedenen Filterdurchläufen unterzogen. Alle Auswertungen erfolgten mit der Statistik-Software SigmaPlot, Version 11.2 (Systat Software Inc., San Jose, CA., USA). Für beide Zelltypen wurden zunächst die zehn höchst signifikant exprimierten Gene, die im ODM gegenüber dem DMEM hoch- und herunterreguliert werden, ermittelt. Um gezielt Unterschiede im Expressionsverhalten beider Zelltypen beim Medienwechsel zu detektieren, wurde ein spezielles Filterverfahren angewendet. Nach alphabetischer Sortierung aller Gene der Zahnkeim- und Beckenkammzellen und Zuordnung der entsprechenden logFC-sowie FDR-Werte, erfolgte über den cut-off FDR $\leq 5 \%$ ein Vergleich der gegenübergestellten Gene beider Zelltypen. Unter Berücksichtigung negativer und positiver Werte des $\log \mathrm{FC}$ wurden hochregulierte und (positive) und herunterregulierte (negative) Genexpressionen voneinander getrennt. Abschließend wurde das differentielle Expressionsprofil beider Zelltypen im osteogenen Medium direkt miteinander verglichen. Mithilfe der Annotationsplattform DAVID wurden Gengruppen detektiert, die in biologischen Prozessen wichtige Funktionen übernehmen. 


\section{Ergebnisse}

Die zu untersuchenden Stro- ${ }^{+}{ }^{-}$Stammzellen wurden einerseits aus der Spongiosa humaner Beckenkammpräparate gewonnen, andererseits dienten Zahnkeime als Probenmaterial. Die Zahnkeime wurden in retinierter Form mit noch nicht abgeschlossenem Wurzelwachstum operativ entfernt. In Abbildung 6 ist die Lage der Zahnkeime der Panoramaschichtaufnahme zu entnehmen. Hierbei handelt es sich um in Entwicklung befindliche Weisheitszähne. Die Gewebegewinnung erfolgte nach Osteotomie der Zahnkeime unter sterilen Bedingungen, wobei apikal bereits makroskopisch die Zahnpapille zu erkennen war. Die Kultivierung der mittels MAC-Sortierung isolierten Stro- $1^{+}$-Zahnkeim- und -Beckenkammzellen wurde anschließend in unterschiedlichen Nährmedien durchgeführt. Die Anzucht erfolgte im DME-Medium (DMEM) und osteogenem Differenzierungsmedium (ODM). Es konnten für beide Gewebearten zwischen 8,4 bis $11,1 \%$ Stro- $1^{+}$markierte Stammzellen aus den Zellkulturen isoliert werden, die für die nachfolgende Microarray-Analyse verwendet wurden. Ziel der Zellkultivierung unter verschiedenen äußeren Bedingungen war die zentrale Fragestellung, wie die beiden Stammzelltypen auf das jeweilig angebotene Nährmedium im Hinblick auf die Genexpression reagieren.

Die zu diesem Zweck angefertigten Microarrays lieferten nachfolgend die entsprechenden Daten, um Unterschiede bzw. Gemeinsamkeiten im Expressionsprofil beider Stammzelltypen ausfindig machen zu können. Die Ergebnisse dieser Microarray-Analyse sollen in den folgenden Kapiteln systematisch dargestellt und statistisch aufbereitet werden.

Zunächst erfolgt eine kurze Zusammenfassung und Beschreibung der gesamten Rohdatenmenge. Anschließend soll mittels spezifischer Kriterien eine tiefergehende Auswertung durchgeführt werden. In Kapitel 3.2 wird hierzu in einem weiteren Arbeitsschritt untersucht, welchen Einfluss das jeweilige Nährmedium (DMEM bzw. ODM) auf die Genexpression der Stro- $1^{+}$-Stammzellen aus Zahnkeimen $\left(\right.$Stro- $\left.1^{+\mathrm{ZK}}\right)$ und Beckenkammspongiosa $\left(\right.$ Stro- $\left.{ }^{+\mathrm{BK}}\right)$ hat. Veränderungen in der Differentialexpression wurden dabei für beide Stammzelltypen zunächst isoliert betrachtet. Ein Vergleich der Genexpression zwischen Stro- $1^{+\mathrm{ZK}}$ und Stro- $1^{+\mathrm{BK}}$ findet dann in den Kapiteln 3.3 und 3.4 statt. 


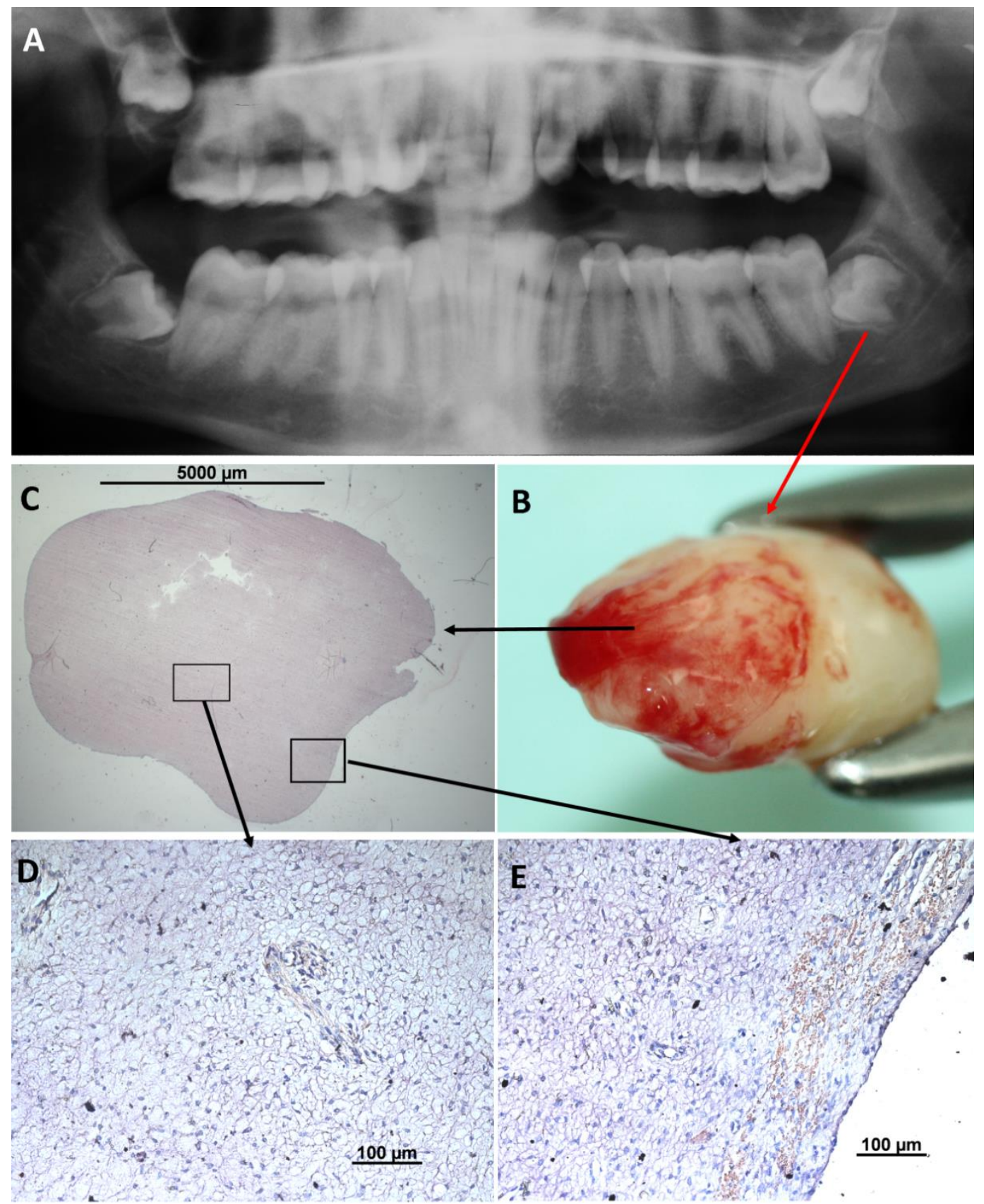

Abbildung 6: Histologische Aufarbeitung der extrahierten Zahnkeime. (A) Panoramaschichtaufnahme mit retinierten Weisheitszahnkeimen. (B) Osteotomierter Zahnkeim mit mineralisierter Krone und anhängender Zahnpapille. (C-D) Histologische Präparate eines ca. $10 \mathrm{~mm}$ im Durchmesser großen Weichgewebeanteils eines Zahnkeimes (Giemsa-Färbung). (C) Axialer Querschnitt durch die annähernd kugelförmige Gestalt des Keimes, nachdem die bereits mineralisierte, noch nicht vollständige Krone entfernt wurde. Das Gewebe stellt die Weiterentwicklung der Zahnpapille dar, welches in einem weiteren Entwicklungsstadium die Pulpa, den Zahnhals und die Zahnwurzel bildet. (D) Ausschnitt aus der Mitte des Zahnkeimes, der aus einer weitestgehend strukturlosen bindegewebigen Zellmasse besteht, die von Blutgefäßen durchsetzt ist. In ihr sind offensichtlich die Stro- $1^{+}$mesenchymalen Stamm- und Vorläuferzellen vorhanden, die angezüchtet wurden. (E) Im Randbereich findet sich ein dünner, einschichtiger Odontoblastensaum, der in dieser Form durch den Abriss vom Hartgewebe entstanden ist. In unmittelbarer Nähe verlaufen erythrozytenhaltige Gefäße. 


\subsection{Analyse der Rohdaten}

Die Rohdaten wiesen für beide Stammzelltypen insgesamt 28.889 Gene auf, wobei sich unter den Messungen auch 6.435 bisher noch unbekannte, nicht näher bezeichnete Gene befanden (Stand 2015). Nach Abzug dieser mit „NA“ gekennzeichneten Gene ergab sich sowohl für die Stro- $1^{+}$-Zahnkeimzellen (ZK) als auch die Stro- $1^{+}$-Beckenkammzellen (BK) eine Anzahl von 22.454 registrierten Genen. Um Unterschiede zwischen den Nährmedien detektieren zu können, wurde die Differenz der Höhe der Genexpression aus logFC gebildet und deren FDR berücksichtigt. Die Differenz „logFC $=\log _{2}(\mathrm{ODM})$ minus $\log _{2}(\mathrm{DMEM})$ “ wird im Folgenden der Kürze halber jeweils ZK2-ZK1 und BK2-BK1 genannt. Die Hoch- bzw. Herunterregulation von Genen in einem Medium ist daher immer im Vergleich zum anderen Medium zu sehen. So ist z. B. ein im ODM hochreguliertes Gen im DMEM herunterreguliert. Durch die Festlegung des FDR-Wertes auf $\leq 1 \%$ wurden die Messwerte für die nachfolgenden Untersuchungen auf ein geringeres Datenvolumen mit hoher Signifikanz begrenzt. Die Tabellen 1 und 2 verdeutlichen diese Abhängigkeit zwischen FDR und Anzahl der statistisch signifikant exprimierten Gene wie sie sich beim Wechsel vom DMEM in das ODM ergeben.

Tabelle 1: Anzahl $\mathrm{n}$ der auf die FDR bezogenen statistisch signifikant exprimierten Gene beim Wechsel vom DMEM in das ODM.

\begin{tabular}{|l|c|c|}
\hline \multicolumn{1}{|c|}{ FDR-Wert } & ZK2-ZK1 $(\mathbf{n}=\mathbf{2 2 . 4 5 4 )}$ & BK2-BK1 $(\mathbf{n}=\mathbf{2 2 . 4 5 4 )}$ \\
\hline FDR $\leq 10 \%$ & 866 & 1227 \\
\hline FDR $\leq 5 \%$ & 696 & 960 \\
FDR $\leq 1 \%$ & 437 & 624 \\
FDR $\leq 0,1 \%$ & 225 & 382 \\
FDR $\leq 0,01 \%$ & 129 & 208 \\
\hline FDR $\leq 0,001 \%$ & 68 & 116 \\
FDR $\leq 0,0001 \%$ & 36 & 70 \\
\hline
\end{tabular}

Tabelle 2: Anzahl $n$ der hochregulierten $(\uparrow)$ und herunterregulierten $(\downarrow)$ Gene im ODM gegenüber dem DMEM je FDR-Wert. Die logFC-Werte können hier $|<1|$ sein.

\begin{tabular}{|c|c|c|c|c|c|c|c|}
\hline FDR-Wert & ZK2-ZK1 & $\downarrow$ & $\uparrow$ & FDR-Wert & BK2-BK1 & $\downarrow$ & $\uparrow$ \\
\hline$\leq 10 \%$ & 866 & 480 & 386 & $\leq 10 \%$ & 1227 & 557 & 670 \\
\hline$\leq 5 \%$ & 696 & 383 & 313 & $\leq 5 \%$ & 960 & 423 & 537 \\
\hline$\leq 1 \%$ & 437 & 234 & 203 & $\leq 1 \%$ & 624 & 274 & 350 \\
\hline$\leq 0,1 \%$ & 225 & 111 & 114 & $\leq 0,1 \%$ & 382 & 153 & 229 \\
\hline$\leq 0,01 \%$ & 129 & 69 & 60 & $\leq 0,01 \%$ & 208 & 82 & 126 \\
\hline$\leq 0,001 \%$ & 68 & 30 & 38 & $\leq 0,001 \%$ & 116 & 40 & 76 \\
\hline$\leq 0,0001 \%$ & 36 & 17 & 19 & $\leq 0,0001 \%$ & 70 & 25 & 45 \\
\hline
\end{tabular}


Wie aus Tabelle 1 ersichtlich, werden unter dem Einfluss des osteogenen Mediums bei den Stro- $1^{+B K}$ erheblich mehr Gene gegenüber dem DMEM signifikant verändert als bei den Stro- $1^{+Z K}$ (Verhältnis $\mathrm{ZK}: \mathrm{BK}=2: 3$ ). Bemerkenswert ist auch die Tatsache, dass die Stro- $1^{+\mathrm{ZK}}$ im ODM zu einem größeren Anteil herunterreguliert und die Stro- $1^{+\mathrm{BK}}$ dagegen hochreguliert werden (Tabelle 2).

Werden die 22.454 Gene nach dem Kriterium FDR $\leq 1 \%$ gefiltert, ergibt sich bei den Stro- $1^{+}$-Zellen aus den Zahnkeimen und dem Beckenkamm eine geringere Anzahl an signifikant hoch- oder herunterregulierten Genen. Die logFC-Werte können $|<1|$ sein. Bei den Zahnkeimzellen konnten insgesamt 437 Gene detektiert werden, die diesem cut-off entsprachen. Die Beckenkammzellen wiesen 624 Gene auf. Innerhalb beider Zellpopulationen wurde in einem weiteren Schritt eine Sortierung anhand der logFC-Werte vorgenommen. Ein positiver $\log$ FC-Wert steht dabei für eine höhere Expression des jeweiligen Gens im ODM gegenüber dem DMEM, ein negativer logFC-Wert dagegen für eine höhere Genexpression im DMEM gegenüber dem ODM. In Abbildung 7 zeigen die übereinanderliegenden Histogramme diese Werte als Überschneidungen der Säulen auch hinsichtlich der Höhe des logFC-Wertes.

Bei den Stro- $1^{+Z K}$ werden folglich im ODM gegenüber dem DMEM 203 Gene hoch- und 234 Gene herunterreguliert. Bei den Stro- $1^{+\mathrm{BK}}$ werden 350 Gene hoch- und 274 Gene herunterreguliert. Unter dem oben genannten Filterkriterium wird bei den Stro- $1^{+Z K}$ im ODM gegenüber dem DMEM die Mehrzahl der Gene herunterreguliert, während bei den Stro- $1^{+\mathrm{BK}}$ überwiegend eine Hochregulation erfolgt. Insgesamt werden in den Stro- $1^{+\mathrm{ZK}}$ weniger Gene signifikant verändert als in den Stro- $1^{+\mathrm{BK}}$. 


\section{Intensitätsverteilung der Gene}
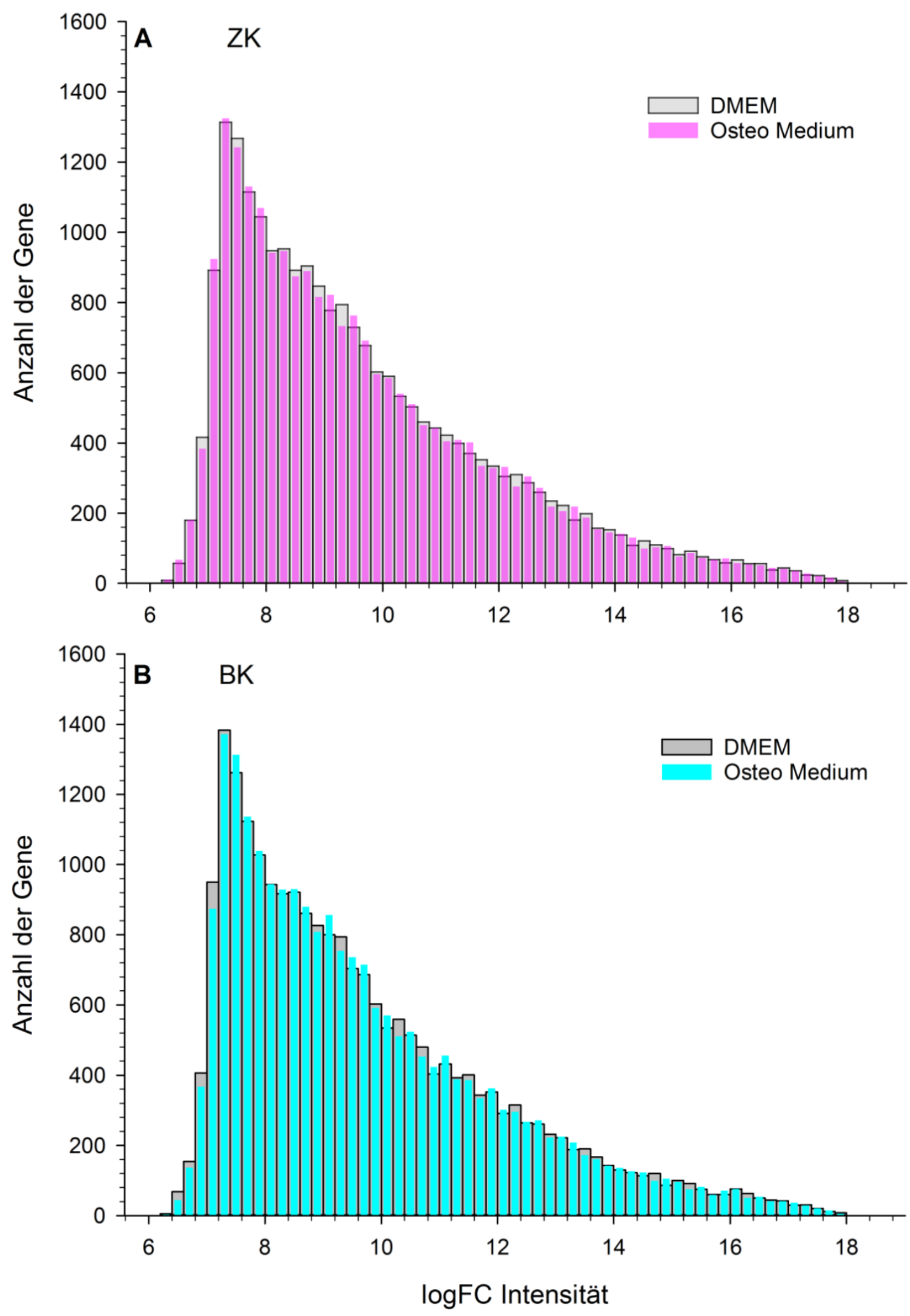

Abbildung 7: Histogramme der logFC-Intensitätsverteilung der Genexpression. Dargestellt ist die Verteilung der Stro- $1^{+}$-Zahnkeimzellen (A) und der Stro- $1^{+}$-Beckenkammzellen (B) im DMEM und osteogenen Medium. Die Anzahl der Verteilungsdifferenzen erstreckt sich über den gesamten logFC-Bereich. Die Histogramme bestehen aus 61 Säulen mit einer logFC-Breite von 0,2 Einheiten $(n=22.454)$. 


\subsection{Der Einfluss der Medien auf die Genexpression}

In Kapitel 3.1 konnten anhand des cut-offs der FDR $\leq 1 \%$ für die Stro- $1^{+\mathrm{ZK}} 437$ Gene und für die Stro- $1^{+\mathrm{BK}} 624$ Gene als signifikant identifiziert werden. Diese zeigten in Abhängigkeit vom jeweiligen Nährmedium eine Hoch- bzw. Herunterregulation in ihrem Expressionsmuster.

Um den Einfluss der beiden Nährmedien auf den jeweiligen Stammzelltypus herausarbeiten zu können, wurden zunächst Unterschiede und Gemeinsamkeiten innerhalb der jeweiligen Zellpopulation betrachtet. Die Genexpression der Stro- $1^{+}$-Zahnkeimzellen (ZK) wurde somit sowohl im DMEM (ZK1) als auch im ODM (ZK2) detektiert und verglichen. Gleiches erfolgte für die Stro- $1^{+}$-Beckenkammzellen (BK) im DMEM (BK1) und ODM (BK2). Ausgehend von den noch strengeren Kriterien FDR $\leq \mathbf{1} \%$ und $|\operatorname{logFC}|>2$ wurden die gesamten Daten der Stro- $1^{+\mathrm{ZK}}$ und Stro- $1^{+\mathrm{BK}}$ statistisch gefiltert. Hierzu wurden die Rohdaten nach den FDR-Werten in aufsteigender Reihenfolge sortiert und anschließend mittels der $\operatorname{logFC}-$ Werte (positiv/negativ) in zwei Gruppen eingeteilt. Bei den Stro- $1^{+Z K}$ waren unter den oben genannten Filterkriterien 60 Gene im ODM gegenüber dem DMEM hochreguliert, wohingegen 52 Gene im DMEM stärker exprimiert wurden. Die Stro- $1^{+\mathrm{BK}}$ zeigten im ODM 84 hochregulierte Gene. Im DMEM waren 66 Gene hochreguliert. Umgekehrt lässt sich hier auch von einer Herunterregulation im ODM sprechen. Diese rein quantitative Auswertung wurde anschließend um eine qualitative Analyse der herausgefilterten Gene ergänzt. Die Anzahl der signifikant unterschiedlich exprimierten Gene lässt aber bereits erste Rückschlüsse auf den Einfluss der Nährmedien zu. Die größere Anzahl von hochregulierten Genen in den Stro- $1^{+\mathrm{BK}}$ deutet auf eine stärkere Stimulation der Beckenkammzellen durch das osteogene Differenzierungsmedium hin. Der genaue Einfluss der Nährmedien lässt sich jedoch nur feststellen, wenn bekannt ist, welche Gene signifikant unterschiedlich reagieren.

In Tabelle 3 finden sich sowohl für die Stro- $1^{+\mathrm{ZK}}$ als auch Stro- $1^{+\mathrm{BK}}$ die zehn Gene, welche aufgrund der oben gewählten cut-offs die höchste signifikante Hoch- bzw. Herunterregulation im ODM gegenüber dem DMEM aufweisen. Doppelt aufgeführte Gene besitzen unterschiedliche Agilent-IDs. In der Gruppe der hochregulierten Gene, aufgeführt in den grün hinterlegten Tabellen, befinden sich vier Gene - SAA1, BMP6, FKBP5 und MAOA - die beim Wechsel in das ODM sowohl in den Stro- $1^{+\mathrm{ZK}}$ als auch Stro- $1^{+\mathrm{BK}}$ hochreguliert werden. Beim Wechsel vom DMEM in das ODM steigt bei den Stro- $1^{+\mathrm{BK}}$ die Expression von SAA1 um das 256-Fache und von BMP6 um das 32-Fache. Bei den Stro- ${ }^{+\mathrm{ZK}}$ verändern 
sich die Expressionen dieser Gene um das 13- bzw. 8-Fache. Auffällig ist, dass die logFCWerte bei den Stro- $1^{+\mathrm{BK}}$ für serum amyloid A1 ungefähr um den Faktor 20 und für BMP6 um den Faktor 4 gegenüber den Stro- $1^{+Z K}$ erhöht sind. Wie aus den rot hinterlegten Tabellen hervorgeht, finden sich bei den Stro- $1^{+\mathrm{ZK}}$ und Stro- $1^{+\mathrm{BK}}$ keine gleichen herunterregulierten Gene. Insgesamt reagieren die Stro- $1^{+\mathrm{BK}}$ wesentlich stärker auf den Wechsel des Mediums als die Stro- ${ }^{+Z K}$. Dies betrifft nicht nur die höhere Anzahl der Gene, die beim Umsetzen in das ODM reagieren, sondern auch die Intensität der Reaktion der Gene. So wurden für die Stro- $1^{+B K}$ die zehn Gene mit der höchsten Signifikanz beim Medienwechsel zwischen dem 8- bis 256-Fachen hoch- und zwischen dem 4- bis 21-Fachen herunterreguliert. Die Stro- $1^{+Z K}$ reagierten mit der 5- bis 22-fachen Hoch- und 8- bis 36-fachen Herunterregulation ihrer Genexpression. Der logFC-Median der höchst signifikant hochregulierten Gene beträgt bei den Stro- $1^{+\mathrm{BK}} 4,29$ und bei den Stro- $1^{+\mathrm{ZK}} 3,54$, während die Mediane der höchst signifikant herunterregulierten Gene jeweils $-3,30$ und $-3,65$ betragen. Die Stro- $1^{+\mathrm{ZK}}$ werden also stärker herunter- und die Stro- $1^{+\mathrm{BK}}$ stärker heraufreguliert.

Die nachfolgende Tabelle 3 fasst die zehn höchst signifikant im ODM gegenüber dem DMEM hoch- bzw. herunterregulierten Gene der Stro- $1^{+\mathrm{ZK}}$ und Stro- $1^{+\mathrm{BK}}$ mit zugehörigen Namen sowie FDR- und logFC-Werten zusammen. 


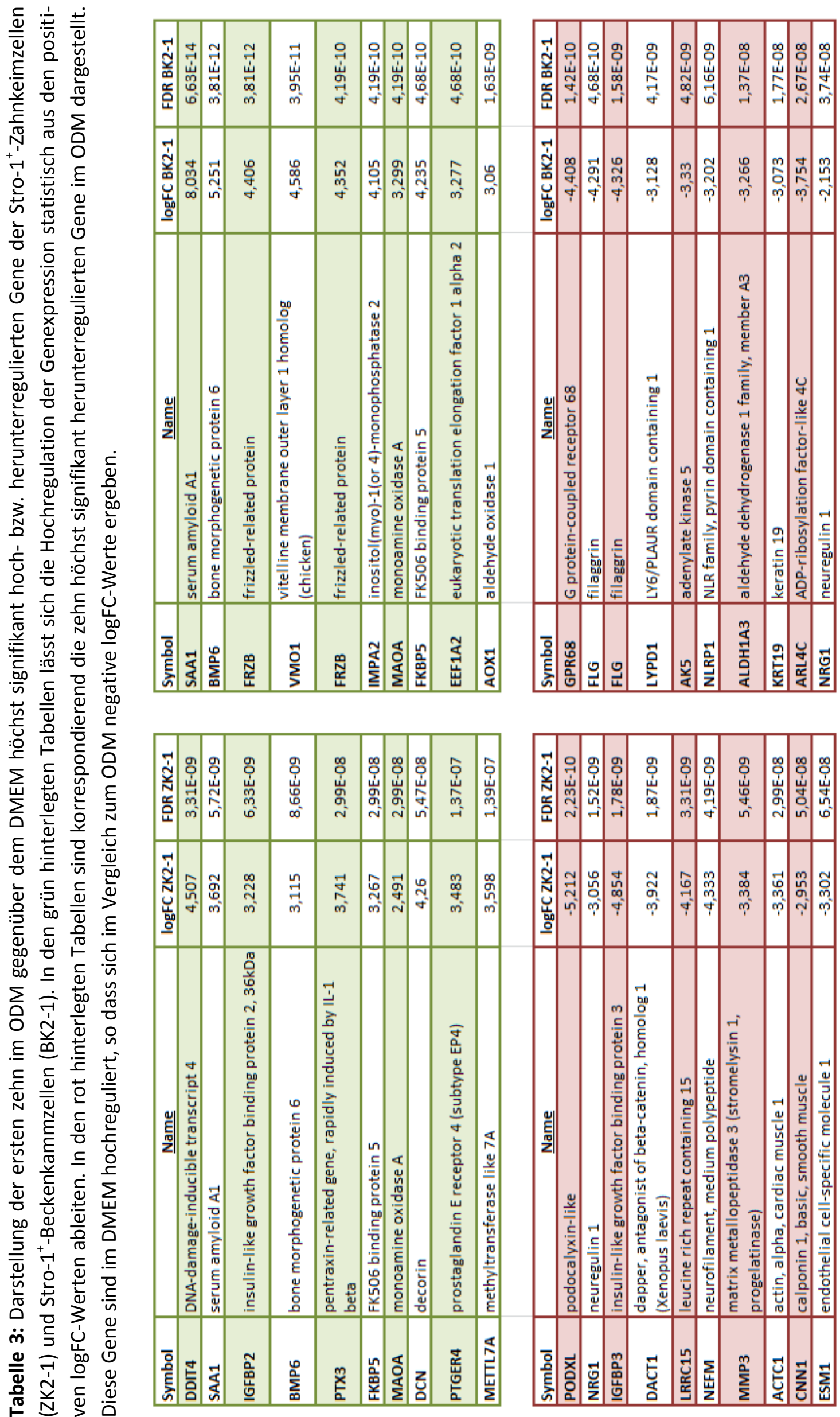




\subsubsection{Funktionelle Genanalyse der Stro-1 ${ }^{+\mathrm{ZK}}$ und Stro-1 ${ }^{+\mathrm{BK}}$}

Da die Auflistung der signifikant über- oder unterexprimierten Gene zunächst keinen Zusammenhang in ihrer funktionellen Bedeutung erkennen lässt, wurden sie in einem weiteren Schritt in das Programm „DAVID Bioinformatics Resources“ (Database for Annotation, Visualization and Integrated Discovery) eingespeist. Diese Software ermöglicht die Evaluierung großer Datenmengen wie sie im Zuge der Auswertung von Microarrays anfallen können und ordnet sie auf Basis von Gene Ontology (GO)-Klassifizierungen nach funktionellen Gruppen. Eine gezielte Analyse bezüglich biologischer Prozesse wurde mittels des Functional Annotation Tool vorgenommen.

Hierzu wurden die nach den Kriterien FDR $\leq 1 \%$ und $|\operatorname{logFC}|>2$ gefilterten Gene getrennt für beide Stammzellpopulationen (Stro- ${ }^{+\mathrm{ZK}}$ bzw. Stro- $1^{+\mathrm{BK}}$ ) sowie sortiert nach dem logFC-Wert (positiv bzw. negativ) dem Programm zugeführt. Über den Befehl „GOTERM_BP_FAT“ wurden insbesondere Gene in den Daten gesucht, die im Zuge von biologischen Prozessen (BP) eine entscheidende Rolle spielen. Die anschließende Visualisierung erfolgte anhand einer tabellarischen Auflistung (Functional Annotation Chart) aller detektierten Gene. Mithilfe dieses Anschauungsmodus findet eine geordnete Darstellung derjenigen Gene in Gruppen statt, die in ausgewählte biologische Prozesse eingebunden sind. Diese werden im Rahmen der Software als terms bezeichnet und sind in der chart nach ihrer Signifikanz entsprechend dem Benjamini- sowie p-Wert aufgelistet. Die Anzahl der zu einem term gehörigen Gene findet sich als Zahlenwert in der Spalte count. Daneben ist die prozentuale Gewichtung der einzelnen Gengruppen im Hinblick auf die Gesamtheit aller eingespeisten Daten gelistet.

Sowohl für die Zahnkeimzellen als auch die Beckenkammzellen ergeben sich jeweils zwei charts. Von den 60 im ODM gegenüber dem DMEM hochregulierten Genen der Stro- $1^{+Z K}$ konnten 37 Gene insgesamt 55 GO-terms zugeordnet werden. Bei den 52 herunterregulierten Genen der Stro- $1^{+\mathrm{ZK}}$ wurden für 38 Gene 113 GO-terms detektiert. Die Stro- $1^{+\mathrm{BK}}$ wiesen für die 84 hochregulierten Gene insgesamt 153 GO-terms mit 56 Genen auf, für die 66 herunterregulierten Gene 123 GO-terms mit 46 Genen. Die ersten zehn signifikant hochbzw. herunterregulierten Gengruppen (terms) der Stro- $1^{+\mathrm{ZK}}$ finden sich jeweils in den Tabellen $4 \mathrm{a}$ und 4b. Die Tabellen 5a und 5b umfassen die ersten zehn Gengruppen der Beckenkammzellen, die entweder im ODM oder DMEM im Hinblick auf ihre Expression hochreguliert sind. 
Tabelle 4a,b: (a) Die ersten zehn im ODM signifikant hochregulierten funktionellen Gruppen der Stro-1 ${ }^{+}$-Zahnkeimzellen (nach DAVID Version 6.7). (b) Die ersten zehn im ODM signifikant herunterregulierten ( $=$ im DMEM signifikant hochregulierten) funktionellen Gruppen der Stro- $1^{+}-$ Zahnkeimzellen. Die zugehörigen Gene der funktionellen Gruppen finden sich im Anhang in Tabelle A-5 und A-6. Die Tabellen sind nach der aufsteigenden Höhe der p-Werte sortiert.

\section{Tabelle 4a}

\begin{tabular}{|l|c|c|c|c|c|}
\hline \multicolumn{1}{|c|}{ Term } & Genes & Count & $\%$ & P-Value & Benjamini \\
\hline response to organic substance & & 10 & 18,5 & $9,9 \mathrm{E}-4$ & $5,1 \mathrm{E}-1$ \\
\hline positive regulation of multicellular organismal process & & 6 & 11,1 & $1,8 \mathrm{E}-3$ & $4,8 \mathrm{E}-1$ \\
\hline response to wounding & & 8 & 14,8 & $2,8 \mathrm{E}-3$ & $4,9 \mathrm{E}-1$ \\
\hline response to endogenous stimulus & & 7 & 13,0 & $3,3 \mathrm{E}-3$ & $4,4 \mathrm{E}-1$ \\
\hline response to steroid hormone stimulus & & 5 & 9,3 & $5,1 \mathrm{E}-3$ & $5,1 \mathrm{E}-1$ \\
\hline negative regulation of inflammatory response & & 3 & 5,6 & $5,6 \mathrm{E}-3$ & $4,9 \mathrm{E}-1$ \\
\hline inflammatory response & & 6 & 11,1 & $6,2 \mathrm{E}-3$ & $4,7 \mathrm{E}-1$ \\
\hline behavior & & 7 & 13,0 & $6,7 \mathrm{E}-3$ & $4,5 \mathrm{E}-1$ \\
\hline negative regulation of glycogen catabolic process & - & 2 & 3,7 & $7,2 \mathrm{E}-3$ & $4,4 \mathrm{E}-1$ \\
\hline negative regulation of defense response & - & 3 & 5,6 & $7,5 \mathrm{E}-3$ & $4,1 \mathrm{E}-1$ \\
\hline
\end{tabular}

\section{Tabelle 4b}

\begin{tabular}{|l|c|c|c|c|c|}
\hline \multicolumn{1}{|c|}{ Term } & Genes & Count & $\%$ & $\underline{\text { P-Value }}$ & Benjamini \\
\hline regulation of cell migration & & 6 & 13,3 & $7,9 \mathrm{E}-5$ & $5,3 \mathrm{E}-2$ \\
\hline striated muscle cell differentiation & & 5 & 11,1 & $8,4 \mathrm{E}-5$ & $2,8 \mathrm{E}-2$ \\
\hline regulation of locomotion & & 6 & 13,3 & $1,4 \mathrm{E}-4$ & $3,2 \mathrm{E}-2$ \\
\hline regulation of cell motion & & 6 & 13,3 & $1,5 \mathrm{E}-4$ & $2,5 \mathrm{E}-2$ \\
\hline striated muscle tissue development & & 5 & 11,1 & $2,7 \mathrm{E}-4$ & $3,6 \mathrm{E}-2$ \\
\hline muscle cell differentiation & & 5 & 11,1 & $2,9 \mathrm{E}-4$ & $3,2 \mathrm{E}-2$ \\
\hline muscle tissue development & & 5 & 11,1 & $3,3 \mathrm{E}-4$ & $3,1 \mathrm{E}-2$ \\
\hline cell adhesion & & 9 & 20,0 & $4,1 \mathrm{E}-4$ & $3,5 \mathrm{E}-2$ \\
\hline negative regulation of secretion & & 4 & 8,9 & $4,1 \mathrm{E}-4$ & $3,1 \mathrm{E}-2$ \\
\hline biological adhesion & & 9 & 20,0 & $4,1 \mathrm{E}-4$ & $2,8 \mathrm{E}-2$ \\
\hline
\end{tabular}


Tabelle 5a,b: (a) Die ersten zehn im ODM signifikant hochregulierten funktionellen Gruppen der Stro-1 ${ }^{+}$-Beckenkammzellen (nach DAVID Version 6.7). (b) Die ersten zehn im ODM signifikant herunterregulierten ( $=$ im DMEM signifikant herunterregulierten) funktionellen Gruppen der Stro- $1^{+}$-Beckenkammzellen. Die zugehörigen Gene der funktionellen Gruppen finden sich im Anhang in Tabelle A-7 und A-8. Die Tabellen sind nach der aufsteigenden Höhe der $p$-Werte sortiert.

\section{Tabelle 5a}

\begin{tabular}{|l|l|l|l|l|l|}
\hline \multicolumn{1}{|c|}{ Term } & Genes & Count & \% & P-Value & Benjamini \\
\hline response to insulin stimulus & & 7 & 9,5 & $6,2 \mathrm{E}-6$ & $5,7 \mathrm{E}-3$ \\
\hline response to endogenous stimulus & & 11 & 14,9 & $1,4 \mathrm{E}-5$ & $6,3 \mathrm{E}-3$ \\
\hline response to hormone stimulus & & 10 & 13,5 & $4,1 \mathrm{E}-5$ & $1,3 \mathrm{E}-2$ \\
\hline response to peptide hormone stimulus & & 7 & 9,5 & $7,2 \mathrm{E}-5$ & $1,6 \mathrm{E}-2$ \\
\hline negative regulation of response to external stimulus & & 5 & 6,8 & $7,9 \mathrm{E}-5$ & $1,4 \mathrm{E}-2$ \\
\hline negative regulation of inflammatory response & & 4 & 5,4 & $3,8 \mathrm{E}-4$ & $5,6 \mathrm{E}-2$ \\
\hline response to organic substance & & 12 & 16,2 & $3,8 \mathrm{E}-4$ & $4,9 \mathrm{E}-2$ \\
\hline regulation of glucose metabolic process & & 4 & 5,4 & $5,4 \mathrm{E}-4$ & $6,0 \mathrm{E}-2$ \\
\hline negative regulation of defense response & & 4 & 5,4 & $6,9 \mathrm{E}-4$ & $6,2 \mathrm{E}-2$ \\
\hline regulation of cellular carbohydrate metabolic process & & 5,4 & $5,4 \mathrm{E}-2$ \\
\hline
\end{tabular}

Tabelle 5b

\begin{tabular}{|c|c|c|c|c|c|}
\hline$\underline{\text { Term }}$ & Genes & Count & $\underline{\%}$ & $\underline{\text { P-Value }}$ & Benjamini \\
\hline negative regulation of secretion & $\bar{z}$ & 5 & 8,6 & $4,9 \mathrm{E}-5$ & $4,2 E-2$ \\
\hline regulation of leukocyte migration & $\bar{E}$ & 4 & 6,9 & $5,2 \mathrm{E}-5$ & $2,2 \mathrm{E}-2$ \\
\hline wound healing & $\bar{\square}$ & 7 & 12,1 & $6,9 \mathrm{E}-5$ & $2,0 \mathrm{E}-2$ \\
\hline regulation of secretion & $\overline{0}$ & 7 & 12,1 & $9,5 \mathrm{E}-5$ & $2,0 \mathrm{E}-2$ \\
\hline angiogenesis & $\bar{z}$ & 6 & 10,3 & $2,1 \mathrm{E}-4$ & $3,6 \mathrm{E}-2$ \\
\hline blood vessel morphogenesis & $\overline{0}$ & 6 & 10,3 & $1,1 \mathrm{E}-3$ & $1,4 \mathrm{E}-1$ \\
\hline positive regulation of leukocyte migration & $\bar{E}$ & 3 & 5,2 & $1,4 \mathrm{E}-3$ & $1,6 \mathrm{E}-1$ \\
\hline negative regulation of transport & $\bar{E}$ & 5 & 8,6 & $1,5 \mathrm{E}-3$ & $1,5 \mathrm{E}-1$ \\
\hline blood vessel development & $\overline{\bar{z}}$ & 6 & 10,3 & $2,0 \mathrm{E}-3$ & $1,8 \mathrm{E}-1$ \\
\hline regulation of cellular localization & 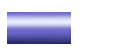 & 6 & 10,3 & $2,2 E-3$ & $1,7 \mathrm{E}-1$ \\
\hline
\end{tabular}


In den Tabellen 4a und 5a finden sich bei den Stro- $1^{+\mathrm{ZK}}$ und Stro- $1^{+\mathrm{BK}}$ vier gleiche funktionelle Gengruppen, welche im ODM gegenüber dem DMEM hochreguliert werden (in den Tabellen gelb markiert). Es handelt sich um die GO-terms response to organic substance, response to endogenous stimulus, negative regulation of inflammatory response sowie negative regulation of defense response. Die Tabellen $4 \mathrm{~b}$ und $5 \mathrm{~b}$ zeigen dagegen nur eine gemeinsame herunterregulierte Gengruppe mit dem GO-term negative regulation of secretion. Um ähnliche bzw. voneinander abweichende Gene innerhalb der Gengruppen ausfindig machen zu können, wurden für alle in den Tabellen 4 und 5 aufgeführten GOterms die zugehörigen Gene getrennt nach Zelltyp aufgelistet. Die entsprechenden Tabellen A-5 bis A-8 finden sich im Anhang. In den jeweiligen Gruppen kommen bestimmte Gene mehrfach vor, da diese in mehreren biologischen Prozessen wichtige Rollen übernehmen. DAVID listet diese Gene entsprechend in allen relevanten terms auf.

\subsubsection{Genexpression der Stro-1 ${ }^{+\mathrm{ZK}}$ im osteogenen und DME-Medium}

Zu den zehn am höchst signifikant exprimierten Genen der Stro- $1^{+Z K}$ zählen SAA1, BMP6, $\boldsymbol{F K B P 5}$ und $\boldsymbol{M A O A}$, die auch in den Stro- $1^{+\mathrm{BK}}$ höchste Signifikanzen zeigen. Auffällig ist, dass das IGFBP2 bei den Zahnkeimzellen im ODM gegenüber dem DMEM eine Hochregulation in seiner Expression erfährt, während das IGFBP3 herunterreguliert wird. Dies bedeutet entsprechend ein umgekehrtes Verhalten im DMEM.

Die für die Stro- $1^{+Z K}$ signifikant veränderten funktionellen Gengruppen sind in den Tabellen $4 \mathrm{a}$ und $4 \mathrm{~b}$ aufgeführt. Tabelle $4 \mathrm{a}$ umfasst jene GO-terms, die im ODM gegenüber dem DMEM hochreguliert werden, während Tabelle $4 \mathrm{~b}$ die herunterregulierten GO-terms auflistet. Im ODM werden insbesondere Gene hochreguliert, die biologischen Prozesse umfassen, welche mit der Reaktion auf organische Substanzen, der Wundheilung und der Entzündungsantwort im Zusammenhang stehen. Exemplarisch stehen hierfür die GO-terms response to organic substance, positive regulation of multicellular organismal process, response to wounding, response to endogenous stimulus, response to steroid hormone stimulus und negative regulation of defense response. Es fällt dabei auf, dass in acht der zehn Gengruppen aus Tabelle 4a das Gen IGF2 (insulin-like growth factor 2) eine zentrale Rolle spielt (Tabelle A-5 im Anhang). Darauf weist bereits die oben genannte hohe Expression von IGFBP2 hin. Demgegenüber sind im ODM funktionelle Gruppen der Zellmigration und Muskeldifferenzierung sowie der Zelladhäsion herunterreguliert (im 
DMEM hochreguliert). In diesen Gruppen dominieren IGFBP3 und IGFBP5 (Tabelle A-6 im Anhang).

Um Aufschluss über die Eigenschaften der Stro- $1^{+\mathrm{ZK}}$ bezüglich ihrer biologischen Funktion zu erhalten, erschien es wichtig, auch einige Gene zu betrachten, die sich trotz unterschiedlicher Nährmedien in ihrer Expression nicht ändern. Beim Wechsel der Stro- $1^{+Z K}$ vom DMEM in das ODM gibt es keine signifikante Expressionsänderung von BMP1, BMP2 und BMP7, aber eine geringe Hochregulierung von BMP4 $(\log \mathrm{FC}=0,782$; FDR $=8,45 E-2$ ) und eine hoch signifikante Überexpression von BMP6 (Tabelle 3). Keine wesentliche Reaktion auf einen Medienwechsel zeigen die für die Körpersegmente zuständigen HOX-Gene der Cluster A-D $(|\operatorname{logFC}|<1$; FDR $=100 \%)$ mit Ausnahme einer geringen Herunterregulierung von $\mathbf{H O X B 2}$ im ODM.

\subsubsection{Genexpression der Stro-1 ${ }^{+B K}$ im osteogenen und DME-Medium}

Neben den Genen, die auch bei den Stro- $1^{+Z K}$ stark exprimiert werden (SAA1, BMP6, FKBP5, MAOA), fällt bei den Stro- $1^{+\mathrm{BK}}$ das Gen VMO1 (vitelline membrane outer layer 1 homolog) auf, ein Protein, das im Zusammenhang mit mesenchymalen, knochenbildenden Stammzellen nicht bekannt ist. Hoch exprimiert wird auch das Gen $\boldsymbol{F R Z B}$ (frizzled-related protein), welches unter zwei verschiedenen Agilent-IDs vorkommt.

Auch bei den Stro- $1^{+B K}$ werden im ODM Gene hochreguliert, die ähnliche biologische Prozesse wie bei den Stro- $1^{+\mathrm{ZK}}$ umfassen, z. B. die terms response to endogenous stimulus, response to organic substance, negative regulation of defense response und negative regulation of inflammatory response. Ferner treten hier die Gruppen response to insulin stimulus, response to hormone stimulus und speziell response to peptide hormone stimulus auf. Die im ODM herunterregulierten (im DMEM hochregulierten) Gengruppen sind größtenteils der Angiogenese zuzuordnen. Das Gen IGFBP3 ist im ODM ebenfalls unterexprimiert $(\log \mathrm{FC}=-1,45 ; \mathrm{FDR}=1,97 \mathrm{E}-3)$, allerdings nicht so deutlich wie bei den Stro- ${ }^{+\mathrm{ZK}}$. Die HOX-Gene zeigen keine signifikante Änderung ihrer Expression mit Ausnahme von HOXB3 und $\boldsymbol{H O X C 8}$, welche im ODM herunterreguliert werden. 


\subsection{Differentielle Genexpression der Stro-1 ${ }^{+\mathrm{ZK}}$ und Stro-1 $^{+\mathrm{BK}}$ in den Medien}

Während in Kapitel 3.2 insbesondere der Einfluss des jeweiligen Nährmediums auf die Stro- $1^{+\mathrm{ZK}}$ bzw. Stro- $1^{+\mathrm{BK}}$ anhand der ersten zehn höchst signifikant hoch- und herunterregulierten Gene sowie funktionellen Gruppen untersucht wurde, soll in diesem Teil der Arbeit durch ein spezielles Filterverfahren ein direkter Vergleich zwischen den beiden Zellpopulationen erfolgen. Dieses Vorgehen gewährleistet eine wesentlich höhere Trennschärfe beider Stammzelltypen hinsichtlich ihrer Genexpression auch in funktioneller Hinsicht.

Um gezielt Unterschiede im Expressionsverhalten der Stro- $1^{+\mathrm{ZK}}$ und Stro- $1^{+\mathrm{BK}}$ beim Medienwechsel herauszufiltern, wurden alle 22.454 Gene zunächst alphabetisch aufsteigend sortiert und ihnen dann die entsprechenden FDR- und logFC-Werte beider Zelltypen zugeordnet, wie sie als Differenzen der Werte beider Medien (ODM minus DMEM) entstehen.

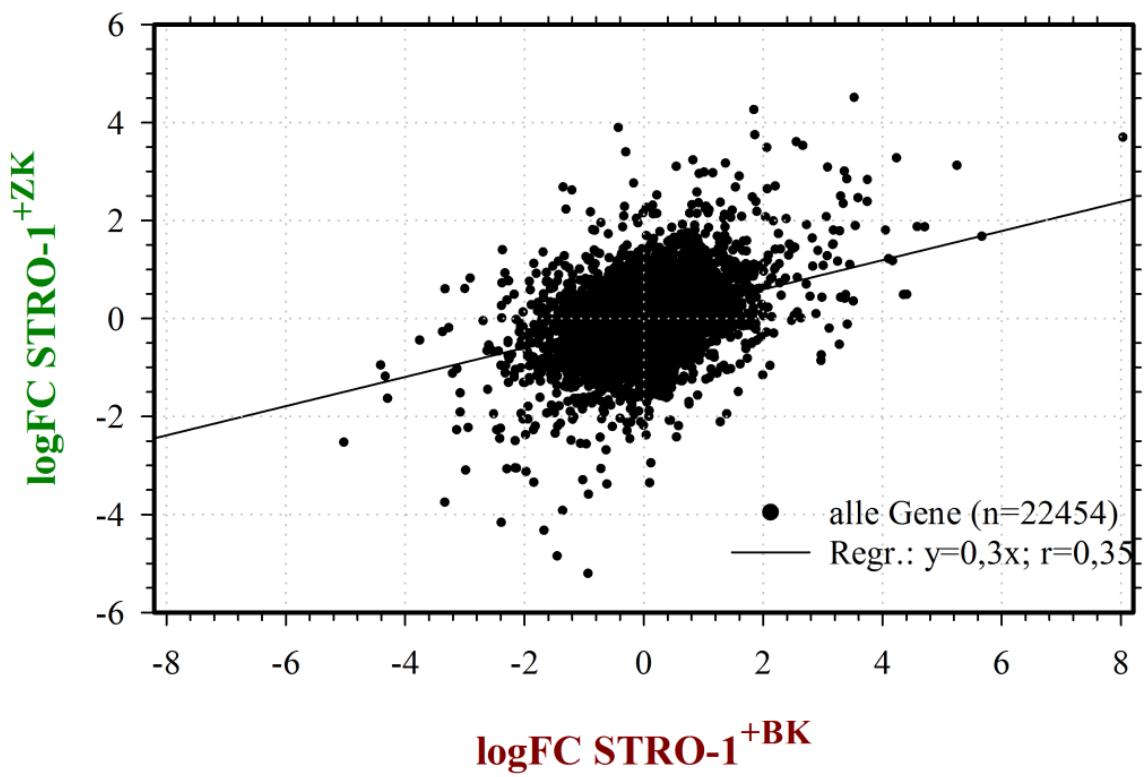

Abbildung 8: Korrelation der logFC-Werte identischer Gene der Stro- $1^{+Z K}$ und Stro- $1^{+B K}$. Die Regression zeigt, dass die Expression der Gene bei den Stro- $1^{+2 \mathrm{~K}}$ im ODM geringer zunimmt als die Expression bei den Stro- $1^{+B K}$.

Anschließend wurden alle Gene nach dem Kriterium FDR $\leq 5 \%$ zunächst nach dem einen und dann nach dem anderen Zelltyp synchron gefiltert. Die nachfolgende Sortierung unter Berïcksichtigung negativer und positiver $\operatorname{logFC}$-Werte sollte hochregulierte (positive) und herunterregulierte (negative) Genexpressionen voneinander trennen. Bei dieser Betrachtung können die Werte des $|\log \mathrm{FC}|<1$ sein. 
Abbildung 8 zeigt eine Grafik, in der alle $\log$ FC-Werte der Stro- $1^{+\mathrm{ZK}}$ und Stro- $1^{+\mathrm{BK}}$ miteinander korreliert sind. Die Regression gibt dabei Aufschluss über die unterschiedliche Expressionsveränderung beider Zelltypen beim Medienwechsel. Während der logFC der Stro- $1^{+\mathrm{BK}}$ um eine Einheit zu- oder abnimmt (= das 2-Fache), verändert er sich bei den Stro- $1^{+Z K}$ lediglich um 0,3 Einheiten, was dem 1,23-Fachen entspricht.

Bei den Stro- $1^{+\mathrm{BK}}$ fanden sich 960 Gene mit signifikanten $\operatorname{logFC}-$ Werten, während bei den Stro- $1^{+Z K} 696$ Gene detektiert wurden, die sich im ODM gegenüber dem DMEM signifikant in ihrer Expression veränderten. Wurden die logFC-Werte paarweise miteinander verglichen, so ergaben sich bei den Stro- $1^{+B K} 720$ signifikante Gene, die bei den Stro- $1^{+Z K}$ keine Signifikanz aufwiesen. Umgekehrt wiesen die Stro- $1^{+\mathrm{ZK}} 456$ Gene auf, die bei den Stro- $1^{+\mathrm{BK}}$ nicht-signifikante $\log \mathrm{FC}-$ Werte zeigten. Diese Gene werden in den folgenden Analysen als ,einseitig signifikant“ bezeichnet.

\subsubsection{Funktionelle Analyse der Gene mit einseitig signifikanten logFC- Werten}

Die Grafik in Abbildung 9 veranschaulicht den Zusammenhang der einseitig signifikanten Gene. Dabei können entweder die Stro- $1^{+\mathrm{BK}}$ beim Wechsel in das ODM signifikant heraufoder herunterreguliert sein, während die Stro- $1^{+\mathrm{ZK}}$ nicht signifikant verändert sind, oder umgekehrt.

Die 720 einseitig signifikanten Gene der Stro-1 ${ }^{+\mathbf{B K}}$ konnten wiederum in 398 hoch- und 322 herunterregulierte Gene separiert werden. Bei den 456 einseitig signifikanten Genen der Stro-1 $^{+\mathbf{Z K}}$ ergaben sich 176 hoch- und 280 herunterregulierte Gene, denen keine signifikant veränderten Gene der Beckenkammzellen gegenüberstanden. Diese vier Gengruppen wurden zur Analyse bezüglich ihrer biologischen Funktion der DAVID-Software zugeführt. Die screenshots in den Tabellen 6 und 7 zeigen die Ergebnisse der Auswertung über das Functional Annotation Clustering mit den empfohlenen Standardeinstellungen für die Stro- $1^{+\mathrm{BK}}$. Das Programm klassifiziert dabei die eingegebenen Gene und ordnet sie funktionellen Gruppen zu. Ähnliche Gengruppen werden in cluster zusammengefasst, um Redundanzen zu vermeiden. In Tabelle 6 zeigt die Analyse 43 cluster, die sich aus den 398 Genen ableiten, die bei den Stro- $1^{+\mathrm{BK}}$ signifikant überexprimiert und bei den Stro- $1^{+\mathrm{ZK}}$ keine signifikante Veränderung aufweisen. Für die 322 einseitig signifikant herunterregulierten Gene der Stro- $1^{+\mathrm{BK}}$ wurden 48 cluster gefunden (Tabelle 7). Die Wichtigkeit der 
entsprechenden Gen-Cluster wird durch den enrichment score beschrieben. Je bedeutender die zu analysierenden Gene für die funktionellen Gruppen sind, desto höher ist der score. Die Functional Annotation Chart im unteren Teil der screenshots gibt die Gewebeart an, in der die entsprechenden einseitig signifikanten Gene der Stro- $1^{+\mathrm{BK}}$ überrepräsentiert vorliegen. Die Stro- $1^{+B K}$ wurden hier als Beispiel für die weitere Betrachtung aufgeführt. Die Tabellen der noch zu beschreibenden Versuchsgruppen befinden sich im Anhang.

\section{Korrelation der $\log \mathrm{FC}$-Werte einseitig signifikanter Gene}

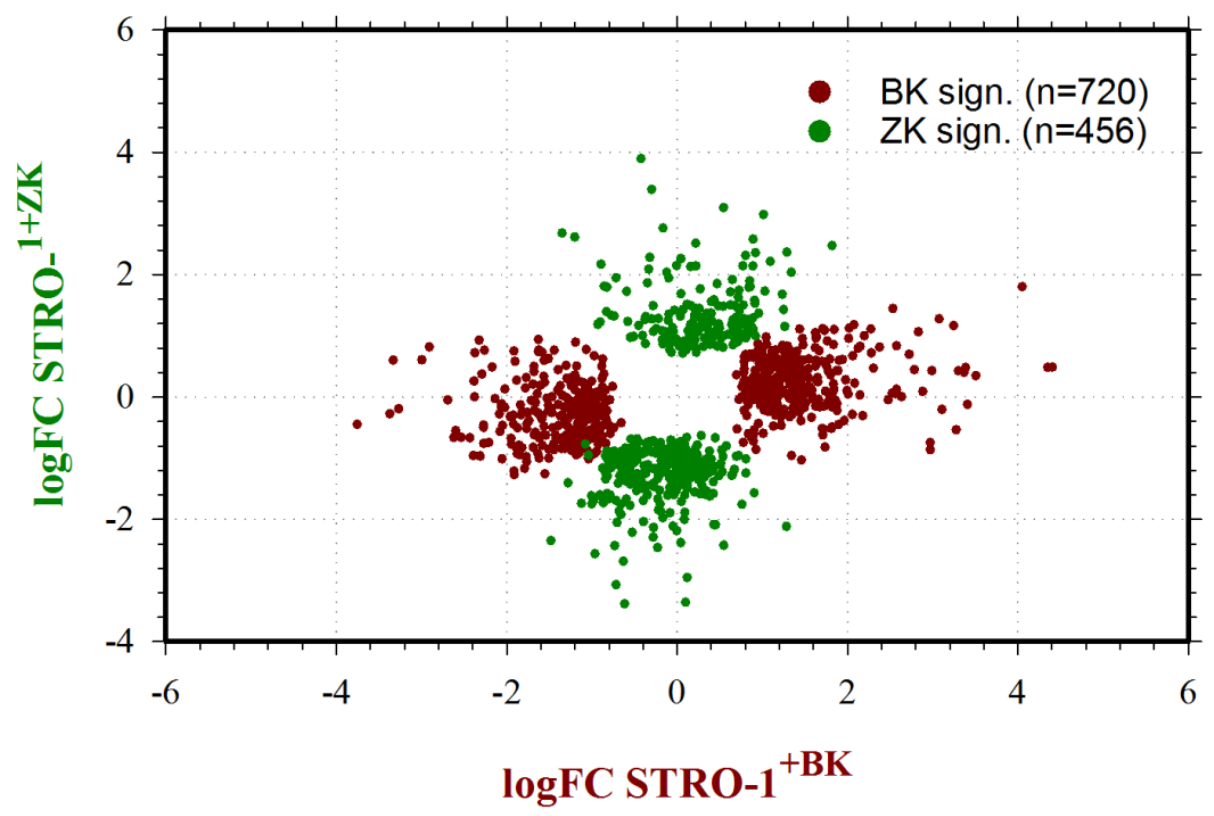

Abbildung 9: Korrelation der logFC-Werte einseitig signifikanter Gene (cut-off FDR $\leq 0,05$ ). Die dunkelroten Punkte stellen signifikante logFC-Werte der Stro- $1^{+\mathrm{BK}}$ dar, denen keine signifikanten Werte bei den Stro- $1^{+Z K}$ entsprechen. Bei den grünen Punkten sind die logFC-Werte der Zahnkeimzellen signifikant und die der Beckenkammzellen nicht. 
3.3.1.1 Gene mit signifikanten $\operatorname{logFC}-$ Werten bei den Stro-1 ${ }^{+B K}$ und nicht signifikanten $\log$ FC-Werten bei den Stro-1 ${ }^{+\mathrm{ZK}}$

Von den 720 einseitig signifikanten Genen der Stro- $1^{+\mathrm{BK}}$ waren 398 Gene hoch- und 322

Gene herunterreguliert, während die gleichen Gene der Stro- $1^{+\mathrm{ZK}}$ keine signifikante Veränderung zeigten. Die zugehörigen Gen-Cluster der DAVID-Auswertung finden sich in den Tabellen 6 und 7. Bei den hochregulierten Genen der Stro- $1^{+\mathrm{BK}}$ sind dies überwiegend Gruppen, die Proteine codieren, welche für die Zellmembran, die extrazelluläre Matrix und die Proteinkonfiguration notwendig sind. Einige dieser Gene haben auch eine große Bedeutung bei der Bildung von Leberzellen, der Plazenta sowie des Serumplasmas (Tabelle 6). Herunterreguliert werden Gene der Stro- $1^{+\mathrm{BK}}$, die an der Angiogenese, der Bildung von Endothelzellen und Signalproteinen (Pleckstrin-Homologie-Domäne) sowie an der Wachstumsfaktoraktivität beteiligt sind. Diese Gene sind außerdem zu einem Großteil in die Bildung von Gehirngewebe involviert (Tabelle 7). Die von DAVID generierte heatmap in Abbildung 10 zeigt die herunterregulierten Gene in den funktionellen Untergruppen zur Angiogenese.

Es fällt auf, dass sowohl bei den hoch- als auch herunterregulierten Genen der Stro- $1^{+\mathrm{BK}}$ gleiche funktionelle Gruppen vorhanden sind. Dies betrifft cluster 1 bei den hoch- und cluster 2 bei den herunterregulierten Genen mit den Untergruppen Glycoprotein, Signal, Secreted, Disulfide Bond und extracellular region. Diese haben bei den hochregulierten Genen aufgrund des höheren enrichment scores allerdings eine wesentlich größere Bedeutung. Wie sich die hoch- und herunterregulierten Gene der funktionellen Untergruppen für cluster 1 und cluster 2 unterscheiden, kann den heatmaps der Abbildungen A-1 und A-2 im Anhang entnommen werden. 
Tabelle 6: Funktionelle Gruppen der Gene, die bei den Stro- ${ }^{+}{ }^{-}$Beckenkammzellen einseitig signifikant hochreguliert sind. Diese zeigen bei den Stro- $1^{+}$-Zahnkeimzellen keine signifikante Veränderung $(n=398)$. In der Tabelle sind von insgesamt 43 clustern nur die ersten drei mit den höchsten enrichment scores dargestellt (screenshot aus DAVID Version 6.8).

\section{Functional Annotation Clustering}

\begin{tabular}{|c|c|c|c|c|c|c|}
\hline Annotation Cluster 1 & Enrichment Score: 12.91 & G & 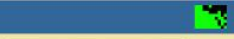 & Count & P_Value & Benjamini \\
\hline UP_KEYWORDS & Glycoprotein & RT & $\overline{\bar{z}}$ & 99 & $8.1 \mathrm{E}-18$ & $2.1 \mathrm{E}-15$ \\
\hline UP_SEQ_FEATURE & signal peptide & RT & $\equiv$ & 84 & $1.1 \mathrm{E}-17$ & $8.9 \mathrm{E}-15$ \\
\hline UP_SEQ_FEATURE & glycosylation site: $\mathrm{N}$-linked (GIcNAc...) & $\underline{\mathbf{R T}}$ & 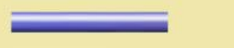 & 90 & $1.9 \mathrm{E}-14$ & $7.4 \mathrm{E}-12$ \\
\hline UP_KEYWORDS & Secreted & $\underline{\mathbf{R T}}$ & $\bar{\square}$ & 57 & $3.6 \mathrm{E}-14$ & $3.1 \mathrm{E}-12$ \\
\hline UP_SEQ_FEATURE & disulfide bond & $\underline{\mathbf{R T}}$ & $\bar{\square}$ & 62 & $2.4 \mathrm{E}-9$ & $6.4 \mathrm{E}-7$ \\
\hline Annotation Cluster 2 & Enrichment Score: 4.6 & (द) & 8 & Count & P_Value & Benjamini \\
\hline UP_KEYWORDS & Membrane & $\underline{\mathbf{R T}}$ & & 115 & $6.4 \mathrm{E}-10$ & $3.3 \mathrm{E}-8$ \\
\hline UP_KEYWORDS & Transmembrane & $\underline{\mathbf{R T}}$ & 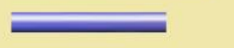 & 89 & $1.5 \mathrm{E}-7$ & $6.5 \mathrm{E}-6$ \\
\hline GOTERM_CC_DIRECT & integral component of membrane & $\underline{\mathbf{R T}}$ & $\overline{\bar{Z}}$ & 77 & $9.7 E-4$ & 2.7E-2 \\
\hline GOTERM_CC_DIRECT & plasma membrane & RT & $\bar{\equiv}$ & 61 & 5.7E-3 & $1.1 \mathrm{E}-1$ \\
\hline UP_SEQ_FEATURE & topological domain:Extracellular & $\underline{\mathbf{R T}}$ & $\bar{\equiv}$ & 40 & $1.2 \mathrm{E}-2$ & 4.2E-1 \\
\hline Annotation Cluster 3 & Enrichment Score: $\mathbf{3 . 9 9}$ & (G) & 7 & Count & P_Value & Benjamini \\
\hline GOTERM_BP_DIRECT & extracellular matrix organization & RT & $\equiv$ & 13 & $1.9 \mathrm{E}-6$ & $1.4 \mathrm{E}-3$ \\
\hline GOTERM_CC_DIRECT & proteinaceous extracellular matrix & $\underline{\text { RT }}$ & $\equiv$ & 12 & $1.6 \mathrm{E}-4$ & $8.9 \mathrm{E}-3$ \\
\hline UP_KEYWORDS & Extracellular matrix & RT & $\bar{\Xi}$ & 9 & $3.5 \mathrm{E}-3$ & $5.8 \mathrm{E}-2$ \\
\hline
\end{tabular}

\section{Functional Annotation Chart}

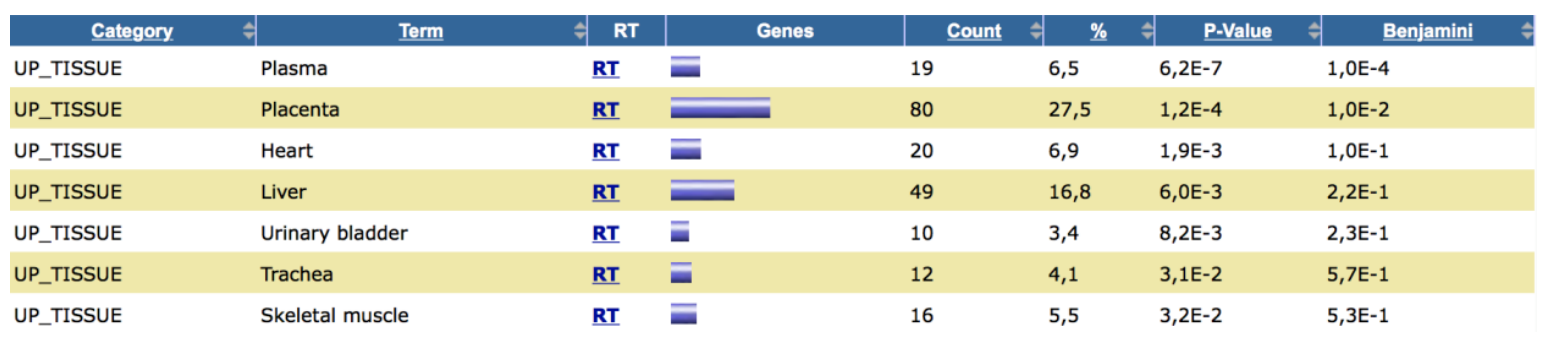


Tabelle 7: Funktionelle Gruppen der Gene, die bei den Stro- $1^{+}$-Beckenkammzellen einseitig signifikant herunterreguliert sind. Diese zeigen bei den Stro- $1^{+}$-Zahnkeimzellen keine signifikante Veränderung $(n=322)$. In der Tabelle sind von insgesamt 48 clustern nur die ersten vier mit den höchsten enrichment scores dargestellt (screenshot aus DAVID Version 6.8).

\section{Functional Annotation Clustering}

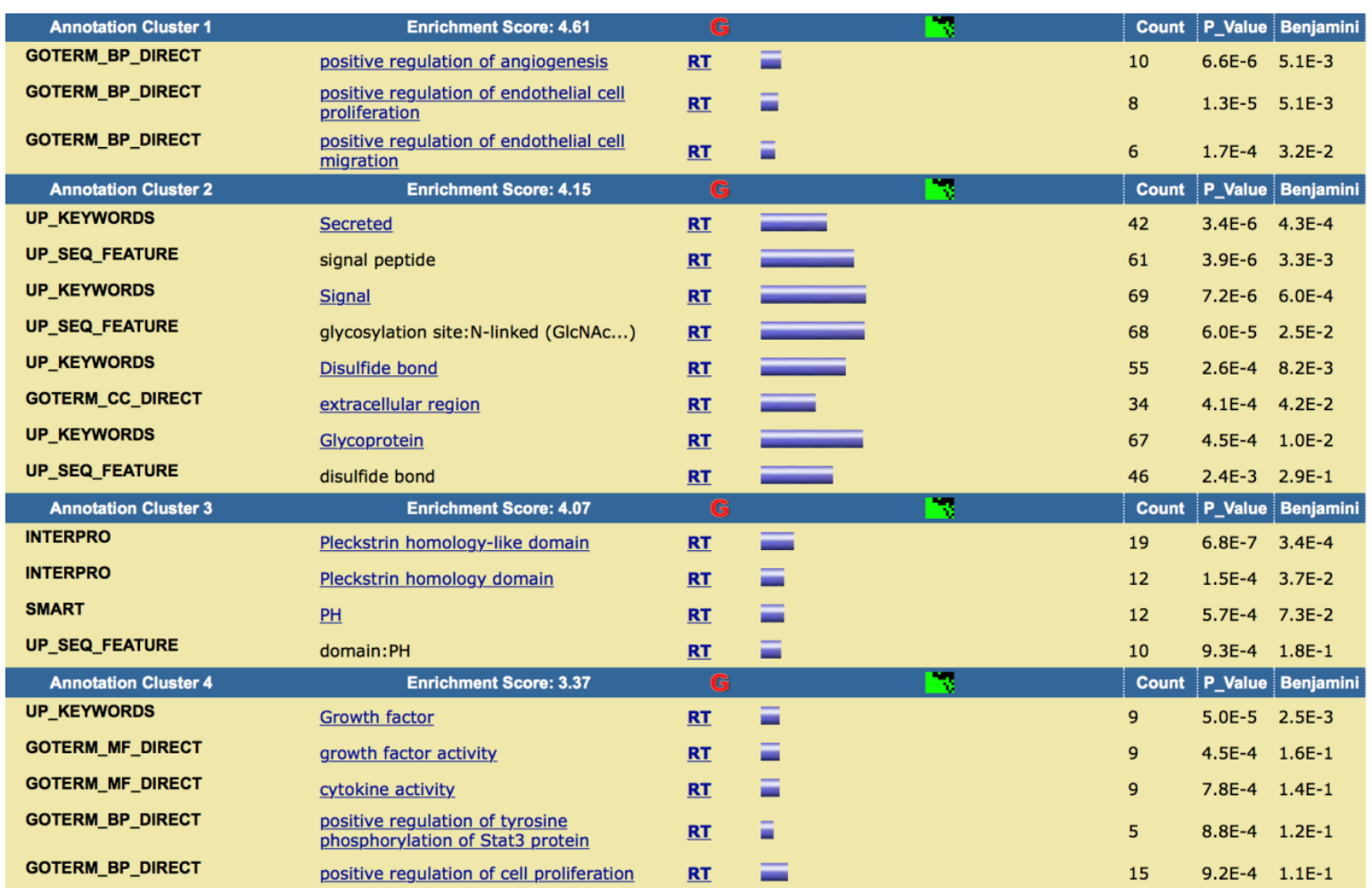

\section{Functional Annotation Chart}

\begin{tabular}{|c|c|c|c|c|c|c|c|}
\hline Category & Term & ثै $R T$ & Genes & Count & $\underline{\%}$ & P-Value & Benjamini \\
\hline UP_TISSUE & Kidney & $\underline{\mathbf{R T}}$ & $\bar{\equiv}$ & 34 & 14,2 & $9,7 E-4$ & $1,5 \mathrm{E}-1$ \\
\hline UP_TISSUE & Brain & $\underline{\mathbf{R T}}$ & $\overline{=}$ & 116 & 48,5 & $1,4 \mathrm{E}-2$ & $6,8 \mathrm{E}-1$ \\
\hline UP_TISSUE & Thyroid & $\underline{\mathbf{R T}}$ & $\bar{\Xi}$ & 6 & 2,5 & $5,4 \mathrm{E}-2$ & $8,9 \mathrm{E}-1$ \\
\hline UP_TISSUE & Thalamus & $\underline{\mathbf{R T}}$ & 三 & 7 & 2,9 & $6,0 \mathrm{E}-2$ & $8,6 \mathrm{E}-1$ \\
\hline
\end{tabular}




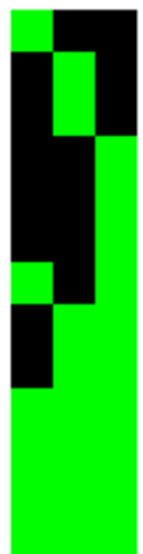

forkhead box P1(FOXP1)

Jun proto-oncogene, AP-1 transcription factor subunit(JUN)

C-C motif chemokine ligand 26(CCL26)

runt related transcription factor 1 (RUNX1)

chitinase 3 like 1(CHI3L1)

GATA binding protein 6 (GATA6)

SAM and $\mathrm{SH} 3$ domain containing 1(SASH1)

placental growth factor(PGF)

semaphorin 5A(SEMA5A)

vascular endothelial growth factor $A(V E G F A)$

Wnt family member 5A(WNT5A)

protein kinase $\mathrm{C}$ alpha(PRKCA)

programmed cell death 6(PDCD6)

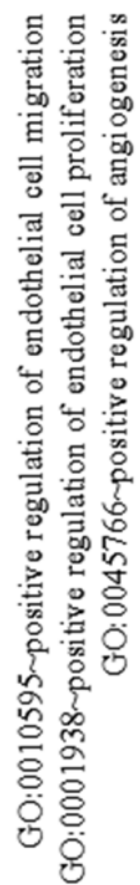

Abbildung 10: Heatmap der für die Angiogenese erkannten Gene der funktionellen Untergruppen aus cluster 1 (Tabelle 7; enrichment score $=4,61$ ). Diese sind bei den Stro- $1^{+}$-Beckenkammzellen signifikant herunterreguliert und zeigen bei den Stro- $1^{+}$-Zahnkeimzellen keine signifikante Veränderung (screenshot aus DAVID Version 6.8). 
3.3.1.2 Gene mit signifikanten $\operatorname{logFC}-$ Werten bei den Stro-1 ${ }^{+\mathrm{ZK}}$ und nicht signifikanten $\log$ FC-Werten bei den Stro-1 ${ }^{+\mathrm{BK}^{+}}$

Die Stro- $1^{+\mathrm{ZK}}$ wiesen 456 einseitig signifikant veränderte Gene auf, die bei den Stro- $1^{+\mathrm{BK}}$ keine Signifikanz zeigten. Dabei war im ODM gegenüber dem DMEM die Expression von 176 Genen hoch- und 280 Genen herunterreguliert.

In der Cluster-Analyse nach DAVID finden sich für die hochregulierten Gene der Stro- $1^{+\mathrm{ZK}}$ mit einem hohen enrichment score gleiche funktionelle Gruppen wie bei den oben beschriebenen Stro- $1^{+\mathrm{BK}}$ (Tabelle A-9 im Anhang). Die übereinstimmenden Untergruppen Glycoprotein, Disulfide Bond und Signal finden sich in cluster 1. Wie aus der heatmap im Anhang (Abbildung A-3) hervorgeht, sind hier jedoch andere Gene involviert. Mit einem relativ hohen enrichment score weist cluster 2 in den funktionellen Untergruppen Gene auf, die eine Rolle bei der Bildung und Funktion von Zellmembranen spielen. Die cluster 3 und 4 beinhalten dagegen Gengruppen, die für die extrazelluläre Matrix, die Kollagen- und Hartsubstanzbildung verantwortlich sind. Unter den hochregulierten Genen befinden sich auch solche, die bei der Bildung von Plazenta- und Lungengewebe eine wichtige Bedeutung haben (Functional Annotation Chart der Tabelle A-9 im Anhang).

Die Gen-Cluster für die herunterregulierten Gene der Stro- $1^{+Z K}$ sind in Tabelle A-10 im Anhang aufgelistet. In cluster 1 (Abbildung A-4 im Anhang) werden auch hier Gene herunterreguliert, die denselben funktionellen Gruppen angehören wie in cluster 1 der oben beschriebenen hochregulierten Gene. Cluster 2 beinhaltet Gene, die an der Synapsenbildung und Zellverbindung beteiligt sind (Abbildung A-5 im Anhang). Cluster 3 bildet wie bei den hochregulierten Genen die Gruppe der extrazellulären Matrix ab (Abbildung A-6 im Anhang). Herunterreguliert werden von den Stro- $1^{+Z K}$ auch Gene, die für die Bildung von Gehirn- und Plazentagewebe sowie für die Skelettmuskulatur verantwortlich sind (Functional Annotation Chart der Tabelle A-10 im Anhang). 
3.3.2 Funktionelle Analyse der Gene mit beidseitig signifikanten logFCWerten

Neben den Genen mit einseitig signifikanten $\operatorname{logFC}$-Werten konnten vier weitere Gruppen herausgefiltert werden, die sich aus jenen Genen zusammensetzen, deren logFC-Werte für beide Zelltypen gemeinsam signifikant waren. Diese als „,beidseits signifikant“ bezeichneten Gengruppen sind in Abbildung 11 dargestellt und korreliert. Es ergaben sich jeweils zwei Gruppen mit gleichsinnig verlaufenden logFC-Werten sowie zwei Gruppen mit gegensinnig verlaufenden $\operatorname{logFC}$-Werten. Das Koordinatensystem der Abbildung 11 wurde hierzu in vier Quadranten (QI bis IV) aufgeteilt. In QI sind die logFC-Werte der Gene beider Zelltypen zu finden, die gleichsinnig im ODM heraufreguliert (++) werden, in QIII sind die gleichsinnig im ODM herunterregulierten (--) logFC-Werte dargestellt. QII und QIV repräsentieren die Gene mit gegensinnigen $\operatorname{logFC}$-Werten.

\section{Korrelation der $\log \mathrm{FC}-$ Werte beidseitig signifikanter Gene}

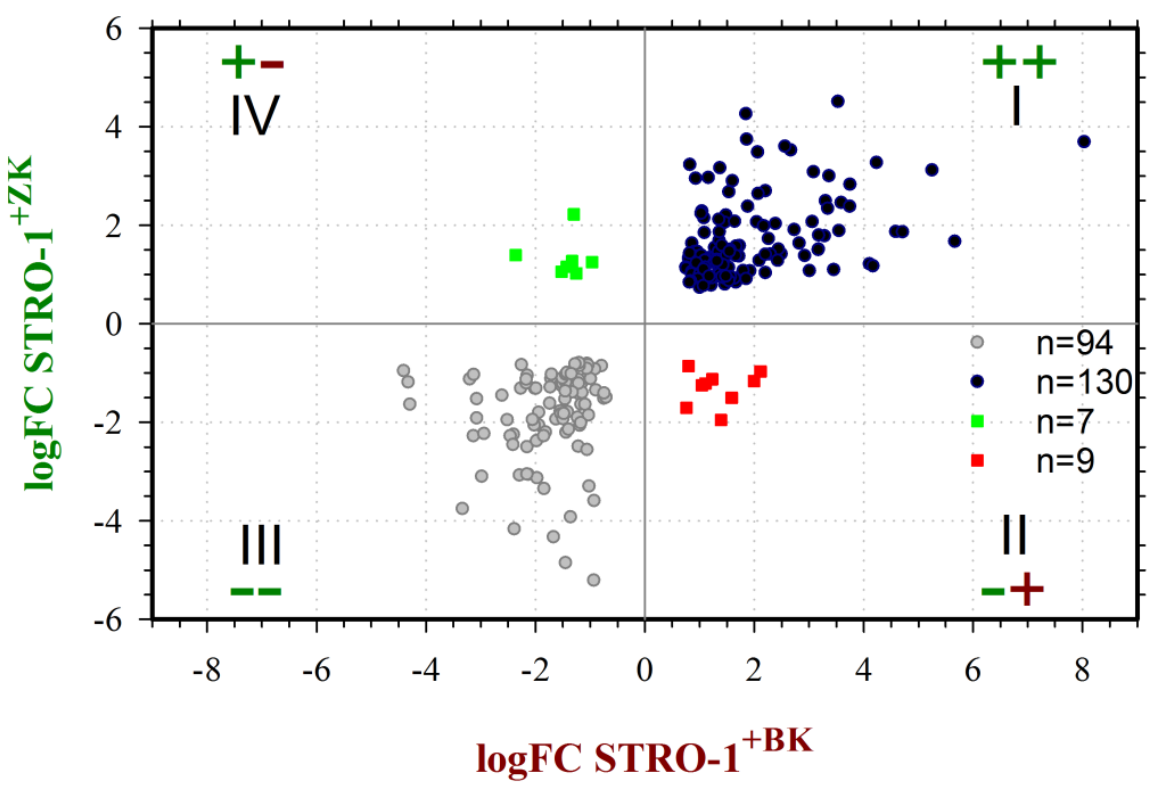

Abbildung 11: Korrelation der logFC-Werte beidseitig signifikanter Gene (cut-off FDR $\leq 0,05$ ). Das Koordinatensystem kann dabei in die oben genannten vier Quadraten aufgeteilt werden, die jeweils charakteristische Werte aufweisen. In den Quadranten I und III verhalten sich beide Zelltypen gleichsinnig. Quadrant I beschreibt die Gene, welche im ODM gleichsinnig heraufreguliert (++) werden. Quadrant III umfasst die gleichsinnig herunterregulierten (--) Gene. In den Quadranten II und IV verhalten sich die Zelltypen gegensinnig, in II wird die Genexpression in den Stro- $1^{+\mathrm{BK}}$ herauf- und in den Stro- $1^{+\mathrm{ZK}}$ herunterreguliert (-+), in Quadrant IV ist es umgekehrt (+-). 
Die 130 gleichsinnig im ODM heraufregulierten Gene werden in der DAVID-Analyse funktionellen Gruppen zugeordnet, die bereits bei den Genen mit einseitig signifikanten $\operatorname{logFC}$-Werten in Kapitel 3.3.1 beschrieben wurden. Ein screenshot der drei wichtigsten Gen-Cluster des Functional Annotation Clustering findet sich im Anhang in Tabelle A-14. Unter cluster 1 werden die funktionellen Gruppen der extrazellulären Matrix zusammengefasst (Abbildung 12). In cluster 2 finden sich die bekannten Untergruppen Secreted, Disulfide Bond, Glycoprotein, Signal und extracellular region (Abbildung 13).

Für die 94 gleichsinnig im ODM herunterregulierten Gene finden sich für beide Zellarten 2 cluster (Tabelle A-15 im Anhang), zu denen unter cluster 1 oben gennannte Untergruppen gehören. Die zugehörige heatmap in Abbildung 15 zeigt aber, dass es sich trotz gleicher funktioneller Untergruppen um verschiedene Gene handelt. Einige der gleichsinnig herunterregulierten Gene finden sich auch in Melanomzellen, dem fetalen Hirn und sind an der Bildung von Serumplasma beteiligt (Functional Annotation Chart der Tabelle A-15 im Anhang).

In den nachfolgenden heatmaps wird die genaue Zusammensetzung der oben beschriebenen Gen-Cluster verdeutlicht und auf Unterschiede bzw. Gemeinsamkeiten hingewiesen. 


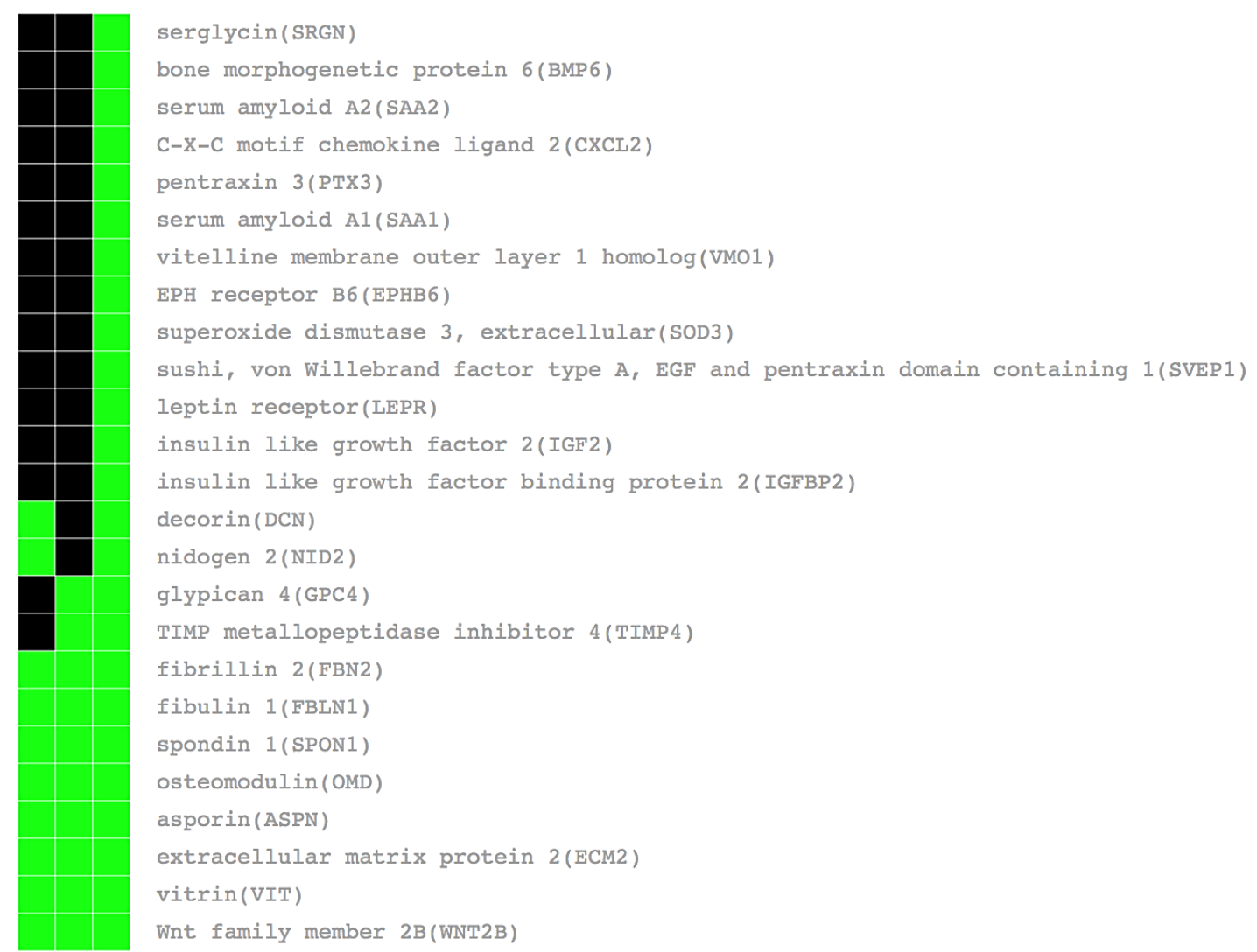

Abbildung 12:

Heatmap der Gene aus cluster 1 mit den funktionellen Untergruppen Extracellular Matrix und Secreted der gleichsinnig signifikant heraufregulierten Gene von Stro- $1^{+Z K}$ und Stro- $1^{+B K}$ (Tabelle A-14; screenshot aus DAVID Version 6.8). Die Gene SAA1, BMP6, IGFBP2 und DCN gehören zu den zehn höchstsignifikant exprimierten Genen. 


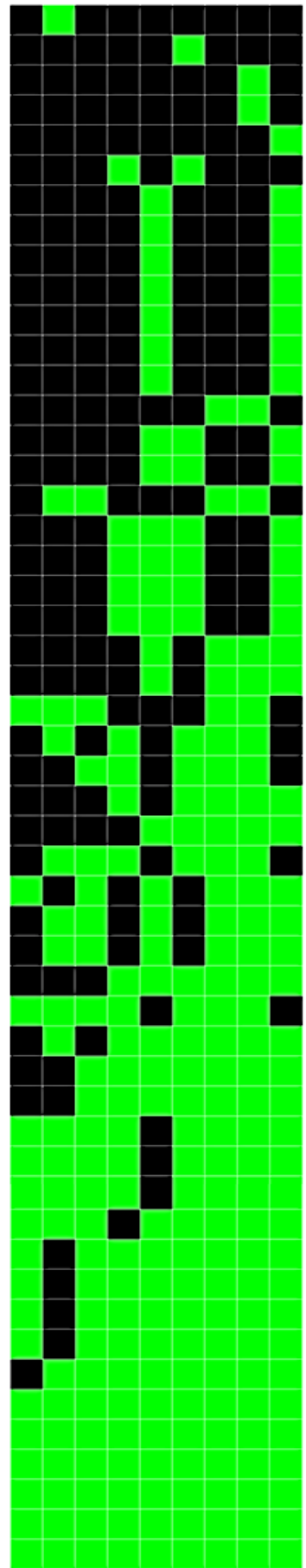

CKLF like MARVEL transmembrane domain containing 8(CMTM8)

thioredoxin interacting protein(TXNIP)

interleukin 1 receptor associated kinase 3(IRAK3)

ubiquitin protein ligase E3 component n-recognin 3 (putative)(UBR3)

peroxisome proliferator activated receptor gamma(PPARG)

glutaredoxin (GLRX)

UDP-GlCNAC: betaGal beta-1,3-N-acetylglucosaminyltransferase 5(B3GNT5)

glycoprotein M6B(GPM6B)

ATP binding cassette subfamily A member 8 (ABCA8)

potassium two pore domain channel subfamily $\mathrm{K}$ member 6 (KCNK6)

solute carrier family 9 member A9(SLC9A9)

adenylate cyclase 3 ( $A D C Y 3$ )

transmembrane and tetratricopeptide repeat containing 1(TMTC1)

methyltransferase like 7A(METTL7A)

carbohydrate sulfotransferase 2(CHST2)

solute carrier family 38 member 4 (SLC38A4)

serum amyloid A2(SAA2)

adrenoceptor alpha 1B(ADRA1B)

prostaglandin E receptor 4 (PTGER4)

prostaglandin $\mathrm{E}$ receptor 2 (PTGER2)

membrane metalloendopeptidase (MME)

APC down-regulated 1 (APCDD1)

reticulocalbin 1 ( $\mathrm{RCN} 1$ )

serum amyloid A1(SAA1)

receptor activity modifying protein 1(RAMP1)

vitelline membrane outer layer 1 homolog(VMO1)

natriuretic peptide receptor 3 (NPR3)

plexin A2 (PLXNA2)

TIMP metallopeptidase inhibitor 4(TIMP4)

EPH receptor B6 (EPHB6)

glypican 4 (GPC4)

extracellular matrix protein 2 (ECM2)

sortilin 1(SORT1)

$\mathrm{C}-\mathrm{X}-\mathrm{C}$ motif chemokine ligand 2(CXCL2)

carboxypeptidase $\mathrm{M}$ ( CPM)

vitrin(VIT)

asporin (ASPN)

serglycin (SRGN)

insulin like growth factor 2(IGF2)

insulin like growth factor binding protein 2(IGFBP2)

Wht family member $2 B$ (WNT2B)

sushi, von willebrand factor type A, EGF and pentraxin domain containing 1 (SVEP1)

leptin receptor(LEPR)

nidogen 2 (NID2)

fibrillin 2(FBN2)

spondin 1 (SPON1)

decorin (DCN)

fibulin 1(FBLN1)

bone morphogenetic protein 6 (BMP6)

osteomodulin (OMD)

superoxide dismutase 3, extracellular(SOD3)

pentraxin $3(\mathrm{PTX} 3)$

\section{Abbildung 13:}

Heatmap der Gene der funktionellen Untergruppen aus cluster 2 der gleichsinnig signifikant heraufregulierten Gene von Stro-1 $1^{+Z K}$ und Stro- $^{1^{+B K}}$ (Tabelle A-14; screenshot aus DAVID Version 6.8). Hier finden sich sechs Gene, die allen funktionellen Gruppen zugeordnet werden können. SAA1 und IGFBP2 zählen zu den am höchsten exprimierten Genen. 


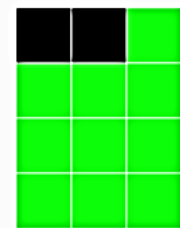

peroxisome proliferator activated receptor gamma(PPARG)

Fos proto-oncogene, AP-1 transcription factor subunit(FOS)

NFKB inhibitor alpha(NFKBIA)

FYN proto-oncogene, Src family tyrosine kinase(FYN)

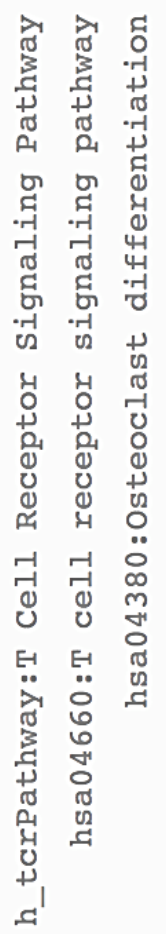

Abbildung 14:

Heatmap der Gene der funktionellen Untergruppen aus cluster 15 (in Tabelle A-14 nicht aufgeführt; screenshot aus DAVID Version 6.8) der gleichsinnig signifikant heraufregulierten Gene von Stro- $1^{+Z K}$ und Stro- $1^{+B K}$. Es sind vier Gene aufgeführt, die für die Osteoklastendifferenzierung wichtig und bei beiden Zellarten hochreguliert sind. 


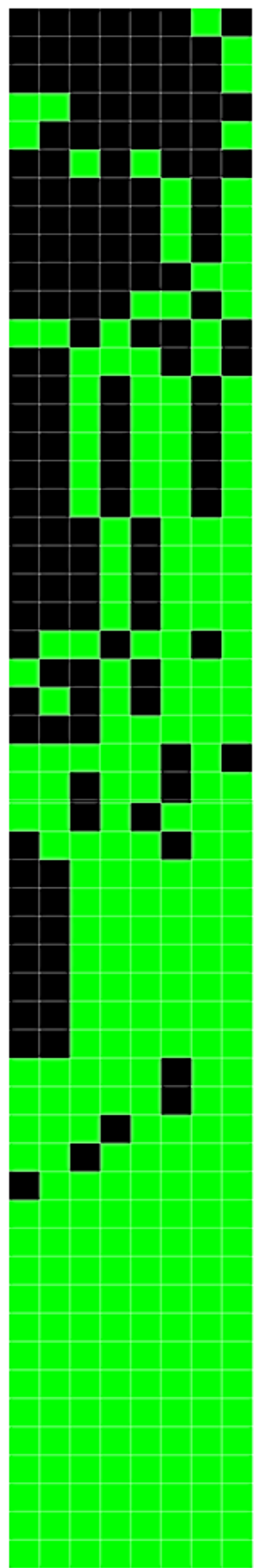

formin homology 2 domain containing 3(FHOD3)

neurofilament, medium polypeptide(NEFM)

internexin neuronal intermediate filament protein alpha(INA)

fibroblast growth factor 2(FGF2)

hemoglobin subunit alpha 1(HBA1)

alpha kinase 2(ALPK2)

immediate early response 3 (IER3)

family with sequence similarity 155 member A(FAM155A)

transmembrane protein 200A(TMEM200A)

ras-related C3 botulinum toxin substrate 2 (rho family, small GTP binding protein Rac2)(RAC2) exostosin glycosyltransferase 1(EXT1)

interleukin 11(IL11)

matrix metallopeptidase 14(MMP14)

adrenoceptor alpha 2C(ADRA2C)

heparan sulfate-glucosamine 3-sulfotransferase 3A1(HS3ST3A1)

exostosin like glycosyltransferase 1 (EXTL1)

bradykinin receptor $\mathrm{B} 1$ (BDKRB1)

G protein-coupled receptor 68 (GPR68)

chromosome 11 open reading frame 87 (C11orf 87$)$

leucine rich repeat containing 15(LRRC15)

podocalyxin like(PODXL)

APC down-regulated 1 like(APCDD1L)

ectonucleotide pyrophosphatase/phosphodiesterase 1(ENPP1)

LY6/PLAUR domain containing 1(LYPD1)

collagen triple helix repeat containing 1(CTHRC1)

repulsive guidance molecule family member $b(R G M B)$

$\mathrm{C}-\mathrm{X}-\mathrm{C}$ motif chemokine ligand 12 ( $\mathrm{CXCL} 12)$

endothelial cell specific molecule 1(ESM1)

arylsulfatase family member I(ARSI)

SPARC/osteonectin, cwCv and kazal like domains proteoglycan 1(SPOCK1)

integrin subunit alpha 2 (ITGA2)

neurotrimin(NTM)

frizzled class receptor 8 (FZD8)

adhesion molecule with Ig like domain 2(AMIGO2)

opioid binding protein/cell adhesion molecule like(OPCML)

netrin G1(NTNG1)

CD44 molecule (Indian blood group) (CD44)

heparin binding EGF like growth factor(HBEGF)

insulin like growth factor binding protein 5(IGFBP5)

neuregulin 1(NRG1)

Wht family member $7 \mathrm{~B}(\mathrm{WNT} 7 \mathrm{~B})$

hemicentin 1 (HMCN1)

ADAM metallopeptidase domain 12 (ADAM12)

plasminogen activator, urokinase(PLAU)

follistatin(FST)

ADAM metallopeptidase with thrombospondin type 1 motif 5 (ADAMTS5)

gremlin 2, DAN family BMP antagonist(GREM2)

inhibin beta A subunit(INHBA)

insulin like growth factor binding protein 3(IGFBP3)

tenascin $\mathrm{C}(\mathrm{TNC})$

clusterin(CLU)

vascular endothelial growth factor C(VEGFC)

matrix metallopeptidase 2 (MMP2)

matrix metallopeptidase 1 (MMP1)

pregnancy specific beta-1-glycoprotein 11(PSG11)

\section{Abbildung 15:}

Heatmap der Gene der funktionellen Untergruppen aus cluster 1 der gleichsinnig signifikant herunterregulierten Gene von Stro- $1^{+Z K}$ und Stro- $1^{+B K}$ (Tabelle A-15; screenshot aus DAVID Version 6.8). 13 Gene gehören den acht Untergruppen gemeinsam an. POXL, GPR68 und IGFBP3 zählen zu den zehn am höchsten herunterregulierten Genen. 
Für beide Stammzelltypen existieren insgesamt 16 Gene, die sich in ihrer Expression gegensinnig verhalten. Davon werden neun Gene bei den Stro-1 ${ }^{+\mathbf{B K}}$ herauf- und bei den Stro- $^{+\mathrm{ZK}}$ herunterreguliert, aufgeführt in Tabelle 8 sowie in Abbildung 16 als heatmap mit den zugehörigen funktionellen Untergruppen des Functional Annotation Clustering (Tabelle A-16 im Anhang). Diese Gene sind an Zelladhäsion, der Glykoprotein- und Signalbildung sowie den Zellmembranproteinen beteiligt. Sechs Gene stehen im Zusammenhang mit Polymorphismus, drei Gene zeigen einen Bezug zu Transkriptionsfaktoren. Drei der neun Gene sind an der Bildung der Skelettmuskulatur beteiligt.

Tabelle 8: Identische Gene, die in den Stro- $1^{+\mathrm{BK}}$ signifikant herauf- und in den Stro- $1^{+Z K}$ herunterreguliert sind $(n=9)$. Die Gene sind alphabetisch aufsteigend nach ihrem Symbol geordnet.

\begin{tabular}{|l|l|}
\hline Gensymbol & Genname \\
\hline ACTG2 & actin, gamma 2, smooth muscle, enteric \\
\hline CD24 & CD24 molecule \\
\hline DUSP26 & dual specificity phosphatase 26 (putative) \\
\hline ITGA7 & integrin, alpha 7 \\
\hline NRP2 & neuropilin 2 \\
\hline NR4A1 & nuclear receptor subfamily 4, group A, member 1 \\
\hline SPP1 & secreted phosphoprotein 1 \\
\hline SORBS1 & sorbin and SH3 domain containing 1 \\
\hline TNFRS21 & tumor necrosis factor receptor superfamily, member 21 \\
\hline
\end{tabular}

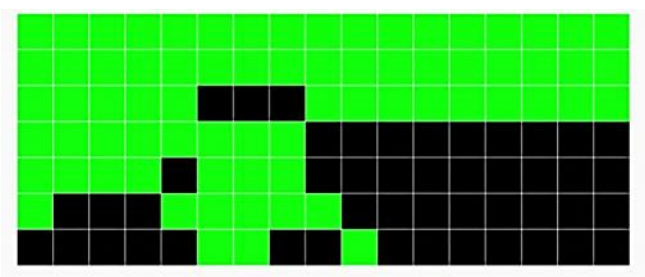

integrin subunit alpha 7 (ITGA7) neuropilin 2(NRP2) TNF receptor superfamily member 21(TNFRSF21) CD24 molecule(CD24) secreted phosphoprotein 1(SPP1) sorbin and SH 3 domain containing 1 (SORBS1) nuclear receptor subfamily 4 group A member 1(NR4A1)

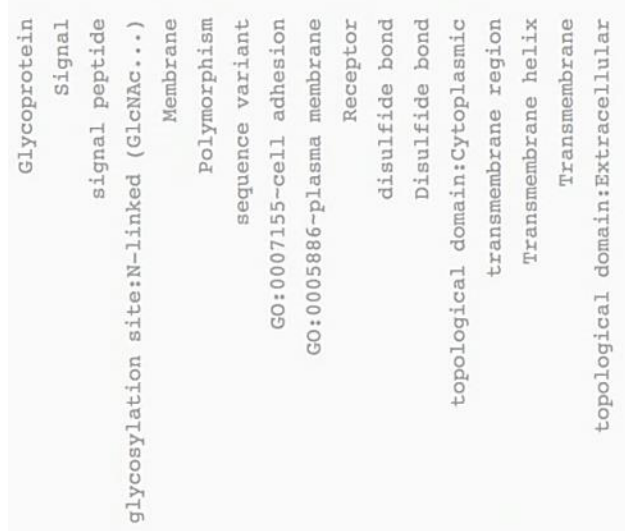

Abbildung 16: Heatmap der gegensinnig exprimierten Gene (horizontale Beschriftung) mit den zugehörigen funktionellen Untergruppen (vertikale Beschriftung). 
Die sieben Gene in Tabelle 9, die bei den Stro-1 ${ }^{+\mathbf{B K}}$ herunter- und bei den Stro-1 ${ }^{+ \text {ZK }}$ heraufreguliert sind, konnten nur jeweils einem einzigen Gen-Cluster mit drei funktionellen Untergruppen zur Membranbildung oder dem alternativen Spleißen der DNA zugeordnet werden (Tabelle A-17 im Anhang).

Tabelle 9: Identische Gene, die in den Stro- $1^{+\mathrm{BK}}$ signifikant herunter- und in den Stro- $1^{+\mathrm{ZK}}$ heraufreguliert sind $(n=7)$. Die Gene sind alphabetisch aufsteigend nach ihrem Symbol geordnet.

\begin{tabular}{|l|l|}
\hline Gensymbol & Genname \\
\hline FOXQ1 & forkhead box Q1 \\
\hline HES1 & hairy and enhancer of split 1, (Drosophila) \\
\hline KIAA1199 & KIAA1199 \\
\hline CMKLR1 & chemokine-like receptor 1 \\
\hline CCL2 & chemokine (C-C motif) ligand 2 \\
\hline PHLDA1 & pleckstrin homology-like domain, family A, member 1 \\
\hline PLEKHA4 & $\begin{array}{l}\text { pleckstrin homology domain containing, family A (phosphoinositide binding specific) } \\
\text { member 4 }\end{array}$ \\
\hline
\end{tabular}




\subsection{Funktionelle Unterschiede der Stro-1 ${ }^{+\mathrm{ZK}}$ und Stro-1 ${ }^{+\mathrm{BK}}$ im osteo- genen Medium}

In den vorangegangenen Kapiteln 3.2 und 3.3 wurde die differentielle Genexpression beider Stammzellpopulationen beim Wechsel vom DMEM ins ODM untersucht. Um einen Vergleich der Genexpression von Stro- $1^{+\mathrm{ZK}}$ und Stro- ${ }^{+\mathrm{BK}}$ im osteogenen Differenzierungsmedium vornehmen zu können, wurden die Rohdaten nach dem Vorgehen in Kapitel 3.1 sortiert. Die Differenzbildung lautete entsprechend „, $\log \mathrm{FC}=\log _{2}(\mathrm{ZK}$ im ODM $)$ minus $\log _{2}(\mathrm{BK}$ im ODM)“ und wird nachfolgend mit ZK2-BK2 abgekürzt. Die anschließende Filterung erfolgte zunächst nach den Kriterien FDR $\leq \mathbf{1} \%$ und $|\operatorname{logFC}|>\mathbf{2}$ und begrenzte die Anzahl von 22.454 Genen auf 375 Gene mit signifikant veränderten Expressionswerten. Davon zeigten 109 Gene eine hochregulierte Expression (positive logFC-Werte) bei den Zahnkeimzellen (ZK2) gegenüber den Beckenkammzellen (BK2). Für 266 Gene war die Expression bei ZK2 im Vergleich zu BK2 herunterreguliert (negative logFCWerte). Umgekehrt entspricht dies einer hochregulierten Genexpression bei den Beckenkammzellen. Mithilfe des Programms DAVID wurden innerhalb der gefilterten Daten über das Functional Annotation Tool Gengruppen detektiert, die in biologischen Prozessen wichtige Funktionen übernehmen.

\subsubsection{Im ODM hochregulierte Gene der Stro-1 ${ }^{+\mathrm{ZK}}$}

Für die 109 Gene, welche im ODM bei den Stro- $1^{+Z K}$ gegenüber den Stro- $1^{+B K}$ eine Hochregulation erfahren, wurden 118 GO-terms der Kategorie biological process gefunden. Die Tabelle 10 listet die ersten zehn funktionellen Gengruppen (terms) auf.

Im ODM exprimieren die Stro- $1^{+\mathrm{ZK}}$ insbesondere Gene, die in die Zellproliferation, Organentwicklung sowie Organisation der extrazellulären Matrix eingebunden sind. Verdeutlicht wird dies durch die GO-terms organ morphogenesis, extracellular matrix/structure organization sowie positive regulation of cell proliferation. Daneben finden sich unter den ersten zehn signifikanten Gengruppen auch Prozesse, die bei der Drüsenentwicklung eine Rolle spielen. Einzelne Gene können dabei Gegenstand verschiedener Gruppen sein, wenn sie für mehrere biologische Prozesse von Bedeutung sind. 
Tabelle 10: Die ersten zehn im ODM bei den Stro-1 ${ }^{+}-$Zahnkeimzellen signifikant hochregulierten (= bei den Stro- $1^{+}$-Beckenkammzellen signifikant herunterregulierten) funktionellen Gruppen (nach DAVID Version 6.8). Die Tabellen sind nach der aufsteigenden Höhe der $p$-Werte sortiert.

\begin{tabular}{|c|c|c|c|c|c|}
\hline Term & Genes & Count & $\underline{\%}$ & P-Value & Benjamini \\
\hline organ morphogenesis & $\overline{\bar{E}}$ & 19 & 20,0 & $1,4 \mathrm{E}-6$ & $3,9 \mathrm{E}-3$ \\
\hline extracellular matrix organization & 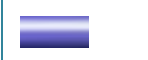 & 11 & 11,6 & $6,1 \mathrm{E}-6$ & $8,3 \mathrm{E}-3$ \\
\hline extracellular structure organization & $\bar{\square}$ & 11 & 11,6 & $6,3 \mathrm{E}-6$ & $5,7 E-3$ \\
\hline epithelium development & $\overline{0}$ & 18 & 18,9 & $1,5 \mathrm{E}-5$ & $1,0 \mathrm{E}-2$ \\
\hline positive regulation of cell proliferation & $\bar{\equiv}$ & 16 & 16,8 & $1,7 \mathrm{E}-5$ & $9,3 E-3$ \\
\hline collagen metabolic process & $\equiv$ & 7 & 7,4 & $1,8 \mathrm{E}-5$ & $8,2 E-3$ \\
\hline mesenchyme development & $\bar{\square}$ & 9 & 9,5 & $2,2 \mathrm{E}-5$ & $8,4 \mathrm{E}-3$ \\
\hline $\begin{array}{l}\text { multicellular organismal macromolecule metabolic } \\
\text { process }\end{array}$ & $=$ & 7 & 7,4 & $2,3 \mathrm{E}-5$ & $7,9 \mathrm{E}-3$ \\
\hline gland development & $\bar{\equiv}$ & 11 & 11,6 & $4,5 E-5$ & $1,4 \mathrm{E}-2$ \\
\hline mammary gland development & $=$ & 7 & 7,4 & $5,1 \mathrm{E}-5$ & $1,4 \mathrm{E}-2$ \\
\hline
\end{tabular}

In den GO-terms organ morphogenesis und epithelium development (in Tabelle 10 gelb markiert) finden sich neben einigen spezifische Homeobox-Genen der Odontogenese (siehe Tabelle 11) weitere wichtige Gene, die im Zusammenhang mit der Zahnentwicklung stehen. Dazu gehören $\boldsymbol{F O X F 1}$ und $\boldsymbol{F O X F 2}$ (forkhead box F1 und F2), welche für die gleichnamigen Transkriptionsfaktoren codieren. Auffällig sind zudem die Gene GREMI (gremlin 1), PTN (pleiotrophin) und $\boldsymbol{F S T}$ (follistatin), welche im ODM bei den Stro- $1^{+Z \mathrm{~K}}$ gegenüber den Stro- $1^{+\mathrm{BK}}$ eine signifikante Hochregulation in ihrer Expression aufweisen.

Tabelle 11: Homeobox-Gene, die bei den Stro- $1^{+2 \mathrm{~K}}$ im ODM für den GO-term organ morphogenesis hochreguliert sind. Die Gene sind aufsteigend nach der Höhe der FDR sortiert.

\begin{tabular}{|l|l|c|c|}
\hline \multicolumn{2}{|l|}{ organ morphogenesis } & logFC ZK2-BK2 & FDR ZK2-BK2 \\
\hline Symbol & Genname & 3,816 & $1,07 E-08$ \\
\hline MSX1 & msh homeobox 1 & 2,639 & $1,40 E-08$ \\
\hline DLX1 & distal-less homeobox 1 & 2,703 & $8,67 E-07$ \\
\hline SIX1 & SIX homeobox 1 & 3,367 & 1,64 E-06 \\
\hline PAX9 & paired box 9 & & \\
\hline
\end{tabular}


Je strenger die Auswahl der Gene über die cut-offs von FDR und $\operatorname{logFC}$ erfolgt, desto signifikanter, aber auch geringer wird die entsprechend selektierte Genanzahl. Die geringe Zahl der hochsignifikanten Gene ist allerdings mit einem Verlust der biologischen Relevanz des Gesamtergebnisses der differentiellen Genexpression verbunden. Aus diesem Grund wurden die 22.454 Gene für ZK2 und BK2 zusätzlich alleine nach dem Kriterium FDR $\leq 5 \%$ gefiltert. Es ergibt sich eine größere Anzahl an Genen, die statistisch weniger signifikant ist, aber das gesamte differentielle Expressionsverhalten der Stro- $1^{+\mathrm{ZK}}$ und Stro- $1^{+\mathrm{BK}}$ besser abbildet. Die $\log \mathrm{FC}-$ Werte können dabei $|\log \mathrm{FC}|<1$ sein. Insgesamt verblieben nach der Filterung 2583 Gene, von denen 1105 Gene bei den Stro-1 ${ }^{+\mathbf{Z K}}$ (positive $\log$ FC-Werte) und 1478 Gene bei den Stro-1 ${ }^{+\mathbf{B K}}$ (negative $\log$ FC-Werte) im ODM hochreguliert waren. Um einen besseren Gesamtüberblick über die funktionellen Zusammenhänge der exprimierten Gene zu erhalten, wurde das Functional Annotation Clustering der DAVID-Software mit den empfohlenen Standardeinstellungen verwendet. Die $1105 \mathrm{im}$ ODM hochregulierten Gene der Stro- $1^{+\mathrm{ZK}}$ konnten auf 151 cluster verteilt werden. Ein screenshot der ersten fünf cluster mit den dazugehörigen Annotationen findet sich in Tabelle 12 .

Die funktionellen Untergruppen der cluster 1,2 und 3 beinhalten für die Stro- $1^{+\mathrm{ZK}}$ Gene, welche die Zellteilung und den Zellzyklus unterstützen, die DNA reparieren und die hierfür benötigte Energie bereitstellen. Diese wurden in den nachfolgenden Abbildungen 17 bis 19 als heatmap visualisiert. Im weiteren Verlauf finden sich in cluster 54 (Abbildung 20) und 126 (Abbildung 21) Homeobox-Gene und Transkriptionsfaktoren, die sich teilweise mit den in Tabelle 11 aufgeführten Genen überschneiden. Im Rahmen der Kollagensynthese in cluster 85 (Abbildung 22) sind die Gene der Kollagene IV, X, XIII und XVIII (COL4A5, COL10A1, COL13A1, COL18A1) bei den Stro-1 ${ }^{+\mathrm{ZK}}$ im ODM überexprimiert. Es finden sich dagegen kaum Gene, die mit der Hartsubstanzbildung im Zusammenhang stehen. 
Tabelle 12: Die ersten fünf signifikant hochregulierten Gen-Cluster der Stro- $1^{+Z K}$ (= herunterregulierten Gen-Cluster der Stro-1 ${ }^{+B K}$ ) im ODM (screenshot aus DAVID Version 6.8).

\section{Functional Annotation Clustering}

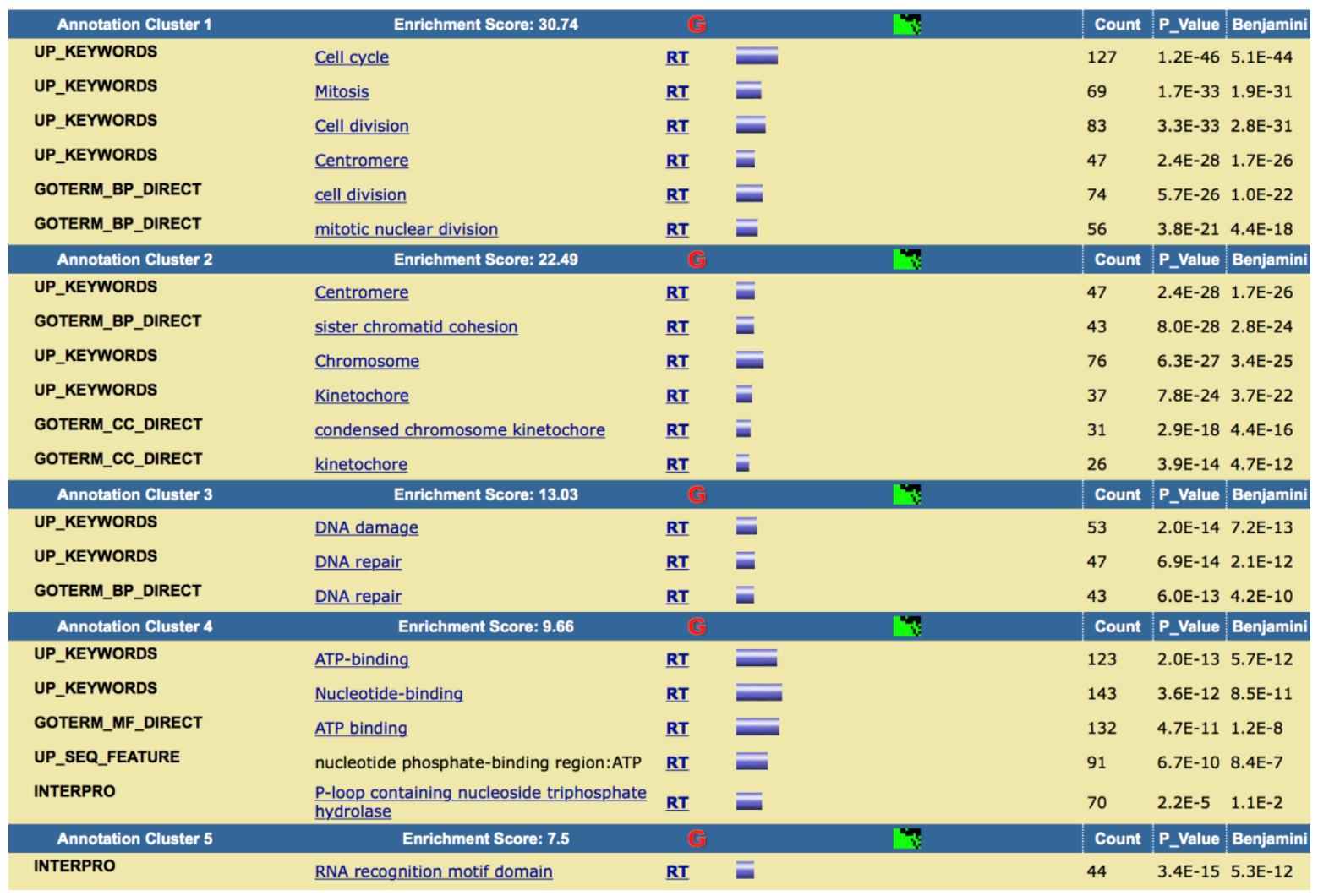



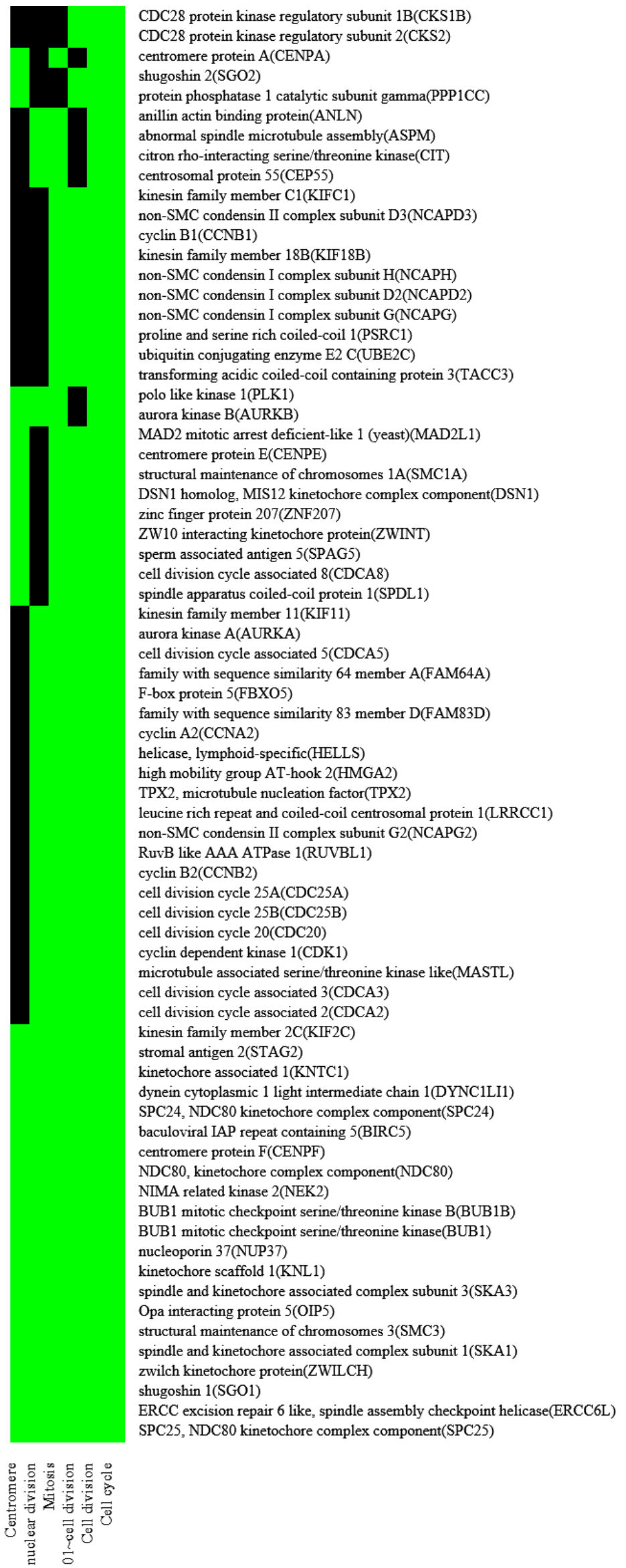

Abbildung 17: Limitierte Darstellung einiger hochregulierter Gene aus cluster 1 (Tabelle 12; enrichment score $=30,74$ ) der Stro- $1^{+\mathrm{ZK}}$ im ODM (screenshot aus DAVID Version 6.8). 


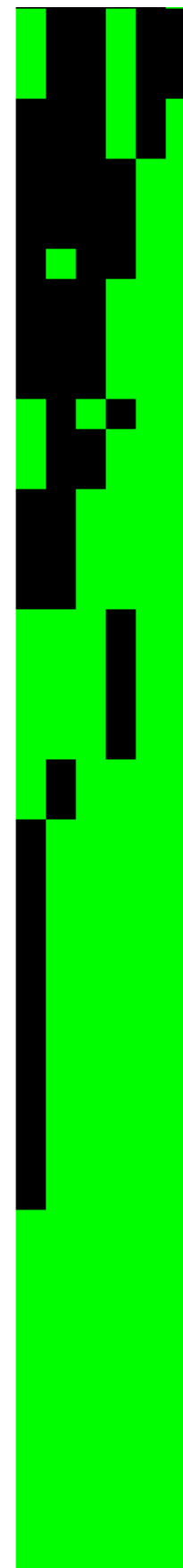

kinesin family member 22(KIF22)

exportin 1 (XPO1)

nucleoporin 160(NUP160)

cell division cycle associated 5(CDCA5)

MRE11 homolog, double strand break repair nuclease(MRE11)

Opa interacting protein 5(OIP5)

suppressor of variegation 3-9 homolog 2(SUV39H2)

CCCTC-binding factor(CTCF)

Holliday junction recognition protein(HJURP)

stromal antigen 2(STAG2)

centromere protein $\mathrm{P}$ (CENPP)

cell division cycle associated 8 (CDCA 8$)$

structural maintenance of chromosomes 3(SMC3)

spindle and kinetochore associated complex subunit 3(SKA3)

aurora kinase B(AURKB)

centromere protein I(CENPI)

DSN1 homolog, MIS12 kinetochore complex component(DSN1)

spindle apparatus coiled-coil protein 1(SPDL1)

spindle and kinetochore associated complex subunit 1(SKA1)

centromere protein A(CENPA)

Ras association domain family member 2(RASSF2)

zinc finger protein $207(\mathrm{ZNF} 207)$

sperm associated antigen 5(SPAG5)

dynein cytoplasmic 1 light intermediate chain 1(DYNC1LI1)

NIMA related kinase 2(NEK2)

polo like kinase 1(PLK1)

centromere protein $\mathrm{F}(\mathrm{CENPF})$

protein phosphatase 1 catalytic subunit gamma(PPP1CC)

centromere protein $\mathrm{N}(\mathrm{CENPN})$

shugoshin 2(SGO2)

kinetochore scaffold $1(\mathrm{KNL} 1)$

kinetochore associated 1(KNTC1)

AT-hook containing transcription factor 1(AHCTF1)

centromere protein $\mathrm{K}$ (CENPK)

SPC24, NDC80 kinetochore complex component(SPC24)

centromere protein $\mathrm{U}(\mathrm{CENPU})$

baculoviral IAP repeat containing 5(BIRC5)

ERCC excision repair 6 like, spindle assembly checkpoint helicase(ERCC6L)

centromere protein $\mathrm{O}(\mathrm{CENPO})$

SPC25, NDC80 kinetochore complex component(SPC25)

kinesin family member $2 \mathrm{C}(\mathrm{KIF} 2 \mathrm{C})$

BUB1 mitotic checkpoint serine/threonine kinase B(BUB1B)

MAD2 mitotic arrest deficient-like 1 (yeast)(MAD2L1)

BUB1 mitotic checkpoint serine/threonine kinase(BUB1)

ZW10 interacting kinetochore protein(ZWINT)

nucleoporin 37(NUP37)

zwilch kinetochore protein $(\mathrm{ZWILCH})$

shugoshin 1(SGO1)

centromere protein $\mathrm{E}$ (CENPE)

structural maintenance of chromosomes $1 \mathrm{~A}(\mathrm{SMC} 1 \mathrm{~A})$

NDC80, kinetochore complex component(NDC80)

nucleoporin 85(NUP85)

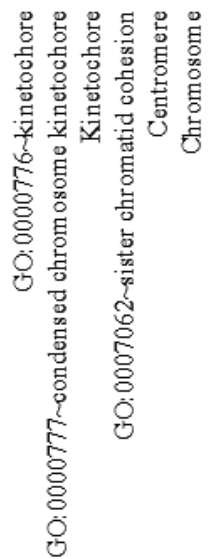

Abbildung 18: Limitierte Darstellung einiger hochregulierter Gene aus cluster 2 (Tabelle 12; enrichment score $=22,49$ ) der Stro- $1^{+\mathrm{ZK}}$ im ODM (screenshot aus DAVID Version 6.8). 


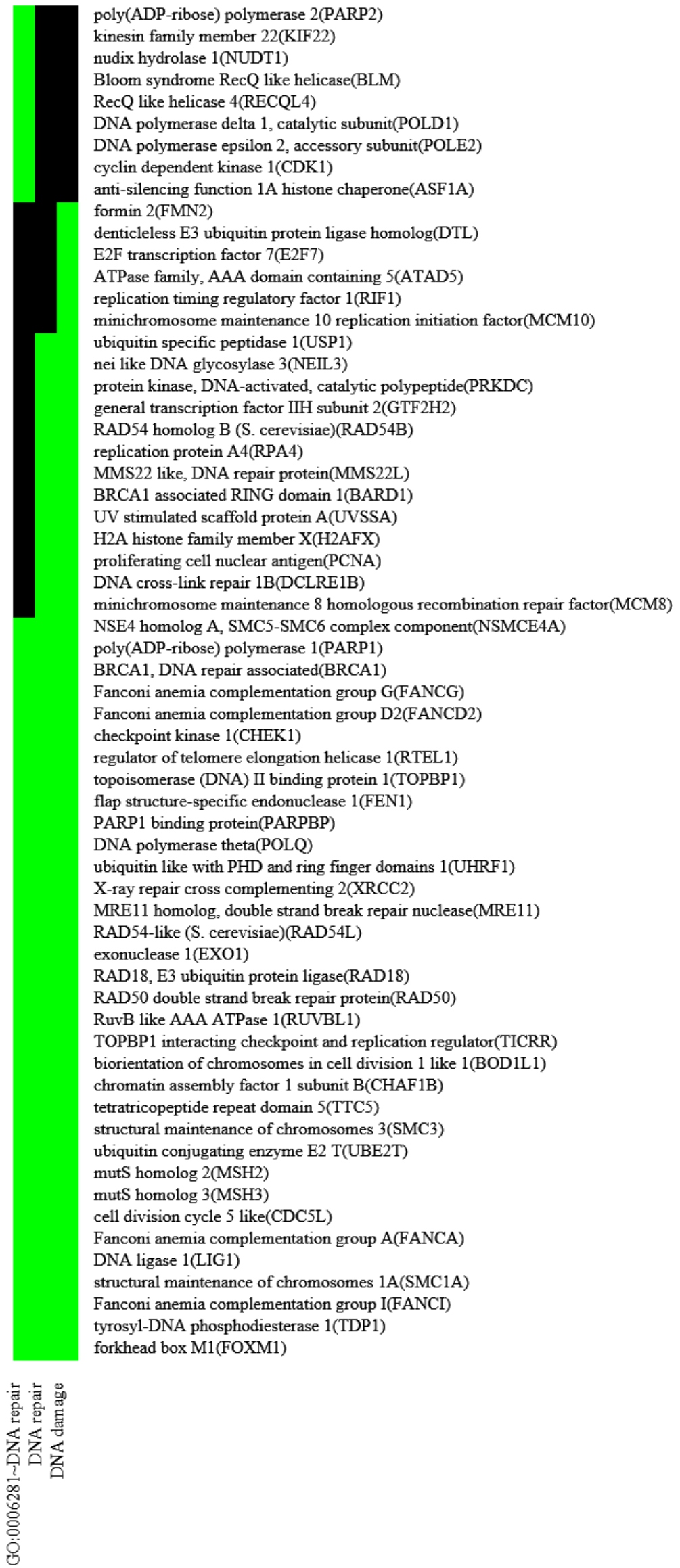

Abbildung 19: Heatmap der hochregulierten Gene aus cluster 3 (Tabelle 12; enrichment score = 13,03 ) der Stro- $1^{+2 K}$ im ODM (screenshot aus DAVID Version 6.8). 


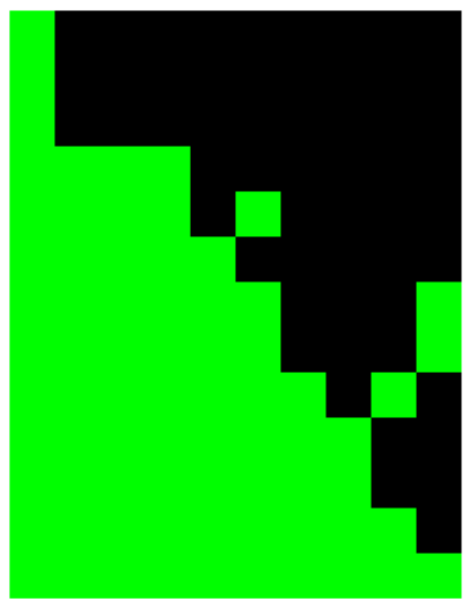

paired box 9(PAX9)

DEK proto-oncogene(DEK)

cell division cycle 5 like(CDC5L)

PBX homeobox 4(PBX4)

mohawk homeobox(MKX)

SATB homeobox 2(SATB2)

SIX homeobox 1(SIX1)

paired related homeobox 1(PRRX1)

hematopoietically expressed homeobox(HHEX)

distal-less homeobox 1(DLX1)

distal-less homeobox 2(DLX2)

BARX homeobox 1(BARX1)

msh homeobox 1(MSX1)

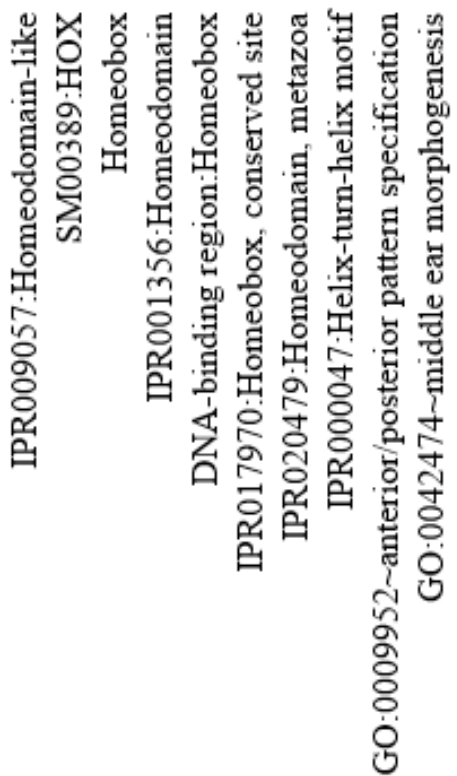

Abbildung 20: Darstellung einiger hochregulierter Gene aus cluster 126 (enrichment score $=0,16$ oder 1,7 ) der Stro- $1^{+2 K}$ im ODM, die mit der Funktion der mRNA in Verbindung stehen (in Tabelle 12 nicht aufgeführt; screenshot aus DAVID Version 6.8). 


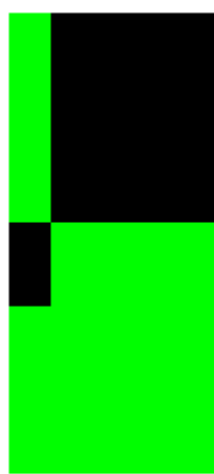

runt related transcription factor 3 (RUNX3)

poly $(\mathrm{rC})$ binding protein 1 (PCBP1)

runt related transcription factor 2 (RUNX2)

cell division cycle 5 like(CDC5L)

prohibitin(PHB)

forkhead box F1(FOXF1)

forkhead box F2(FOXF2)

forkhead box M1(FOXM1)

forkhead box D2(FOXD2)

forkhead box D1(FOXD1)

forkhead box Q1(FOXQ1)

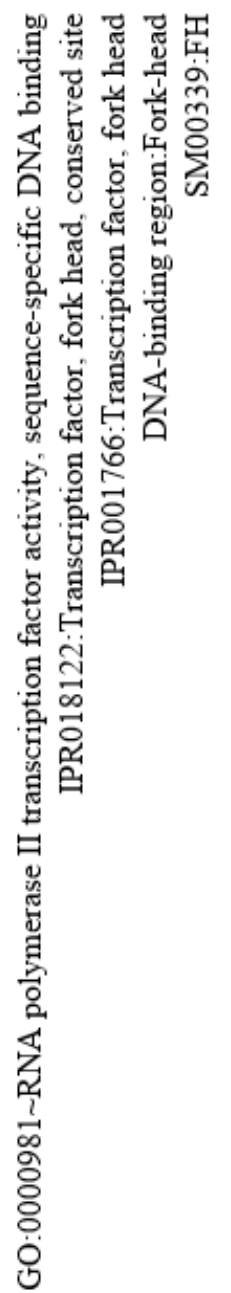

Abbildung 21: Darstellung einiger hochregulierter Gene für Transkriptionsfaktoren aus cluster 54 (enrichment score $=1,0$ ) der Stro- $1^{+\mathrm{ZK}}$ im ODM (in Tabelle 12 nicht aufgeführt; screenshot aus DAVID Version 6.8). 


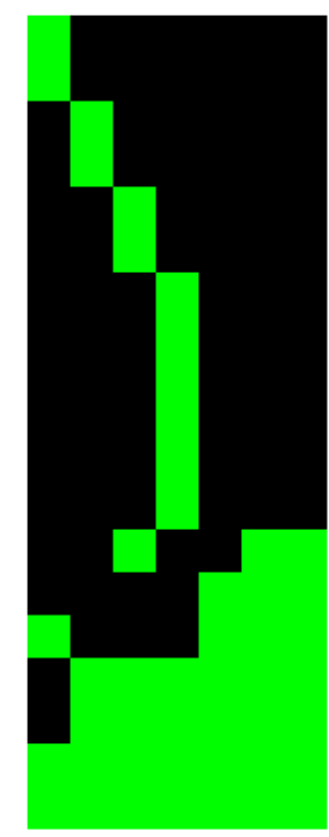

C-type lectin domain family 2 member D(CLEC2D)

thrombomodulin(THBD)

solute carrier family 8 member A1(SLC8A1)

membrane metalloendopeptidase(MME)

matrix metallopeptidase 3(MMP3)

cathepsin $\mathrm{K}$ (CTSK)

ribonuclease T2(RNASET2)

UDP-glucose glycoprotein glucosyltransferase 1(UGGT1)

cathepsin Z(CTSZ)

cathepsin C(CTSC)

coagulation factor $\mathrm{X}(\mathrm{F} 10)$

Wnt family member $5 \mathrm{~A}(\mathrm{WNT} 5 \mathrm{~A})$

matrix metallopeptidase 1 (MMP1)

collagen and calcium binding EGF domains 1(CCBE1)

collectin subfamily member 12(COLEC12)

collagen type $\mathrm{X}$ alpha 1 chain(COL10A1)

collagen type XIII alpha 1 chain(COL13A1)

collagen type XVIII alpha 1 chain(COL18A1)

collagen type IV alpha 5 chain(COL4A5)

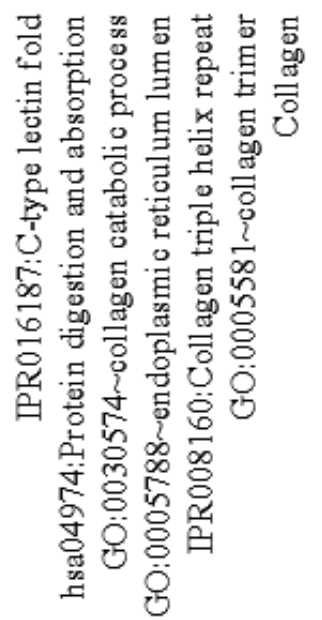

Abbildung 22: Darstellung einiger hochregulierter Gene aus cluster 85 (enrichment score $=0,45$ ) der Stro- $1^{+Z K}$ im ODM, die für die Kollagensynthese und benachbarte Funktionen zuständig sind (in Tabelle 12 nicht aufgeführt; screenshot aus DAVID Version 6.8). 


\subsubsection{Im ODM hochregulierte Gene der Stro-1 ${ }^{+\mathrm{BK}}$}

Nach den Kriterien FDR $\leq 1 \%$ und $|\operatorname{logFC}|>2$ gefiltert, wiesen die Stro- $1^{+\mathrm{BK}}$ gegenüber den Stro- $1^{+Z K}$ im ODM 266 hochregulierte Gene auf, für die 121 GO-terms der Kategorie „biological process“ detektiert wurden. Die ersten zehn funktionellen Gengruppen finden sich in Tabelle 13.

Auch bei den Stro- $1^{+\mathrm{BK}}$ werden im ODM biologische Prozesse hochreguliert, die sich mit der Organ- und Strukturentwicklung befassen, wobei ein Schwerpunkt auf die skelettale Entwicklung entfällt. Der für die Stro- $1^{+\mathrm{BK}}$ als hochsignifikant gelistete GO-term skeletal system development (in Tabelle 13 gelb markiert) enthält eine Reihe von HomeoboxGenen, die sich von den Stro- $1^{+Z K}$ unterscheiden (Tabelle 14). Ein Großteil der hochregulierten Gengruppen beschreibt daneben Vorgänge, die mit der Gefäßentwicklung in Verbindung stehen, z. B. die GO-terms angiogenesis, vasculature development und blood vessel development.

Bei einem cut-off der FDR $\leq 5 \%$ zeigten 1478 Gene bei den Stro- $1^{+\mathrm{BK}}$ eine hochregulierte Expression gegenüber den Stro- $1^{+Z K}$ im ODM. Die über DAVID ermittelten 177 cluster des Functional Annotation Clustering bilden dabei nicht immer die funktionellen Gengruppen aus Tabelle 13 ab, ergänzen sie aber, da es häufig Überschneidungen der aufgeführten Gene gibt. In Tabelle 15 finden sich exemplarisch die ersten drei cluster mit den entsprechenden Untergruppen. Die Untergruppen von cluster 2 (Abbildung 23) und cluster 163 (Abbildung 25) sind mit Homeobox-Genen und Transkriptionsfaktoren belegt, die bereits im oben genannten GO-term skeletal system development eine wichtige Rolle spielen. Entsprechend der heatmap von cluster 72 (Abbildung 24) exprimieren die Stro- $1^{+\mathrm{BK}}$ mit einem signifikant höheren logFC-Wert die für Kollagene codierenden Gene COLAA1, COLAA2, COL11A1, COL12A1 und COL6A2. Die Gene aus cluster 174 (Abbildung 26), welche mit der Zellteilung und dem Zellzyklus verbunden sind, haben für die Stro- $1^{+\mathrm{BK}}$ nur eine geringe Bedeutung. 
Tabelle 13: Die ersten zehn im ODM bei den Stro- $1^{+}$-Beckenkammzellen signifikant hochregulierten ( $=$ bei den Stro- $1^{+}$-Zahnkeimzellen signifikant herunterregulierten) funktionellen Gruppen (nach DAVID Version 6.8). Die Tabellen sind nach der aufsteigenden Höhe der p-Werte sortiert.

\begin{tabular}{|l|c|c|c|c|c|}
\hline \multicolumn{1}{|c|}{ Term } & Genes & $\underline{\text { Count }}$ & $\underline{\%}$ & $\underline{\text { P-Value }}$ & $\underline{\text { Benjamini }}$ \\
\hline skeletal system development & & 31 & 13,1 & $3,3 \mathrm{E}-13$ & $1,1 \mathrm{E}-9$ \\
\hline extracellular matrix organization & & 24 & 10,2 & $2,2 \mathrm{E}-11$ & $3,8 \mathrm{E}-8$ \\
\hline extracellular structure organization & & 24 & 10,2 & $2,4 \mathrm{E}-11$ & $2,7 \mathrm{E}-8$ \\
\hline angiogenesis & & 24 & 10,2 & $1,5 \mathrm{E}-9$ & $1,2 \mathrm{E}-6$ \\
\hline vasculature development & & 29 & 12,3 & $1,7 \mathrm{E}-9$ & $1,2 \mathrm{E}-6$ \\
\hline blood vessel development & & 28 & 11,9 & $2,2 \mathrm{E}-9$ & $1,2 \mathrm{E}-6$ \\
\hline blood vessel morphogenesis & & 25 & 10,6 & $8,3 \mathrm{E}-9$ & $4,0 \mathrm{E}-6$ \\
\hline organ morphogenesis & & 36 & 15,3 & $1,3 \mathrm{E}-8$ & $5,6 \mathrm{E}-6$ \\
\hline cardiovascular system development & & 35 & 14,8 & $1,4 \mathrm{E}-8$ & $5,2 \mathrm{E}-6$ \\
\hline circulatory system development & & 35 & 14,8 & $1,4 \mathrm{E}-8$ & $5,2 \mathrm{E}-6$ \\
\hline
\end{tabular}

Tabelle 14: Homeobox-Gene, die bei den Stro- $1^{+\mathrm{BK}}$ im ODM für den GO-term skeletal system development hochreguliert sind. Die Gene sind aufsteigend nach der Höhe der FDR sortiert.

\begin{tabular}{|l|l|c|c|}
\hline \multicolumn{2}{|l|}{ skeletal system development } & logFC ZK2-BK2 & FDR ZK2-BK2 \\
\hline Symbol & Genname & $-6,222$ & $6,58 \mathrm{E}-12$ \\
\hline HOXC9 & homeobox C9 & $-4,073$ & $3,82 \mathrm{E}-10$ \\
\hline HOXB6 & homeobox B6 & $-3,793$ & $1,54 \mathrm{E}-08$ \\
\hline HOXA9 & homeobox A9 & $-4,878$ & $4,90 \mathrm{E}-08$ \\
\hline HOXB2 & homeobox B2 & $-2,595$ & $5,73 \mathrm{E}-08$ \\
\hline HOXA10 & homeobox A10 & $-3,325$ & $7,44 \mathrm{E}-08$ \\
\hline HOXB3 & homeobox B3 & $-3,644$ & $3,96 \mathrm{E}-07$ \\
\hline HOXA7 & homeobox A7 & $-3,354$ & $1,23 \mathrm{E}-06$ \\
\hline HOXC8 & homeobox C8 & $-2,263$ & $2,73 \mathrm{E}-05$ \\
\hline HOXB4 & homeobox B4 & $-2,801$ & $4,70 \mathrm{E}-04$ \\
\hline HOXC10 & homeobox C10 & & \\
\hline
\end{tabular}


Tabelle 15: Die ersten drei signifikant hochregulierten Gen-Cluster der Stro- $1^{+B K}$ (= herunterregulierten Gen-Cluster der Stro- $1^{+Z K}$ ) im ODM (screenshot aus DAVID Version 6.8).

\section{Functional Annotation Clustering}

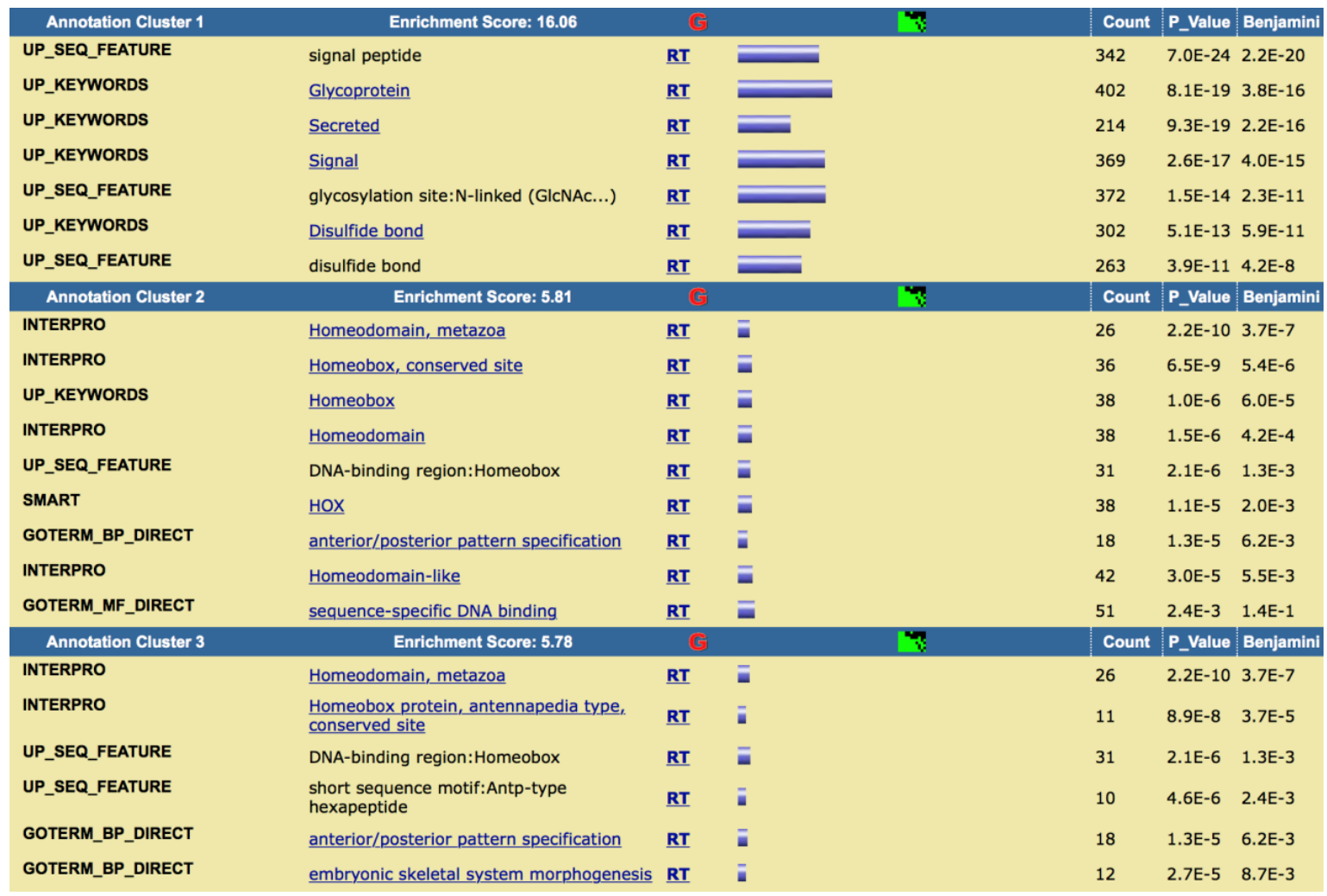




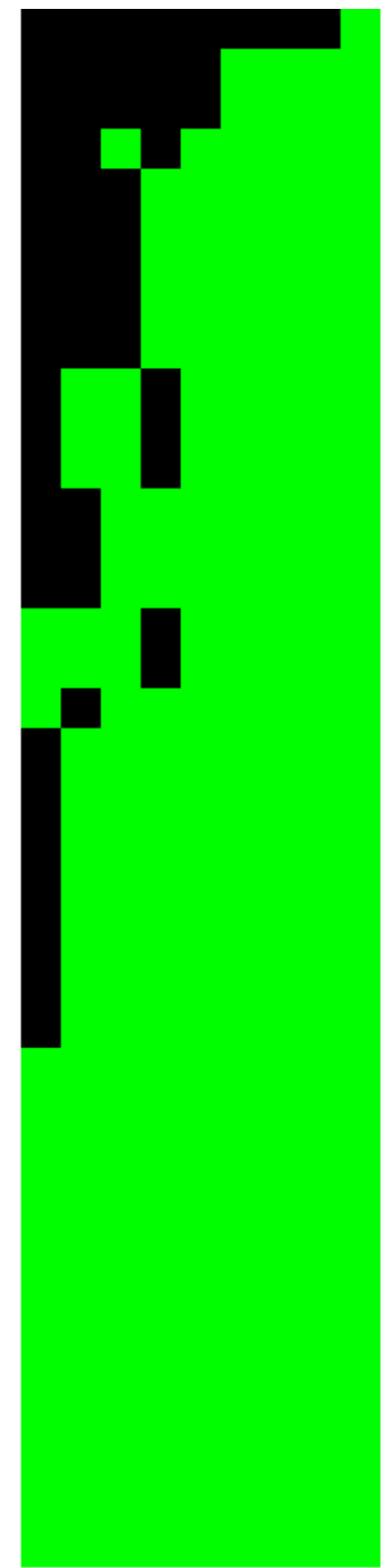

paired box 8(PAX8)

Meis homeobox 3 pseudogene 1(MEIS3P1)

Meis homeobox 1(MEIS1)

SIX homeobox 2(SIX2)

iroquois homeobox 2(IRX2)

zinc finger homeobox 2 (ZFHX2)

zinc finger homeobox $4(\mathrm{ZFHX} 4)$

iroquois homeobox 5(IRX5)

iroquois homeobox 3(IRX3)

engrailed homeobox 1(EN1)

NK2 homeobox 1(NKX2-1)

NK3 homeobox 2(NKX3-2)

goosecoid homeobox(GSC)

short stature homeobox 2(SHOX2)

short stature homeobox(SHOX)

homeobox B5(HOXB5)

homeobox D9(HOXD9)

LIM homeobox 1(LHX1)

empty spiracles homeobox 1(EMX1)

T-cell leukemia homeobox 2(TLX2)

NK2 homeobox 8(NKX2-8)

homeobox A4(HOXA4)

mesenchyme homeobox 2(MEOX2)

paired like homeodomain 2(PITX2)

NK1 homeobox 2(NKX1-2)

homeobox D8(HOXD8)

empty spiracles homeobox 2(EMX2)

homeobox B6(HOXB6)

homeobox B7(HOXB7)

homeobox $\mathrm{C} 8(\mathrm{HOXC8})$

homeobox $\mathrm{C} 9$ (HOXC9)

homeobox $\mathrm{C} 10(\mathrm{HOXC10})$

homeobox A9(HOXA9)

homeobox A7(HOXA7)

homeobox A10(HOXA10)

homeobox B3(HOXB3)

homeobox B2(HOXB2)

homeobox B4(HOXB4)

homeobox D3(HOXD3)

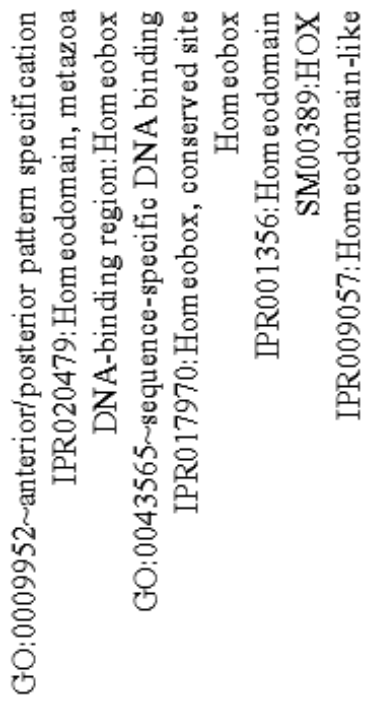

Abbildung 23: Limitierte Darstellung einiger hochregulierter Homeobox-Gene aus cluster 2 (Tabelle 15 ; enrichment score $=5,81$ ) der Stro- $1^{+B K}$ im ODM (screenshot aus DAVID Version 6.8). 


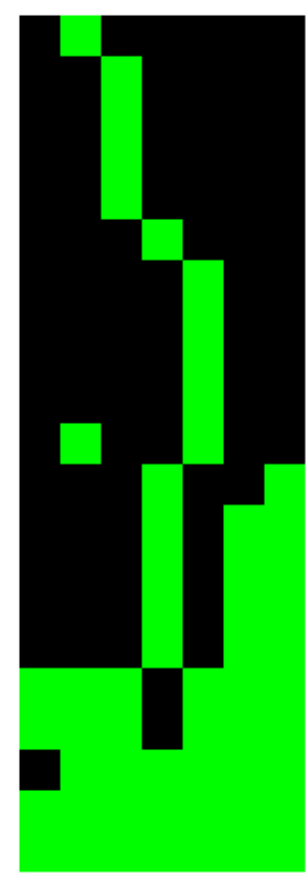

protease, serine 3 (PRSS3)

furin, paired basic amino acid cleaving enzyme(FURIN)

matrix metallopeptidase 15(MMP15)

cathepsin D(CTSD)

ADAM metallopeptidase with thrombospondin type 1 motif 2(ADAMTS2)

lysyl oxidase(LOX)

endothelial PAS domain protein 1(EPAS1)

hypoxia inducible factor 1 alpha subunit(HIF1A)

protein S (alpha)(PROS1)

latent transforming growth factor beta binding protein 2(LTBP2)

elastin(ELN)

TIMP metallopeptidase inhibitor 1(TIMP1)

$\mathrm{C} 1 \mathrm{q}$ and tumor necrosis factor related protein 5(C1QTNF5)

gliomedin(GLDN)

scavenger receptor class A member 3(SCARA3)

collagen triple helix repeat containing 1(CTHRC1)

collagen type IV alpha 1 chain(COL4A1)

collagen type IV alpha 2 chain(COL4A2)

collagen type XII alpha 1 chain(COL12A1)

collagen type XI alpha 1 chain(COL11A1)

collagen type VI alpha 2 chain(COL6A2)

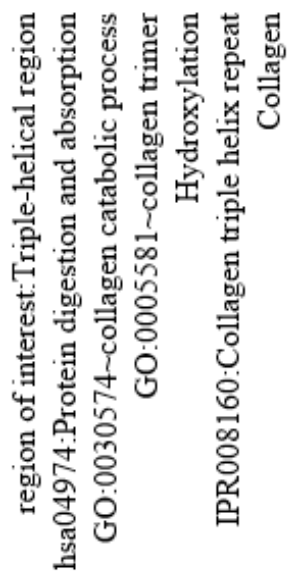

Abbildung 24: Heatmap der hochregulierten Gene aus cluster 72 (enrichment score $=0,8$ ) der Stro- $1^{+B K}$ im ODM, die für Kollagene codieren (in Tabelle 15 nicht aufgeführt; screenshot aus DAVID Version 6.8). 

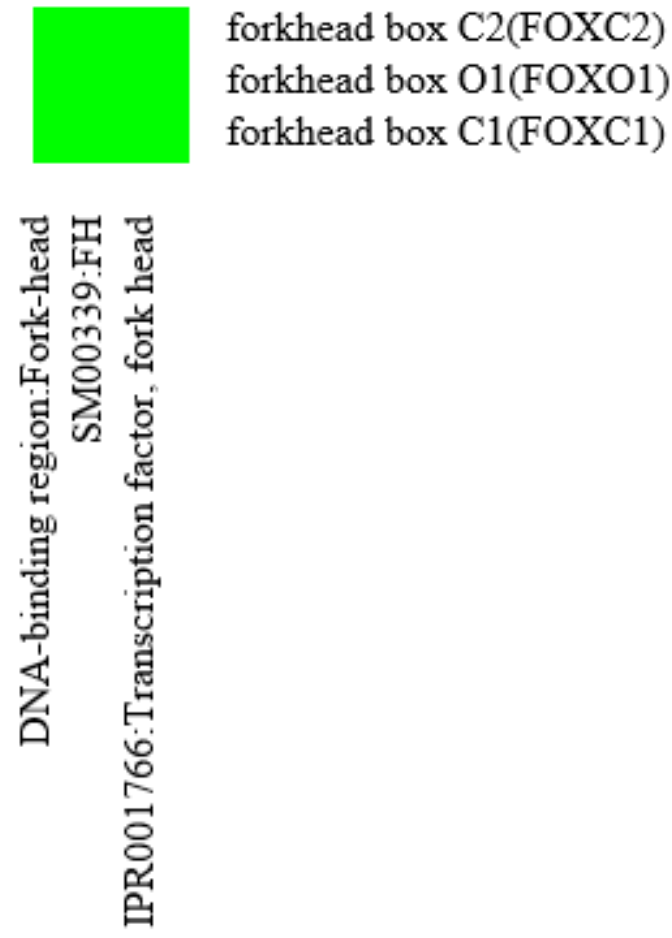

Abbildung 25: Heatmap der hochregulierten Gene für Transkriptionsfaktoren aus cluster 163 (enrichment score $=0,08$ ) der Stro- $1^{+B K}$ im ODM (in Tabelle 15 nicht aufgeführt; screenshot aus DAVID Version 6.8). 


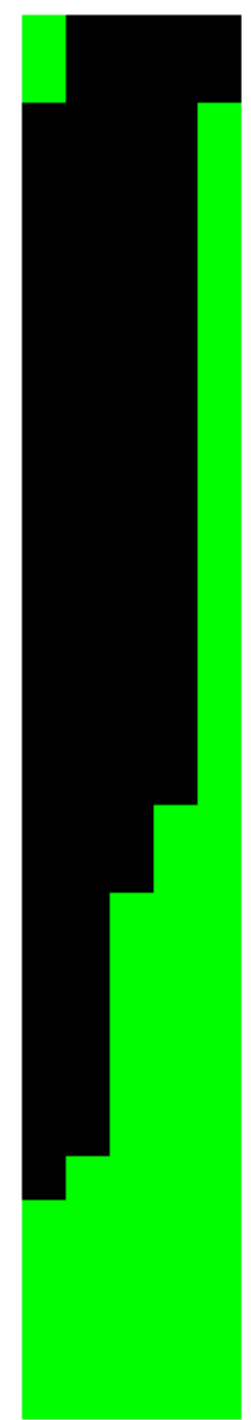

dynactin subunit 1 (DCTN1)

clathrin heavy chain like 1 (CLTCL1)

$\mathrm{G}$ protein-coupled estrogen receptor 1(GPER1)

cyclin dependent kinase inhibitor $1 \mathrm{~A}(\mathrm{CDKN} 1 \mathrm{~A})$

cyclin dependent kinase inhibitor $1 \mathrm{C}(\mathrm{CDKN} 1 \mathrm{C})$

thioredoxin interacting protein(TXNIP)

dual specificity phosphatase 1(DUSP1)

regulator of cell cycle(RGCC)

salt inducible kinase 1 (SIK1)

potassium channel tetramerization domain containing 11(KCTD11)

cell cycle progression 1 (CCPG1)

protein tyrosine phosphatase type IVA, member 1(PTP4A1)

cell growth regulator with EF-hand domain 1(CGREF1)

polo like kinase 3(PLK3)

mitogen-activated protein kinase 3(MAPK3)

MARVEL domain containing 1(MARVELD1)

arginine vasopressin induced 1(AVPI1)

$\mathrm{BMP} /$ retinoic acid inducible neural specific 1(BRINP1)

ras homolog family member $\mathrm{A}(\mathrm{RHOA})$

septin 5(SEPT5)

hemicentin 1(HMCN1)

cyclin dependent kinase $14(\mathrm{CDK} 14)$

cyclin $\mathrm{O}(\mathrm{CCNO})$

charged multivesicular body protein $1 \mathrm{~B}$ (CHMP1B)

par- 6 family cell polarity regulator gamma(PARD6G)

$\mathrm{Cdk} 5$ and $\mathrm{Abl}$ enzyme substrate 1(CABLES1)

MAU2 sister chromatid cohesion factor(MAU2)

kelch like family member 21(KLHL21)

neural precursor cell expressed, developmentally down-regulated 9(NEDD9)

receptor accessory protein 3 (REEP3)

TRIO and $\mathrm{F}$-actin binding protein(TRIOBP)

large tumor suppressor kinase 2(LATS2)

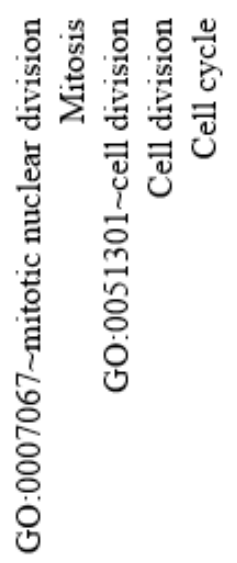

Abbildung 26: Heatmap der überexprimierten Gene des Zellzyklus aus cluster 174 (enrichment score $=0,0$ ) der Stro- $1^{+B K}$ im ODM (in Tabelle 15 nicht aufgeführt; screenshot aus DAVID Version 6.8). 


\subsection{Zusammenfassung der Ergebnisse}

Die Auswertung der Microarray-Daten wurde nach drei unterschiedlichen Kriterien vorgenommen:

1) Zunächst wurden für beide Stammzelltypen die zehn höchst signifikant hoch- und herunterregulierten Gene bestimmt und ihre funktionellen Gruppen ermittelt, wie sie sich beim Wechsel vom DMEM in das ODM ergeben.

2) In einer weiteren Sortierung wurden Gene ermittelt, die bei einem Zelltyp signifikante $\operatorname{logFC}$-Werte aufweisen und bei dem jeweils anderen Zelltyp keine entsprechende Veränderung zeigen. Bei beiden Stammzelltypen wurden zusätzlich identische Gene gesucht, die gemeinsam über- bzw. unterexprimiert werden oder sich in ihrer Expression gegensätzlich verhalten.

3) Abschließend wurde das differentielle Expressionsprofil beider Stammzelltypen im ODM untersucht.

Ad 1) Stro- $1^{+Z K}$ und Stro- $1^{+B K}$ zeigen beim Wechsel vom DME-Medium in das osteogene Differenzierungsmedium ein unterschiedliches Verhalten in ihrer Genexpression. Unter den zehn höchst signifikant hochregulierten Genen befinden sich vier Gene, die bei beiden Zelltypen identisch sind (SAA1, BMP6, FKBP5, MAOA). Bei den zehn höchst signifikant herunterregulierten Genen finden sich für beide Zelltypen keine identischen Gene.

Die im ODM gegenüber dem DMEM hochregulierten Gene der Stro- $1^{+Z K}$ werden anteilsmäßig vor allem durch die funktionellen Gruppen response to organic substance, response to wounding, response to endogenous stimulus und behavior repräsentiert. Die überwiegende Anzahl der herunterregulierten Gene der Stro- ${ }^{+\mathrm{ZK}}$ findet sich in den Gruppen biological adhesion, cell adhesion, regulation of cell motion, regulation of locomotion und regulation of cell migration. Die hochregulierten Gene der Stro- ${ }^{+\mathrm{BK}}$ sind größtenteils den Gruppen response to organic substance, response to endogenous stimulus, response to hormon stimulus, response to peptide hormon stimulus und response to insulin stimulus zuzuordnen. Die herunterregulierten Gene der Stro- $1^{+\mathrm{BK}}$ werden hauptsächlich durch die Gruppen wound healing, regulation of secretion, angiogenesis, blood vessel morphogenesis und blood vessel development bestimmt. 
Ad 2) Beim Medienwechsel vom DMEM ins ODM werden bei einer FDR $\leq 5 \%$ für die Stro- $1^{+\mathrm{BK}} 720$ Gene mit signifikant veränderten $\operatorname{logFC}$-Werten detektiert, deren identische Gene bei den Stro- $1^{+Z K}$ keine signifikante Veränderung aufzeigen. Bei den Stro- $1^{+Z K}$ weisen wiederum 456 Gene signifikante $\log F C$-Werte auf, denen keine signifikant veränderten Werte bei den Stro- $1^{+B K}$ gegenüberstehen. Die einseitig signifikant hoch- und herunterregulierten Gene der Stro- $1^{+Z K}$ weisen als wesentliche funktionelle Gruppen Glycoprotein, Disulfide Bond und Signal in der Cluster-Analyse auf. Die hochregulierten Gene der Stro- $1^{+Z K}$ werden zudem Gruppen zugeordnet, die im Zusammenhang mit der Zellmembran und der extrazellulären Matrix stehen. Diese Gruppen sind auch der primäre Bestandteil der Gen-Cluster, die sich aus den einseitig signifikant hochregulierten Genen der Stro- $1^{+\mathrm{BK}}$ ableiten. An erster Stelle der herunterregulierten funktionellen Gruppen bei den Stro- $1^{+\mathrm{BK}}$ stehen Gene, die für die Angiogenese und die Bildung von Endothelzellen verantwortlich sind.

Für beide Zellarten werden beim Wechsel in das ODM gemeinsam 130 identische Gene hoch- und 94 Gene herunterreguliert. 16 Genpaare verhalten sich in ihrer Expression gegensinnig. Die gleichsinnig hoch- sowie herunterregulierten Genpaare der Stro- $1^{+Z K}$ und der Stro- $1^{+\mathrm{BK}}$ werden hauptsächlich durch die bereits oben beschriebenen funktionellen Gruppen Glycoprotein, Disulfide Bond und Signal charakterisiert. Bei den Stro- ${ }^{+\mathrm{BK}}$ signifikant hoch- und den Stro- $1^{+Z K}$ herunterreguliert werden Gene, die Proteine codieren, welche die Zelladhäsion und Zellmembran beeinflussen. Die Gene, die umgekehrt bei den Stro- $1^{+\mathrm{BK}}$ herunter- und den Stro- $1^{+\mathrm{ZK}}$ hochreguliert werden, codieren ebenfalls Proteine, die für Zellmembraneigenschaften stehen oder aber für alternatives Spleißen der DNA verantwortlich sind.

Ad 3) Wird das Expressionsprofil beider Zelltypen im ODM verglichen, so ergeben sich bei den cut-offs FDR $\leq 1 \%$ und $|\operatorname{logFC}|>2$ eine Anzahl von 375 signifikant veränderten Genen. Die 109 hochregulierten Gene der Stro- $1^{+Z K}$ werden vor allem funktionellen Gruppen zugeordnet, die für die Zellproliferation, Organentwicklung und extrazelluläre Matrix wichtig sind. Hierzu gehören neben Homeobox-Genen auch die Gene GREM1, $P T N$ und FST, welche eine Rolle bei der Odontogenese spielen. Bei den Stro- $1^{+\mathrm{BK}}$ werden 266 Gene hochreguliert, die an der Skelettentwicklung und Angiogenese beteiligt sind. 
Bei dem weiter gefassten cut-off der FDR $\leq 5 \%$ ergeben sich signifikant veränderte logFCWerte für 2583 Gene, von denen 1105 Gene bei den Stro- $1^{+Z K}$ und 1478 Gene bei den Stro- $1^{+\mathrm{BK}}$ hochreguliert waren. Bei den Zahnkeimzellen codieren diese Gene überwiegend Proteine, die in die Zellteilung eingreifen, den Zellzyklus unterstützen, die DNA reparieren und die Bereitstellung der dafür notwendigen Energie sichern. Bei den Beckenkammzellen sind funktionellen Gengruppen hochreguliert, die Proteine codieren, welche an der skelettalen Morphogenese beteiligt sind, wie z. B. Homeobox-Gene. Die Stro- $1^{+\mathrm{BK}}$ exprimieren mit einem signifikant höheren $\operatorname{logFC}$ die für Kollagene codierenden Gene COLAA1, COLAA2, COL11A1, COL12A1 und COL6A2. 


\section{Diskussion}

Mithilfe der Microarrays wurde die Genexpression als durchschnittliche cDNA(mRNA)Level der Stro- $1^{+}$-Zellen aus den Mischpopulationen der Zahnkeime und des Beckenkamms gemessen. Da es kein Maß für die absolute Höhe der Genexpression gibt, sind alle Messungen nur dann sinnvoll, wenn die Expressionshöhe eines bestimmten Gens in zwei verschiedenen biologischen Zuständen betrachtet wird. In der vorliegenden Arbeit sollten daher die beiden Medien DMEM und ODM den Schwerpunkt des Vergleichs bilden und gezeigt werden, ob sich die Stro- $1^{+}$-Zahnkeim- und -Beckenkammzellen in den Medien unterschiedlich in ihrer Genexpression darstellen. Alle Aussagen sind daher relative Feststellungen. Aus diesem Grund werden in der vorliegenden Arbeit die unterschiedlichen Expressionshöhen der gleichen Gene zum einen durch die unterschiedlichen Medien und zum anderen durch den unterschiedlichen Ursprung der Stro- $1^{+}$-Zellen determiniert. Bei allen Untersuchungen zur Höhe einer mRNA-Expression liegt die Annahme zugrunde, dass die Höhe des Expressionsniveaus auch die Höhe des synthetisierten Proteins definiert, falls die RNA ein Protein codiert.

Während die Erfassung der mRNA-Expression in den 90er-Jahren des letzten Jahrhunderts noch eine außerordentliche methodische Schwierigkeit darstellte, hat die Entwicklung der Microarray-Technik die fast vollständige Erfassung der Genexpression des Transkriptoms ermöglicht (Schena et a. 1995). Die aktuelle Herausforderung liegt aber nach wie vor in der Interpretation und Sinngebung der gewaltigen Datenmengen. Der Vorteil sowie der Schwerpunkt der Microarray-Analyse liegt daher nicht in erster Linie darin, Aussagen über die individuelle Höhe der Expression einzelner Gene zu machen, sondern biologische Prozesse zu erkennen und zu verstehen (Miller et al. 2002).

\subsection{Methodik}

Mithilfe der DNA-Sequenzierung konnte im April 2003 das gesamte menschliche Genom mit seinen 20.000 bis 30.000 Genen dekodiert werden (U.S. Department of Energy: $\mathrm{Hu-}$ man Genome Project). Die Microarray-Technologie erlaubt eine funktionelle Analyse, indem sie Gen-Transkripte detektiert und somit das Transkriptom ,entschlüsselt“. Anhand der gewonnenen Daten lassen sich Rückschlüsse auf die genetische Aktivität unterschiedlicher Zelltypen schließen. 
In Abhängigkeit von der Größe des gewählten Microarray-Chips können spezifisch die Expressionswerte einer Vielzahl von Genen ermittelt werden. In der vorliegenden Arbeit wurden Human Genome Chips des Herstellers Agilent verwendet. Diese stellen das komplette menschliche Genom zur Genexpressionsanalyse zur Verfügung. Entsprechend ergibt sich eine umfassende molekulargenetische Charakterisierung der jeweiligen Zelltypen im Probenmaterial. Gleichzeitig fallen jedoch enorme Datenmengen an, die einer gezielten Auswertung bedürfen. Ein spezieller Erkenntnisgewinn wird auch dadurch erschwert, wenn Untersuchungen von Geweben oder Zellkulturen vorgenommen werden, in denen verschiedene Zellpopulationen oder Zelltypen vorliegen. Bei der Isolierung der mRNA liegt dann ein „mRNA-Gemisch“ vor, welches es möglicherweise nicht erlaubt, die Genexpression einzelner, spezieller Zellen zu detektieren und somit ihre funktionelle Bedeutung zu erkennen. Da Stro- $1^{+}$-Zellen bereits im Fokus neuerer Erkenntnisse standen (Rolf et al. 2008, 2012), sollte hier dieser Zelltyp aus Zahnkeimen und Beckenkamm untersucht werden, um signifikante Veränderungen seiner Genexpression zu registrieren. Gleichzeitig sollte der Einfluss unterschiedlicher Kulturmedien analysiert werden. Die Detektion differentiell exprimierter Gene erfolgte daher einerseits zwischen den Stro- $1^{+\mathrm{ZK}}$ und Stro- $1^{+\mathrm{BK}}$, andererseits in Abhängigkeit von den beiden Kulturmedien DMEM und ODM.

Diese gewaltige Datenmenge von zehntausenden Genen kann in der Vielfalt der hier zugrunde liegenden vier Datensätze nur mit Computersoftware-Programmen bewältigt werden, die Speicherung, Analyse, Datentransfer und Visualisierung übernehmen müssen (Stoeckert et al. 2002). Der Datenanalyse lagen zwei wichtige, international anerkannte Kenngrößen zugrunde. Die Fluoreszenz-Intensitätswerte der Genexpression sowie die Differenzen zweier Expressionszustände werden als das Vielfache des 2er Logarithmus $\left(\log _{2}\right)$ angegeben und als logFC-Wert (englisch: fold change) beschrieben. Gegenüber der Verwendung einfacher Quotienten zweier zu vergleichender Intensitäten hat dies den Vorteil, dass die $\log _{2}$-Werte bei gleicher Über- oder Unterexpression symmetrisch zu Null sind (Lee und Saeed 2007).

Aufgrund der Verwendung des binären Logarithmus ergeben sich folgende Berechnungen:

\begin{tabular}{|c|c|c|}
\hline$>$ 2-fold upregulation & $\log _{2}(2)$ & $\log F C=1$ \\
\hline 2-fold downregulation & $\log _{2}(1 / 2)$ & $\log \mathrm{FC}=-1$ \\
\hline
\end{tabular}


Eine Einheit in der logFC-Skalierung entspricht folglich einer zweifachen Veränderung in der Genexpression. Diese Darstellung vereinfacht die Auswertung der gemessenen Fluoreszenz-Intensitäten, da absolute Werte in Relation zueinander gesetzt werden. Differentiell exprimierte Gene lassen sich über das (negative/positive) Vorzeichen der logFC-Werte leichter ermitteln und einteilen.

Neben dieser Umwandlung der komplexen Datensätze in "handliche" Zahlenwerte spielt die statistische Signifikanz eine wichtige Rolle. Bei der Überprüfung einer einzelnen Alternativhypothese wird die Möglichkeit eines Fehlers 1. Art (Ablehnung der Nullhypothese) über die Irrtumswahrscheinlichkeit p kontrolliert. Die Gültigkeit der Alternativhypothese ist nur dann gegeben, wenn der zugehörige p-Wert das zuvor festgelegte Signifikanzniveau $\alpha$ nicht überschreitet. Die statistische Auswertung von Microarrays erfordert dagegen die Überprüfung mehrerer tausend Gene gleichzeitig. Infolge dieser multiplen Testung ergibt sich ein erhöhtes Risiko für das Auftreten falschpositiver Ergebnisse. Die bekannteste Methode zur Vermeidung dieser Problematik ist die Bonferroni-Korrektur. Über eine Adjustierung der p-Werte oder des Signifikanzniveaus (nach Bonferroni-Holm) ergeben sich engere Grenzen für die Datenanalyse. Eine weitere Möglichkeit bietet die explorative Benjamini-Hochberg-Prozedur. Hierbei wird über die false discovery rate (FDR) der erwartete Anteil (in \%) falschpositiv signifikanter Gene an allen signifikanten Genen ausgedrückt (Benjamini und Hochberg 1995, Benjamini et al. 2001, Tusher et al. 2001). Sie kann als p-Wert-Korrektur nach multipler Testung angesehen werden und entspricht einem ad-hoc-Test nach durchgeführter ANOVA. Ein hoher Wert des $\operatorname{logFC}$ und eine niedrige FDR können daher als hohe Wahrscheinlichkeit einer Änderung der Genexpression gelten. Die biologische Bedeutung von Genexpressionen mit niedrigen logFC-Werten und hoher FDR sowie umgekehrt wird durch die statistische Aussage jedoch nicht unbedingt wiedergegeben. Durch die individuelle, teils intuitive Entscheidung der Wahl der jeweiligen cut-offs von logFC und FDR kann die Interpretation der Ergebnisse verschiedener Forschergruppen selbst bei exakt reproduzierbaren Array-Versuchen unterschiedlich ausfallen (Dalman et al. 2012). Es wird daher eine Standardisierung von Genarray-Versuchen gefordert, insbesondere wenn die Daten in internationale Pools eingegeben werden (Ashburner et al. 2000, Taylor et al. 2008). 
Um eine schärfere Aussage für das hier vorliegende Experiment machen zu können, wurden nicht, wie in vielen international vorhandenen Arbeiten, die Genexpressionen von Zahnkeim- oder Beckenkammzellen untersucht, die als Mischkulturen betrachtet werden müssen, sondern ausschließlich nur ein bestimmter Zelltyp, die Stro- $1^{+}$-Zellen. Da jedem zu untersuchenden Zustand Triplets zugrunde lagen, deren Standardabweichung äußerst gering war, wurde auf zusätzliche Verifizierung der Ergebnisse mit anderen Methoden (z. B. RT-PCR) verzichtet.

Um aus dem Genpool der signifikant veränderten Gene sowohl beim Medienwechsel der beiden Zellarten als auch bei ihrem direkten Vergleich miteinander im ODM funktionelle Gruppen im biologischen Kontext zu ermitteln, wurde die DAVID-Software genutzt. Das Programm ist über das Internet frei zugänglich, international anerkannt und mit über 20.000 Publikationen eines der am häufigsten verwendeten Tools (Huang et al. 2007). Das Functional Annotation Clustering des Programms kreiert aus der eingegebenen Genliste funktionelle Gruppen (terms) mit einer Rank-Einteilung (enrichment score), welche die Bedeutung des biologischen Prozesses der jeweiligen Gruppe hervorhebt. Je höher dieser score ausfällt, desto bedeutender ist die jeweilige Gruppe für die eingegebene Genliste. Ein score von 1,3 entspricht einem p-Wert von 0,05, daher sollte den Gruppen mit einem score $\geq 1,3$ höhere Beachtung geschenkt werden. 


\subsection{Ergebnisse}

Aus der Pulpa extrahierter Weisheitszähne konnten dentale Stammzellen (DPSCs) isoliert, kultiviert und charakterisiert werden. In Mäuse reimplantierte Zellen aus Kulturen können ektopisches Dentin und Pulpa-ähnliches Gewebe bilden (Gronthos et al. 2000). Sie weisen ähnliche Eigenschaften wie die aus dem Beckenkamm isolierten mesenchymalen Stammzellen (BMSCs) auf. Beide sind plastikadhärent, zeigen ein klonogenes Wachstum und exprimieren die Stammzellmarker CD44, CD106, CD146 sowie Stro-1 (Gronthos et al. 2002, Gronthos et al. 2000, Lei et al. 2014, Shi et al. 2001). Trotz vieler Ähnlichkeiten verhalten sich DPSCs und BMSCs in Kulturen unterschiedlich. Beide sezernieren kalzifizierte Ablagerungen. Während diese bei den DPSCs härter sind und langsamer in geringerem Ausmaß entstehen, sind die BMSCs in der Lage, diese in größeren Mengen viel schneller zu bilden (Batouli et al. 2003, Gronthos et al. 2002, Gronthos et al. 2000). Aufgrund der multiplen Expression der Oberflächen-Epitope bei DPSCs und BMSCs in den oben genannten Untersuchungen kann davon ausgegangen werden, dass es sich bei beiden Zelltypen um eine heterogene Zellpopulation handelt. Die Analyse der Genexpression heterogener Zellpopulationen zeichnet kein klares Ergebnis, da sich bezogen auf ein Gen je nach Zelltyp unterschiedliche Expressionshöhen ergeben können, die zu einer Nivellierung des Endergebnisses führen. Daher wurde in der vorliegenden Arbeit nur die Genexpression der Stro- $1^{+}$-Zellen untersucht.

Das stromale Stro-1-Zelloberflächen-Antigen wurde erstmals von Simmons und TorokStorb 1991 beschrieben. Mit einem monoklonalen Stro-1-Antikörper in Kombination mit der fluoreszenz- oder magnetisch-aktivierten Zellsortierung (FACS, MACS) können mesenchymale Stammzellen aus verschiedenen Geweben isoliert oder in diesen markiert werden (Gronthos et al. 1994, Simmons und Torok-Storb 1991, Stewart et al. 2003). Stro- $1^{+}$-Zellen können in Adipozyten, Fibroblasten, Chondroblasten und Osteoblasten differenzieren und sind daher multipotente Stammzellen (Atkins et al. 2003, Byers et al. 1999, Mödder et al. 2012). 


\subsubsection{Analyse der Rohdaten}

Für den cut-off der FDR $\leq 1 \%$ ergeben sich beim Vergleich der in DMEM und ODM kultivierten Stro- ${ }^{+Z K} 437$ und Stro- $1^{+B K} 624$ signifikant in ihrer Höhe der Expression veränderte Gene $(n=22.454)$. Damit ist der Einfluss des Medienwechsels wesentlich geringer als der differentielle Unterschied beider Zelltypen im DMEM, der von Oellerich bei identischem cut-off mit 2293 Genen $(n=22.454)$ angegeben wird (Oellerich 2016). Der Einfluss des ODM auf die Stro- $1^{+\mathrm{ZK}}$ ist ca. $30 \%$ geringer im Vergleich zu den Stro- $1^{+\mathrm{BK}}$. Beim Wechsel der Stro- $1^{+Z K}$ in das ODM verändert sich ihre Genexpression gegenüber ihrem Expressionsmuster im DMEM folglich weniger signifikant als bei den Stro- $1^{+\mathrm{BK}}$. Gegenüber dem DMEM wird im ODM die Mehrzahl der Gene der Stro- $1^{+\mathrm{ZK}}$ herunterreguliert ( $\downarrow 234: \uparrow 203)$, während sie bei den Stro- $1^{+\mathrm{BK}}$ überwiegend hochreguliert wird $(\downarrow 274: \uparrow 350)$.

Es erscheint interessant, von den jeweils zehn Genen, die bei beiden Zelltypen am signifikantesten hoch- oder herunterreguliert sind, die wesentlichen zu betrachten, um eventuell daraus schon Hinweise auf ihren Zusammenhang hinsichtlich ihrer funktionellen Bedeutung zu erhalten (Tabelle 3). Die im ODM gegenüber dem DMEM hochregulierten Gene sind in den folgenden Kapiteln 4.2.2 und 4.2.3 grün markiert, die herunterregulierten Gene rot.

\subsubsection{Der Einfluss der Medien auf die Genexpression von Stro-1 ${ }^{+\mathrm{ZK}}$}

Bei der Betrachtung der Stro- $1^{+Z K}$ fällt zunächst auf, dass die zehn höchst signifikanten Gene im ODM weniger hoch exprimiert sind als bei den Stro- $1^{+\mathrm{BK}}$ (Tabelle 3). Im Folgenden sollen von einigen Genen die wichtigsten Eigenschaften und ihre funktionelle Bedeutung kurz beschrieben werden.

Das Gen DDIT4 (DNA-damage-inducible transcript 4, syn. REDD1) zeigt höchste logFCund niedrigste FDR-Werte. Das Gen codiert ein Protein, das als upstream repressor mTOR (mechanistic target of rapamycin) inaktiviert, eine Serin-Threonin-Kinase, die Wachstum, Proliferation und Autophagie von Zellen regelt (Ellisen 2005). Unter Autophagie wird ein kataboler zellulärer Prozess verstanden, der bei Substratmangel das Zellüberleben garantiert, indem zelluläre Komponenten zu Molekülen degradiert und recycelt werden (Marino et al. 2014a, 2014b). Autophagie ist verantwortlich für die Entfernung alter oder beschädigter Zellorganellen und wird mit dem Überleben von Tumorzellen in Ver- 
bindung gebracht (Kimmelman 2011). Eine Fehlfunktion von DDIT4 wird daher auch mit vielen Erkrankungen verbunden. Dazu gehören Diabetes, Krebs (Zoncu et al. 2011), Präeklampsie (Hu et al. 2012), die ischämische proliferative Retinopathie (Brafman et al. 2004) und neurodegenerative Erkrankungen (Kim et al. 2003, Malagelada et al. 2011). Eine besondere Rolle spielt mTOR bei der Steuerung der inaktiven Ruhephase, der Selbsterneuerung und der Differenzierung von Stamm- und deren Tochterzellen. Anhand von MSCs konnte nachgewiesen werden, dass DDIT4 direkt in die Steuerung des mTORSignalwegs eingreift und ihre Stammzelleigenschaften aufrechterhält. Es steuert die Expression von Pluripotenzgenen, die Differenzierung und Proliferation von MSCs und deren Progenitorzellen (Gharibi et al. 2016). Hohe Expressionswerte von mTOR wurden auch in Experimenten mit Peroxiden in Zusammenhang mit der Zellalterung gefunden. Dabei wurde festgestellt, dass auch IGFBP3 mTOR beeinflusst und es hochregulieren kann (Hong und Kim 2018). Da bei den Stro- $1^{+Z K}$ IGFBP3 stark herunter- und DDIT4 hochreguliert wurde, ergänzen sich beide Mechanismen in ihrer Wirkung. Es kann daher vermutet werden, dass die Zahnkeimstammzellen im ODM die Expression von mTOR supprimieren.

Das Gen SAA1 (serum amyloid A1) codiert das Protein SAA1, welches hauptsächlich in Hepatozyten synthetisiert wird und als Reaktion auf Infektionen, Gewebeverletzungen oder Tumore gebildet wird (Lowell et al. 1986). Die Expression von SAAl wird im Wesentlichen durch die für das Entzündungsgeschehen verantwortlichen Zytokine IL-1 $\beta$, IL-6 und TNF- $\alpha$ stimuliert. Es ist wie das C-reaktive Protein (CRP) ein Akute-Phase-Protein der Entzündungsreaktion und hat eine starke chemotaktische Wirkung auf Makrophagen und neutrophile Granulozyten (De Buck et al. 2016, 2018). In der Literatur wird beschrieben, dass es mit äußeren Membranproteinen diverser gramnegativer Bakterien, wie E. coli, P. aeruginosa, Salmonellen und Cholerabakterien reagiert. Es wird vermutet, dass es auch in Makrophagen und Epithelzellen produziert wird (Su und Weindl 2018).

Das Gen IGFBP2 (insulin-like growth factor binding protein 2) ist im ODM stark heraufreguliert, während IGFBP3 ebenso stark herunterreguliert wurde. Erhöhte Serumwerte von IGFBP2 sind nach klinischen Beobachtungen mit einer erhöhten Knochenresorption und einer erniedrigten Knochenmineraldichte (BMD = bone mineral density) bei älteren Patienten verbunden (Amin et al. 2007). Die Serumwerte von IGFBP2 steigen mit zunehmendem Alter, während die Werte von IGFBP3 sinken (Amin et al. 2004). Die kurzzeitige Gabe von IGF2 und IGFBP2 konnte eine postoperativ eintretende BMD verhindern (Conover et al. 2002). Glukokortikoide supprimieren die Expression aller IGFBPs. 
Das Gen BMP6 (bone morphogenetic protein 6) ist ebenfalls sowohl in den Stro- $1^{+\mathrm{ZK}}$ als auch in den Stro- $1^{+\mathrm{BK}}$ hoch exprimiert. BMP6 ist wie alle BMPs ein Mitglied der TGF- $\beta$ Familie. BMP6 stimuliert in Osteoblasten die Bildung von alkalischer Phosphatase (ALP) und führt in den entsprechenden Zellkulturen zu ektopischer Mineralisation (Eyckmans und Luyten 2006). In ovarektomierten Ratten führt die systemische Gabe von BMP6 zu einer Steigerung des Knochenvolumens (Simic et al. 2006). Eine erhöhte Expression von BMP6 konnte zudem im Zahnfollikel nachgewiesen werden und steht vermutlich mit der Knochenbildung während des Zahndurchbruchs in Verbindung (Yao et al. 2013).

Das Gen PTX3 (pentraxin 3) codiert für den gleichnamigen, frei im Blut zirkulierenden, solublen Rezeptor der Pentraxin-Familie, die auch als pattern recognition receptors (PRRs) bezeichnet werden. Der Rezeptor aktiviert über die Bindung von Antigenen im Blut das Komplementsystem, so dass neutrophile Granulozyten das Antigen phagozytieren können. Dieser Mechanismus wird auch zur Elimination von körpereigenem Gewebe genutzt, um beispielsweise Zellfragmente nach der Apoptose zu entfernen. Die PRRs gehören zum angeborenen Immunsystem und haben eine eher hemmende Wirkung auf das erworbene Immunsystem (Baruah et al. 2006, Erreni et al. 2017, Presta et al. 2007). Es kann daher vermutet werden, dass Stro- $1^{+Z K}$ über die Synthese von PTX3 Granulozyten rekrutieren, um bei der Zahnbildung Zelldetritus zu entfernen.

Das Gen MAOA ist bei den Stro- $1^{+\mathrm{ZK}}$ signifikant hochreguliert. Es codiert für das Enzym MAO-A, welches zusammen mit MAO-B zu den Monoaminoxidasen (MAO) gehört. Die Gene beider Formen sind auf dem X-Chromosom lokalisiert, was es einerseits schwierig macht, Erkenntnisse aus Tierversuchen auf den Menschen zu übertragen und andererseits gleichgültige Aussagen für beide Geschlechter zu treffen. Monoaminoxidasen sind mitochondrale Enzyme, die Gifte oder aktive Substanzen durch Desaminierung degradieren, deren Endprodukte dann Ammoniak, Aldehyde, Karbonsäuren oder Peroxide sein können. MAO-A baut z. B. Serotonin, Melatonin und die Katecholamine Noradrenalin und Adrenalin ab, MAO-B vorwiegend Benzylamin und Phenylethylamin. Beide bauen Tyramin, Tryptamin und Dopamin ab (Shih et al. 1999). MAO-A ist hauptsächlich im ZNS, in den Nervenenden des Sympathikus, den Schleimhäuten des Darms und in der Plazenta zu finden (Riederer et al. 1987, Nagatsu 2004). Ihr Ausfall ist mit dem BrunnerSyndrom verbunden, das familiär auftritt und mit geistiger Retardierung sowie einem stark erhöhten Aggressionspotential verbunden ist (Brunner et al. 1993, Whibley et al. 2010). Daher ist die überwiegende Mehrheit der Publikationen in der Neurologie und Psychiatrie 
verortet. Über die Bedeutung der MAO im Zusammenhang mit der Hartgewebeforschung ist so gut wie nichts bekannt. Es wird lediglich in einer Publikation beschrieben, dass der Polymorphismus der MAOA durch variable Anzahl der Tandemwiederholungen möglicherweise die Knochendichte (BMD) beeinflusst, da Personen mit einer höheren Anzahl von Tandemwiederholungen eine höhere BMD aufwiesen als Personen mit weniger Wiederholungen (Yamada et al. 2008).

Das von FKBP5 (FK506 binding protein 5) codierte gleichnamige Protein bindet FK506, auch Tacrolimus genannt, und Rapamycin. FK506 inhibiert Calcineurin, welches die T-Lymphozyten aktiviert. Es gilt daher als Immunsuppressivum und wird bei Organtransplantationen verwendet. Ähnlich wie MAOA wird auch FKBP5 häufig im Zusammenhang mit neurologischen Erkrankungen, wie Depression oder Schizophrenie, in der Literatur erwähnt, da es mit Antidepressiva (Lithium) interferiert (Kato 2007). Die Bindung an FKBP5 hemmt die Wirkung von FK506 und Rapamycin (Baughman et al. 1995). Das oben genannte DDIT4 wird bei den Stro- $1^{+Z K}$ durch die Bindung von Rapamycin von FKBP5 in seiner Wirkung, die Stammzelleigenschaften von MSCs aufrechtzuerhalten, unterstützt.

Das Protein Decorin wird vom Gen $D C N$ (decorin) codiert, ist ein kleines Matrixproteoglykan und strukturell eng verwandt mit Biglycan. Es wird vermutet, dass beide das Ergebnis einer Genduplikation sein könnten. Während Biglycan an Kollagenfibrillen des Typ I bindet, einer Komponente des Bindegewebes und der extrazellulären Matrix, interagiert Decorin mit Fibronektin, Thrombospontin, dem epidermal growth factor receptor (EGFR) und dem transforming growth factor beta (TGF- $\beta$ ) (Hildebrand et al. 1994, Lysiak et al. 1995, Schönherr et al. 1998). Ferner reguliert es maßgeblich die Aktivität des Matrixassoziierten Wachstumsfaktors FGF-2. Decorin inhibiert die Angiogenese und interagiert dabei hochspeziell mit VEGFR2 (vascular endothelial growth factor receptor 2) (Järveläinen et al. 2015), was auch zu steigenden Expressionen des Tumorsuppressor-Gens PEG3 führt (Buraschi et al. 2013, Neill et al. 2013). Parathormon steigert die Expression von $D C N$, das ebenso wie die BMPs zu den Genen der Knochenbildung zählt (Onyia et al. 2005). Es wird in verschiedenen Geweben des cranio-facialen Komplexes hoch exprimiert und führt bei Biglycan- und Decorin-doppelt-defizienten Mäusen zu Hypomineralisationen der Schädelsuturen (Wadhwa et al. 2007). Eine reduzierte Decorinexpression ist mit starker Narben- und Keloidbildung verbunden. Decorin wird nach dem heutigen Stand des Wissens mit der Regulierung des Zellzyklus, der Autophagie von Endothelzellen und Angiogenese assoziiert. Offensichtlich spielt es auch eine wichtige Rolle bei der Zahnbil- 
dung, da diese vier Regulierungsprozesse beim komplexen Ablauf der Dentition beteiligt sein müssen.

Das von PTGER4 (prostaglandin E receptor 4) codierte Protein ist einer von vier Prostaglandin-Rezeptoren für das Prostaglandin $\mathbf{E}_{\mathbf{2}}\left(\mathrm{PGE}_{2}\right)$. Das Gen wird in vielen verschiedenen Geweben, wie Herz, Darm, Lunge, Nieren, Thymus, Uterus, in den dorsalen Ganglien und im Gehirn exprimiert. Das Protein ist hauptsächlich in der Tunica media vieler Gefäße, wie Lungenvenen, Aorta, im Corpus cavernosum und auch in den Nierenglomeruli zu finden ist. Die Bindung von $\mathrm{PGE}_{2}$ an den Rezeptor führt zur Relaxation der glatten Muskulatur, wenn sie zuvor aktiviert wurde und zu einer Mobilisierung des G-Proteins. Nach Zerfall des G-Proteins in seine Untereinheiten $G \alpha_{\mathrm{s}}$ und $\mathrm{G} \beta \gamma$ aktivieren diese wiederum bestimmte Zellsignalketten. G $\alpha_{s}$ stimuliert z. B. die Adenylylcyclase, welche die Konzentration des cAMP in der Zelle erhöht, was wiederum die PKA (Proteinkinase A) aktiviert, in deren Folge der Transkriptionsfaktor CREB aktiviert wird. CREB sorgt dann für die Expression von c-fos und Somatostatin, die die zelluläre Proliferation und Differenzierung, sowie die Angiogenese regulieren (Inada et al. 2015, McKinnon und Mellor 2017, Przygrodzka et al. 2016). Über die Aktivierung des G-Proteins wird auch der mTORSignalweg aktiviert.

Bei dem Gen METTL7A (methyltransferase like 7A) wird angenommen, dass es eine Methyltransferase codiert, da es wenig untersucht ist (McKinnon und Mellor 2017). Die Übertragung von Methylgruppen auf DNA dient dazu, Gene abzuschalten bzw. ihr Ablesen von der DNA zu unterbinden (DNA silencing), ohne die Sequenz zu verändern (Zhou et al. 2017).

Das am höchsten herunterregulierte Gen der Stro- ${ }^{+Z K}$ im ODM ist PODXL (podocalyxinlike). Es codiert ein Protein, das in glomerulären Podozyten, Endothelzellen, Drüsenzellen und im Uterus vornehmlich in den Plasmamembranen, Mikrotubuli oder Vesikeln präsent ist. Eine Inaktivierung des Gens führt zur Anurie und zum perinatalen Tod. Hohe Expressionswerte sind mit einer schlechten Prognose bei Patienten mit Nierenkrebs assoziiert (Doyonnas et al. 2001, Kang et al. 2017).

Das von IGFBP3 (insulin-like growth factor binding protein 3) codierte Protein bindet mit hoher Affinität IGF1 und IGF2. Es ist sowohl intra- als auch extrazellulär vorhanden und das wichtigste Transportprotein für IGF1 und 2 im Blut. In malignen Tumoren sind hohe Konzentrationen von IGFBP3 mit einer schlechten Prognose verbunden (Bao et al. 2016). 


\subsubsection{Der Einfluss der Medien auf die Genexpression von Stro-1 ${ }^{+\mathrm{BK}}$}

Die Gene SAA1, BMP6, FKBP5 und MAOA sind ebenfalls bei den Stro- $1^{+\mathrm{BK}}$ unter den zehn höchst signifikant exprimierten Genen zu finden. Das am höchsten exprimierte Gen in den Stro- $1^{+B K}$ ist $S A A 1$. Es ist hier um das ca. 20-Fache höher exprimiert als bei den Stro- $1^{+Z K}$. Auch BMP6 liegt um das etwa 4-Fache höher exprimiert vor als bei den Stro- $1^{+\mathrm{ZK}}$.

Das Gen FRZB (frizzled-related protein) wird in Chondrozyten exprimiert und codiert ein Protein, das im Wnt-Signalweg und in der embryonalen Entwicklung bedeutend ist (Hoang et al. 1996, Zorn 1997). Es aktiviert die G-Proteine. Ursprünglich wurde es als chondrogener Faktor bei der Morphogenese von embryonalem Knochen identifiziert (EnomotoIwamoto et al. 2002, Lodewyckx et al. 2012) und auch als Marker für MSCs aus der Neuralleiste beschrieben, die das Zahnsäckchen bilden, aus dem die Zahnentwicklung hervorgeht (Sarkar und Sharpe 1999). In Knochenmetastasen von hepatozellulären Karzinomen ist FRZB überexprimiert (Huang et al. 2015).

Das Gen VMO1 (vitelline membrane outer layer 1) codiert ein Protein, das die äußere Schicht der Eimembran, bei Hühnern direkt unter der Eierschale gelegen, bildet, wobei Vitellin neben der mechanischen Schutzfunktion starke antimikrobielle Eigenschaften aufweist (Da Silva et al. 2019, Kido et al. 1995, Shamsi et al. 2011). Vitellin ist nicht nur in Vogeleiern, sondern auch in den Eiern von Parasiten, wie Ascaris lumbricoides und vielen Nematoden, nachweisbar (Gerton und Hedrick 1986, Mahmoud und el-Alfy 2003, Ravaglia und Maggese 2003, Shinn et al. 2016). Das menschliche Gen stimmt zu 52,2 \% mit dem Gen des Huhnes überein (Guyot et al. 2016). Das entsprechende Protein wurde bei Menschen, Schafen, Kühen und Kamelen in der Tränenflüssigkeit nachgewiesen (Shamsi et al. 2011). Über die Funktion und Bedeutung dieses Gens in mesenchymalen Stammoder Progenitorzellen liegen bislang keine Erkenntnisse vor.

Das durch IMPA2 (inositol(myo)-1(or4)-monophosphatase 2) codierte Gen spaltet Phosphat von Myo-Inositol-Monophosphat und wird in der Literatur im Zusammenhang mit manisch-depressiven Erkrankungen erwähnt (Arai et al. 2007, Kato 2007, Tomioka et al. 2018). Im Zusammenhang mit MSCs findet sich in der Literatur keine Erwähnung. 
Das Gen EEF1A2 (eukaryotic translation elongation factor 1 alpha 2) codiert die Isoform der alpha-2-Untereinheit des elongation factor-1 complex, die maßgeblich am Transport der tRNA zu den Ribosomen während der Proteinsynthese beteiligt ist. Alpha 2 wird in den Zellen des zentralen Nervensystem, Herz- und Skelettmuskeln exprimiert, während alpha 1 neben dem Gehirn auch in Plazenta, Lunge, Leber, Pankreas und Niere vorkommt (Newbery et al. 2007). Das Gen ist in Prostatakarzinomen überexprimiert (Worst et al. 2017). Es findet sich eine Publikation, die bei zwei Patienten einen Zusammenhang zwischen EEF1A2-Mutationen und neurologischen Erkrankungen kombiniert mit Fehlbildungen im Lippenbereich beschreibt (Nakajima et al. 2015).

Das Gen AOX1 (aldehyde oxidase 1) codiert ein Enzym, das den Abbau von Aldehyden katalysiert. Es ist homolog zur Xanthindehydrogenase. Das Enzym ist im Zytosol von Leber-, Lungen-, Fett- und Skelettmuskelzellen lokalisiert (Kurosaki et al. 2013). Es ist von großer Wichtigkeit für die Funktion der Adipozyten, da es die Ausschüttung von Adiponektin regelt. In Leberzellen bewirkt Adiponektin die Herunterregulierung von AOX1, wodurch die Fettausschüttung aus den Zellen reduziert wird (Weigert et al. 2008).

Die am höchsten herunterregulierten Gene der Stro- $1^{+\mathrm{BK}}$ sind ebenfalls in Tabelle 3 aufgeführt. Dazu gehört das Gen GPR68 (G protein-coupled receptor 68 ). Es codiert einen G-Protein vernetzten Rezeptor, der $\mathrm{pH}$-empfindlich agiert. Er ist physiologisch im leicht sauren Bereich bei pH 6,8 aktiv und wird im basischen Bereich ab pH 7,8 inaktiv (Weiß et al. 2017). Mutationen des Gens bewirken die Amelogenesis imperfecta (Parry et al. 2016). Es ist vermutlich auch in Osteoblasten aktiv und vermittelt in Verbindung mit den G-Proteinen die Kalziummobilisation sowie die Inositolphosphat-Produktion. Eine weitere Funktion ist die eines Suppressor-Gens beim Prostatakarzinom. Ein wichtiges Paralog von GPR68 ist das LPAR5 (Justus et al. 2013, Wiley et al. 2019).

Das Gen FLG (filaggrin) codiert die Proteingruppe der Filaggrine, die in Keratinozyten gebildet werden, welche die Verhornung der Haut bewirken und somit strukturbildende Funktionen für die Epidermis haben. Hierbei dient ionisiertes Kalzium als Kofaktor. Mutationen führen zur erblichen Form der Ichthyosis vulgaris oder zur atopischen Dermatitis in Verbindung mit Allergien (Cabanillas und Novak 2016, Elmose und Thomsen 2015, Emons und Gerth van Wijk 2018, Kezic und Jakasa 2016). Für den physiologisch niedrigen, bakteriziden pH-Wert des Stratum corneum wird u. a. die Degradation der Filaggrine verantwortlich gemacht (Proksch 2018). Die starke Herunterregulierung dieses Gens ist plausibel, da seine Funktionen weder bei den mesenchymalen Zellen der Zahnkeime noch 
Beckenkammzellen benötigt wird. Überraschend ist jedoch, dass Eigenschaften ektodermaler Zellen auch in mesenchymalen Zellen geregelt werden.

\subsubsection{Funktionelle Genanalyse der Stro-1 ${ }^{+\mathrm{ZK}}$ und Stro-1 $^{+\mathrm{BK}}$}

Während im DMEM gegenüber dem ODM bei den Stro- $1^{+Z K}$ funktionelle Gruppen der Zellmigration, Muskelzelldifferenzierung sowie Zelladhäsion im Vordergrund stehen, finden sich bei den Stro- $1^{+\mathrm{BK}}$ gehäuft Gengruppen, die in Verbindung mit der Angiogenese stehen. Im ODM tritt ein Wechsel der Genexpression ein, bei der Gruppen der Antwort auf Wundheilung und Entzündung überrepräsentiert sind. Es ist hinlänglich bekannt, dass Wundheilung und Entzündung ähnliche Reaktionen auslösen und identische pathophysiologische Abläufe aufweisen können. Dass der Mineralisationsprozess eventuell auch in diesen funktionellen Formenkreis passt, ist bislang weniger bekannt. Es wurde allerdings beschrieben, dass die Zytokine IL-1 $\beta$ und TNF- $\alpha$ in Kulturen von MSCs aus humanem Beckenkamm eine starke Mineralisation bewirken können (Ferreira et al. 2013).

Auffällig ist, dass das Gen $\mathbf{I G F 2}$ bei den Stro- $1^{+\mathrm{ZK}}$ in acht der ersten zehn im ODM signifikant hochregulierten funktionellen Gruppen dominiert und somit offensichtlich eine zentrale Rolle spielt, während im Milieu des DMEM die Gene seiner Bindungsproteine IGFBP3 und 5 am häufigsten erscheinen (Tabelle A-6 im Anhang). IGF2 besitzt eine strukturelle Ähnlichkeit mit Insulin. Es wird vermutet, dass es ein wichtiger fetaler Wachstumsfaktor ist, der seine Wirkung vornehmlich während der Schwangerschaft entfaltet. IGF1 wird dagegen eine hauptsächliche Wirkungsentfaltung im Erwachsenen zugeschrieben (Barroca et al. 2017). Beide weisen insulinähnliche, wachstumsfördernde und mitogene Eigenschaften auf (Frasca et al. 1999). IGF2 bindet an den IGF1-Rezeptor oder die kurze Isoform des Insulin-Rezeptors (IR-A). Bei Bindung an den IGF2-Rezeptor bleibt IGF2 wirkungslos. Es konnte ferner gezeigt werden, dass IGF2 die Überlebensrate von neuen Hippocampusneuronen unterstützt und daher möglicherweise anxiolytische Wirkung bei exzessiven Angstneurosen besitzen könnte (Barroca et al. 2017).

Im DMEM dominieren funktionelle Gruppen, in denen nicht $I G F 2$, sondern die Gene für seine Bindungsproteine 3 und 5 am häufigsten vertreten sind. Im Blut und in der extrazellulären Flüssigkeit sind die IGF-Proteine instabil und fragmentieren leicht. Die Bindung an ihre Bindungsproteine erhöht ihre Stabilität und stellt daher ihre Transportform im Blut und in den extrazellulären Körperflüssigkeiten dar. Die IGFBPs sind evolutionär hoch 
konservierte Gene, was ihre Bedeutung unterstreicht. Das Gen IGFBP3 ist verantwortlich für die Translation des gleichnamigen Proteins, das an IGF1 und 2 bindet und für deren Transport verantwortlich ist. Da IGF1 und 2 eine höhere Affinität zu IGFBP3 als zu ihren Rezeptoren haben, kann es deren Bindung an die entsprechenden Rezeptoren blockieren. IGFBP3 interagiert auch mit den Oberflächenrezeptoren von Zellen und kann somit ihre Signalkaskaden blockieren (Bergman et al. 2013).

\subsubsection{Differentielle Genexpression der Stro-1 ${ }^{+\mathrm{ZK}}$ und Stro-1 $^{+\mathrm{BK}}$ in den Medien}

Die Stro- $1^{+\mathrm{ZK}}$ und Stro- $1^{+\mathrm{BK}}$ haben 224 identische Gene, die beim Wechsel vom DMEM in das ODM gleichsinnig hoch- und herunterreguliert werden. Diese Reaktion ihrer Genexpression auf den Medienwechsel könnte neben der gemeinsamen Expression des Oberflächenmarkers Stro-1 ihre Verwandtschaft dokumentieren. Andererseits verändert der Medienwechsel bei den Stro- $1^{+\mathrm{ZK}} 456$ Gene signifikant, deren identische Partner bei den Stro- $1^{+\mathrm{BK}}$ keine signifikante Veränderung erfahren. Umgekehrt zeigen die Stro- $1^{+\mathrm{BK}} 720$ signifikant veränderte Gene, denen bei den Stro- $1^{+Z K}$ keine signifikante Reaktion beim Medienwechsel gegenübersteht. Würde das Verhältnis ihrer Reaktion auf den Medienwechsel im übertragenen Sinne als Verwandtschaftsverhältnis ausgedrückt, so wären beide Zelltypen keine „Geschwister“ oder gar „Zwillinge“, sondern eher „Halbgeschwister“ oder „Verwandte zweiten Grades“. Da die Zahnkeimbildung eine Interaktion zwischen Zellen ektodermalen und mesenchymalen Ursprungs darstellt (Gronthos et al. 2000), ist es naheliegend, dass die Stro- $1^{+\mathrm{ZK}}$ anders konditioniert sind als die Stro- $1^{+\mathrm{BK}}$. Dies könnte möglicherweise durch eine epithelial-mesenchymale Transition (EMT) während der Zahnkeimentwicklung entstanden sein, wie sie auch bei der Tumorentstehung beschrieben wird (Mimeault und Batra 2011).

Bei den gleichsinnig hochregulierten Genen beider Zelltypen stellen die funktionellen Untergruppen von cluster 1 der DAVID-Analyse eine wichtige Gemeinsamkeit dar (Tabelle A-14 im Anhang). Hier finden sich Gengruppen, die mit der Bildung und Aufrechterhaltung der extrazellulären Matrix sowie Adhäsionsmolekülen (secreted) in der Plasmamembran von Zellen zusammenhängen, die den Zell-Matrix-Kontakt vermitteln. Unter den Genen von cluster 1 befinden sich auch die vier Gene SAA1, BMP6, IGFBP2 und DCN, die zu den zehn am höchst signifikant exprimierten Genen der Stro- $1^{+Z K}$ gehören. Ferner findet sich hier auch VMO1, das bei den Stro- $1^{+\mathrm{BK}}$ zu den zehn Genen mit höchster Signifikanz zählt. Die extrazelluläre Matrix (EZM) steht mit den Zellen, die sie bilden und abbauen, in 
ständiger Wechselwirkung. Die Bindung an die EZM durch Zellrezeptoren und Adhäsionsmoleküle kann die Expression von Genen in den Zellen modifizieren (Halper und Kjaer 2014). Auch können Strukturproteine wie das Decorin in diesem Zusammenhang als Botenstoffe oder Signalmoleküle wirken, so dass Zellmigration, Zelladhäsion und Zellproliferation beeinflusst werden können (Gubbiotti et al. 2016, Hildebrand et al. 1994, Miyachi et al. 2018). Ferner besteht auf diesem Weg die Möglichkeit, den Auf-, Um- und Abbau der EZM zu regulieren. Die EZM ist nicht nur im Knochen oder in den Zähnen als mineralisierte Matrix von Bedeutung, sondern spielt auch bei der Bildung jeglicher Gewebe eine entscheidende Rolle, da sie die Grundsubstanz bildet. So befindet sich beispielsweise das Epithel der Haut auf der Basalmembran, die von der EZM gebildet wird. Der Ab- und Umbau der EZM wird hauptsächlich mithilfe von Matrix-Metalloproteasen vorgenommen (Rodríguez et al. 2010). Zu den gemeinsam überexprimierten Genen beider Zellarten gehört auch TIMP4 (tissue inhibitor of metalloproteinase 4), welches ein Protein codiert, das die Aktivität von Matrix-Metalloproteasen hemmt (Brew und Nagase 2010).

In diesem Zusammenhang erscheint es äußerst interessant, dass die gleichsinnig herunterregulierten Gene beider Zelltypen in cluster 1 funktionelle Untergruppen wie Glycoprotein, Disulfide Bond, Signal, Secreted und extracellular region aufweisen (Tabelle A-15 im Anhang), die im Zusammenhang mit dem Abbau der EZM stehen. Hier sind insbesondere die codierenden Gene der Matrix-Metalloproteasen 1, 2 und 14 (MMP1, MMP2, MMP14) zu nennen, die als herunterreguliert aufgeführt werden. Nach der funktionellen Einteilung baut MMP1 Kollagen ab, MMP2 gilt als Gelatinase und MMP14 zählt zu den Membranbezogenen Proteasen (Rodríguez et al. 2010, Van Doren 2015).

Für die einseitig signifikant herunterregulierten Gene der Stro- $1^{+\mathrm{BK}}$ finden sich in cluster 1 der DAVID-Analyse funktionelle Gruppen, die für die Angiogenese zuständig sind (Abbildung 10). Die Herunterregulierung der Angiogenese wird durch die Herunterregulierung der MMPs unterstützt, da MMP2 und 14 auch die Bildung von Blutgefäßen fördern. Eine wichtige Rolle bei der Angiogenese spielt das bei den Stro- ${ }^{+\mathrm{ZK}}$ hoch exprimierte Decorin. Es kann sowohl die Angiogenese fördern als auch hemmenden Einfluss auf sie ausüben (Järveläinen et al. 2015). Das Kernprotein von Decorin stimuliert die Expression von MMP1. MMP1 ist wiederum in der Lage, die Expression von VEGFR2 (vasculsar endothelial growth factor receptor 2) über die Aktivierung von PAR1 (protease-activated receptor 1) und NF- $\mathrm{NB}$ (nuclear factor $\kappa B$ ) zu initiieren. Interessanterweise zählt das Gen des NF-kB Inhibitors (NFKB1A) zu den gemeinsam signifikant heraufregulierten Genen 
der funktionellen Gruppen osteoclast differentiation und receptor signaling pathway aus cluster 15 (Abbildung 14). Decorin stimuliert ferner die Bildung von MMP2, die das Kollagen IV der Basalmembran degradiert (Schönherr et al. 1998).

Die wichtigsten Adhäsionsproteine, die für die Zelladhäsion an der EZM Bedeutung haben, sind die Integrine. Sie bestehen aus Alpha- und Beta-Untereinheiten, die durch $\mathrm{Ca}^{++}$ miteinander verbunden sind. Das Gen der Alpha-Untereinheit ist bei den Stro- $1^{+\mathrm{BK}}$ heraufreguliert, während es bei den Stro- $1^{+Z K}$ herunterreguliert wird. Da die Gene der Integrine und HOX-Familie auf der gleichen Seite desselben Chromosoms liegen, wird vermutet, dass sie sich während der Evolution parallel entwickelt haben (Wang et al. 1995).

\subsubsection{Differentialexpression der Gene von Stro-1 ${ }^{+\mathrm{ZK}}$ und Stro-1 ${ }^{+\mathrm{BK}}$ im osteo- genen Medium und ihre biologisch-funktionellen Gruppen}

Bei dem Vergleich der differentiellen Genexpression im ODM werden im Hinblick auf die funktionellen Gruppen Unterschiede deutlich, die eine Charakterisierung der beiden Zelltypen unabhängig vom Medienwechsel ermöglichen.

Die 109 Gene der Stro- ${ }^{+Z K}$, die gegenüber den Stro- $1^{+B K}$ im ODM höchst signifikant hochreguliert werden, gehören insbesondere Gruppen an, die an Zellproliferation, Organentwicklung und Organisation der extrazellulären Matrix beteiligt sind. Der weniger streng gewählte cut-off von FDR $\leq 5 \%$ ordnet die Genexpression der Stro- $1^{+Z K}$ dagegen in einen größeren Gesamtkontext von höherer biologischer Relevanz ein. Danach sind bei den Stro- $1^{+Z K}$ gegenüber den Stro- $1^{+\mathrm{BK}}$ im ODM hauptsächlich Gengruppen überexprimiert, die mit der Zellteilung und ihren Modalitäten im Zellkern und Zytoplasma verbunden sind. Eine hohe Relevanz nimmt auch die wichtige Funktion der DNA-Reparatur in cluster 3 der DAVID-Analyse ein. Im Vergleich dazu sind bei den Stro- $1^{+\mathrm{BK}}$ Gene funktioneller Gruppen überexprimiert, die wichtige Proteine der extrazellulären Matrix bilden und die „Bauplan-Gene“ (HOX-Gene in cluster 2 mit ES = 5,81; Abbildung 23) der Körpersegmente codieren. Unter den ersten zehn höchst signifikant hochregulierten funktionellen Gruppen der Stro- ${ }^{+\mathrm{BK}}$ finden sich Prozesse, die der Organ- und Skelettentwicklung angehören. Unter dem GO-term skeletal system development findet sich HOX-Gene der Cluster A-C, was vermuten lässt, dass den Stro- $1^{+\mathrm{BK}}$ eine höhere Bedeutung bezüglich der Strukturgebung von Geweben zukommt als den Stro- $1^{+Z K}$. Auch die Stro- $1^{+Z K}$ exprimieren einige Homeobox-Gene, wobei diese im Gesamtzusammenhang in ihrer 
funktionellen Bedeutung als gering eingestuft werden (cluster 126 mit ES = 0,16; Abbildung 20).

Interessant sind dagegen die in den funktionellen Gruppen der Stro- $1^{+\mathrm{ZK}}$ hochregulierten Gene GREM1, PTN und FST. GREM1 (gremlin 1) codiert für ein Protein, welches als extrazellulärer Antagonist von BMP 2, 4 und 7 in den TGF $\beta$-Signalweg eingreift. Es spielt eine entscheidende Rolle bei der Organentwicklung, Gewebedifferenzierung, Angiogenese sowie Entstehung von Tumoren (Sneddon et al. 2006). Auch für die Zahnentwicklung konnte anhand genmodifizierter Mäuse nachgewiesen werden, dass eine Überexpression von GREM1 neben der bekannten Verminderung der Knochendichte zu Zähnen mit erweiterten Pulpenkammern und ausgedünntem Hartsubstanzmantel führt (Gazzerro et al. 2005, Nagatomo et al. 2008). PTN (pleiotrophin) codiert für einen Heparin-bindenden Wachstumsfaktor, der Zelldifferenzierung und -migration beeinflusst. Es wird in mesodermalen und extodermalen Zellen exprimiert und ist wesentlich an epithelial-mesenchymalen Interaktionen während der Morphogense beteiligt (Mitsiadis et al. 1995). Da auch die Odontogenese auf derartigen Wechselwirkungen beruht, konnte PTN in den Inzisivi und Molaren von Mäusen nachgewiesen werden, wobei mit zunehmendem Differenzierungsgrad der zahnbildenden Amelo- und Odontoblasten eine verstärkte Expression auftrat (Erlandsen et al. 2012). In PTN-defizienten Mäusen kam es zur Ausbildung von hypomineralisierten Zähnen mit vergrößerten Pulpenkammern (Stidham et al. 2009). Auch das durch $\boldsymbol{F S T}$ (follistatin) codierte Glykoprotein hat über die Bindung von Activin einen antagonistisches Effekt auf den TGF $\beta$-Signalweg. Activin tritt während der Zahnentwicklung als wichtiges Signalmolekül im Mesenchym von Zahnkeimen auf (Ferguson et al. 1998). In Versuchen mit FST-Knockout-Mäusen kam es zu fehlerhaften Ausbildungen der Zahnleiste und ihrer Schmelzknoten. Eine Überexpression von FST resultierte dagegen in irregulären Zahnkronen sowie Aplasie aller dritten Molaren (Wang et al. 2004).

Unter den hochregulierten Gruppen der Stro- $1^{+\mathrm{BK}}$ gegenüber den Stro- $1^{+\mathrm{ZK}}$ im ODM finden sich weiterhin Prozesse der Angiogense, wobei dies nicht im Widerspruch zu den unter 1.2.4 erwähnten Ergebnissen steht. Zwar werden Vorgänge, die sich mit der Gefäßentwicklung befassen, bei den Stro- $1^{+\mathrm{BK}}$ beim Wechsel vom DMEM in das ODM herunterreguliert, jedoch nicht in dem Ausmaß, dass sie unter die Expressionswerte der entsprechenden Gene bei den Stro- $1^{+Z K}$ fallen. Im direkten Vergleich beider Zelltypen im ODM wird also deutlich, dass sich die Stro- $1^{+\mathrm{BK}}$ tatsächlich eher um ihr extrazelluläres Milieu kümmern, während die Stro- $1^{+Z K}$ in erster Linie zellbezogene Prozesse steuern. Interessant scheint 
daher ein Überblick, welche Gene beide Zelltypen hinsichtlich der Kollagensynthese im ODM differentiell exprimieren.

Im ODM sind bei den Stro- $1^{+Z K}$ die Gene der Kollagene IV, X, XIII und XVIII (COL4A5, COL10A1, COL13A1, COL18A1) überexprimiert. Das Gen COL4A5 codiert das Kollagen IV mit der alpha-Kette 5, eine der sechs Untereinheiten des Kollagen IV, die als Hauptstruktureinheiten der Basalmembran fungieren und wie Kollagen VIII und X als netzbildende Kollagene bezeichnet werden (Pozzi et al. 2017). Das vom Gen COL10A1 codierte Kollagen wird auch von Chondroblasten bei der enchondralen Ossifikation gebildet und gilt wie Kollagen VIII als kurzkettiges Kollagen (Hansen et al. 2016). Es erscheint daher eher ungewöhnlich, dass es in den Stro- $1^{+Z K}$ exprimiert wird. Kollagen XIII spielt ebenfalls bei der enchondralen Ossifikation eine Rolle, ist aber auch an der Zell-Matrix-Bindung und der Zelladhäsion beteiligt. Das C-terminale Ende von Kollagen XVIII inhibiert die Angiogenese und sorgt so für eine gefäßfreie Knorpelbildung (Marneros und Olsen 2005, Pufe et al. 2004, Sertié et al. 2000). Es könnte daher vermutet werden, dass für die Stro- $1^{+}$Zahnkeimzellen das ODM nicht das physiologische Medium darstellt und sie in Richtung der chondralen Ossifikation gedrängt werden, da diese Kollagene bei der Zahnbildung keine Rolle spielen.

Die Stro- $1^{+\mathrm{BK}}$ exprimieren mit einem signifikant höheren $\log \mathrm{FC}$ die Gene der Kollagene COL4A1, COL4A2, COL6A2, COL11A1 und COL12A1. Das Kollagen vom Typ COL4A2 ist ein integraler Bestandteil der Basalmembran und wirkt inhibierend auf die Zellmigration von Endothelzellen und die Zellproliferation. Des Weiteren induziert es die FAS-abhängige Apoptose und aktiviert die Caspase-Aktivität (Maeshima et al. 2000). Kollagen VI als perlschnurartiges Kollagen ist Bestandteil der extrazellulären Matrix der Skelettmuskeln und verankert die Basalmembran mit dem interstitiellen Gewebe (Endicott et al. 2017) . Die autosomal dominanten und rezessiv vererbten Genmutationen sind mit der kongenitalen Ullrich-Muskeldystrophie, der Bethlem-Myopathie oder einer starken Keloid-Bildung nach Hautverletzungen verbunden (Echeverria et al. 2017). Kollagen XII gehört zu den fibrillenassoziierten Kollagenen und ist mit Kollagen XIV in embryonalen Basalmembranen anzutreffen (Thierry et al. 2004). 


\section{Zusammenfassung}

Die Vermutung, dass Zellen auf physiologische Veränderungen ihres Milieus reagieren, ist in vielen Fällen nachgewiesen, jedoch nicht vollständig geklärt, da die einzelnen Zelltypen in einem Gewebeverband oder in der Zellkultur selten isoliert betrachtet werden. Diese Frage ist jedoch für das tissue engineering von entscheidender Bedeutung. In der vorliegenden Arbeit sollte daher der Frage nachgegangen werden, ob und wie sich aus Zahnkeimen und Beckenkamm isolierte, Stro- $1^{+}$-Zellen in verschiedenen Medien in ihrer Genexpression unterscheiden.

Dazu wurden die isolierten Zellen in DME-Medium und einem osteogenen Differenzierungsmedium kultiviert. Die Genexpression wurde mithilfe von Microarrays ermittelt. Für jeden Zelltyp wurden in beiden Medien jeweils drei Arrays angelegt, sodass die Auswertung für die Intensitätsdaten der Gene $(\mathrm{n}=28.889)$ als Triplets erfolgte. Nach Normalisierung der Daten wurden aus den Mittelwerten der Intensitäten die $\log _{2}$ FC-Werte und die FDR ermittelt. Anhand dieser beiden Größen wurden unter Abzug noch unbekannter Gene die Daten von 22.454 Genen nach signifikant differentiell exprimierten Genen gefiltert. In einem zweiten, speziellen Filterverfahren wurden alle Gene alphabetisch geordnet und die $\operatorname{logFC}$ - und FDR-Werte der Stro- $1^{+\mathrm{ZK}}$ und Stro- $1^{+\mathrm{BK}}$ jeweils den identischen Genen zugeordnet, um anschließend eine synchrone Filterung beider Zelltypen vornehmen zu können. Dabei ergaben sich für beide Zellarten signifikante Werte, die jedoch zahlenmäßig und bei vielen Genen nicht mit der jeweils anderen Zellart übereinstimmten. Abschließend erfolgte eine Betrachtung des differentiellen Expressionsprofils von Stro- $1^{+\mathrm{ZK}}$ und Stro- $1^{+\mathrm{BK}}$ im osteogenen Differenzierungsmedium, um beide Zelltypen direkt miteinander vergleichen zu können. Die anhand dieser Methodik gewonnenen Daten wurden mit dem SoftwareProgramm DAVID analysiert oder durch Einzelbeobachtung beschrieben.

Dabei wurden als wesentliche Ergebnisse folgende Erkenntnisse gewonnen:

Bei einem Wechsel vom DMEM in das osteogene Medium werden bei den Stro- $1^{+\mathrm{BK}}$ erheblich mehr Gene signifikant verändert als bei den Stro- $1^{+Z K}$ (Verhältnis $\mathrm{ZK}: \mathrm{BK}=2: 3$ ). Dabei werden die Gene der Stro- $1^{+\mathrm{ZK}}$ Zu einem höheren Anteil im ODM herunterreguliert, während bei den Stro- $1^{+\mathrm{BK}}$ größtenteils eine Heraufregulation erfolgt. Insgesamt werden in den Stro- $1^{+\mathrm{ZK}}$ weniger Gene signifikant verändert als in den Stro- $1^{+\mathrm{BK}}$, d. h. die Stro- $1^{+}$-Beckenkammzellen werden durch das osteogene Differenzierungsmedium stärker stimuliert als die Stro- $1^{+}$-Zahnkeimzellen. Zusätzlich fällt die 
Intensität der Genexpression bei den Stro- $1^{+\mathrm{BK}}$ wesentlich höher aus als bei den Stro- $1^{+\mathrm{ZK}}$. Der logFC-Median der zehn höchst signifikant hochregulierten Gene beträgt bei den Stro- $1^{+\mathrm{ZK}} 3,54$ und bei den Stro- $1^{+\mathrm{BK}} 4,29$, während die Mediane der zehn höchst signifikant herunterregulierten Gene jeweils $-3,65$ und $-3,30$ betragen. Die Gene der Stro- $1^{+Z K}$ werden also stärker herunter- und die der Stro- $1^{+\mathrm{BK}}$ stärker heraufreguliert. Für beide Zelltypen fanden sich unter den zehn im ODM gegenüber dem DMEM höchst signifikant hochregulierten Genen die vier identischen Gene SAA1, BMP6, FKBP5 und MAOA. Die funktionelle DAVID-Analyse zeigte für die Stro- $1^{+\mathrm{ZK}}$ und Stro- $1^{+\mathrm{BK}}$ beim Wechsel in das ODM eine Überrepräsentierung von biologischen Prozessen, die mit der Antwort auf Wundheilung und Entzündung zusammenhängen.

Durch die zweite, synchrone Filterung aller Gene beider Zelltypen nach alphabetischer Sortierung konnten bei einem cut-off der FDR $\leq 5 \%$ für die Stro- $1^{+Z K} 696$ Gene mit signifikant veränderten $\log \mathrm{FC}-$ Werten beim Wechsel vom DMEM in das ODM detektiert werden. Von diesen zeigten 456 Gene bei den Stro- $1^{+\mathrm{BK}}$ keine signifikante Veränderung. Die Stro- $1^{+\mathrm{BK}}$ wiesen 960 Gene mit signifikanten $\operatorname{logFC}$-Werten auf, von denen 720 Gene bei den Stro- $1^{+Z K}$ nicht signifikant verändert wurden. Dagegen existierten für beide Zelltypen 130 identische Gene, die gleichsinnig signifikant herauf-, und 94 identische Gene, die gleichsinnig signifikant herunterreguliert wurden. Folglich reagierten 224 Gene für beide Zelltypen gleichartig beim Wechsel vom DMEM in das osteogene Medium. 16 Genpaare verhielten sich gegensätzlich. Davon waren sieben Gene bei den Stro- $1^{+Z K}$ hoch- und den Stro- $1^{+\mathrm{BK}}$ herunterreguliert, neun Gene zeigten ein umgekehrtes Verhalten. Sowohl die einseitig bei einem Zelltyp signifikant veränderten Gene als auch die gleich- und gegensinnig veränderten Gene wurden in der funktionellen DAVID-Analyse hauptsächlich Gruppen zugeordnet, die im Zusammenhang mit Zellmembraneigenschaften und der extrazellulären Matrix stehen. Die einseitig signifikant herunterregulierten Gene der Stro- $1^{+\mathrm{BK}}$ repräsentieren dagegen auch funktionelle Gruppen, die für die Angiogenese und Bildung von Endothelzellen verantwortlich sind.

Im direkten Vergleich beider Zelltypen im osteogenen Medium werden für die cut-offs FDR $\leq 1 \%$ und $|\operatorname{logFC}|>2$ bei den Stro- $1^{+\mathrm{ZK}} 109$ Gene signifikant gegenüber den Stro- $1^{+\mathrm{BK}}$ hochreguliert, während diese mit 266 hochregulierten Genen eine stärkere Beeinflussung der Genexpression zeigen. Bei den zugehörigen funktionellen Gruppen der Stro- $1^{+\mathrm{BK}}$ sind vor allem Prozesse der Skelettentwicklung und Organisation der extrazellulären Matrix überrepräsentiert. Hier finden sich HOX-Gene der Cluster A-C, während bei den Stro- $1^{+Z K}$ die für die Odontogenese wichtigen Gene MSX1, DLX1, SIX1 und PAX9 
hochreguliert werden. Anhand des weniger streng gefassten cut-offs der FDR $\leq 5 \%$ konnte deutlich gemacht werden, dass im Gesamtkontext der Genexpression neben den statistisch hochsignifikanten Gengruppen auch biologische Prozesse relevant sind, die sich mit grundlegenden Zellfunktionen wie Proliferation und Energiestoffwechsel befassen.

Die Ergebnisse der vorliegenden Arbeit zeigen, dass die Stro- ${ }^{+\mathrm{BK}}$ eine stärkere Stimulation in ihrer Genexpression bezogen auf Genanzahl und Intensität durch das osteogene Differenzierungsmedium erfahren. Beide Stammzelltypen reagieren beim Wechsel vom DMEM in das osteogene Medium zwar mit einer Hochregulation ähnlicher Gene und funktioneller Gruppen, im direkten Vergleich miteinander grenzen sich die Stro- ${ }^{+\mathrm{BK}}$ jedoch deutlicher von den Stro- ${ }^{+\mathrm{ZK}}$ als „,knochenbildende Zellen“ 


\section{Anhang}

Tabelle A-1: Die 84 Gene der Stro-1 ${ }^{+}$-Beckenkammzellen, die gegenüber dem DMEM (BK1) im osteogenen Medium (BK2) hochsignifikant heraufreguliert sind. Die Gene sind nach der Höhe der FDR aufsteigend sortiert. Die Auswahlkriterien waren $|\operatorname{logFC}|>2$ und FDR $\leq 0,01$.

\begin{tabular}{|c|c|c|c|c|}
\hline AgilentID & Symbol & Genname & $\log \mathrm{FC}$ BK2-1 & FDR BK2-1 \\
\hline A_24_P335092 & SAA1 & serum amyloid $\mathrm{A} 1$ & 8,034 & $6,63 \mathrm{E}-14$ \\
\hline A_23_P19624 & BMP6 & bone morphogenetic protein 6 & 5,251 & $3,81 \mathrm{E}-12$ \\
\hline A_23_P10902 & FRZB & frizzled-related protein & 4,406 & $3,81 \mathrm{E}-12$ \\
\hline A_23_P55356 & VMO1 & vitelline membrane outer layer 1 homolog (chicken) & 4,586 & $3,95 \mathrm{E}-11$ \\
\hline A_23_P363778 & FRZB & frizzled-related protein & 4,352 & $4,19 \mathrm{E}-10$ \\
\hline A_23_P50081 & IMPA2 & inositol(myo)-1(or 4)-monophosphatase 2 & 4,105 & $4,19 \mathrm{E}-10$ \\
\hline A_23_P83857 & MAOA & monoamine oxidase $\mathrm{A}$ & 3,299 & $4,19 \mathrm{E}-10$ \\
\hline A_24_P38081 & FKBP5 & FK506 binding protein 5 & 4,235 & $4,68 \mathrm{E}-10$ \\
\hline A_23_P256033 & EEF1A2 & eukaryotic translation elongation factor 1 alpha 2 & 3,277 & $4,68 \mathrm{E}-10$ \\
\hline A_23_P154037 & AOX1 & aldehyde oxidase 1 & 3,060 & $1,63 \mathrm{E}-09$ \\
\hline A_23_P306203 & SAA2 & serum amyloid $A 2$ & 5,669 & $4,82 \mathrm{E}-09$ \\
\hline A_23_P111206 & FKBP5 & FK506 binding protein 5 & 3,590 & $4,83 \mathrm{E}-09$ \\
\hline A_23_P203957 & TMTC1 & transmembrane and tetratricopeptide repeat containing 1 & 3,175 & $4,83 \mathrm{E}-09$ \\
\hline A_24_P296772 & PPP1R14A & protein phosphatase 1 , regulatory (inhibitor) subunit $14 \mathrm{~A}$ & 4,168 & $1,02 \mathrm{E}-08$ \\
\hline A_24_P397817 & LEP & leptin & 3,301 & $1,13 \mathrm{E}-08$ \\
\hline A_24_P231104 & LEPR & leptin receptor & 3,745 & $1,13 \mathrm{E}-08$ \\
\hline A_24_P938352 & CPM & carboxypeptidase M & 3,283 & $1,22 \mathrm{E}-08$ \\
\hline A_23_P216596 & SVEP1 & $\begin{array}{l}\text { sushi, von Willebrand factor type A, EGF and pentraxin domain } \\
\text { containing } 1\end{array}$ & 2,922 & $1,37 \mathrm{E}-08$ \\
\hline A_23_P356004 & KCNIP3 & $\mathrm{Kv}$ channel interacting protein 3 , calsenilin & 3,167 & $1,45 \mathrm{E}-08$ \\
\hline A_23_P166376 & GGT5 & gamma-glutamyltransferase 5 & 2,885 & $3,74 \mathrm{E}-08$ \\
\hline A_23_P253692 & GPR64 & G protein-coupled receptor 64 & 2,479 & $3,74 \mathrm{E}-08$ \\
\hline A_23_P104318 & DDIT4 & DNA-damage-inducible transcript 4 & 3,528 & $3,84 \mathrm{E}-08$ \\
\hline A_23_P378416 & GPM6B & glycoprotein M6B & 3,454 & $5,64 \mathrm{E}-08$ \\
\hline A_23_P7144 & CXCL1 & $\begin{array}{l}\text { chemokine (C-X-C motif) ligand } 1 \text { (melanoma growth stimulating } \\
\text { activity, alpha) }\end{array}$ & 2,306 & $5,70 \mathrm{E}-08$ \\
\hline A_24_P297182 & GGT5 & gamma-glutamyltransferase 5 & 3,511 & $7,34 \mathrm{E}-08$ \\
\hline A_23_P254741 & SOD3 & superoxide dismutase 3 , extracellular & 3,178 & $8,33 \mathrm{E}-08$ \\
\hline A_23_P162668 & CPM & carboxypeptidase M & 3,547 & $9,89 \mathrm{E}-08$ \\
\hline A_24_P117620 & CAMK2N1 & calcium/calmodulin-dependent protein kinase II inhibitor 1 & 2,523 & $1,08 \mathrm{E}-07$ \\
\hline A_23_P201587 & SORT1 & sortilin 1 & 2,492 & 1,23E-07 \\
\hline A_32_P114284 & IKZF2 & IKAROS family zinc finger 2 (Helios) & 3,008 & $1,23 \mathrm{E}-07$ \\
\hline A_23_P204937 & C13orf15 & chromosome 13 open reading frame 15 & 4,711 & $1,24 \mathrm{E}-07$ \\
\hline A_32_P154911 & PRR15 & proline rich 15 & 3,411 & $1,25 \mathrm{E}-07$ \\
\hline A_23_P91230 & SLPI & secretory leukocyte peptidase inhibitor & 2,633 & $1,44 \mathrm{E}-07$ \\
\hline A_23_P127948 & ADM & adrenomedullin & 2,989 & $1,71 \mathrm{E}-07$ \\
\hline A_23_P50946 & RAMP1 & receptor (G protein-coupled) activity modifying protein 1 & 2,388 & $1,88 \mathrm{E}-07$ \\
\hline A_23_P252062 & PPARG & peroxisome proliferator-activated receptor gamma & 2,088 & $2,53 \mathrm{E}-07$ \\
\hline A_24_P264943 & COMP & cartilage oligomeric matrix protein & 2,973 & $2,77 \mathrm{E}-07$ \\
\hline A_23_P397999 & FZD5 & frizzled homolog 5 (Drosophila) & 2,279 & $2,77 \mathrm{E}-07$ \\
\hline A_24_P325520 & SORT1 & sortilin 1 & 2,822 & $3,64 \mathrm{E}-07$ \\
\hline
\end{tabular}




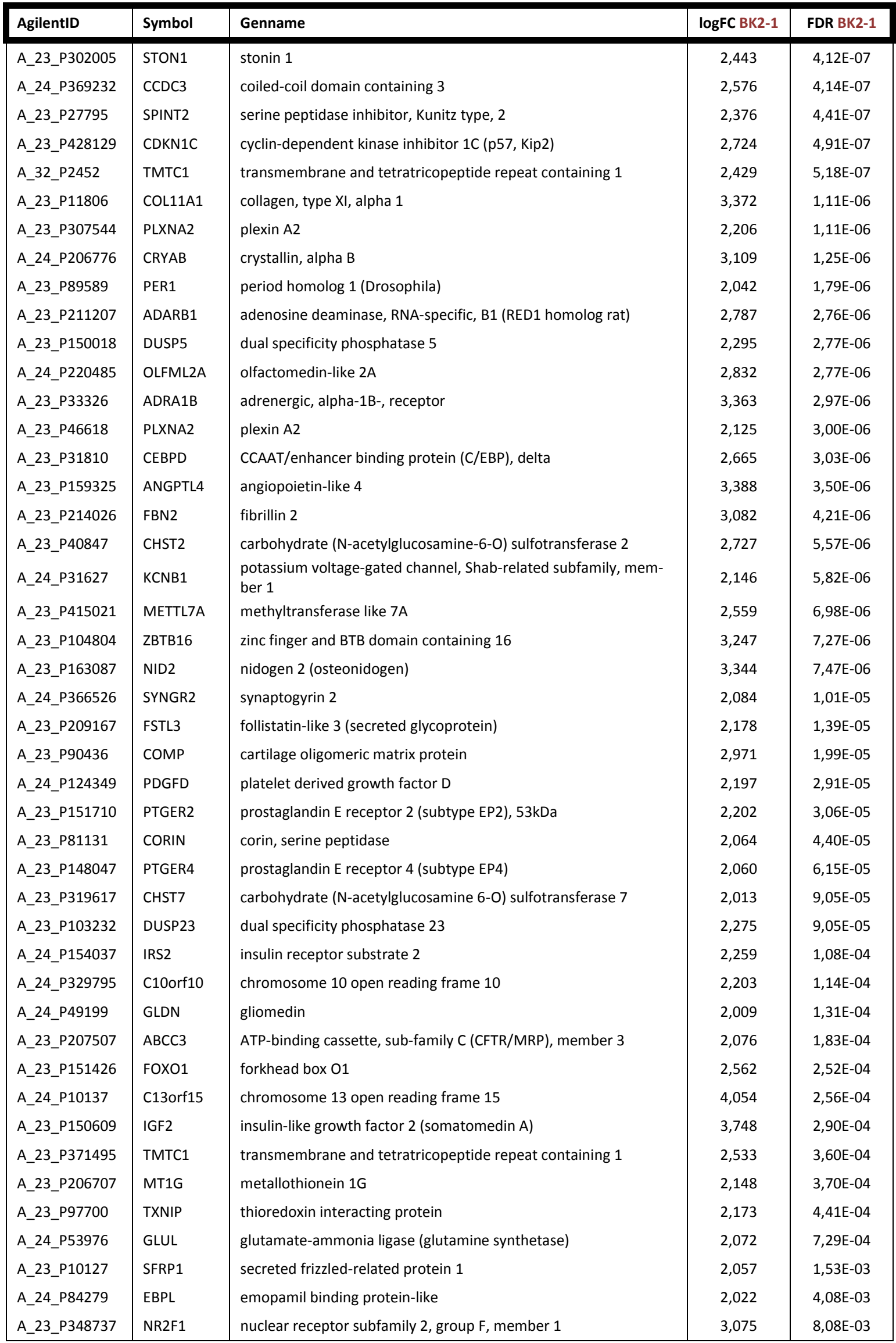


Tabelle A-2: Die 66 Gene der Stro-1+-Beckenkammzellen, die gegenüber dem DMEM (BK1) im osteogenen Medium (BK2) hochsignifikant herunterreguliert sind. Die Gene sind nach der Höhe der FDR aufsteigend sortiert. Die Auswahlkriterien waren $|\operatorname{logFC}|>2$ und FDR $\leq 0,01$.

\begin{tabular}{|c|c|c|c|c|}
\hline AgilentID & Symbol & Genname & $\operatorname{logFC~BK2-1}$ & FDR BK2-1 \\
\hline A_24_P931443 & GPR68 & G protein-coupled receptor 68 & $-4,408$ & $1,42 \mathrm{E}-10$ \\
\hline A_24_P34199 & FLG & filaggrin & $-4,291$ & $4,68 \mathrm{E}-10$ \\
\hline A_32_P387648 & FLG & filaggrin & $-4,326$ & $1,58 \mathrm{E}-09$ \\
\hline A_23_P419696 & LYPD1 & LY6/PLAUR domain containing 1 & $-3,128$ & 4,17E-09 \\
\hline A_23_P200015 & AK5 & adenylate kinase 5 & $-3,330$ & $4,82 \mathrm{E}-09$ \\
\hline A_23_P107351 & NLRP1 & NLR family, pyrin domain containing 1 & $-3,202$ & $6,16 \mathrm{E}-09$ \\
\hline A_23_P205959 & ALDH1A3 & aldehyde dehydrogenase 1 family, member $A 3$ & $-3,266$ & $1,37 \mathrm{E}-08$ \\
\hline A_23_P66798 & KRT19 & keratin 19 & $-3,073$ & $1,77 \mathrm{E}-08$ \\
\hline A_23_P317620 & ARL4C & ADP-ribosylation factor-like $4 \mathrm{C}$ & $-3,754$ & $2,67 \mathrm{E}-08$ \\
\hline A_23_P315815 & NRG1 & neuregulin 1 & $-2,153$ & $3,74 \mathrm{E}-08$ \\
\hline A_23_P360777 & NRG1 & neuregulin 1 & $-2,982$ & $4,93 \mathrm{E}-08$ \\
\hline A_24_P288890 & FAM101A & family with sequence similarity 101 , member $A$ & $-2,392$ & $1,09 \mathrm{E}-07$ \\
\hline A_23_P67529 & KCNN4 & $\begin{array}{l}\text { potassium intermediate/small conductance calcium-activated } \\
\text { channel, subfamily } \mathrm{N} \text {, member } 4\end{array}$ & $-2,167$ & $1,23 \mathrm{E}-07$ \\
\hline A_23_P202269 & ANK3 & ankyrin 3, node of Ranvier (ankyrin G) & $-2,909$ & $1,24 \mathrm{E}-07$ \\
\hline A_23_P1691 & MMP1 & matrix metallopeptidase 1 (interstitial collagenase) & $-2,941$ & $1,25 \mathrm{E}-07$ \\
\hline A_23_P320054 & WNT7B & wingless-type MMTV integration site family, member 7B & $-2,253$ & $1,71 \mathrm{E}-07$ \\
\hline A_23_P108842 & DUSP2 & dual specificity phosphatase 2 & $-2,272$ & $2,09 \mathrm{E}-07$ \\
\hline A_23_P40415 & ADAMTS5 & ADAM metallopeptidase with thrombospondin type 1 motif, 5 & $-3,335$ & 2,13E-07 \\
\hline A_24_P205994 & EPGN & epithelial mitogen homolog (mouse) & $-2,057$ & $3,26 \mathrm{E}-07$ \\
\hline A_23_P110531 & FST & follistatin & $-3,134$ & $4,41 \mathrm{E}-07$ \\
\hline A_23_P16523 & GDF15 & growth differentiation factor 15 & $-2,597$ & $4,46 \mathrm{E}-07$ \\
\hline A_23_P122924 & INHBA & inhibin, beta A & $-3,072$ & $4,91 \mathrm{E}-07$ \\
\hline A_32_P164246 & FOXQ1 & forkhead box Q1 & $-2,365$ & $6,32 \mathrm{E}-07$ \\
\hline A_32_P24382 & KRTAP2-4 & keratin associated protein $2-4$ & $-2,412$ & $7,76 \mathrm{E}-07$ \\
\hline A_23_P219197 & RGS3 & regulator of G-protein signaling 3 & $-2,623$ & $9,14 \mathrm{E}-07$ \\
\hline A_23_P42257 & IER3 & immediate early response 3 & $-2,613$ & 1,19E-06 \\
\hline A_23_P156970 & MEST & mesoderm specific transcript homolog (mouse) & $-2,690$ & $1,34 \mathrm{E}-06$ \\
\hline A_23_P141624 & KRTAP1-1 & keratin associated protein 1-1 & $-2,513$ & $1,87 E-06$ \\
\hline A_24_P827037 & LRRC15 & leucine rich repeat containing 15 & $-2,388$ & $2,08 \mathrm{E}-06$ \\
\hline A_32_P200697 & FAM101A & family with sequence similarity 101 , member $A$ & $-3,372$ & $2,59 \mathrm{E}-06$ \\
\hline A_23_P120883 & HMOX1 & heme oxygenase (decycling) 1 & $-2,054$ & $3,88 \mathrm{E}-06$ \\
\hline A_23_P218928 & C4orf18 & chromosome 4 open reading frame 18 & $-2,433$ & 4,07E-06 \\
\hline A_23_P251075 & MAMLD1 & mastermind-like domain containing 1 & $-2,537$ & $6,03 E-06$ \\
\hline A_23_P301530 & ANK3 & ankyrin 3, node of Ranvier (ankyrin G) & $-2,996$ & $7,27 \mathrm{E}-06$ \\
\hline A_23_P216167 & PSD3 & pleckstrin and Sec7 domain containing 3 & $-2,322$ & $7,39 \mathrm{E}-06$ \\
\hline A_23_P87150 & LPXN & leupaxin & $-2,313$ & $1,00 \mathrm{E}-05$ \\
\hline A_23_P15876 & ALPK2 & alpha-kinase 2 & $-2,148$ & 1,07E-05 \\
\hline A_23_P99063 & LUM & lumican & $-2,293$ & $1,31 \mathrm{E}-05$ \\
\hline A_24_P275073 & ADAMTS14 & ADAM metallopeptidase with thrombospondin type 1 motif, 14 & $-2,378$ & $1,38 \mathrm{E}-05$ \\
\hline A_23_P148990 & HMCN1 & hemicentin 1 & $-2,166$ & $1,84 \mathrm{E}-05$ \\
\hline A_24_P122137 & LIF & leukemia inhibitory factor (cholinergic differentiation factor) & $-2,020$ & $2,18 \mathrm{E}-05$ \\
\hline A_24_P302584 & sox11 & SRY (sex determining region Y)-box 11 & $-2,049$ & $2,70 \mathrm{E}-05$ \\
\hline A_32_P101031 & LYPD1 & LY6/PLAUR domain containing 1 & $-5,025$ & $3,50 \mathrm{E}-05$ \\
\hline A_32_P24376 & KRTAP2-4 & keratin associated protein 2-4 & $-2,292$ & $3,71 \mathrm{E}-05$ \\
\hline
\end{tabular}




\begin{tabular}{|c|c|c|c|c|}
\hline AgilentID & Symbol & Genname & $\operatorname{logFC~BK2-1}$ & FDR BK2-1 \\
\hline A_23_P90626 & CYTIP & cytohesin 1 interacting protein & $-2,384$ & $3,89 E-05$ \\
\hline A_23_P202448 & CXCL12 & chemokine (C-X-C motif) ligand 12 (stromal cell-derived factor 1 ) & $-2,132$ & $3,93 \mathrm{E}-05$ \\
\hline A_23_P58796 & RGMB & RGM domain family, member B & $-2,462$ & $3,93 \mathrm{E}-05$ \\
\hline A_24_P137434 & DCBLD2 & discoidin, CUB and LCCL domain containing 2 & $-2,311$ & $3,95 \mathrm{E}-05$ \\
\hline A_24_P245379 & SERPINB2 & serpin peptidase inhibitor, clade B (ovalbumin), member 2 & $-2,085$ & $6,13 \mathrm{E}-05$ \\
\hline A_23_P10206 & HAS2 & hyaluronan synthase 2 & $-2,210$ & $6,15 \mathrm{E}-05$ \\
\hline A_23_P71037 & IL6 & interleukin 6 (interferon, beta 2) & $-2,272$ & $6,69 \mathrm{E}-05$ \\
\hline A_23_P75310 & ARHGAP22 & Rho GTPase activating protein 22 & $-2,053$ & 7,17E-05 \\
\hline A_24_P354689 & SPOCK1 & $\begin{array}{l}\text { sparc/osteonectin, cwcv and kazal-like domains proteoglycan } \\
\text { (testican) } 1\end{array}$ & $-2,021$ & $7,30 \mathrm{E}-05$ \\
\hline A_23_P24104 & PLAU & plasminogen activator, urokinase & $-2,267$ & $8,07 \mathrm{E}-05$ \\
\hline A_24_P298224 & NAP5 & Nck-associated protein 5 & $-2,022$ & $8,66 \mathrm{E}-05$ \\
\hline A_23_P384044 & $\mathrm{CNIH} 3$ & cornichon homolog 3 (Drosophila) & $-2,079$ & $9,67 \mathrm{E}-05$ \\
\hline A_23_P202327 & ADAM12 & ADAM metallopeptidase domain 12 & $-2,400$ & $1,73 \mathrm{E}-04$ \\
\hline A_32_P185140 & TPM1 & tropomyosin 1 (alpha) & $-2,155$ & $2,42 \mathrm{E}-04$ \\
\hline A_24_P362931 & SLC4A7 & $\begin{array}{l}\text { solute carrier family } 4 \text {, sodium bicarbonate cotransporter, mem- } \\
\text { ber } 7\end{array}$ & $-2,272$ & $2,69 \mathrm{E}-04$ \\
\hline A_24_P254789 & COL14A1 & collagen, type XIV, alpha 1 & $-2,171$ & 2,96E-04 \\
\hline A_23_P84063 & NTM & neurotrimin & $-2,011$ & $3,54 \mathrm{E}-04$ \\
\hline A_23_P211926 & WNT5A & wingless-type MMTV integration site family, member $5 \mathrm{~A}$ & $-2,061$ & $3,63 \mathrm{E}-04$ \\
\hline A_23_P70398 & VEGFA & vascular endothelial growth factor $A$ & $-2,052$ & $4,15 \mathrm{E}-04$ \\
\hline A_24_P12401 & VEGFA & vascular endothelial growth factor $A$ & $-2,057$ & $5,01 E-03$ \\
\hline A_23_P417918 & PENK & proenkephalin & $-2,375$ & $5,12 \mathrm{E}-03$ \\
\hline A_23_P372234 & CA12 & carbonic anhydrase XII & $-2,262$ & $5,23 E-03$ \\
\hline
\end{tabular}


Tabelle A-3: Die 60 Gene der Stro-1 ${ }^{+}$-Zahnkeimzellen, die gegenüber dem DMEM (ZK1) im osteogenen Medium (ZK2) hochsignifikant heraufreguliert sind. Die Gene sind nach der Höhe der FDR aufsteigend sortiert. Die Auswahlkriterien waren $|\operatorname{logFC}|>2$ und FDR $\leq 0,01$.

\begin{tabular}{|c|c|c|c|c|}
\hline AgilentID & Symbol & Genname & $\operatorname{logFC}$ ZK2-1 & FDR ZK2-1 \\
\hline A_23_P104318 & DDIT4 & DNA-damage-inducible transcript 4 & 4,507 & $3,31 \mathrm{E}-09$ \\
\hline A_24_P335092 & SAA1 & serum amyloid A1 & 3,692 & $5,72 \mathrm{E}-09$ \\
\hline A_23_P119943 & IGFBP2 & insulin-like growth factor binding protein $2,36 \mathrm{kDa}$ & 3,228 & $6,33 \mathrm{E}-09$ \\
\hline A_23_P19624 & BMP6 & bone morphogenetic protein 6 & 3,115 & $8,66 \mathrm{E}-09$ \\
\hline A_23_P121064 & PTX3 & pentraxin-related gene, rapidly induced by IL-1 beta & 3,741 & $2,99 \mathrm{E}-08$ \\
\hline A_24_P38081 & FKBP5 & FK506 binding protein 5 & 3,267 & $2,99 \mathrm{E}-08$ \\
\hline A_23_P83857 & MAOA & monoamine oxidase $\mathrm{A}$ & 2,491 & $2,99 \mathrm{E}-08$ \\
\hline A_23_P64873 & DCN & decorin & 4,260 & $5,47 \mathrm{E}-08$ \\
\hline A_23_P148047 & PTGER4 & prostaglandin E receptor 4 (subtype EP4) & 3,483 & $1,37 \mathrm{E}-07$ \\
\hline A_23_P415021 & METTL7A & methyltransferase like $7 \mathrm{~A}$ & 3,598 & $1,39 \mathrm{E}-07$ \\
\hline A_23_P31810 & CEBPD & CCAAT/enhancer binding protein (C/EBP), delta & 3,522 & $1,39 \mathrm{E}-07$ \\
\hline A_23_P337262 & APCDD1 & adenomatosis polyposis coli down-regulated 1 & 2,947 & $2,01 \mathrm{E}-07$ \\
\hline A_23_P19894 & AQP1 & aquaporin 1 (Colton blood group) & 3,391 & $2,24 \mathrm{E}-07$ \\
\hline A_23_P372834 & AQP1 & aquaporin 1 (Colton blood group) & 3,893 & $2,24 \mathrm{E}-07$ \\
\hline A_24_P260101 & MME & membrane metallo-endopeptidase & 2,900 & $2,48 \mathrm{E}-07$ \\
\hline A_23_P94397 & OMD & osteomodulin & 2,380 & $4,47 \mathrm{E}-07$ \\
\hline A_23_P154037 & AOX1 & aldehyde oxidase 1 & 2,072 & $5,00 \mathrm{E}-07$ \\
\hline A_24_P131622 & FAM107A & family with sequence similarity 107 , member $A$ & 2,283 & $5,15 \mathrm{E}-07$ \\
\hline A_23_P39237 & ZFP36 & zinc finger protein $36, \mathrm{C} 3 \mathrm{H}$ type, homolog (mouse) & 2,147 & $8,80 \mathrm{E}-07$ \\
\hline A_23_P111206 & FKBP5 & FK506 binding protein 5 & 2,455 & $1,24 \mathrm{E}-06$ \\
\hline A_23_P18372 & B3GNT5 & UDP-GIcNAc:betaGal beta-1,3-N-acetylglucosaminyltransferase 5 & 2,201 & $1,44 \mathrm{E}-06$ \\
\hline A_23_P415401 & KLF9 & Kruppel-like factor 9 & 2,963 & $1,48 \mathrm{E}-06$ \\
\hline A_24_P289471 & RNASET2 & ribonuclease $\mathrm{T} 2$ & 2,137 & $1,48 \mathrm{E}-06$ \\
\hline A_24_P64167 & PTGS1 & $\begin{array}{l}\text { prostaglandin-endoperoxide synthase } 1 \text { (prostaglandin G/H syn- } \\
\text { thase and cyclooxygenase) }\end{array}$ & 2,367 & $1,69 \mathrm{E}-06$ \\
\hline A_23_P128974 & BATF & basic leucine zipper transcription factor, ATF-like & 3,164 & $1,82 \mathrm{E}-06$ \\
\hline A_23_P69497 & CLEC3B & C-type lectin domain family 3 , member B & 2,981 & 2,13E-06 \\
\hline A_23_P89589 & PER1 & period homolog 1 (Drosophila) & 2,066 & $2,38 \mathrm{E}-06$ \\
\hline A_23_P216630 & SLC44A1 & solute carrier family 44 , member 1 & 2,140 & $2,75 \mathrm{E}-06$ \\
\hline A_23_P50946 & RAMP1 & receptor ( $G$ protein-coupled) activity modifying protein 1 & 2,031 & $2,81 \mathrm{E}-06$ \\
\hline A_23_P151710 & PTGER2 & prostaglandin E receptor 2 (subtype EP2), 53kDa & 2,694 & $3,79 \mathrm{E}-06$ \\
\hline A_24_P231104 & LEPR & leptin receptor & 2,380 & 7,33E-06 \\
\hline A_23_P214026 & FBN2 & fibrillin 2 & 3,083 & $7,41 \mathrm{E}-06$ \\
\hline A_23_P216966 & PTGS1 & $\begin{array}{l}\text { prostaglandin-endoperoxide synthase } 1 \text { (prostaglandin G/H syn- } \\
\text { thase and cyclooxygenase) }\end{array}$ & 3,095 & $8,50 \mathrm{E}-06$ \\
\hline A_23_P335920 & RPS6KA2 & ribosomal protein $\mathrm{S} 6$ kinase, $90 \mathrm{kDa}$, polypeptide 2 & 2,238 & $9,96 \mathrm{E}-06$ \\
\hline A_23_P33326 & ADRA1B & adrenergic, alpha-1B-, receptor & 3,000 & $2,11 \mathrm{E}-05$ \\
\hline A_24_P734953 & TRNP1 & TMF1-regulated nuclear protein 1 & 2,056 & $2,34 \mathrm{E}-05$ \\
\hline A_23_P89431 & CCL2 & chemokine ( $\mathrm{C}-\mathrm{C}$ motif) ligand 2 & 2,221 & $3,60 \mathrm{E}-05$ \\
\hline A_24_P48204 & SECTM1 & secreted and transmembrane 1 & 2,613 & $4,03 E-05$ \\
\hline A_23_P354694 & WISP1 & WNT1 inducible signaling pathway protein 1 & 2,259 & $4,64 \mathrm{E}-05$ \\
\hline A_24_P360269 & RNASET2 & ribonuclease $\mathrm{T} 2$ & 2,511 & $5,17 \mathrm{E}-05$ \\
\hline A_24_P53976 & GLUL & glutamate-ammonia ligase (glutamine synthetase) & 2,640 & $7,08 \mathrm{E}-05$ \\
\hline A_23_P40880 & СMTM8 & CKLF-like MARVEL transmembrane domain containing 8 & 2,675 & $1,00 \mathrm{E}-04$ \\
\hline A_23_P2705 & P2RY5 & purinergic receptor P2Y, G-protein coupled, 5 & 2,312 & $1,14 \mathrm{E}-04$ \\
\hline
\end{tabular}




\begin{tabular}{|c|c|c|c|c|}
\hline AgilentID & Symbol & Genname & $\operatorname{logFC}$ ZK2-1 & FDR ZK2-1 \\
\hline A_23_P215566 & AHR & aryl hydrocarbon receptor & 2,085 & $1,72 \mathrm{E}-04$ \\
\hline A_23_P31064 & MOXD1 & monooxygenase, DBH-like 1 & 2,126 & $1,99 \mathrm{E}-04$ \\
\hline A_23_P212061 & MME & membrane metallo-endopeptidase & 2,214 & $2,00 \mathrm{E}-04$ \\
\hline A_23_P209625 & CYP1B1 & cytochrome P450, family 1 , subfamily B, polypeptide 1 & 2,675 & $2,19 E-04$ \\
\hline A_23_P398294 & HIP1R & huntingtin interacting protein 1 related & 2,117 & $3,05 \mathrm{E}-04$ \\
\hline A_23_P433016 & FBLN1 & fibulin 1 & 2,073 & $3,64 \mathrm{E}-04$ \\
\hline A_23_P9232 & GCNT1 & $\begin{array}{l}\text { glucosaminyl ( } \mathrm{N} \text {-acetyl) transferase } 1 \text {, core } 2 \text { (beta-1,6-N- } \\
\text { acetylglucosaminyltransferase) }\end{array}$ & 2,033 & $4,27 \mathrm{E}-04$ \\
\hline A_23_P69030 & COL8A1 & collagen, type VIII, alpha 1 & 2,575 & $6,84 \mathrm{E}-04$ \\
\hline A_23_P163087 & NID2 & nidogen 2 (osteonidogen) & 2,342 & $7,20 \mathrm{E}-04$ \\
\hline A_23_P136347 & EPS8 & epidermal growth factor receptor pathway substrate 8 & 2,356 & $8,05 \mathrm{E}-04$ \\
\hline A_23_P501007 & EFEMP1 & EGF-containing fibulin-like extracellular matrix protein 1 & 2,278 & $1,38 \mathrm{E}-03$ \\
\hline A_23_P72737 & IFITM1 & interferon induced transmembrane protein 1 (9-27) & 2,137 & $2,00 \mathrm{E}-03$ \\
\hline A_23_P17095 & TFPI & $\begin{array}{l}\text { tissue factor pathway inhibitor (lipoprotein-associated coagula- } \\
\text { tion inhibitor) }\end{array}$ & 2,759 & $2,49 \mathrm{E}-03$ \\
\hline A_32_P138348 & LY6K & lymphocyte antigen 6 complex, locus $\mathrm{K}$ & 2,145 & $2,90 \mathrm{E}-03$ \\
\hline A_23_P82868 & PLAT & plasminogen activator, tissue & 2,168 & $3,38 \mathrm{E}-03$ \\
\hline A_24_P693986 & TRNP1 & TMF1-regulated nuclear protein 1 & 2,470 & $5,13 \mathrm{E}-03$ \\
\hline A_23_P150609 & IGF2 & insulin-like growth factor 2 (somatomedin A) & 2,827 & $7,59 \mathrm{E}-03$ \\
\hline
\end{tabular}

Tabelle A-4: Die 52 Gene der Stro-1+-Zahnkeimzellen, die gegenüber dem DMEM (ZK1) im osteogenen Medium (ZK2) hochsignifikant herunterreguliert sind. Die Gene sind nach der Höhe der FDR aufsteigend sortiert. Die Auswahlkriterien waren $|\log F C|>2$ und FDR $\leq 0,01$.

\begin{tabular}{|c|c|c|c|c|}
\hline AgilentID & Symbol & Genname & $\log F C$ ZK2-1 & FDR ZK2-1 \\
\hline A_23_P215060 & PODXL & podocalyxin-like & $-5,212$ & $2,23 \mathrm{E}-10$ \\
\hline A_23_P315815 & NRG1 & neuregulin 1 & $-3,056$ & $1,52 \mathrm{E}-09$ \\
\hline A_23_P215634 & IGFBP3 & insulin-like growth factor binding protein 3 & $-4,854$ & $1,78 \mathrm{E}-09$ \\
\hline A_23_P65518 & DACT1 & dapper, antagonist of beta-catenin, homolog 1 (Xenopus laevis) & $-3,922$ & $1,87 \mathrm{E}-09$ \\
\hline A_24_P827037 & LRRC15 & leucine rich repeat containing 15 & $-4,167$ & 3,31E-09 \\
\hline A_24_P264832 & NEFM & neurofilament, medium polypeptide & $-4,333$ & 4,19E-09 \\
\hline A_23_P161698 & MMP3 & matrix metallopeptidase 3 (stromelysin 1, progelatinase) & $-3,384$ & $5,46 \mathrm{E}-09$ \\
\hline A_23_P205894 & ACTC1 & actin, alpha, cardiac muscle 1 & $-3,361$ & 2,99E-08 \\
\hline A_23_P125233 & CNN1 & calponin 1 , basic, smooth muscle & $-2,953$ & $5,04 \mathrm{E}-08$ \\
\hline A_23_P144843 & ESM1 & endothelial cell-specific molecule 1 & $-3,302$ & $6,54 \mathrm{E}-08$ \\
\hline A_23_P40415 & ADAMTS5 & ADAM metallopeptidase with thrombospondin type 1 motif, 5 & $-3,757$ & $9,32 \mathrm{E}-08$ \\
\hline A_23_P67169 & IL11 & interleukin 11 & $-3,134$ & $1,37 \mathrm{E}-07$ \\
\hline A_23_P14083 & AMIGO2 & adhesion molecule with Ig-like domain 2 & $-3,350$ & 2,07E-07 \\
\hline A_23_P138194 & NCF2 & neutrophil cytosolic factor 2 & $-2,297$ & $5,22 \mathrm{E}-07$ \\
\hline A_23_P202448 & CXCL12 & chemokine (C-X-C motif) ligand 12 (stromal cell-derived factor 1 ) & $-3,063$ & $6,94 \mathrm{E}-07$ \\
\hline A_23_P396858 & FZD8 & frizzled homolog 8 (Drosophila) & $-2,559$ & $7,17 \mathrm{E}-07$ \\
\hline A_23_P136493 & NRG1 & neuregulin 1 & $-3,101$ & $9,65 \mathrm{E}-07$ \\
\hline A_32_P24382 & KRTAP2-4 & keratin associated protein $2-4$ & $-2,455$ & $1,18 \mathrm{E}-06$ \\
\hline A_23_P363344 & TPM1 & tropomyosin 1 (alpha) & $-2,503$ & $1,24 \mathrm{E}-06$ \\
\hline A_32_P24376 & KRTAP2-4 & keratin associated protein $2-4$ & $-3,078$ & $1,48 \mathrm{E}-06$ \\
\hline A_23_P360777 & NRG1 & neuregulin 1 & $-2,381$ & $1,52 \mathrm{E}-06$ \\
\hline A_24_P402510 & SAMD11 & sterile alpha motif domain containing 11 & $-2,144$ & $2,18 \mathrm{E}-06$ \\
\hline
\end{tabular}




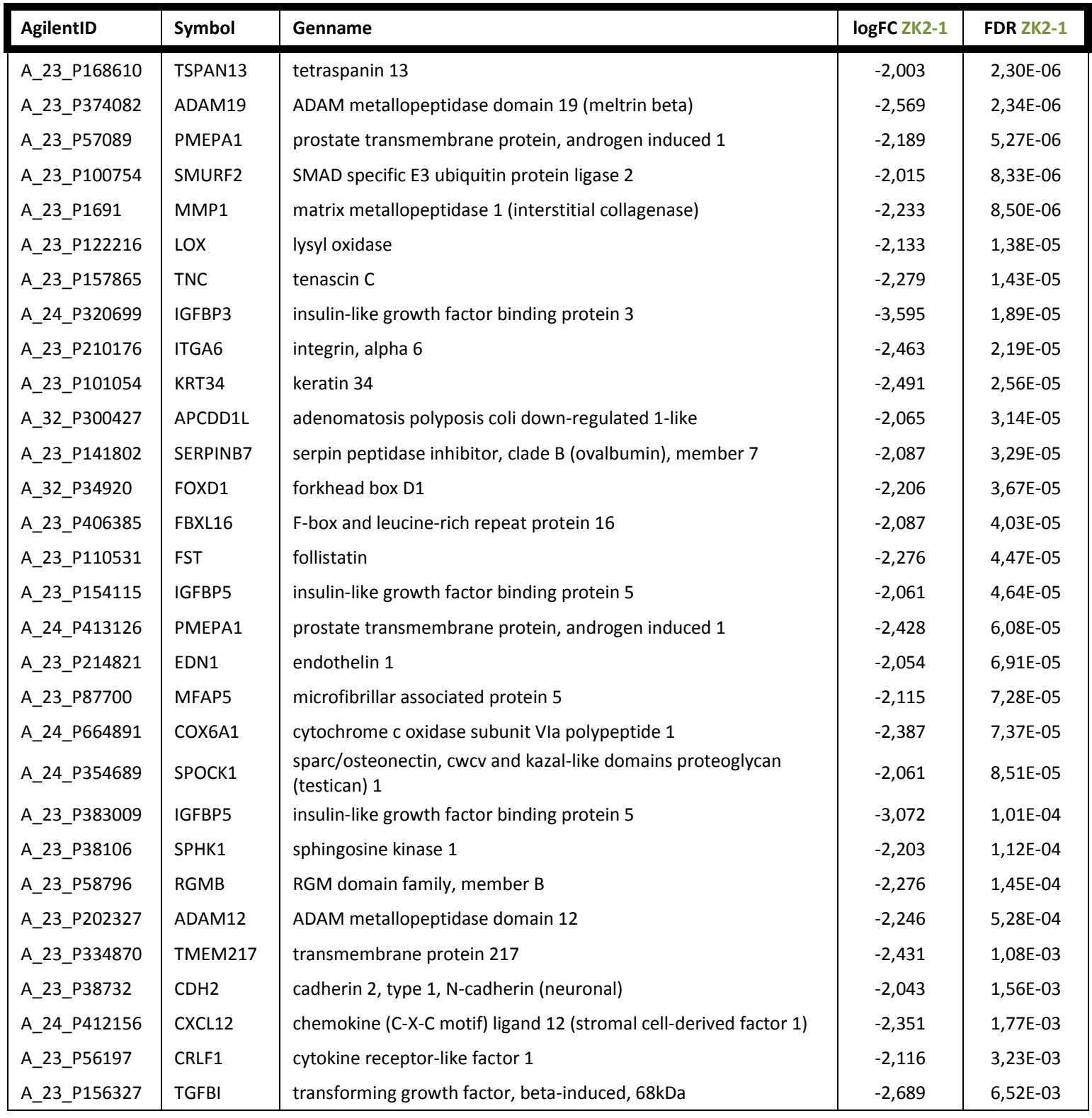


Tabelle A-5: Gene der ersten zehn im ODM gegenüber dem DMEM signifikant hochregulierten funktionellen Gruppen der Stro- $1^{+}$-Zahnkeimzellen (siehe Tabelle 4a).

\begin{tabular}{|c|c|}
\hline Symbol & Genname \\
\hline \multicolumn{2}{|c|}{ response to organic substance $(n=10)$} \\
\hline adra1b & adrenergic, alpha-1B-, receptor \\
\hline aqp1 & aquaporin 1 (Colton blood group) \\
\hline Ccl2 & chemokine ( $\mathrm{C}-\mathrm{C}$ motif) ligand 2 \\
\hline CYP1B1 & $\begin{array}{l}\text { cytochrome P450, family } 1 \text {, subfamily B, polypep- } \\
\text { tide } 1\end{array}$ \\
\hline Eps8 & $\begin{array}{l}\text { epidermal growth factor receptor pathway sub- } \\
\text { strate } 8\end{array}$ \\
\hline GLUL & glutamate-ammonia ligase (glutamine synthetase) \\
\hline IGF2 & $\begin{array}{l}\text { insulin-like growth factor } 2 \text { (somatomedin A); } \\
\text { insulin; INS-IGF2 readthrough transcript }\end{array}$ \\
\hline igfbp2 & insulin-like growth factor binding protein $2,36 \mathrm{kDa}$ \\
\hline LEPR & leptin receptor \\
\hline Ptgs1 & $\begin{array}{l}\text { prostaglandin-endoperoxide synthase } 1 \text { (prostag- } \\
\text { landin } \mathrm{G} / \mathrm{H} \text { synthase and cyclooxygenase) }\end{array}$ \\
\hline \multicolumn{2}{|c|}{ positive regulation of multicellular organismal process $(n=6)$} \\
\hline adra1b & adrenergic, alpha-1B-, receptor \\
\hline BMP6 & bone morphogenetic protein 6 \\
\hline Ccl2 & chemokine ( $\mathrm{C}-\mathrm{C}$ motif) ligand 2 \\
\hline IGF2 & $\begin{array}{l}\text { insulin-like growth factor } 2 \text { (somatomedin A); } \\
\text { insulin; INS-IGF2 readthrough transcript }\end{array}$ \\
\hline Ptgs1 & $\begin{array}{l}\text { prostaglandin-endoperoxide synthase } 1 \text { (prostag- } \\
\text { landin } \mathrm{G} / \mathrm{H} \text { synthase and cyclooxygenase) }\end{array}$ \\
\hline SAA1 & serum amyloid $\mathrm{A} 1$ \\
\hline \multicolumn{2}{|c|}{ response to wounding $(n=8)$} \\
\hline AOX1 & aldehyde oxidase 1 \\
\hline BMP6 & bone morphogenetic protein 6 \\
\hline $\mathrm{Ccl} 2$ & chemokine ( $\mathrm{C}-\mathrm{C}$ motif) ligand 2 \\
\hline IGF2 & $\begin{array}{l}\text { insulin-like growth factor } 2 \text { (somatomedin A); } \\
\text { insulin; INS-IGF2 readthrough transcript }\end{array}$ \\
\hline Ptx3 & $\begin{array}{l}\text { pentraxin-related gene, rapidly induced by } \mathrm{IL}-1 \\
\text { beta }\end{array}$ \\
\hline PLAT & plasminogen activator, tissue \\
\hline SAA1 & serum amyloid $\mathrm{A} 1$ \\
\hline TFPI & $\begin{array}{l}\text { tissue factor pathway inhibitor (lipoprotein- } \\
\text { associated coagulation inhibitor) }\end{array}$ \\
\hline \multicolumn{2}{|c|}{ response to endogenous stimulus $(n=7)$} \\
\hline adra1b & adrenergic, alpha-1B-, receptor \\
\hline aqp1 & aquaporin 1 (Colton blood group) \\
\hline $\mathrm{Ccl} 2$ & chemokine ( $\mathrm{C}-\mathrm{C}$ motif) ligand 2 \\
\hline IGF2 & $\begin{array}{l}\text { insulin-like growth factor } 2 \text { (somatomedin A); } \\
\text { insulin; INS-IGF2 readthrough transcript }\end{array}$ \\
\hline igfbp2 & insulin-like growth factor binding protein $2,36 \mathrm{kDa}$ \\
\hline LEPR & leptin receptor \\
\hline Ptgs1 & $\begin{array}{l}\text { prostaglandin-endoperoxide synthase } 1 \text { (prostag- } \\
\text { landin } \mathrm{G} / \mathrm{H} \text { synthase and cyclooxygenase) }\end{array}$ \\
\hline
\end{tabular}

\begin{tabular}{|c|c|}
\hline Symbol & Genname \\
\hline \multicolumn{2}{|c|}{ response to steroid hormone stimulus $(n=5)$} \\
\hline aqp1 & aquaporin 1 (Colton blood group) \\
\hline $\mathrm{Ccl} 2$ & chemokine ( $\mathrm{C}-\mathrm{C}$ motif) ligand 2 \\
\hline igfbp2 & insulin-like growth factor binding protein $2,36 \mathrm{kDa}$ \\
\hline LEPR & leptin receptor \\
\hline Ptgs1 & $\begin{array}{l}\text { prostaglandin-endoperoxide synthase } 1 \text { (prostag- } \\
\text { landin } \mathrm{G} / \mathrm{H} \text { synthase and cyclooxygenase) }\end{array}$ \\
\hline \multicolumn{2}{|c|}{ negative regulation of inflammatory response $(n=3)$} \\
\hline IGF2 & $\begin{array}{l}\text { insulin-like growth factor } 2 \text { (somatomedin A); } \\
\text { insulin; INS-IGF2 readthrough transcript }\end{array}$ \\
\hline SAA1 & serum amyloid $\mathrm{A} 1$ \\
\hline ZFP36 & zinc finger protein $36, \mathrm{C} 3 \mathrm{H}$ type, homolog (mouse) \\
\hline \multicolumn{2}{|c|}{ inflammatory response $(n=6)$} \\
\hline AOX1 & aldehyde oxidase 1 \\
\hline BMP6 & bone morphogenetic protein 6 \\
\hline $\mathrm{Ccl} 2$ & chemokine (C-C motif) ligand 2 \\
\hline IGF2 & $\begin{array}{l}\text { insulin-like growth factor } 2 \text { (somatomedin A); } \\
\text { insulin; INS-IGF2 readthrough transcript }\end{array}$ \\
\hline Ptx3 & $\begin{array}{l}\text { pentraxin-related gene, rapidly induced by IL-1 } \\
\text { beta }\end{array}$ \\
\hline SAA1 & serum amyloid $A 1$ \\
\hline \multicolumn{2}{|c|}{ behavior $(n=7)$} \\
\hline CMTM8 & $\begin{array}{l}\text { CKLF-like MARVEL transmembrane domain con- } \\
\text { taining } 8\end{array}$ \\
\hline adra1b & adrenergic, alpha-1B-, receptor \\
\hline $\mathrm{Ccl} 2$ & chemokine ( $\mathrm{C}-\mathrm{C}$ motif) ligand 2 \\
\hline Eps8 & $\begin{array}{l}\text { epidermal growth factor receptor pathway sub- } \\
\text { strate } 8\end{array}$ \\
\hline LEPR & leptin receptor \\
\hline MAOA & monoamine oxidase $\mathrm{A}$ \\
\hline SAA1 & serum amyloid $\mathrm{A} 1$ \\
\hline \multicolumn{2}{|c|}{ negative regulation of glycogen catabolic process $(n=2)$} \\
\hline adra1b & adrenergic, alpha-1B-, receptor \\
\hline IGF2 & $\begin{array}{l}\text { insulin-like growth factor } 2 \text { (somatomedin A); } \\
\text { insulin; INS-IGF2 readthrough transcript }\end{array}$ \\
\hline \multicolumn{2}{|c|}{ negative regulation of defense response $(n=3)$} \\
\hline IGF2 & $\begin{array}{l}\text { insulin-like growth factor } 2 \text { (somatomedin A); } \\
\text { insulin; INS-IGF2 readthrough transcript }\end{array}$ \\
\hline SAA1 & serum amyloid $\mathrm{A} 1$ \\
\hline ZFP36 & zinc finger protein $36, \mathrm{C} 3 \mathrm{H}$ type, homolog (mouse) \\
\hline
\end{tabular}


Tabelle A-6: Gene der ersten zehn im ODM gegenüber dem DMEM signifikant herunterregulierten funktionellen Gruppen der Stro- $1^{+}$-Zahnkeimzellen (siehe Tabelle 4b).

\begin{tabular}{|c|c|}
\hline Symbol & Genname \\
\hline \multicolumn{2}{|c|}{ regulation of cell migration $(n=6)$} \\
\hline CXCL12 & $\begin{array}{l}\text { chemokine ( } \mathrm{C}-\mathrm{X}-\mathrm{C} \text { motif) ligand } 12 \text { (stromal cell- } \\
\text { derived factor } 1 \text { ) }\end{array}$ \\
\hline EDN1 & endothelin 1 \\
\hline igfbp3 & insulin-like growth factor binding protein 3 \\
\hline IGFBP5 & insulin-like growth factor binding protein 5 \\
\hline SPHK1 & sphingosine kinase 1 \\
\hline TPM1 & tropomyosin 1 (alpha) \\
\hline \multicolumn{2}{|c|}{ striated muscle cell differentiation $(n=5)$} \\
\hline adam12 & ADAM metallopeptidase domain 12 \\
\hline Actc1 & actin, alpha, cardiac muscle 1 \\
\hline NRG1 & neuregulin 1 \\
\hline TNC & tenascin C \\
\hline TPM1 & tropomyosin 1 (alpha) \\
\hline \multicolumn{2}{|c|}{ regulation of locomotion $(n=6)$} \\
\hline CXCL12 & $\begin{array}{l}\text { chemokine (C-X-C motif) ligand } 12 \text { (stromal cell- } \\
\text { derived factor } 1 \text { ) }\end{array}$ \\
\hline EDN1 & endothelin 1 \\
\hline igfbp3 & insulin-like growth factor binding protein 3 \\
\hline IGFBP5 & insulin-like growth factor binding protein 5 \\
\hline SPHK1 & sphingosine kinase 1 \\
\hline TPM1 & tropomyosin 1 (alpha) \\
\hline \multicolumn{2}{|c|}{ regulation of cell motion $(n=6)$} \\
\hline CXCL12 & $\begin{array}{l}\text { chemokine (C-X-C motif) ligand } 12 \text { (stromal cell- } \\
\text { derived factor } 1 \text { ) }\end{array}$ \\
\hline EDN1 & endothelin 1 \\
\hline igfbp3 & insulin-like growth factor binding protein 3 \\
\hline IGFBP5 & insulin-like growth factor binding protein 5 \\
\hline SPHK1 & sphingosine kinase 1 \\
\hline TPM1 & tropomyosin 1 (alpha) \\
\hline \multicolumn{2}{|c|}{ striated muscle tissue development $(n=5)$} \\
\hline Actc1 & actin, alpha, cardiac muscle 1 \\
\hline IGFBP5 & insulin-like growth factor binding protein 5 \\
\hline NRG1 & neuregulin 1 \\
\hline TNC & tenascin C \\
\hline TPM1 & tropomyosin 1 (alpha) \\
\hline \multicolumn{2}{|c|}{ muscle cell differentiation $(n=5)$} \\
\hline adam12 & ADAM metallopeptidase domain 12 \\
\hline Actc1 & actin, alpha, cardiac muscle 1 \\
\hline NRG1 & neuregulin 1 \\
\hline TNC & tenascin C \\
\hline TPM1 & tropomyosin 1 (alpha) \\
\hline
\end{tabular}

\begin{tabular}{|c|c|}
\hline Symbol & Genname \\
\hline \multicolumn{2}{|c|}{ muscle tissue development $(n=5)$} \\
\hline Actc1 & actin, alpha, cardiac muscle 1 \\
\hline IGFBP5 & insulin-like growth factor binding protein 5 \\
\hline NRG1 & neuregulin 1 \\
\hline TNC & tenascin C \\
\hline TPM1 & tropomyosin 1 (alpha) \\
\hline \multicolumn{2}{|c|}{ cell adhesion $(n=9)$} \\
\hline adam12 & ADAM metallopeptidase domain 12 \\
\hline rgmb & RGM domain family, member B \\
\hline AMIGO2 & adhesion molecule with Ig-like domain 2 \\
\hline $\mathrm{CDH} 2$ & cadherin 2 , type $1, \mathrm{~N}$-cadherin (neuronal) \\
\hline CXCL12 & $\begin{array}{l}\text { chemokine (C-X-C motif) ligand } 12 \text { (stromal cell- } \\
\text { derived factor } 1 \text { ) }\end{array}$ \\
\hline itga6 & integrin, alpha 6 \\
\hline Spock1 & $\begin{array}{l}\text { sparc/osteonectin, cwcv and kazal-like domains } \\
\text { proteoglycan (testican) } 1\end{array}$ \\
\hline TNC & tenascin C \\
\hline tgfbi & transforming growth factor, beta-induced, $68 \mathrm{kDa}$ \\
\hline \multicolumn{2}{|c|}{ negative regulation of secretion $(n=4)$} \\
\hline EDN1 & endothelin 1 \\
\hline Fst & follistatin \\
\hline IL11 & interleukin 11 \\
\hline NRG1 & neuregulin 1 \\
\hline \multicolumn{2}{|c|}{ biological adhesion $(n=9)$} \\
\hline adam12 & ADAM metallopeptidase domain 12 \\
\hline rgmb & RGM domain family, member B \\
\hline AMIGO2 & adhesion molecule with Ig-like domain 2 \\
\hline $\mathrm{CDH} 2$ & cadherin 2 , type $1, \mathrm{~N}$-cadherin (neuronal) \\
\hline CXCL12 & $\begin{array}{l}\text { chemokine (C-X-C motif) ligand } 12 \text { (stromal cell- } \\
\text { derived factor } 1 \text { ) }\end{array}$ \\
\hline itga6 & integrin, alpha 6 \\
\hline Spock1 & $\begin{array}{l}\text { sparc/osteonectin, cwcv and kazal-like domains } \\
\text { proteoglycan (testican) } 1\end{array}$ \\
\hline TNC & tenascin C \\
\hline tgfbi & transforming growth factor, beta-induced, $68 \mathrm{kDa}$ \\
\hline
\end{tabular}


Tabelle A-7: Gene der ersten zehn im ODM gegenüber dem DMEM signifikant hochregulierten funktionellen Gruppen der Stro- $1^{+}$-Beckenkammzellen (siehe Tabelle 5a).

\begin{tabular}{|c|c|}
\hline Symbol & Genname \\
\hline \multicolumn{2}{|c|}{ response to insulin stimulus $(n=7)$} \\
\hline ADM & adrenomedullin \\
\hline foxo1 & forkhead box 01 \\
\hline irs2 & insulin receptor substrate 2 \\
\hline IGF2 & $\begin{array}{l}\text { insulin-like growth factor } 2 \text { (somatomedin A); } \\
\text { insulin; INS-IGF2 readthrough transcript }\end{array}$ \\
\hline LEP & leptin \\
\hline PPARG & peroxisome proliferator-activated receptor gamma \\
\hline Sort1 & sortilin 1 \\
\hline \multicolumn{2}{|c|}{ response to endogenous stimulus $(n=11)$} \\
\hline adra1b & adrenergic, alpha-1B-, receptor \\
\hline ADM & adrenomedullin \\
\hline CRYAB & crystallin, alpha B \\
\hline foxo1 & forkhead box 01 \\
\hline irs2 & insulin receptor substrate 2 \\
\hline IGF2 & $\begin{array}{l}\text { insulin-like growth factor } 2 \text { (somatomedin A); } \\
\text { insulin; INS-IGF2 readthrough transcript }\end{array}$ \\
\hline LEP & leptin \\
\hline LEPR & leptin receptor \\
\hline PPARG & peroxisome proliferator-activated receptor gamma \\
\hline Sort1 & sortilin 1 \\
\hline TXNIP & thioredoxin interacting protein \\
\hline \multicolumn{2}{|c|}{ response to hormone stimulus $(n=10)$} \\
\hline ADM & adrenomedullin \\
\hline CRYAB & crystallin, alpha B \\
\hline foxo1 & forkhead box 01 \\
\hline irs2 & insulin receptor substrate 2 \\
\hline IGF2 & $\begin{array}{l}\text { insulin-like growth factor } 2 \text { (somatomedin A); } \\
\text { insulin; INS-IGF2 readthrough transcript }\end{array}$ \\
\hline LEP & leptin \\
\hline LEPR & leptin receptor \\
\hline PPARG & peroxisome proliferator-activated receptor gamma \\
\hline Sort1 & sortilin 1 \\
\hline TXNIP & thioredoxin interacting protein \\
\hline \multicolumn{2}{|c|}{ response to peptide hormone stimulus $(n=7)$} \\
\hline ADM & adrenomedullin \\
\hline foxo1 & forkhead box 01 \\
\hline irs2 & insulin receptor substrate 2 \\
\hline IGF2 & $\begin{array}{l}\text { insulin-like growth factor } 2 \text { (somatomedin A); } \\
\text { insulin; INS-IGF2 readthrough transcript }\end{array}$ \\
\hline LEP & leptin \\
\hline PPARG & peroxisome proliferator-activated receptor gamma \\
\hline Sort1 & sortilin 1 \\
\hline
\end{tabular}

\begin{tabular}{|c|c|}
\hline Symbol & Genname \\
\hline \multicolumn{2}{|c|}{ negative regulation of response to external stimulus $(n=5)$} \\
\hline IGF2 & $\begin{array}{l}\text { insulin-like growth factor } 2 \text { (somatomedin A); } \\
\text { insulin; INS-IGF2 readthrough transcript }\end{array}$ \\
\hline LEP & leptin \\
\hline PPARG & peroxisome proliferator-activated receptor gamma \\
\hline SAA1 & serum amyloid $\mathrm{A} 1$ \\
\hline SAA2 & serum amyloid $\mathrm{A} 2$ \\
\hline \multicolumn{2}{|c|}{ negative regulation of inflammatory response $(n=4)$} \\
\hline IGF2 & $\begin{array}{l}\text { insulin-like growth factor } 2 \text { (somatomedin A); } \\
\text { insulin; INS-IGF2 readthrough transcript }\end{array}$ \\
\hline PPARG & peroxisome proliferator-activated receptor gamma \\
\hline SAA1 & serum amyloid $\mathrm{A} 1$ \\
\hline SAA2 & serum amyloid $\mathrm{A} 2$ \\
\hline \multicolumn{2}{|c|}{ response to organic substance $(n=12)$} \\
\hline adra1b & adrenergic, alpha-1B-, receptor \\
\hline ADM & adrenomedullin \\
\hline CRYAB & crystallin, alpha B \\
\hline foxo1 & forkhead box $\mathrm{O} 1$ \\
\hline GLUL & glutamate-ammonia ligase (glutamine synthetase) \\
\hline irs2 & insulin receptor substrate 2 \\
\hline IGF2 & $\begin{array}{l}\text { insulin-like growth factor } 2 \text { (somatomedin A); } \\
\text { insulin; INS-IGF2 readthrough transcript }\end{array}$ \\
\hline LEP & leptin \\
\hline LEPR & leptin receptor \\
\hline PPARG & peroxisome proliferator-activated receptor gamma \\
\hline Sort1 & sortilin 1 \\
\hline TXNIP & thioredoxin interacting protein \\
\hline \multicolumn{2}{|c|}{ regulation of glucose metabolic process $(n=4)$} \\
\hline adra1b & adrenergic, alpha-1B-, receptor \\
\hline irs2 & insulin receptor substrate 2 \\
\hline IGF2 & $\begin{array}{l}\text { insulin-like growth factor } 2 \text { (somatomedin A); } \\
\text { insulin; INS-IGF2 readthrough transcript }\end{array}$ \\
\hline LEP & leptin \\
\hline \multicolumn{2}{|c|}{ negative regulation of defense response $(n=4)$} \\
\hline IGF2 & $\begin{array}{l}\text { insulin-like growth factor } 2 \text { (somatomedin A); } \\
\text { insulin; INS-IGF2 readthrough transcript }\end{array}$ \\
\hline PPARG & peroxisome proliferator-activated receptor gamma \\
\hline SAA1 & serum amyloid $\mathrm{A} 1$ \\
\hline SAA2 & serum amyloid $\mathrm{A} 2$ \\
\hline \multicolumn{2}{|c|}{ regulation of cellular carbohydrate metabolic process $(n=4)$} \\
\hline adra1b & adrenergic, alpha-1B-, receptor \\
\hline irs2 & insulin receptor substrate 2 \\
\hline IGF2 & $\begin{array}{l}\text { insulin-like growth factor } 2 \text { (somatomedin A); } \\
\text { insulin; INS-IGF2 readthrough transcript }\end{array}$ \\
\hline LEP & leptin \\
\hline
\end{tabular}


Tabelle A-8: Gene der ersten zehn im ODM gegenüber dem DMEM signifikant herunterregulierten funktionellen Gruppen der Stro-1 ${ }^{+}$-Beckenkammzellen (siehe Tabelle $5 b$ ).

\begin{tabular}{|c|c|}
\hline Symbol & Genname \\
\hline \multicolumn{2}{|c|}{ negative regulation of secretion $(n=5)$} \\
\hline Fst & follistatin \\
\hline hmox1 & heme oxygenase (decycling) 1 \\
\hline INHBA & inhibin, beta $\mathrm{A}$ \\
\hline LIF & $\begin{array}{l}\text { leukemia inhibitory factor (cholinergic differentia- } \\
\text { tion factor) }\end{array}$ \\
\hline NRG1 & neuregulin 1 \\
\hline \multicolumn{2}{|c|}{ regulation of leukocyte migration $(n=4)$} \\
\hline CXCL12 & $\begin{array}{l}\text { chemokine (C-X-C motif) ligand } 12 \text { (stromal cell- } \\
\text { derived factor } 1 \text { ) }\end{array}$ \\
\hline hmox1 & heme oxygenase (decycling) 1 \\
\hline IL6 & interleukin 6 (interferon, beta 2) \\
\hline VEGFA & vascular endothelial growth factor $A$ \\
\hline \multicolumn{2}{|c|}{ wound healing $(n=7)$} \\
\hline dcbld2 & discoidin, CUB and LCCL domain containing 2 \\
\hline hmox1 & heme oxygenase (decycling) 1 \\
\hline Hmcn1 & hemicentin 1 \\
\hline IL6 & interleukin 6 (interferon, beta 2) \\
\hline NRG1 & neuregulin 1 \\
\hline PLAU & plasminogen activator, urokinase \\
\hline SERPINB2 & $\begin{array}{l}\text { serpin peptidase inhibitor, clade B (ovalbumin), } \\
\text { member } 2\end{array}$ \\
\hline \multicolumn{2}{|c|}{ regulation of secretion $(n=7)$} \\
\hline Fst & follistatin \\
\hline hmox1 & heme oxygenase (decycling) 1 \\
\hline INHBA & inhibin, beta $A$ \\
\hline IL6 & interleukin 6 (interferon, beta 2) \\
\hline LIF & $\begin{array}{l}\text { leukemia inhibitory factor (cholinergic differentia- } \\
\text { tion factor) }\end{array}$ \\
\hline NRG1 & neuregulin 1 \\
\hline KCNN4 & $\begin{array}{l}\text { potassium intermediate/small conductance calci- } \\
\text { um-activated channel, subfamily } \mathrm{N} \text {, member } 4\end{array}$ \\
\hline \multicolumn{2}{|c|}{ angiogenesis $(n=6)$} \\
\hline $\begin{array}{l}\text { ARH- } \\
\text { GAP22 }\end{array}$ & Rho GTPase activating protein 22 \\
\hline CXCL12 & $\begin{array}{l}\text { chemokine (C-X-C motif) ligand } 12 \text { (stromal cell- } \\
\text { derived factor } 1 \text { ) }\end{array}$ \\
\hline EPGN & epithelial mitogen homolog (mouse) \\
\hline hmox1 & heme oxygenase (decycling) 1 \\
\hline PLAU & plasminogen activator, urokinase \\
\hline VEGFA & vascular endothelial growth factor $\mathrm{A}$ \\
\hline
\end{tabular}

\begin{tabular}{|c|c|}
\hline Symbol & Genname \\
\hline \multicolumn{2}{|c|}{ blood vessel morphogenesis $(n=6)$} \\
\hline $\begin{array}{l}\text { ARH- } \\
\text { GAP22 }\end{array}$ & Rho GTPase activating protein 22 \\
\hline CXCL12 & $\begin{array}{l}\text { chemokine (C-X-C motif) ligand } 12 \text { (stromal cell- } \\
\text { derived factor } 1 \text { ) }\end{array}$ \\
\hline EPGN & epithelial mitogen homolog (mouse) \\
\hline hmox1 & heme oxygenase (decycling) 1 \\
\hline PLAU & plasminogen activator, urokinase \\
\hline VEGFA & vascular endothelial growth factor $A$ \\
\hline \multicolumn{2}{|c|}{ positive regulation of leukocyte migration $(n=3)$} \\
\hline CXCL12 & $\begin{array}{l}\text { chemokine (C-X-C motif) ligand } 12 \text { (stromal cell- } \\
\text { derived factor } 1 \text { ) }\end{array}$ \\
\hline IL6 & interleukin 6 (interferon, beta 2) \\
\hline VEGFA & vascular endothelial growth factor $\mathrm{A}$ \\
\hline \multicolumn{2}{|c|}{ negative regulation of transport $(n=5)$} \\
\hline Fst & follistatin \\
\hline hmox1 & heme oxygenase (decycling) 1 \\
\hline INHBA & inhibin, beta $A$ \\
\hline LIF & $\begin{array}{l}\text { leukemia inhibitory factor (cholinergic differentia- } \\
\text { tion factor) }\end{array}$ \\
\hline NRG1 & neuregulin 1 \\
\hline \multicolumn{2}{|c|}{ blood vessel development $(n=6)$} \\
\hline $\begin{array}{l}\text { ARH- } \\
\text { GAP22 }\end{array}$ & Rho GTPase activating protein 22 \\
\hline CXCL12 & $\begin{array}{l}\text { chemokine (C-X-C motif) ligand } 12 \text { (stromal cell- } \\
\text { derived factor } 1 \text { ) }\end{array}$ \\
\hline EPGN & epithelial mitogen homolog (mouse) \\
\hline hmox1 & heme oxygenase (decycling) 1 \\
\hline PLAU & plasminogen activator, urokinase \\
\hline VEGFA & vascular endothelial growth factor $A$ \\
\hline \multicolumn{2}{|c|}{ regulation of cellular localization $(n=6)$} \\
\hline Fst & follistatin \\
\hline hmox1 & heme oxygenase (decycling) 1 \\
\hline INHBA & inhibin, beta $A$ \\
\hline IL6 & interleukin 6 (interferon, beta 2) \\
\hline LIF & $\begin{array}{l}\text { leukemia inhibitory factor (cholinergic differentia- } \\
\text { tion factor) }\end{array}$ \\
\hline KCNN4 & $\begin{array}{l}\text { potassium intermediate/small conductance calci- } \\
\text { um-activated channel, subfamily } N \text {, member } 4\end{array}$ \\
\hline
\end{tabular}


Die folgenden Tabellen sind Ergebnisse der Auswertung mit dem DAVID-Programm. Jede Tabelle beinhaltet zwei screenshots. Das Functional Annotation Clustering zeigt funktionelle Gruppen von Genen (cluster) mit mehreren funktionellen, verwandten Untereinheiten (terms), die jeweils gleiche Gene beinhalten können. Die zweite Functional Annotation Chart bezieht sich auf Gruppen von Genen, die in bestimmten Geweben gehäuft exprimiert werden und dort funktionelle Einheiten bilden. 

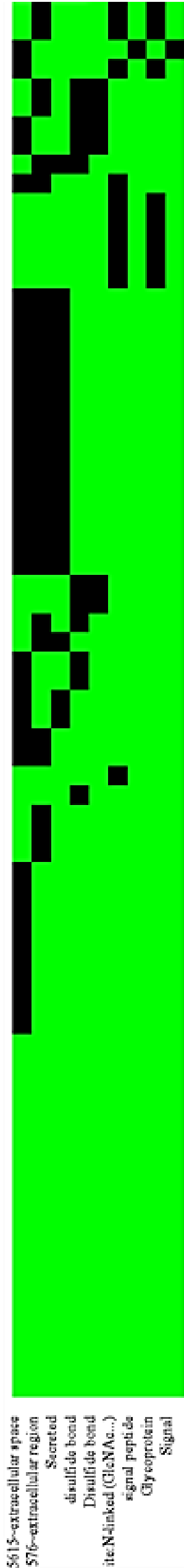

secretory leukocyte peptidase inhibitor(SL.PI)

WAP four-disulfide core domain 1(WFDC1)

eorin, serine peptidase(CORIN)

matrilin 3(MATN3)

zymogen granule protein 16B(ZG16B)

serpin family I member 1(SERPINI1)

arylsutfatase family member J(ARSJ)

inter-2lpha-trypsin inhibitor heavy chain 3(TTIH3)

alkaline phosphatase, liver bone kidney (ALPL)

olfactomedin like 2A(OLFML2A)

C-C motif ebemokine ligand 13(CCL13)

adrencenedullin(ADM)

leptin(LEP)

C-X-C motif ebemokine ligand 1(CXCL1)

complement fector D(CFD)

endothelin receptor type B(EDNRB)

TNF receptor superfamily member 21(TNFRSF21)

chromesome 10 open teading frame 54 (C10orf54)

sidekick cell adhesion molecule 1(SDK1)

frizzled class receptor S(FZDS)

neuronal growth regulator 1(NEGR1)

integrin subunit alpha V(ITGAV)

integrin subunit alpha 1(ITGA1)

integrin sobunit alpha S(TTGAS)

sushi domain containing 2(SUSD2)

ADP-ribosyltransferase 3(ART3)

nectin cell adhesion molecule 3(NECTIN3)

frizzled class receptor 4(FZDA)

contactin 3(CNTN3)

junctional adhesion molecule 2(JAM2)

serpin family A member 3(SERPINA3)

selenoprotein P(SEL.ENOP)

mucin 1, cell surface associated(MUC1)

intercellular adhesion molecule L(ICAM1)

collagen type XI alpha 1 chain(COLI1A $)$

fin bud initiation factor bomolog (zebrafish)(FIBIN)

serine peptidase intabitor, Kunitz type 2(SPINT2)

choedroatis sulfate peoteoglycan 4(CSPG4)

SPARC related modular calcium binding 2(SMOC2)

fibrinogen like 2(FGL2)

insulin like gronth factos 2(TGF2)

collagen type XII alpha 1 chsin(COL.12A1)

angiopoietin tike I(ANGPTLI)

spondin 1(SPON1)

ADAM metallepeptidsse with throesbospendia type 1 mocif (ADAMTS9)

neuronal cell adhesion molecule(NRCAM)

platelet derived growth factor receptor like(PDGFRL)

R-spondin 1(RSPO1)

sushi, von Willebrand factor type A, EGF and pentraxin domain coetaining 1(SVEP1)

leptin receptor(LEPR)

R-spondin 3(RSPO3)

nidezen 1NIDI)

bedgehog interacting protein(HHIP)

alpha-2-macroglobalin(A2M)

fibulin 1(FBLN1)

angiopoictin L(ANGPT1)

noggin(NOG)

interleukin 6 receptor(IL 6R)

frizzled-related protein(FRZB)

angiopoictin tike 4(ANGPTL4)

cartilsge oligomeric matrix protein(COMP)

apolipoprotein B(APOB)

platelet derived growth factor DPDGFD)

collagen type VII alpha 1 chxin(COL.7A1)

haptoglobin(HP)

protein S (alpha)(PROS1)

C-X-C motif ebemokine ligand 16(CXCL.16)

secreted frizled related protein 1(SFRPI)

fibulin S(FBLNS)

complement factor $\mathrm{H}(\mathrm{CFH})$

ptolise and arginise rich end leucise rich fopeat protein(PREL.P)

follistatin like 3(FSTL.3)

coemplement CS(CS)

\begin{abstract}
Abbildung A-1:
Darstellung einer reduzierten Anzahl von Genen der funktionellen Gruppen aus cluster 1, die bei den Stro- $1^{+}$-Beckenkammzellen signifikant hochreguliert sind und bei den Stro- $1^{+}$-Zahnkeimzellen keine signifikante Veränderung aufzeigen (siehe Tabelle 6) Die Heatmap wurde im oberen Teil aus Darstellungsgründen gekappt.
\end{abstract}




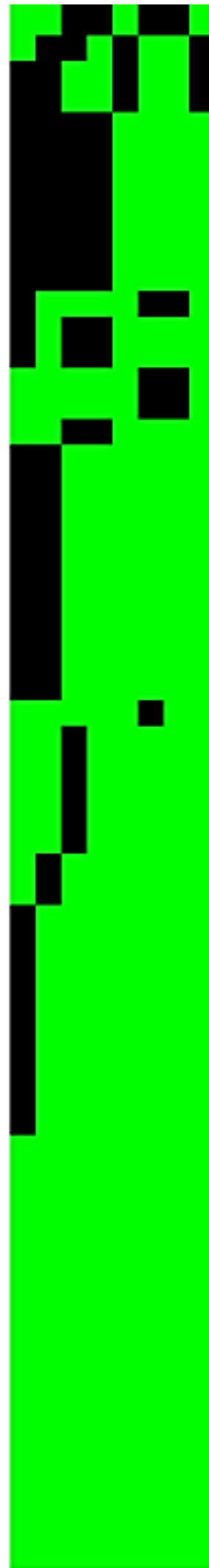

HtrA serine peptidase 3(HTRA3)

LFNG O-fucosylpeptide 3-beta-N-acetylglucosaminyltransferase(LFNG)

CD36 molecule(CD36)

ST8 alpha-N-acetyl-neuraminide alpha-2,8-sialyltransferase 1(ST8SIA1)

sulfatase 2(SULF2)

EPH receptor A5(EPHA5)

neuraminidase 1(NEU1)

chromosome 11 open reading frame 87 (C11orf87)

$\mathrm{G}$ protein-coupled receptor class $\mathrm{C}_{\text {group }} 5$ member $\mathrm{C}$ (GPRC5C)

protein tyrosine phosphatase, receptor type E(PTPRE)

ecotropic viral integration site 2A(EVI2A)

C.C motif chemokine ligand 26(CCL26)

adhesion $\mathrm{G}$ protein-coupled receptor G1(ADGRG1)

syndecan 1 (SDC1)

secretogranin V(SCG5)

proenkephalin(PENK)

neuron derived neurotrophic factor(NDNF)

cathepsin A(CTSA)

carbonic anhydrase 12(CA12)

semaphorin SA(SEMASA)

heparan sulfate-glucosamine 3-sulfotransferase 1(HS3ST1)

colony stimulating factor 1 receptor(CSF1R)

discoidin, CUB and LCCL domain containing 2(DCBLD2)

sialic acid binding Ig like lectin 15(SIGLEC15)

opioid binding protein/cell adhesion molecule like(OPCML)

cell adhesion molecule 1(CADM1)

leucine rich repeat containing $G$ protein-coupled receptor 4(LGR4)

lumican(LUM)

collagen type XIV alpha 1 chain(COL 14A1)

HHIP like 2(HHIPL2)

collagen type XV alpha 1 chain(COL15A1)

Wnt family member 5A(WNT5A)

anosmin 1(ANOS1)

thrombospondin 2(THBS2)

nerve growth factor receptor(NGFR)

chitinase 3 like 1(CHI3L1)

carboxypeptidase A4(CPA4)

lymphocyte antigen 96(LY96)

ADAM metallopeptidase with thrombospondin type 1 motif 6(ADAMTS6)

matrix metallopeptidase 16(MMP16)

interferon epsilon(IFNE)

lysyl oxidase like 2(LOXL2)

ADAMTS like 1(ADAMTSL1)

epithelial mitogen(EPGN)

placental growth factor(PGF)

vascular endothelial growth factor A(VEGFA)

IFI30, lysosomal thiol reductase(IFI30)

serpin family B member 2(SERPINB2)

laminin subunit alpha 4(LAMA4)

immunoglobulin superfamily containing leucine rich repeat(ISLR)

growth differentiation factor 15 (GDF15)

interleukin 6(IL6)

gremlin 2, DAN family BMP antagonist(GREM2)

growth differentiation factor 5(GDFS)

von Willebrand factor $\mathrm{C}$ and EGF domains(VWCE)

semaphorin 3A(SEMA3A)

ADAM metallopeptidase with thrombospondin type 1 motif 14(ADAMTS14)

leukemia inhibitory factor(LIF)

anthrax toxin receptor 2(ANTXR2)

platelet derived growth factor C(PDGFC)

nectin cell adhesion molecule 1 (NECTIN1)

\section{Abbildung A-2:}

Darstellung einer reduzierten Anzahl von Genen der funktionellen Gruppen aus cluster 2 , die bei den Stro- $1^{+}$-Beckenkammzellen signifikant herunterreguliert sind und bei den Stro- $1^{+}$-Zahnkeimzellen keine signifikante Veränderung aufzeigen (siehe Tabelle 7). Die funktionellen Gruppen von cluster 1 der hoch- und cluster 2 der herunterregulierten Gene der Stro- ${ }^{+\mathrm{BK}}$ sind identisch, aber ihre Genzusammensetzung nicht. 
Tabelle A-9: Funktionelle Gruppen der Gene, die bei den Stro- $1^{+}$-Zahnkeimzellen signifikant hochreguliert sind und bei den Stro- $1^{+}$-Beckenkammzellen keine signifikante Veränderung aufzeigen ( $n=176)$. In der Tabelle sind von insgesamt 36 clustern nur die ersten vier mit den höchsten enrichment scores dargestellt.

\section{Functional Annotation Clustering}

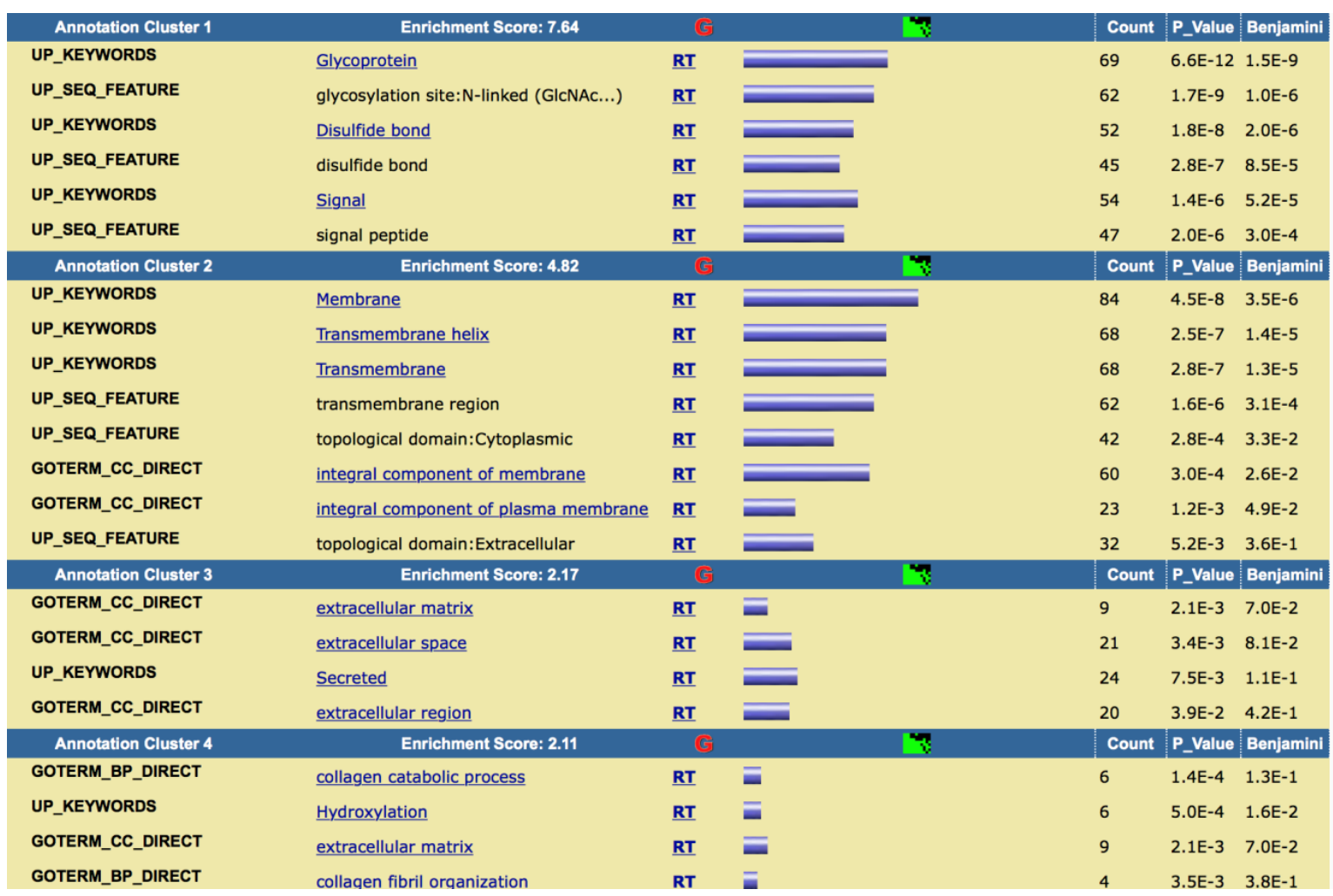

\section{Functional Annotation Chart}

\begin{tabular}{|c|c|c|c|c|c|c|c|}
\hline Category. & Term & ज RT & Genes & Count & $\underline{\%}$ & P-Value & Benjamini \\
\hline UP_TISSUE & Colon endothelium & $\underline{\text { RT }}$ & 三 & 6 & 3,6 & $2,9 E-5$ & $4,1 \mathrm{E}-3$ \\
\hline UP_TISSUE & Placenta & RT & $\bar{\equiv}$ & 44 & 26,7 & $9,6 \mathrm{E}-3$ & $5,0 E-1$ \\
\hline UP_TISSUE & Lung & $\underline{\mathbf{R T}}$ & $\bar{\square}$ & 36 & 21,8 & $1,4 \mathrm{E}-2$ & $4,1 \mathrm{E}-1$ \\
\hline
\end{tabular}




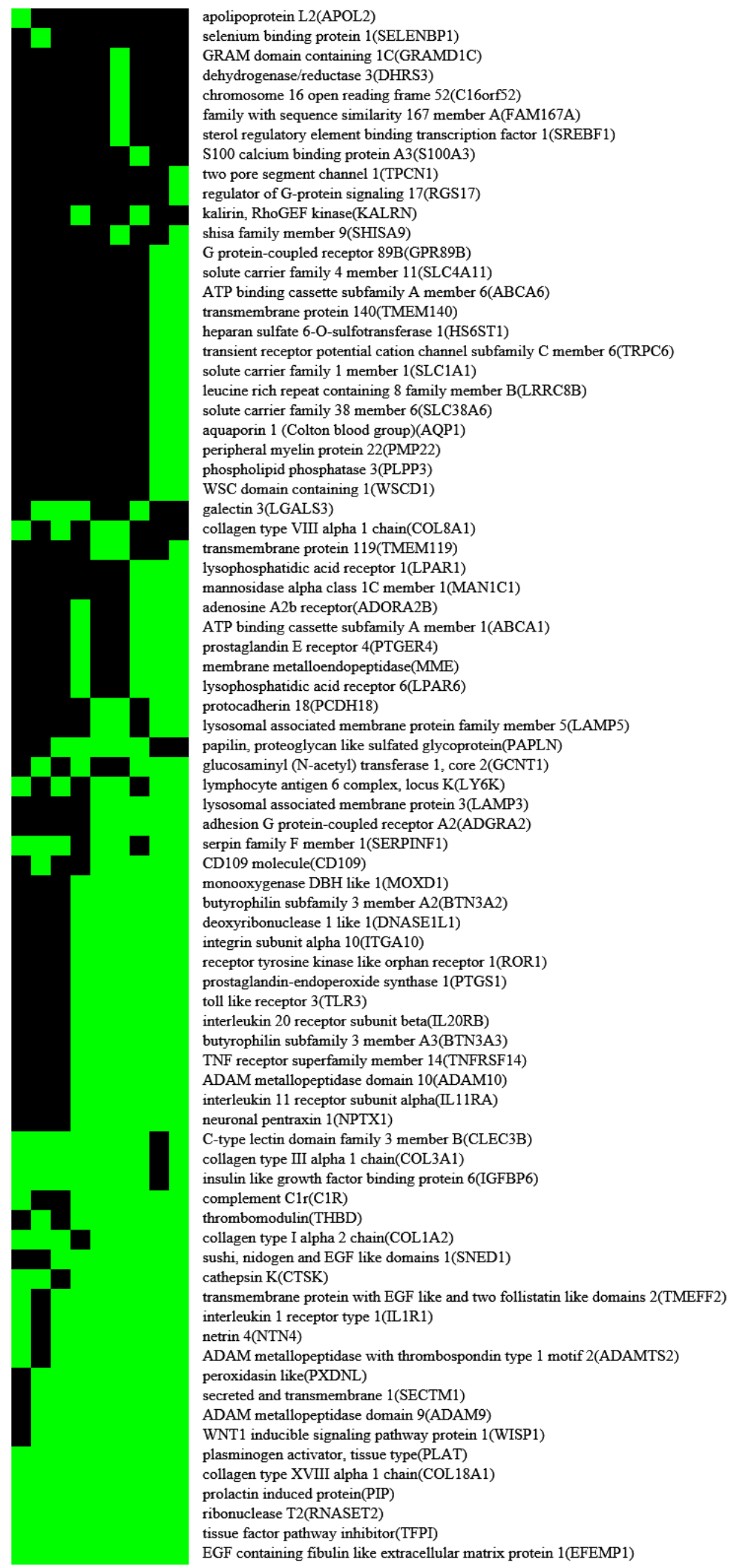

\section{Abbildung A-3:}

Heatmap der Gene der funktionellen Gruppen aus cluster 1, die bei den Stro- $1^{+}$-Zahnkeimzellen signifikant hochreguliert sind und bei den Stro- $1^{+}$-Beckenkammzellen keine signifikante Veränderung aufzeigen (siehe Tabelle A-9). 
Tabelle A-10: Funktionelle Gruppen der Gene, die bei den Stro- $1^{+}$-Zahnkeimzellen signifikant herunterreguliert sind und bei den Stro- $1^{+}$-Beckenkammzellen keine signifikante Veränderung aufzeigen $(n=280)$. In der Tabelle sind von insgesamt 42 clustern nur die ersten vier mit den höchsten enrichment scores dargestellt.

\section{Functional Annotation Clustering}

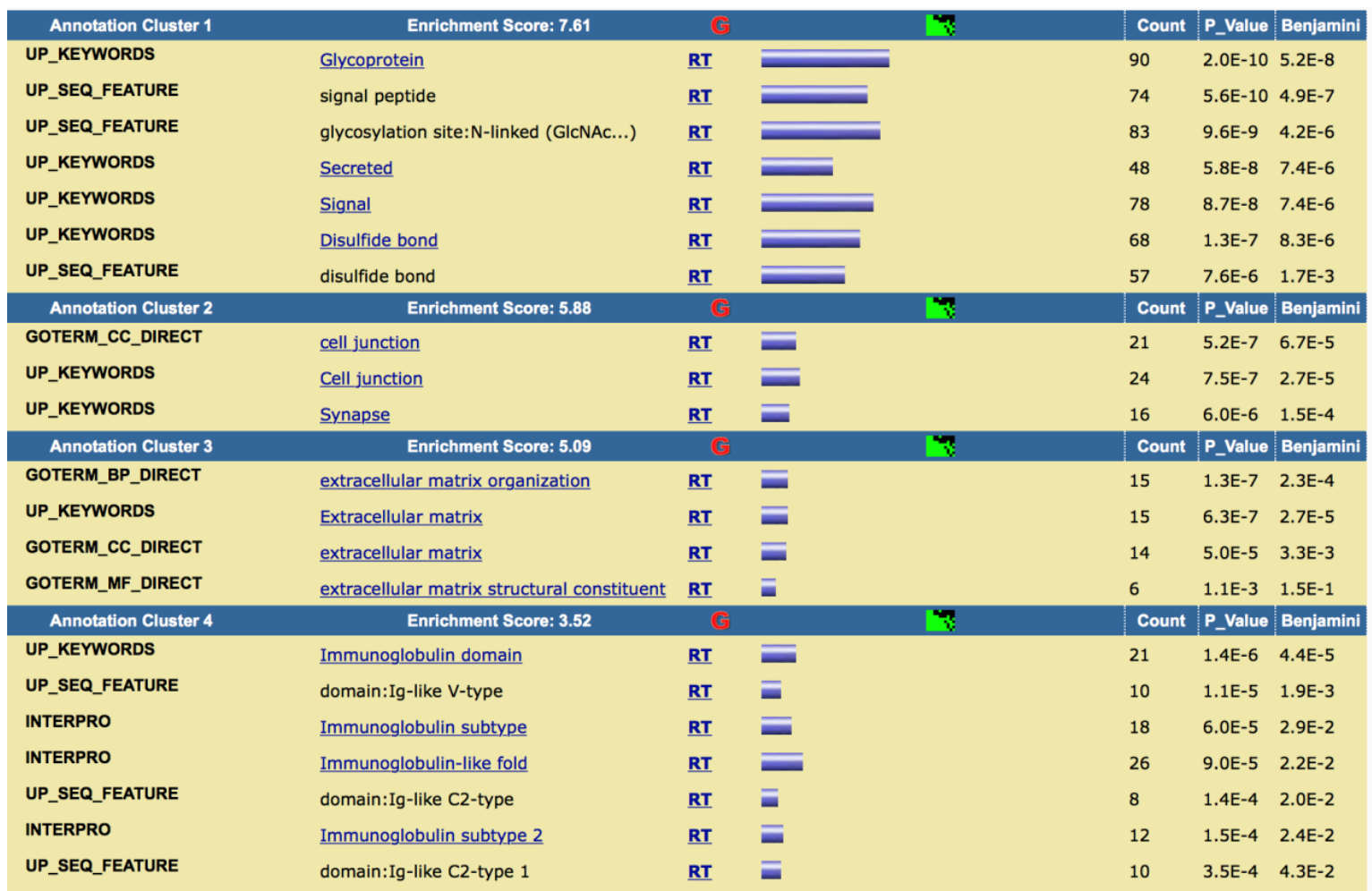

\section{Functional Annotation Chart}

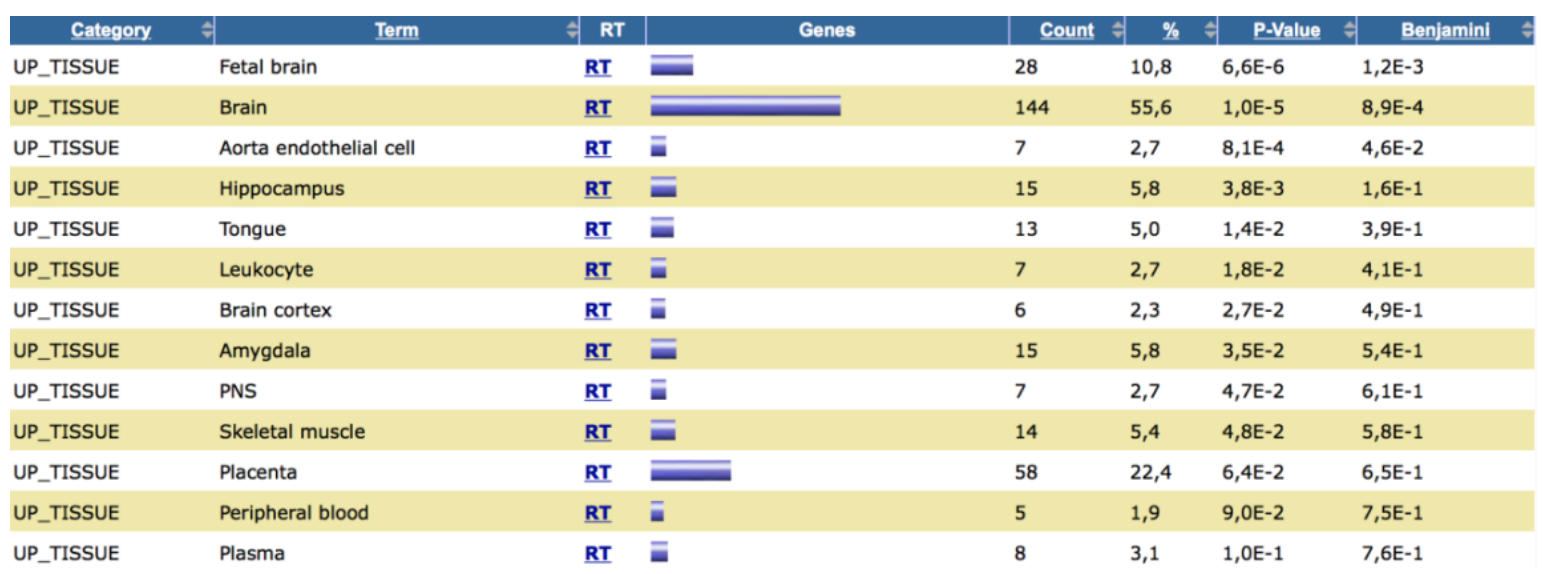




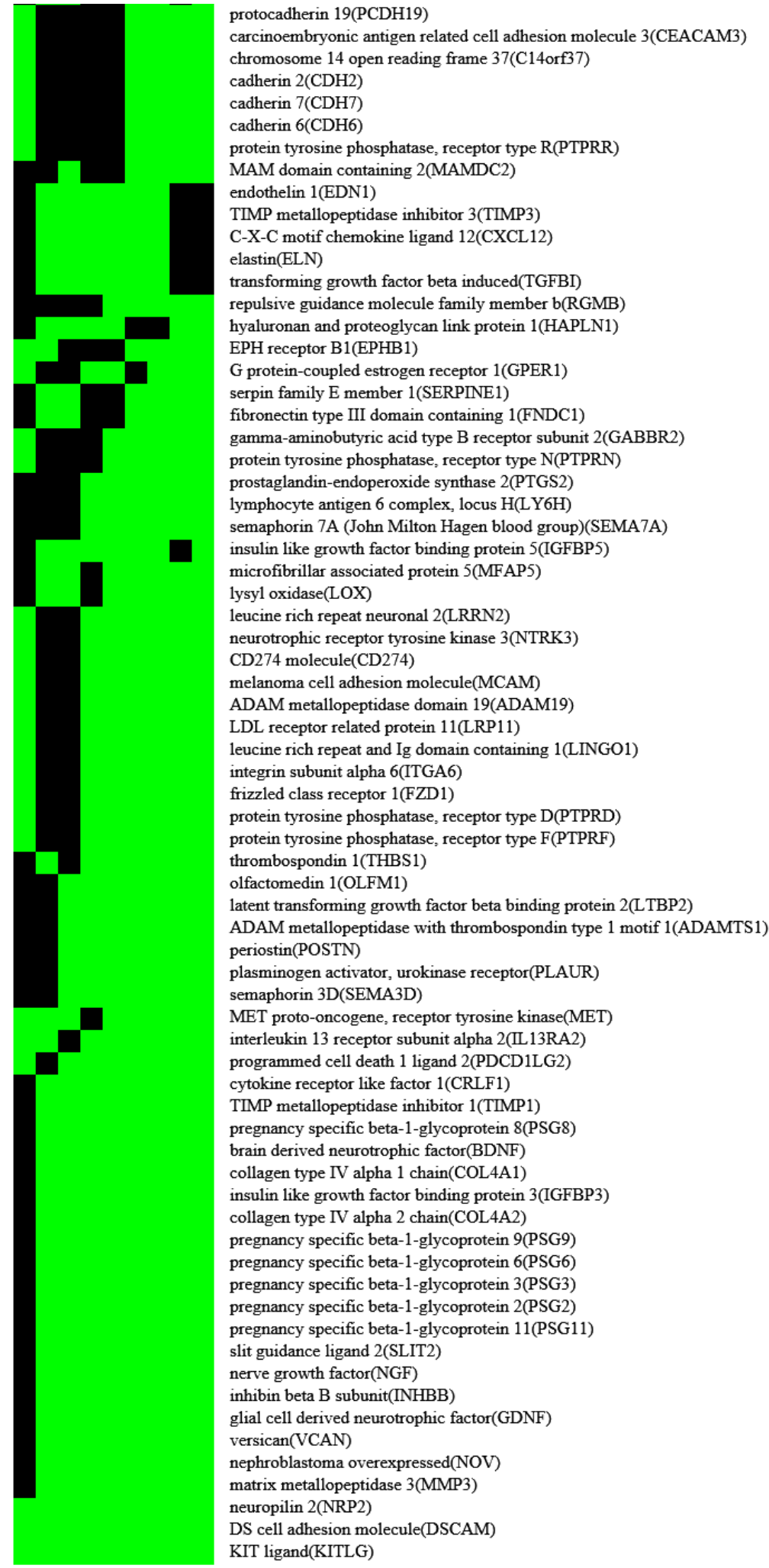

Abbildung A-4:

Heatmap der Gene der funktionellen Gruppen aus cluster 1, die bei den Stro- $1^{+}$-Zahnkeimzellen signifikant herunterreguliert sind und bei den Stro- $1^{+}$-Beckenkammzellen keine signifikante Veränderung aufzeigen (siehe Tabelle A-10). Die Heatmap wurde im oberen Teil aus Darstellungsgründen gekappt. 


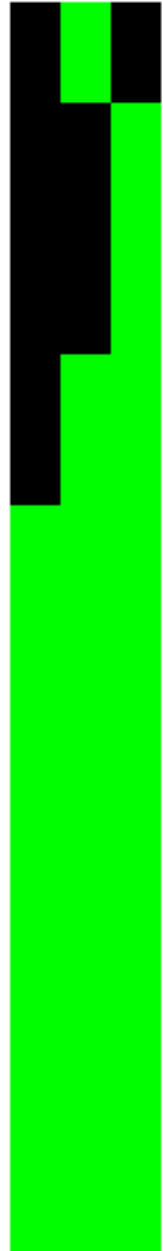

nuclear receptor interacting protein 1(NRIP1)

protein tyrosine phosphatase, receptor type R(PTPRR)

formin 1(FMN1)

catenin delta 2(CTNND2)

nephroblastoma overexpressed(NOV)

plasminogen activator, urokinase receptor(PLAUR)

NADPH oxidase 4 (NOX4)

TBC1 domain family member 2(TBC1D2)

testin LIM domain protein(TES)

desmoplakin(DSP)

$\mathrm{G}$ protein-coupled estrogen receptor 1(GPER1)

cytoplasmic polyadenylation element binding protein 4(CPEB4)

syntaxin 1A(STX1A)

septin 3(SEPT3)

discs large MAGUK scaffold protein 2(DLG2)

neuronal calcium sensor 1 (NCS1)

synuclein alpha(SNCA)

protein kinase $\mathrm{C}$ and casein kinase substrate in neurons 1(PACSIN1)

synapse differentiation inducing 1 (SYNDIG1)

olfactomedin 1(OLFM1)

synapsin II(SYN2)

DS cell adhesion molecule(DSCAM)

gamma-aminobutyric acid type $B$ receptor subunit 2(GABBR2)

dishevelled binding antagonist of beta catenin 1(DACT1)

protein tyrosine phosphatase, receptor type N(PTPRN)

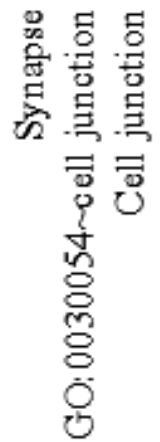

Abbildung A-5: Heatmap der Gene der funktionellen Gruppen aus cluster 2, die bei den Stro- $1^{+}-$ Zahnkeimzellen signifikant herunterreguliert sind und bei den Stro- $1^{+}$-Beckenkammzellen keine signifikante Veränderung aufzeigen (siehe Tabelle A-10). 


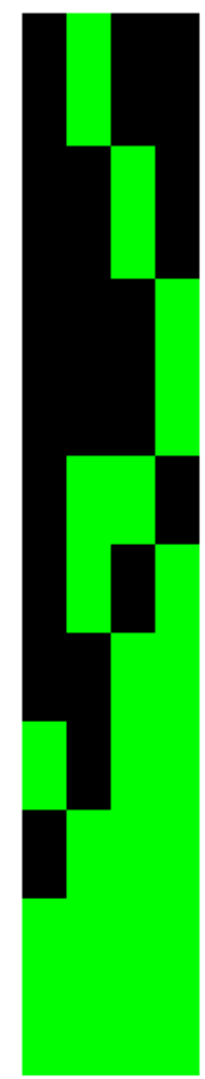

apolipoprotein E(APOE)

nephroblastoma overexpressed(NOV)

desmoplakin(DSP)

MAM domain containing 2(MAMDC2)

matrix metallopeptidase 3(MMP3)

ADAM metallopeptidase with thrombospondin type 1 motif 1(ADAMTS1)

lysyl oxidase(LOX)

SRY-box 9(SOX9)

fibroblast growth factor 2(FGF2)

integrin subunit alpha 6(ITGA6)

TIMP metallopeptidase inhibitor 3(TIMP3)

latent transforming growth factor beta binding protein 2(LTBP2)

serpin family E member 1(SERPINE1)

thrombospondin 1(THBS1)

collagen type $\mathrm{X}$ alpha 1 chain(COL10A1)

coiled-coil domain containing 80 (CCDC 80 )

elastin(ELN)

microfibrillar associated protein 5(MFAP5)

transforming growth factor beta induced(TGFBI)

periostin(POSTN)

hyaluronan and proteoglycan link protein 1(HAPLN1)

versican(VCAN)

collagen type IV alpha 1 chain(COL4A1)

collagen type IV alpha 2 chain(COL4A2)

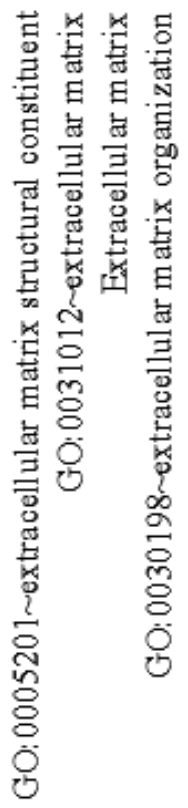

Abbildung A-6: Heatmap der Gene der funktionellen Gruppen aus cluster 3, die bei den Stro- $1^{+}$ Zahnkeimzellen signifikant herunterreguliert sind und bei den Stro- $1^{+}$-Beckenkammzellen keine signifikante Veränderung aufzeigen (siehe Tabelle A-10). 
Tabelle A-11: Gene der Stro- $1^{+}-$Beckenkamm- und -Zahnkeimzellen mit beidseits signifikanten logFC-Werten, die gleichsinnig im ODM heraufreguliert werden $(n=130)$. Die Gene sind in der Tabelle alphabetisch aufsteigend nach ihrem Symbol geordnet.

\begin{tabular}{|c|c|c|c|c|c|}
\hline Agilent ID & Symbol & $\operatorname{logFC}$ BK2-1 & FDR BK2-1 & $\operatorname{logFC}$ ZK2-1 & FDR ZK2-1 \\
\hline A_23_P104318 & DDIT4 & 3,528 & $3,836 e-8$ & 4,507 & $3,310 e-9$ \\
\hline A_24_P335092 & SAA1 & 8,034 & $6,634 \mathrm{e}-14$ & 3,692 & $5,719 e-9$ \\
\hline A_23_P119943 & IGFBP2 & 0,825 & 0,034 & 3,228 & $6,331 e-9$ \\
\hline A_23_P19624 & BMP6 & 5,251 & $3,809 \mathrm{e}-12$ & 3,115 & $8,659 e-9$ \\
\hline A_23_P83857 & MAOA & 3,299 & $4,193 e-10$ & 2,491 & $2,993 e-8$ \\
\hline A_24_P38081 & FKBP5 & 4,235 & $4,680 e-10$ & 3,267 & $2,993 e-8$ \\
\hline A_23_P121064 & PTX3 & 1,863 & $1,246 e-4$ & 3,741 & $2,993 e-8$ \\
\hline A_23_P64873 & $\mathrm{DCN}$ & 1,846 & $9,115 e-4$ & 4,260 & $5,468 \mathrm{e}-8$ \\
\hline A_23_P148047 & PTGER4 & 2,060 & $6,148 e-5$ & 3,483 & $1,368 \mathrm{e}-7$ \\
\hline A_23_P31810 & CEBPD & 2,665 & $3,028 e-6$ & 3,522 & $1,386 e-7$ \\
\hline A_23_P415021 & METTL7A & 2,559 & $6,985 e-6$ & 3,598 & $1,386 \mathrm{e}-7$ \\
\hline A_23_P337262 & APCDD1 & 0,930 & 0,049 & 2,947 & $2,007 e-7$ \\
\hline A_24_P260101 & MME & 1,601 & $2,516 e-4$ & 2,900 & $2,483 e-7$ \\
\hline A_23_P94397 & OMD & 1,878 & $5,349 e-6$ & 2,380 & $4,466 \mathrm{e}-7$ \\
\hline A_23_P154037 & AOX1 & 3,060 & $1,633 \mathrm{e}-9$ & 2,072 & $5,001 e-7$ \\
\hline A_24_P131622 & FAM107A & 1,045 & $3,212 e-3$ & 2,283 & $5,147 e-7$ \\
\hline A_23_P39237 & ZFP36 & 1,078 & $1,845 e-3$ & 2,147 & $8,796 \mathrm{e}-7$ \\
\hline A_23_P111206 & FKBP5 & 3,590 & $4,832 e-9$ & 2,455 & $1,244 \mathrm{e}-6$ \\
\hline A_23_P18372 & B3GNT5 & 1,483 & $1,139 \mathrm{e}-4$ & 2,201 & $1,439 \mathrm{e}-6$ \\
\hline A_23_P415401 & KLF9 & 1,160 & 0,030 & 2,963 & $1,477 e-6$ \\
\hline A_32_P35512 & SSB & 1,088 & $5,643 e-4$ & 1,847 & $1,513 e-6$ \\
\hline A_23_P128974 & BATF & 1,373 & 0,015 & 3,164 & $1,824 \mathrm{e}-6$ \\
\hline A_23_P89589 & PER1 & 2,042 & $1,787 e-6$ & 2,066 & $2,383 e-6$ \\
\hline A_23_P50946 & RAMP1 & 2,388 & $1,883 e-7$ & 2,031 & $2,808 \mathrm{e}-6$ \\
\hline A_23_P151710 & PTGER2 & 2,202 & $3,055 e-5$ & 2,694 & $3,790 e-6$ \\
\hline A_24_P231104 & LEPR & 3,745 & $1,131 \mathrm{e}-8$ & 2,380 & $7,332 \mathrm{e}-6$ \\
\hline A_23_P214026 & FBN2 & 3,082 & $4,206 e-6$ & 3,083 & $7,409 e-6$ \\
\hline A_23_P55356 & VMO1 & 4,586 & $3,950 e-11$ & 1,868 & $8,498 \mathrm{e}-6$ \\
\hline A_23_P335920 & RPS6KA2 & 1,029 & 0,028 & 2,238 & $9,955 e-6$ \\
\hline A_23_P33326 & ADRA1B & 3,363 & $2,966 \mathrm{e}-6$ & 3,000 & $2,108 \mathrm{e}-5$ \\
\hline A_24_P734953 & TRNP1 & 1,457 & $7,521 \mathrm{e}-4$ & 2,056 & $2,339 e-5$ \\
\hline A_23_P106002 & NFKBIA & 1,274 & $2,068 \mathrm{e}-4$ & 1,542 & $3,564 \mathrm{e}-5$ \\
\hline A_23_P105794 & EPSTI1 & 0,858 & 0,021 & 1,634 & $3,564 e-5$ \\
\hline A_24_P921436 & FBN2 & 0,909 & $5,880 e-3$ & 1,463 & $4,643 e-5$ \\
\hline A_24_P938352 & CPM & 3,283 & $1,224 \mathrm{e}-8$ & 1,780 & $4,926 e-5$ \\
\hline A_24_P53976 & GLUL & 2,072 & $7,290 \mathrm{e}-4$ & 2,640 & $7,077 e-5$ \\
\hline A_23_P203957 & TMTC1 & 3,175 & $4,832 e-9$ & 1,513 & $9,928 e-5$ \\
\hline A_23_P40880 & СMTM8 & 1,538 & 0,022 & 2,675 & $1,003 e-4$ \\
\hline A_24_P16124 & IFITM4P & 0,801 & 0,017 & 1,330 & $1,187 \mathrm{e}-4$ \\
\hline A_23_P216429 & ASPN & 1,345 & $2,125 e-4$ & 1,461 & $1,187 \mathrm{e}-4$ \\
\hline A_23_P109171 & BFSP1 & 0,960 & $7,673 e-3$ & 1,461 & $1,188 \mathrm{e}-4$ \\
\hline A_23_P254741 & SOD3 & 3,178 & $8,335 e-8$ & 1,794 & $1,772 \mathrm{e}-4$ \\
\hline A_23_P252062 & PPARG & 2,088 & $2,528 \mathrm{e}-7$ & 1,285 & $1,880 \mathrm{e}-4$ \\
\hline A_23_P118615 & ABCA 8 & 1,590 & $4,859 e-5$ & 1,450 & 2,131e-4 \\
\hline
\end{tabular}




\begin{tabular}{|c|c|c|c|c|c|}
\hline Agilent ID & Symbol & $\operatorname{logFC~BK2-1~}$ & FDR BK2-1 & $\operatorname{logFC}$ ZK2-1 & FDR ZK2-1 \\
\hline A_23_P331670 & PYGB & 1,730 & $5,613 e-5$ & 1,582 & $2,316 e-4$ \\
\hline A_23_P201587 & SORT1 & 2,492 & $1,227 e-7$ & 1,412 & $2,383 e-4$ \\
\hline A_23_P13222 & $\mathrm{RCN} 1$ & 0,949 & $7,982 e-3$ & 1,368 & $2,398 e-4$ \\
\hline A_23_P87545 & IFITM3 & 0,818 & 0,043 & 1,429 & $2,398 \mathrm{e}-4$ \\
\hline A_23_P144476 & SPRY1 & 1,157 & $7,837 e-4$ & 1,331 & $2,477 e-4$ \\
\hline A_23_P302005 & STON1 & 2,443 & $4,118 e-7$ & 1,512 & $2,577 e-4$ \\
\hline A_23_P216596 & SVEP1 & 2,922 & $1,372 \mathrm{e}-8$ & 1,381 & $2,809 e-4$ \\
\hline A_24_P20327 & KLF15 & 1,669 & $9,673 e-5$ & 1,574 & $2,828 \mathrm{e}-4$ \\
\hline A_23_P356004 & KCNIP3 & 3,167 & $1,448 e-8$ & 1,500 & $2,911 \mathrm{e}-4$ \\
\hline A_23_P398294 & HIP1R & 1,352 & 0,020 & 2,117 & $3,046 e-4$ \\
\hline A_23_P433016 & FBLN1 & 1,640 & $3,123 e-3$ & 2,073 & $3,644 \mathrm{e}-4$ \\
\hline A_23_P162668 & CPM & 3,547 & $9,887 e-8$ & 1,887 & $3,863 e-4$ \\
\hline A_23_P145935 & EPHB6 & 1,328 & $2,368 e-4$ & 1,301 & $4,268 \mathrm{e}-4$ \\
\hline A_24_P325520 & SORT1 & 2,822 & $3,636 e-7$ & 1,633 & $4,895 e-4$ \\
\hline A_23_P56578 & VIT & 1,721 & $2,758 e-5$ & 1,371 & $5,374 e-4$ \\
\hline A_23_P40847 & CHST2 & 2,727 & $5,566 e-6$ & 1,906 & $5,758 e-4$ \\
\hline A_23_P163087 & NID2 & 3,344 & $7,474 \mathrm{e}-6$ & 2,342 & $7,200 e-4$ \\
\hline A_23_P77048 & SLC25A29 & 0,748 & 0,036 & 1,147 & $7,914 \mathrm{e}-4$ \\
\hline A_23_P128967 & ALDH6A1 & 0,752 & 0,032 & 1,125 & $8,743 e-4$ \\
\hline A_23_P47135 & NR1H3 & 0,985 & $8,000 e-3$ & 1,259 & $8,988 \mathrm{e}-4$ \\
\hline A_23_P76914 & SIX1 & 1,359 & $6,295 e-3$ & 1,690 & $9,169 e-4$ \\
\hline A_24_P137522 & USP53 & 1,112 & $5,068 e-3$ & 1,321 & $1,175 e-3$ \\
\hline A_23_P120594 & ACSS1 & 1,030 & 0,017 & 1,389 & $1,230 \mathrm{e}-3$ \\
\hline A_23_P150018 & DUSP5 & 2,295 & $2,767 e-6$ & 1,408 & $1,296 e-3$ \\
\hline A_23_P106194 & FOS & 1,553 & $6,983 e-4$ & 1,508 & $1,355 e-3$ \\
\hline A_32_P70315 & TIMP4 & 1,660 & $1,240 \mathrm{e}-4$ & 1,380 & $1,363 e-3$ \\
\hline A_23_P97700 & TXNIP & 2,173 & $4,409 e-4$ & 1,983 & $1,665 e-3$ \\
\hline A_32_P2452 & TMTC1 & 2,429 & $5,184 \mathrm{e}-7$ & 1,283 & $1,756 \mathrm{e}-3$ \\
\hline A_23_P303671 & ECM2 & 1,096 & $7,624 \mathrm{e}-3$ & 1,289 & $2,004 \mathrm{e}-3$ \\
\hline A_23_P50081 & IMPA2 & 4,105 & 4,193e-10 & 1,210 & $2,044 \mathrm{e}-3$ \\
\hline A_23_P435407 & GPC4 & 1,269 & $1,159 e-3$ & 1,243 & $2,070 e-3$ \\
\hline A_23_P81158 & $\mathrm{ADH} 1 \mathrm{C}$ & 1,497 & $7,290 e-4$ & 1,389 & $2,265 e-3$ \\
\hline A_23_P116414 & PLA2G16 & 1,362 & 0,033 & 1,860 & $2,295 e-3$ \\
\hline A_23_P48676 & PYGL & 0,861 & 0,015 & 1,061 & $2,614 \mathrm{e}-3$ \\
\hline A_23_P138352 & WNT2B & 1,384 & $8,071 e-5$ & 1,031 & $2,879 e-3$ \\
\hline A_24_P154037 & IRS2 & 2,259 & $1,080 e-4$ & 1,724 & $2,879 e-3$ \\
\hline A_23_P85682 & NFIA & 1,140 & $4,052 e-4$ & 0,956 & $3,638 \mathrm{e}-3$ \\
\hline A_23_P88303 & HSPA2 & 0,940 & 0,038 & 1,234 & $4,138 e-3$ \\
\hline A_23_P101551 & BCAT2 & 1,027 & $4,999 e-4$ & 0,861 & $4,405 e-3$ \\
\hline A_23_P32404 & ISG20 & 1,089 & $2,574 \mathrm{e}-3$ & 1,058 & $4,580 \mathrm{e}-3$ \\
\hline A_24_P406060 & RNF144B & 1,664 & $1,519 e-6$ & 0,842 & $5,655 e-3$ \\
\hline A_32_P157846 & DUSP5P & 1,349 & $7,377 e-4$ & 1,138 & $5,892 e-3$ \\
\hline A_32_P175301 & DENND3 & 1,078 & $5,418 e-4$ & 0,878 & $6,187 e-3$ \\
\hline A_23_P325690 & ANKRD35 & 1,409 & 0,015 & 1,588 & $6,310 e-3$ \\
\hline A_23_P58359 & $\mathrm{ADH} 1 \mathrm{~A}$ & 1,363 & $1,168 \mathrm{e}-3$ & 1,192 & $6,377 e-3$ \\
\hline A_23_P150609 & IGF2 & 3,748 & $2,897 e-4$ & 2,827 & $7,593 e-3$ \\
\hline A_23_P113111 & AR & 1,395 & $8,444 \mathrm{e}-5$ & 0,943 & $7,632 e-3$ \\
\hline
\end{tabular}




\begin{tabular}{|c|c|c|c|c|c|}
\hline Agilent ID & Symbol & $\operatorname{logFC~BK2-1~}$ & FDR BK2-1 & logFC ZK2-1 & FDR ZK2-1 \\
\hline A_23_P254507 & HOPX & 1,495 & $3,973 e-4$ & 1,153 & $7,999 e-3$ \\
\hline A_32_P56661 & IGF2 & 1,191 & $3,973 e-4$ & 0,912 & $8,692 e-3$ \\
\hline A_23_P52727 & NAV2 & 1,412 & $2,501 \mathrm{e}-4$ & 1,032 & $9,022 \mathrm{e}-3$ \\
\hline A_23_P307544 & PLXNA2 & 2,206 & $1,112 \mathrm{e}-6$ & 1,035 & $9,464 \mathrm{e}-3$ \\
\hline A_23_P259166 & TCEAL4 & 1,462 & $9,644 \mathrm{e}-6$ & 0,802 & 0,010 \\
\hline A_23_P69908 & GLRX & 1,532 & $3,602 e-4$ & 1,141 & 0,010 \\
\hline A_23_P204937 & C13orf15 & 4,711 & $1,238 \mathrm{e}-7$ & 1,861 & 0,010 \\
\hline A_23_P56734 & HNMT & 0,855 & 0,042 & 1,009 & 0,013 \\
\hline A_23_P306203 & SAA2 & 5,669 & $4,819 e-9$ & 1,668 & 0,014 \\
\hline A_23_P67864 & ADCY3 & 1,000 & 0,011 & 0,999 & 0,015 \\
\hline A_32_P46214 & SLC9A9 & 1,026 & $5,013 e-3$ & 0,933 & 0,016 \\
\hline A_24_P329795 & C10orf10 & 2,203 & $1,139 e-4$ & 1,404 & 0,017 \\
\hline A_23_P161458 & OLAH & 1,368 & $5,878 e-4$ & 1,008 & 0,017 \\
\hline A_23_P31873 & RAB11FIP1 & 0,969 & $7,915 e-3$ & 0,905 & 0,019 \\
\hline A_23_P217688 & TSC22D3 & 1,921 & $2,832 e-5$ & 1,068 & 0,019 \\
\hline A_32_P83256 & IRAK3 & 1,213 & $1,731 \mathrm{e}-4$ & 0,782 & 0,021 \\
\hline A_23_P134085 & CNKSR3 & 1,795 & $8,072 e-5$ & 1,073 & 0,023 \\
\hline A_32_P114284 & IKZF2 & 3,008 & $1,227 e-7$ & 1,074 & 0,025 \\
\hline A_24_P74828 & MT1JP & 1,083 & 0,025 & 1,115 & 0,025 \\
\hline A_23_P86653 & SRGN & 1,544 & 0,012 & 1,466 & 0,026 \\
\hline A_23_P31143 & TPD52L1 & 1,104 & 0,027 & 1,144 & 0,026 \\
\hline A_23_P253536 & NPR3 & 1,635 & $4,859 e-5$ & 0,922 & 0,026 \\
\hline A_24_P372625 & RNF141 & 1,452 & $2,456 e-4$ & 0,927 & 0,030 \\
\hline A_23_P51339 & DNAJB4 & 1,564 & $2,778 e-4$ & 0,951 & 0,030 \\
\hline A_23_P57856 & BCL6 & 1,428 & $4,458 \mathrm{e}-3$ & 1,195 & 0,030 \\
\hline A_23_P315364 & CXCL2 & 1,000 & $1,127 e-3$ & 0,736 & 0,030 \\
\hline A_23_P352402 & C10orf47 & 1,537 & $6,363 e-5$ & 0,869 & 0,032 \\
\hline A_24_P296772 & PPP1R14A & 4,168 & $1,018 \mathrm{e}-8$ & 1,171 & 0,036 \\
\hline A_24_P321581 & SLC38A4 & 1,074 & 0,036 & 1,103 & 0,038 \\
\hline A_23_P5405 & UBR3 & 1,214 & $2,265 e-3$ & 0,925 & 0,038 \\
\hline A_23_P502142 & FYN & 1,072 & $1,233 e-3$ & 0,770 & 0,040 \\
\hline A_23_P378416 & GPM6B & 3,454 & $5,637 e-8$ & 1,094 & 0,041 \\
\hline A_24_P78590 & ELF1 & 0,836 & 0,017 & 0,866 & 0,041 \\
\hline A_23_P82047 & STXBP5 & 0,815 & 0,015 & 0,842 & 0,042 \\
\hline A_24_P262543 & KCNK6 & 1,411 & $7,280 \mathrm{e}-4$ & 0,951 & 0,044 \\
\hline A_24_P393958 & DNAJB4 & 1,175 & $3,091 \mathrm{e}-3$ & 0,961 & 0,046 \\
\hline A_23_P29784 & ARMC8 & 1,482 & $5,639 e-4$ & 0,965 & 0,049 \\
\hline A_23_P58676 & C5orf23 & 1,317 & 0,029 & 1,274 & 0,050 \\
\hline A_24_P916965 & ITGBL1 & 1,853 & $2,435 e-5$ & 0,912 & 0,050 \\
\hline
\end{tabular}


Tabelle A-12: Gene der Stro- $1^{+}-$Beckenkamm- und -Zahnkeimzellen mit beidseits signifikanten logFC-Werten, die gleichsinnig im ODM herunterreguliert werden $(n=94)$. Die Gene sind in der Tabelle alphabetisch aufsteigend nach ihrem Symbol geordnet.

\begin{tabular}{|c|c|c|c|c|c|}
\hline Agilent ID & Symbol & $\operatorname{logFC}$ BK2-1 & FDR BK2-1 & $\operatorname{logFC}$ ZK2-1 & FDR ZK2-1 \\
\hline A_23_P202327 & ADAM12 & $-2,400$ & $1,731 \mathrm{e}-4$ & $-2,246$ & $5,276 e-4$ \\
\hline A_23_P40415 & ADAMTS5 & $-3,335$ & $2,131 \mathrm{e}-7$ & $-3,757$ & $9,323 e-8$ \\
\hline A_23_P256158 & ADRA2C & $-1,164$ & 0,026 & $-1,638$ & $1,313 e-3$ \\
\hline A_23_P15876 & ALPK2 & $-2,148$ & $1,070 e-5$ & $-1,049$ & 0,032 \\
\hline A_23_P14083 & AMIGO2 & $-1,841$ & $2,169 \mathrm{e}-4$ & $-3,350$ & $2,072 e-7$ \\
\hline A_32_P300427 & APCDD1L & $-1,190$ & $8,218 e-3$ & $-2,065$ & $3,138 e-5$ \\
\hline A_23_P19030 & ARSI & $-1,274$ & $1,457 \mathrm{e}-4$ & $-0,820$ & 0,019 \\
\hline A_23_P128744 & BDKRB1 & $-1,545$ & 0,028 & $-1,777$ & 0,011 \\
\hline A_24_P919850 & BDKRB1 & $-1,530$ & $7,395 e-3$ & $-1,834$ & $1,600 e-3$ \\
\hline A_24_P50228 & C11orf87 & $-1,149$ & $5,660 e-3$ & $-1,401$ & $1,018 \mathrm{e}-3$ \\
\hline A_24_P130296 & C17orf79 & $-0,789$ & 0,028 & $-0,855$ & 0,018 \\
\hline A_23_P410717 & C1orf51 & $-1,063$ & $1,025 e-3$ & $-0,913$ & $6,704 e-3$ \\
\hline A_23_P60227 & CCIN & $-1,057$ & $3,170 e-3$ & $-0,809$ & 0,050 \\
\hline A_23_P24870 & CD44 & $-1,496$ & $3,602 \mathrm{e}-4$ & $-1,932$ & $2,990 e-5$ \\
\hline A_23_P215913 & CLU & $-1,027$ & 0,029 & $-1,855$ & $9,660 e-5$ \\
\hline A_23_P106322 & CPEB1 & $-1,730$ & $1,187 e-4$ & $-1,286$ & $4,061 \mathrm{e}-3$ \\
\hline A_23_P111888 & CTHRC1 & $-0,746$ & 0,020 & $-1,411$ & $3,595 e-5$ \\
\hline A_24_P944054 & CXCL12 & $-1,939$ & $6,927 e-5$ & $-1,802$ & $2,383 e-4$ \\
\hline A_23_P202448 & CXCL12 & $-2,132$ & $3,931 e-5$ & $-3,063$ & 6,937e-7 \\
\hline A_23_P65518 & DACT1 & $-1,360$ & $4,946 e-4$ & $-3,922$ & $1,867 e-9$ \\
\hline A_23_P28595 & DLX2 & $-1,198$ & $8,479 e-4$ & $-0,855$ & 0,011 \\
\hline A_23_P28598 & DLX2 & $-1,423$ & $7,181 e-5$ & $-0,992$ & $8,141 \mathrm{e}-3$ \\
\hline A_24_P45980 & DLX2 & $-1,346$ & $6,097 e-5$ & $-1,019$ & $3,823 e-3$ \\
\hline A_23_P40217 & DOK5 & $-0,710$ & 0,028 & $-1,495$ & $1,436 e-5$ \\
\hline A_23_P156880 & ENPP1 & $-1,457$ & $2,422 \mathrm{e}-4$ & $-1,531$ & $2,021 \mathrm{e}-4$ \\
\hline A_23_P144843 & ESM1 & $-1,021$ & 0,029 & $-3,302$ & $6,542 \mathrm{e}-8$ \\
\hline A_23_P43273 & EXT1 & $-1,228$ & 0,017 & $-1,323$ & 0,011 \\
\hline A_23_P62999 & EXTL1 & $-1,056$ & 0,019 & $-1,108$ & 0,016 \\
\hline A_24_P706340 & FAM155A & $-1,715$ & $1,541 \mathrm{e}-4$ & $-1,116$ & 0,018 \\
\hline A_32_P34444 & FHOD3 & $-1,093$ & $8,180 e-3$ & $-1,637$ & $1,655 \mathrm{e}-4$ \\
\hline A_32_P387648 & FLG & $-4,326$ & $1,577 \mathrm{e}-9$ & $-1,188$ & $5,666 e-3$ \\
\hline A_24_P34199 & FLG & $-4,291$ & $4,680 e-10$ & $-1,638$ & 4,879e-4 \\
\hline A_32_P34920 & FOXD1 & $-1,440$ & $2,808 \mathrm{e}-3$ & $-2,206$ & $3,675 e-5$ \\
\hline A_23_P26037 & FRMD5 & $-1,447$ & $1,224 \mathrm{e}-3$ & $-1,187$ & 0,012 \\
\hline A_24_P330303 & FRMD6 & $-1,211$ & 0,016 & $-1,422$ & $4,551 \mathrm{e}-3$ \\
\hline A_23_P110531 & FST & $-3,134$ & $4,405 e-7$ & $-2,276$ & $4,468 \mathrm{e}-5$ \\
\hline A_23_P396858 & FZD8 & $-1,057$ & 0,011 & $-2,559$ & $7,170 e-7$ \\
\hline A_23_P257043 & GEM & $-1,508$ & $4,686 e-4$ & $-1,103$ & 0,015 \\
\hline A_24_P931443 & GPR68 & $-4,408$ & $1,419 e-10$ & $-0,955$ & 0,019 \\
\hline A_23_P97181 & GREM2 & $-1,624$ & $9,484 e-3$ & $-1,936$ & 0,019 \\
\hline A_23_P329822 & GREM2 & $-1,443$ & $1,372 \mathrm{e}-4$ & $-1,030$ & $6,799 e-3$ \\
\hline A_23_P37856 & HBA1 & $-1,324$ & $3,820 \mathrm{e}-4$ & $-1,388$ & $3,258 \mathrm{e}-4$ \\
\hline A_24_P140608 & HBEGF & $-1,414$ & 2,981e-3 & $-1,793$ & $3,352 \mathrm{e}-4$ \\
\hline A_23_P148990 & HMCN1 & $-2,166$ & $1,838 e-5$ & $-1,205$ & 0,014 \\
\hline
\end{tabular}




\begin{tabular}{|c|c|c|c|c|c|}
\hline Agilent ID & Symbol & $\operatorname{logFC~BK2-1~}$ & FDR BK2-1 & $\operatorname{logFC}$ ZK2-1 & FDR ZK2-1 \\
\hline A_23_P120883 & HMOX1 & $-2,054$ & $3,880 e-6$ & $-1,946$ & $1,267 e-5$ \\
\hline A_23_P66525 & HS3ST3A1 & $-1,211$ & 0,017 & $-1,136$ & 0,038 \\
\hline A_23_P42257 & IER3 & $-2,613$ & $1,195 \mathrm{e}-6$ & $-1,456$ & $1,792 \mathrm{e}-3$ \\
\hline A_32_P145502 & IGFBP3 & $-0,926$ & 0,026 & $-3,595$ & $1,893 e-5$ \\
\hline A_23_P215634 & IGFBP3 & $-1,450$ & $1,971 \mathrm{e}-3$ & $-4,854$ & $1,777 e-9$ \\
\hline A_23_P383009 & IGFBP5 & $-1,937$ & 0,010 & $-2,061$ & $4,643 e-5$ \\
\hline A_23_P67169 & IL11 & $-1,970$ & $3,055 e-5$ & $-3,134$ & $1,368 \mathrm{e}-7$ \\
\hline A_23_P35444 & INA & $-1,036$ & $2,090 e-3$ & $-0,839$ & 0,021 \\
\hline A_23_P122924 & INHBA & $-3,072$ & $4,908 e-7$ & $-1,529$ & $3,081 e-3$ \\
\hline A_32_P208076 & ITGA2 & $-1,523$ & $1,607 e-3$ & $-1,259$ & 0,014 \\
\hline A_23_P67529 & KCNN4 & $-2,167$ & $1,227 e-7$ & $-1,128$ & $6,029 e-4$ \\
\hline A_23_P48327 & KCTD4 & $-0,993$ & $2,460 e-3$ & $-1,118$ & $9,890 e-4$ \\
\hline A_23_P66798 & KRT19 & $-3,073$ & $1,775 e-8$ & $-1,917$ & $1,389 e-5$ \\
\hline A_23_P101054 & KRT34 & $-1,215$ & 0,032 & $-2,491$ & $2,558 e-5$ \\
\hline A_23_P141624 & KRTAP1-1 & $-2,513$ & $1,874 \mathrm{e}-6$ & $-1,955$ & $6,589 e-5$ \\
\hline A_32_P24376 & KRTAP2-4 & $-2,292$ & $3,714 \mathrm{e}-5$ & $-3,078$ & $1,477 e-6$ \\
\hline A_32_P24382 & KRTAP2-4 & $-2,412$ & $7,756 \mathrm{e}-7$ & $-2,455$ & $1,175 e-6$ \\
\hline A_32_P82462 & LOC554202 & $-1,211$ & $8,588 e-4$ & $-1,214$ & $1,230 e-3$ \\
\hline A_24_P827037 & LRRC15 & $-2,388$ & $2,081 e-6$ & $-4,167$ & $3,310 e-9$ \\
\hline A_23_P419696 & LYPD1 & $-3,128$ & $4,167 e-9$ & $-1,033$ & $4,039 e-3$ \\
\hline A_23_P102681 & MGC4294 & $-1,203$ & $4,796 e-4$ & $-0,796$ & 0,038 \\
\hline A_23_P1691 & MMP1 & $-2,941$ & $1,254 \mathrm{e}-7$ & $-2,233$ & $8,498 e-6$ \\
\hline A_24_P82106 & MMP14 & $-1,153$ & 0,029 & $-1,202$ & 0,026 \\
\hline A_23_P163787 & MMP2 & $-1,989$ & $3,094 e-5$ & $-1,314$ & $4,167 e-3$ \\
\hline A_24_P264832 & NEFM & $-1,669$ & $3,716 e-4$ & $-4,333$ & $4,191 e-9$ \\
\hline A_23_P107351 & NLRP1 & $-3,202$ & $6,159 e-9$ & $-1,124$ & $3,304 e-3$ \\
\hline A_23_P420873 & NR1D1 & $-1,738$ & $2,033 e-6$ & $-1,619$ & $8,335 e-6$ \\
\hline A_23_P136493 & NRG1 & $-1,980$ & $1,461 \mathrm{e}-4$ & $-2,381$ & $1,515 e-6$ \\
\hline A_23_P360777 & NRG1 & $-2,982$ & $4,926 e-8$ & $-3,101$ & $9,652 e-7$ \\
\hline A_23_P315815 & NRG1 & $-2,153$ & $3,740 e-8$ & $-3,056$ & $1,523 e-9$ \\
\hline A_23_P84063 & NTM & $-2,011$ & $3,536 e-4$ & $-1,315$ & 0,032 \\
\hline A_23_P201547 & NTNG1 & $-0,897$ & 0,026 & $-1,346$ & $6,392 e-4$ \\
\hline A_32_P160563 & OPCML & $-1,455$ & $2,213 e-4$ & $-1,370$ & $6,196 e-4$ \\
\hline A_23_P24104 & PLAU & $-2,267$ & $8,071 e-5$ & $-1,311$ & 0,031 \\
\hline A_23_P215060 & PODXL & $-0,934$ & 0,042 & $-5,212$ & $2,225 e-10$ \\
\hline A_24_P810290 & PPAPDC1A & $-1,499$ & $1,282 \mathrm{e}-3$ & $-1,219$ & 0,014 \\
\hline A_23_P218774 & RAC2 & $-1,066$ & 0,028 & $-0,871$ & 0,012 \\
\hline A_23_P76731 & RAGE & $-0,750$ & 0,037 & $-1,516$ & $3,675 e-5$ \\
\hline A_23_P58796 & RGMB & $-2,462$ & $3,931 e-5$ & $-2,276$ & $1,446 e-4$ \\
\hline A_24_P402510 & SAMD11 & $-1,397$ & $2,561 \mathrm{e}-4$ & $-2,144$ & $2,180 e-6$ \\
\hline A_24_P686965 & SH2D5 & $-0,913$ & $3,805 e-3$ & $-0,921$ & $4,630 e-3$ \\
\hline A_23_P100754 & SMURF2 & $-1,173$ & $2,579 e-3$ & $-2,015$ & $8,335 e-6$ \\
\hline A_23_P38106 & SPHK1 & $-1,817$ & $6,840 e-4$ & $-2,203$ & $1,124 \mathrm{e}-4$ \\
\hline A_24_P354689 & SPOCK1 & $-2,021$ & $7,304 e-5$ & $-2,061$ & $8,511 e-5$ \\
\hline A_32_P40288 & TMEM200A & $-1,707$ & $1,014 \mathrm{e}-5$ & $-1,026$ & $4,405 e-3$ \\
\hline A_23_P157865 & TNC & $-1,846$ & $1,139 e-4$ & $-2,279$ & $1,428 e-5$ \\
\hline A_23_P363344 & TPM1 & $-1,231$ & $3,045 e-3$ & $-1,901$ & $9,057 e-6$ \\
\hline A_32_P185140 & TPM1 & $-2,155$ & $2,420 e-4$ & $-2,503$ & $1,239 e-6$ \\
\hline
\end{tabular}




\begin{tabular}{|l|l|c|c|c|c|}
\hline Agilent ID & Symbol & logFC BK2-1 & FDR BK2-1 & logFC ZK2-1 & FDR ZK2-1 \\
\hline A_23_P167096 & VEGFC & $-1,483$ & $2,580 \mathrm{e}-4$ & $-1,828$ & $3,595 \mathrm{e}-5$ \\
A_23_P320054 & WNT7B & $-2,253$ & $1,709 \mathrm{e}-7$ & $-0,835$ & 0,023 \\
\hline
\end{tabular}

Tabelle A-13: Gene der Stro- $1^{+}-$Beckenkamm- und -Zahnkeimzellen mit beidseits signifikanten logFC-Werten, die sich gegensinnig verhalten $(n=16)$. Positive logFC-Werte stehen für eine Hochregulation im ODM gegenüber dem DMEM, negative logFC-Werte für eine Herunterregulation.

\begin{tabular}{|l|l|c|c|c|c|}
\hline Agilent ID & Symbol & logFC BK2-1 & FDR BK2-1 & logFC ZK2-1 & FDR ZK2-1 \\
\hline A_32_P164246 & FOXQ1 & $-2,365$ & $6,317 \mathrm{e}-7$ & 1,394 & $6,330 \mathrm{e}-4$ \\
A_23_P17998 & HES1 & $-1,522$ & $1,133 \mathrm{e}-3$ & 1,061 & 0,048 \\
A_32_P161855 & KIAA1199 & $-1,427$ & $1,080 \mathrm{e}-3$ & 1,160 & 0,012 \\
A_24_P766716 & CMKLR1 & $-1,330$ & 0,022 & 1,275 & 0,041 \\
A_23_P89431 & CCL2 & $-1,301$ & $8,032 \mathrm{e}-3$ & 2,221 & $3,595 \mathrm{e}-5$ \\
A_24_P915692 & PHLDA1 & $-1,253$ & $5,752 \mathrm{e}-3$ & 1,023 & 0,046 \\
A_24_P408047 & PLEKHA4 & $-0,965$ & $5,356 \mathrm{e}-3$ & 1,253 & $4,879 \mathrm{e}-4$ \\
\hline A_23_P39955 & ACTG2 & 1,994 & $3,082 \mathrm{e}-6$ & $-1,161$ & $2,416 \mathrm{e}-3$ \\
A_23_P85250 & CD24 & 1,390 & 0,015 & $-1,952$ & $6,440 \mathrm{e}-4$ \\
A_23_P146134 & DUSP26 & 1,105 & 0,039 & $-1,211$ & 0,024 \\
A_23_P128084 & ITGA7 & 1,230 & $1,926 \mathrm{e}-3$ & $-1,128$ & $6,207 \mathrm{e}-3$ \\
A_23_P209669 & NRP2 & 0,797 & 0,029 & $-0,861$ & 0,019 \\
A_23_P128230 & NR4A1 & 1,587 & $3,856 \mathrm{e}-4$ & $-1,499$ & $1,021 \mathrm{e}-3$ \\
A_23_P7313 & SPP1 & 0,759 & 0,031 & $-1,707$ & $7,853 \mathrm{e}-6$ \\
A_24_P317907 & SORBS1 & 2,114 & 0,043 & $-0,967$ & 0,015 \\
A_23_P30666 & TNFRSF21 & 1,042 & $8,120 \mathrm{e}-3$ & $-1,245$ & $1,821 \mathrm{e}-3$ \\
\hline
\end{tabular}


Tabelle A-14: Funktionelle Gruppen der Gene, die bei den Stro- $1^{+}$-Beckenkamm- und -Zahnkeimzellen im ODM gleichsinnig signifikant hochreguliert sind $(n=130)$. In der Tabelle sind von insgesamt 20 clustern nur die ersten drei mit den höchsten enrichment scores dargestellt.

\section{Functional Annotation Clustering}

\begin{tabular}{|c|c|c|c|c|c|c|}
\hline Annotation Cluster 1 & Enrichment Score: 4.25 & (도 & 3 & Count & P_Value & Benjamini \\
\hline UP_KEYWORDS & Extracellular matrix & RT & $\equiv$ & 10 & $1.7 \mathrm{E}-5$ & $3.6 \mathrm{E}-3$ \\
\hline GOTERM_CC_DIRECT & proteinaceous extracellular matrix & $\underline{\mathbf{R T}}$ & $\equiv$ & 10 & $4.1 \mathrm{E}-5$ & $5.3 \mathrm{E}-3$ \\
\hline Annotation Cluster 2 & Enrichment Score: $\mathbf{2 . 3 7}$ & (⿷) & 7 & Count & P_Value & Benjamini \\
\hline UP_KEYWORDS & Secreted & $\underline{\mathbf{R T}}$ & $\bar{\equiv}$ & 25 & $2.5 \mathrm{E}-4$ & $2.6 \mathrm{E}-2$ \\
\hline GOTERM_CC_DIRECT & extracellular space & $\underline{\mathbf{R T}}$ & $\bar{\square}$ & 20 & $5.3 \mathrm{E}-4$ & $3.3 \mathrm{E}-2$ \\
\hline UP_SEQ_FEATURE & signal peptide & $\underline{\mathbf{R T}}$ & $\overline{2}$ & 33 & $2.8 \mathrm{E}-3$ & $4.2 \mathrm{E}-1$ \\
\hline UP_KEYWORDS & Glycoprotein & $\underline{\mathbf{R T}}$ & $\bar{\equiv}$ & 40 & $3.4 \mathrm{E}-3$ & $1.1 \mathrm{E}-1$ \\
\hline UP_SEQ_FEATURE & disulfide bond & $\underline{\mathbf{R T}}$ & $\bar{\equiv}$ & 28 & $1.0 \mathrm{E}-2$ & $6.9 \mathrm{E}-1$ \\
\hline UP_KEYWORDS & Signal & $\underline{\mathbf{R T}}$ & $\overline{\overline{20}}$ & 35 & $1.4 \mathrm{E}-2$ & $3.1 \mathrm{E}-1$ \\
\hline UP_SEQ_FEATURE & glycosylation site: $\mathrm{N}$-linked (GIcNAc...) & $\underline{\mathbf{R T}}$ & $\bar{\equiv}$ & 35 & $2.9 \mathrm{E}-2$ & $7.0 \mathrm{E}-1$ \\
\hline GOTERM_CC_DIRECT & Golgi lumen & $\underline{\mathbf{R T}}$ & 三 & 4 & $2.1 \mathrm{E}-2$ & $4.2 \mathrm{E}-1$ \\
\hline GOTERM_CC_DIRECT & Iysosomal lumen & $\underline{\mathbf{R T}}$ & ב & 3 & $9.6 \mathrm{E}-2$ & $7.3 \mathrm{E}-1$ \\
\hline Annotation Cluster 4 & Enrichment Score: 1.52 & (단 & 7 & Count & P_Value & Benjamini \\
\hline
\end{tabular}

\section{Functional Annotation Chart}

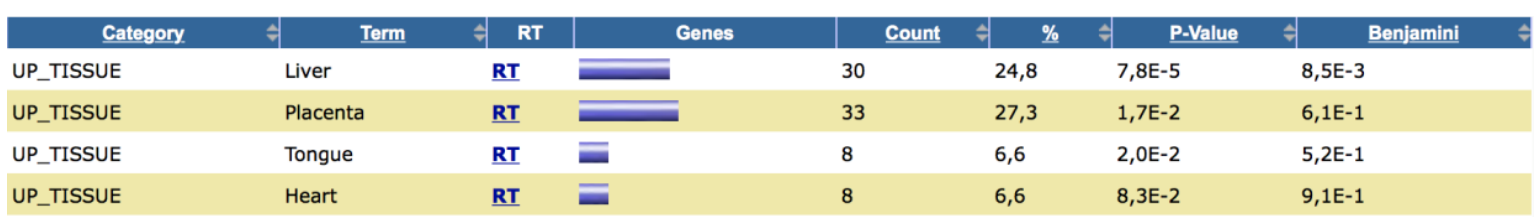


Tabelle A-15: Funktionelle Gruppen der Gene, die bei den Stro- $1^{+}-$Beckenkamm- und -Zahnkeimzellen im ODM gleichsinnig signifikant herunterreguliert sind $(n=94)$. In der Tabelle sind beide ermittelten cluster dargestellt.

\section{Functional Annotation Clustering}

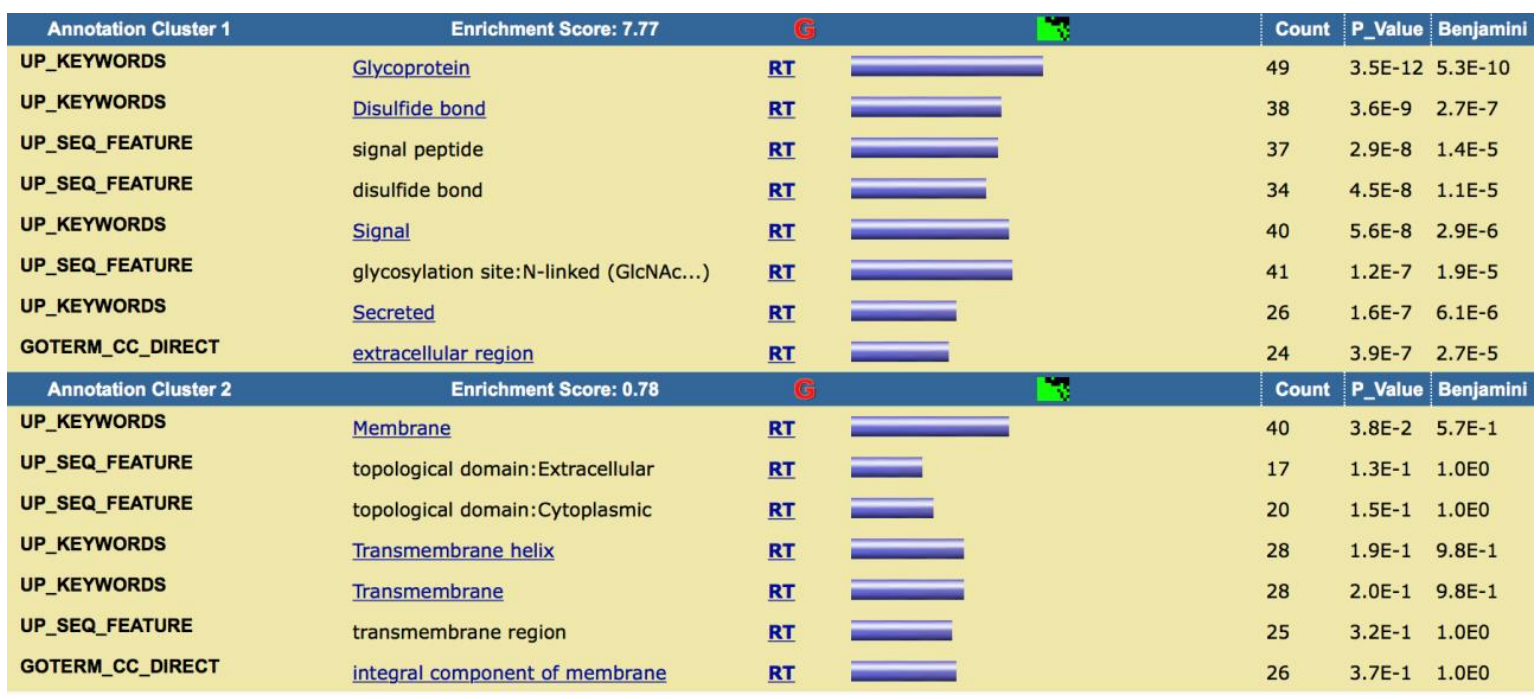

\section{Functional Annotation Chart}

\begin{tabular}{|c|c|c|c|c|c|c|c|}
\hline Category & Term & $\Leftrightarrow \quad R T$ & Genes & Count & $\Leftrightarrow$ & P-Value & Benjamini \\
\hline UP_TISSUE & Foreskin & RT & ㅍ & 3 & 3,4 & $2,5 \mathrm{E}-2$ & $9,4 \mathrm{E}-1$ \\
\hline UP_TISSUE & Scalp & $\underline{\text { RT }}$ & $\overline{\mathbf{E}}$ & 3 & 3,4 & $3,8 \mathrm{E}-2$ & $8,8 \mathrm{E}-1$ \\
\hline UP_TISSUE & Fetal brain & $\underline{\mathbf{R T}}$ & $\bar{\equiv}$ & 8 & 9,1 & $6,2 \mathrm{E}-2$ & $8,3 E-1$ \\
\hline UP_TISSUE & Melanoma & $\underline{\mathbf{R T}}$ & $\equiv$ & 5 & 5,7 & $6,9 E-2$ & $7,9 \mathrm{E}-1$ \\
\hline
\end{tabular}


Tabelle A-16: Funktionelle Gruppen der Gene, die bei den Stro-1 ${ }^{+}$-Zellen aus dem Beckenkamm signifikant hochreguliert und den Zahnkeimen signifikant herunterreguliert sind, sich in ihrer Expression also gegensinnig verhalten $(n=9)$. In der Tabelle sind beide ermittelten cluster dargestellt.

\section{Functional Annotation Clustering}

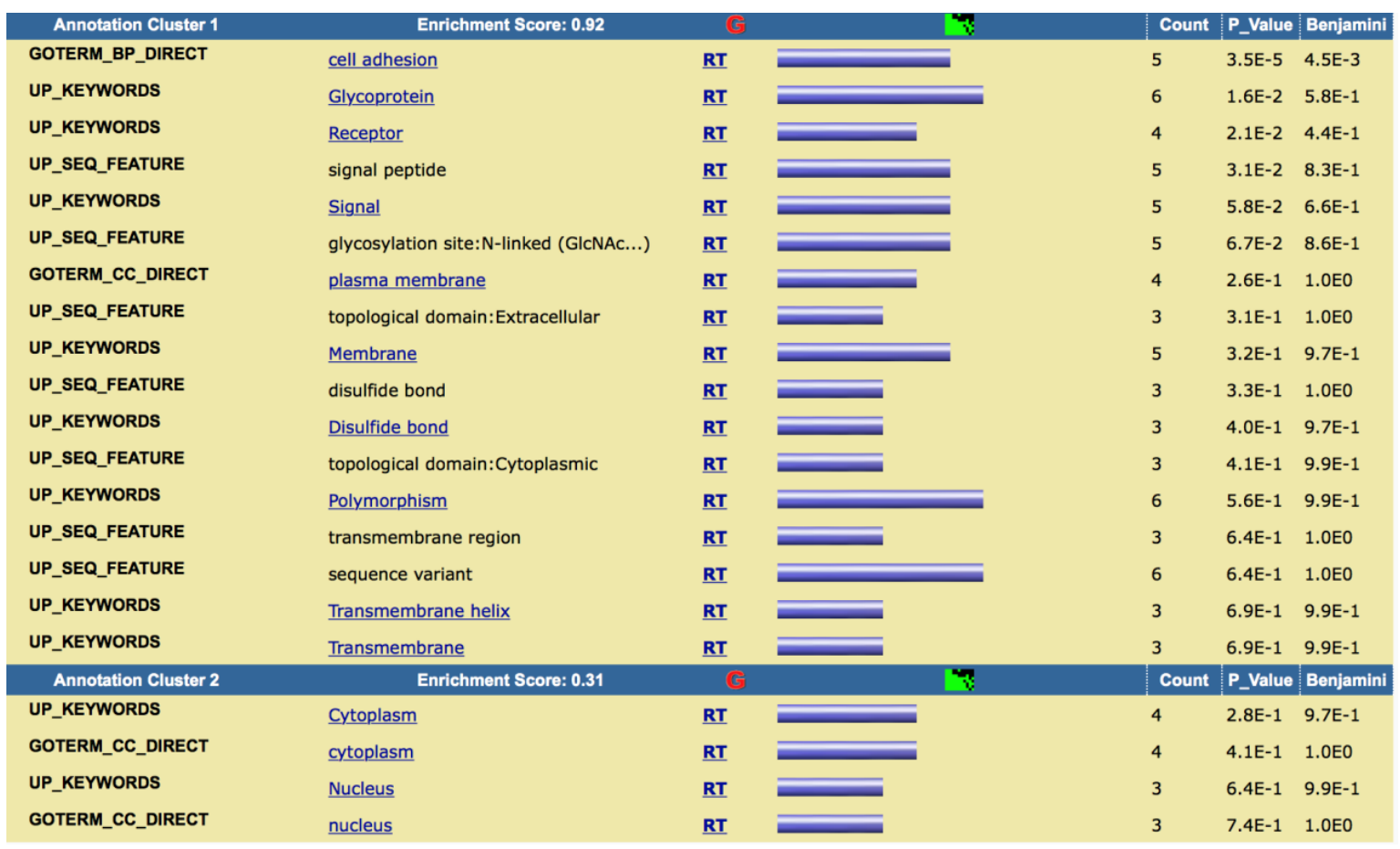

\section{Functional Annotation Chart}

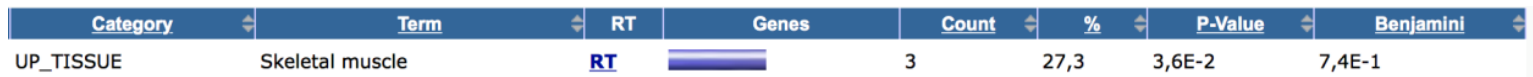

Tabelle A-17: Funktionelle Gruppen der Gene, die bei den Stro- $1^{+}$-Zellen aus dem Beckenkamm signifikant herunterreguliert und den Zahnkeimen signifikant hochreguliert sind, sich in ihrer Expression also gegensinnig verhalten $(n=7)$. Es wurde nur ein cluster ermittelt. Für die Functional Annotation Chart konnten keine Gengruppen für eine Überexpression in bestimmten Geweben ermittelt werden.

\section{Functional Annotation Clustering}

\begin{tabular}{|c|c|c|c|c|c|c|}
\hline Annotation Cluster 1 & Enrichment Score: 0.11 & (G) & & Count & P_Value & Benjamini \\
\hline UP_KEYWORDS & Membrane & RT & $\bar{\square}$ & 3 & $7.1 \mathrm{E}-1$ & $1.0 \mathrm{EO}$ \\
\hline UP_SEQ_FEATURE & splice variant & $\underline{\mathbf{R T}}$ & $\bar{\square}$ & 3 & $7.5 \mathrm{E}-1$ & $1.0 \mathrm{EO}$ \\
\hline
\end{tabular}


Tabelle A-18: Die 109 Gene der Stro- $1^{+}$-Zahnkeimzellen, die gegenüber den Stro- $1^{+}$ Beckenkammzellen im ODM hochreguliert sind. Die Gene sind nach der Höhe der FDR aufsteigend sortiert. Die Auswahlkriterien waren $|\log F C|>2$ und FDR $\leq 0,01$.

\begin{tabular}{|c|c|c|c|c|}
\hline AgilentID & Symbol & Genname & $\operatorname{logFC~ZK2-BK2~}$ & FDR ZK2-BK2 \\
\hline A_23_P337262 & APCDD1 & adenomatosis polyposis coli down-regulated 1 & 6,374 & $2,83 \mathrm{E}-12$ \\
\hline A_23_P372834 & AQP1 & aquaporin 1 (Colton blood group) & 6,634 & $5,35 \mathrm{E}-11$ \\
\hline A_23_P67847 & GALNT14 & $\begin{array}{l}\text { UDP-N-acetyl-alpha-D-galactosamine:polypeptide N- } \\
\text { acetylgalactosaminyltransferase } 14 \text { (GalNAc-T14) }\end{array}$ & 4,469 & $6,64 \mathrm{E}-11$ \\
\hline A_23_P154566 & TOX2 & TOX high mobility group box family member 2 & 3,317 & $1,21 \mathrm{E}-10$ \\
\hline A_23_P118254 & FOXF1 & forkhead box F1 & 3,426 & $1,66 \mathrm{E}-10$ \\
\hline A_23_P19894 & AQP1 & aquaporin 1 (Colton blood group) & 4,947 & $3,49 \mathrm{E}-10$ \\
\hline A_23_P94800 & S100A4 & S100 calcium binding protein A4 & 5,011 & $4,81 \mathrm{E}-10$ \\
\hline A_23_P79482 & CHN1 & chimerin (chimaerin) 1 & 4,172 & $6,15 \mathrm{E}-10$ \\
\hline A_23_P145054 & FAM162B & family with sequence similarity 162 , member $B$ & 4,263 & $1,61 \mathrm{E}-09$ \\
\hline A_32_P208350 & TDRD9 & tudor domain containing 9 & 3,280 & $2,38 \mathrm{E}-09$ \\
\hline A_23_P257924 & ETS2 & $\begin{array}{l}\text { v-ets erythroblastosis virus E26 oncogene homolog } 2 \\
\text { (avian) }\end{array}$ & 2,643 & 2,61E-09 \\
\hline A_24_P500584 & XIST & X (inactive)-specific transcript (non-protein coding) & 7,301 & $2,77 \mathrm{E}-09$ \\
\hline A_24_P260101 & MME & membrane metallo-endopeptidase & 3,474 & $5,05 E-09$ \\
\hline A_23_P384044 & $\mathrm{CNIH} 3$ & cornichon homolog 3 (Drosophila) & 4,013 & $7,28 \mathrm{E}-09$ \\
\hline A_23_P212800 & FGF5 & fibroblast growth factor 5 & 3,157 & $7,28 \mathrm{E}-09$ \\
\hline A_23_P32279 & BARX1 & BARX homeobox 1 & 4,074 & $8,18 \mathrm{E}-09$ \\
\hline A_23_P110430 & MSX1 & msh homeobox 1 & 3,816 & $1,07 E-08$ \\
\hline A_23_P205713 & STXBP6 & syntaxin binding protein 6 (amisyn) & 2,762 & $1,09 \mathrm{E}-08$ \\
\hline A_23_P4536 & EPB41L3 & erythrocyte membrane protein band 4.1-like 3 & 2,567 & $1,15 \mathrm{E}-08$ \\
\hline A_32_P142818 & DLX1 & distal-less homeobox 1 & 2,639 & $1,40 \mathrm{E}-08$ \\
\hline A_23_P144326 & ASB5 & ankyrin repeat and SOCS box-containing 5 & 4,178 & $1,58 \mathrm{E}-08$ \\
\hline A_23_P303087 & PTN & pleiotrophin & 3,662 & $2,04 \mathrm{E}-08$ \\
\hline A_23_P200015 & AK5 & adenylate kinase 5 & 2,700 & $2,31 \mathrm{E}-08$ \\
\hline A_23_P110957 & FOXF2 & forkhead box F2 & 4,116 & $2,33 \mathrm{E}-08$ \\
\hline A_24_P375691 & LOC100131606 & hypothetical protein LOC100131606 & 2,279 & $2,47 \mathrm{E}-08$ \\
\hline A_24_P64167 & PTGS1 & $\begin{array}{l}\text { prostaglandin-endoperoxide synthase } 1 \text { (prostaglandin } \\
\text { G/H synthase and cyclooxygenase) }\end{array}$ & 2,853 & $3,03 E-08$ \\
\hline A_23_P103672 & NES & nestin & 3,082 & $4,63 \mathrm{E}-08$ \\
\hline A_23_P34744 & CTSK & cathepsin K & 4,055 & $6,04 \mathrm{E}-08$ \\
\hline A_23_P120472 & TFAP2C & $\begin{array}{l}\text { transcription factor AP-2 gamma (activating enhancer } \\
\text { binding protein } 2 \text { gamma) }\end{array}$ & 2,246 & $6,48 \mathrm{E}-08$ \\
\hline A_23_P213562 & $\mathrm{F} 2 \mathrm{R}$ & coagulation factor II (thrombin) receptor & 3,044 & $6,50 \mathrm{E}-08$ \\
\hline A_23_P216655 & TRIM14 & tripartite motif-containing 14 & 2,029 & $7,44 \mathrm{E}-08$ \\
\hline A_24_P10214 & STXBP6 & syntaxin binding protein 6 (amisyn) & 2,251 & $8,18 \mathrm{E}-08$ \\
\hline A_24_P870620 & PTN & pleiotrophin & 3,377 & $8,48 \mathrm{E}-08$ \\
\hline A_23_P19987 & IGF2BP3 & insulin-like growth factor 2 mRNA binding protein 3 & 3,647 & $1,04 \mathrm{E}-07$ \\
\hline A_24_P882959 & LOC284344 & hypothetical protein LOC284344 & 2,550 & $1,08 \mathrm{E}-07$ \\
\hline A_23_P216966 & PTGS1 & $\begin{array}{l}\text { prostaglandin-endoperoxide synthase } 1 \text { (prostaglandin } \\
\text { G/H synthase and cyclooxygenase) }\end{array}$ & 3,716 & $1,64 \mathrm{E}-07$ \\
\hline A_23_P156861 & RGS17 & regulator of G-protein signaling 17 & 2,073 & $1,84 \mathrm{E}-07$ \\
\hline A_23_P28898 & PLCB4 & phospholipase C, beta 4 & 3,143 & $2,62 \mathrm{E}-07$ \\
\hline A_23_P383819 & TBX3 & T-box 3 & 2,077 & $2,73 \mathrm{E}-07$ \\
\hline A_23_P211212 & COL18A1 & collagen, type XVIII, alpha 1 & 3,365 & $2,74 \mathrm{E}-07$ \\
\hline A_23_P362719 & LSM14B & LSM14B, SCD6 homolog B (S. cerevisiae) & 2,774 & $2,95 \mathrm{E}-07$ \\
\hline A_23_P258136 & MXRA5 & matrix-remodelling associated 5 & 3,079 & $3,09 E-07$ \\
\hline
\end{tabular}




\begin{tabular}{|c|c|c|c|c|}
\hline AgilentID & Symbol & Genname & $\operatorname{logFC~ZK2-BK2~}$ & FDR ZK2-BK2 \\
\hline A_24_P233786 & FAM129A & family with sequence similarity 129 , member $A$ & 2,111 & $3,53 \mathrm{E}-07$ \\
\hline A_32_P60065 & F2RL2 & coagulation factor II (thrombin) receptor-like 2 & 2,437 & 3,97E-07 \\
\hline A_24_P664891 & COX6A1 & cytochrome c oxidase subunit Vla polypeptide 1 & 3,164 & $5,42 \mathrm{E}-07$ \\
\hline A_23_P251421 & CDCA7 & cell division cycle associated 7 & 3,014 & $5,57 \mathrm{E}-07$ \\
\hline A_23_P45365 & COL4A5 & collagen, type IV, alpha 5 & 2,481 & $6,37 \mathrm{E}-07$ \\
\hline A_23_P317591 & SEMA3A & $\begin{array}{l}\text { sema domain, immunoglobulin domain (Ig), short basic } \\
\text { domain, secreted, (semaphorin) } 3 \mathrm{~A}\end{array}$ & 2,185 & $6,45 \mathrm{E}-07$ \\
\hline A_23_P76914 & SIX1 & SIX homeobox 1 & 2,703 & $8,67 \mathrm{E}-07$ \\
\hline A_23_P214144 & COL10A1 & collagen, type $X$, alpha 1 & 2,636 & $1,15 \mathrm{E}-06$ \\
\hline A_23_P408996 & MBOAT1 & $\begin{array}{l}\text { membrane bound O-acyltransferase domain containing } \\
1\end{array}$ & 2,605 & $1,16 \mathrm{E}-06$ \\
\hline A_24_P314179 & ETS2 & $\begin{array}{l}\text { v-ets erythroblastosis virus E26 oncogene homolog } 2 \\
\text { (avian) }\end{array}$ & 2,364 & $1,47 \mathrm{E}-06$ \\
\hline A_32_P70818 & PAX9 & paired box 9 & 3,367 & $1,64 \mathrm{E}-06$ \\
\hline A_23_P127911 & DKFZP586H2123 & regeneration associated muscle protease & 2,042 & $1,65 \mathrm{E}-06$ \\
\hline A_32_P29118 & SEMA3D & $\begin{array}{l}\text { sema domain, immunoglobulin domain (Ig), short basic } \\
\text { domain, secreted, (semaphorin) 3D }\end{array}$ & 2,032 & $2,00 \mathrm{E}-06$ \\
\hline A_32_P208076 & ITGA2 & $\begin{array}{l}\text { integrin, alpha } 2 \text { (CD49B, alpha } 2 \text { subunit of VLA-2 } \\
\text { receptor) }\end{array}$ & 2,479 & $2,20 \mathrm{E}-06$ \\
\hline A_23_P110531 & FST & follistatin & 2,576 & $2,36 \mathrm{E}-06$ \\
\hline A_23_P214026 & FBN2 & fibrillin 2 & 2,984 & $2,45 \mathrm{E}-06$ \\
\hline A_23_P30315 & TRIM7 & tripartite motif-containing 7 & 2,128 & $2,73 E-06$ \\
\hline A_23_P256470 & NPY & neuropeptide $Y$ & 3,493 & $2,78 \mathrm{E}-06$ \\
\hline A_32_P34444 & FHOD3 & formin homology 2 domain containing 3 & 2,034 & $3,05 \mathrm{E}-06$ \\
\hline A_23_P316612 & GLIS1 & GLIS family zinc finger 1 & 2,209 & $3,24 \mathrm{E}-06$ \\
\hline A_24_P115762 & CTSC & cathepsin C & 2,177 & $3,92 \mathrm{E}-06$ \\
\hline A_24_P915692 & PHLDA1 & pleckstrin homology-like domain, family A, member 1 & 2,197 & $3,97 \mathrm{E}-06$ \\
\hline A_23_P16944 & SDC1 & syndecan 1 & 3,025 & 4,47E-06 \\
\hline A_23_P212061 & MME & membrane metallo-endopeptidase & 2,667 & $5,50 \mathrm{E}-06$ \\
\hline A_24_P345837 & MSX1 & msh homeobox 1 & 2,419 & $5,50 \mathrm{E}-06$ \\
\hline A_23_P124905 & NPTX1 & neuronal pentraxin I & 2,467 & $5,85 \mathrm{E}-06$ \\
\hline A_23_P1331 & COL13A1 & collagen, type XIII, alpha 1 & 2,440 & $6,37 \mathrm{E}-06$ \\
\hline A_23_P255331 & C4orf49 & chromosome 4 open reading frame 49 & 2,410 & $6,64 \mathrm{E}-06$ \\
\hline A_23_P125383 & TMEFF2 & $\begin{array}{l}\text { transmembrane protein with EGF-like and two follistat- } \\
\text { in-like domains } 2\end{array}$ & 2,247 & $7,12 \mathrm{E}-06$ \\
\hline A_24_P197964 & TRIM14 & tripartite motif-containing 14 & 2,081 & $8,54 \mathrm{E}-06$ \\
\hline A_23_P108170 & PSG6 & pregnancy specific beta-1-glycoprotein 6 & 2,268 & $8,91 \mathrm{E}-06$ \\
\hline A_24_P942493 & WSCD1 & WSC domain containing 1 & 2,049 & $8,96 \mathrm{E}-06$ \\
\hline A_23_P323930 & TSPAN5 & tetraspanin 5 & 2,124 & $9,26 \mathrm{E}-06$ \\
\hline A_23_P128974 & BATF & basic leucine zipper transcription factor, ATF-like & 2,460 & $1,03 E-05$ \\
\hline A_23_P45324 & TMEM35 & transmembrane protein 35 & 2,749 & $1,07 E-05$ \\
\hline A_23_P164451 & TBX2 & T-box 2 & 2,227 & $1,15 \mathrm{E}-05$ \\
\hline A_23_P258493 & LMNB1 & lamin B1 & 2,270 & $1,34 \mathrm{E}-05$ \\
\hline A_23_P55544 & CCBE1 & collagen and calcium binding EGF domains 1 & 2,771 & 1,37E-05 \\
\hline A_24_P90005 & COL13A1 & collagen, type XIII, alpha 1 & 2,189 & $1,41 \mathrm{E}-05$ \\
\hline A_23_P21324 & TWIST2 & twist homolog 2 (Drosophila) & 2,744 & $1,58 \mathrm{E}-05$ \\
\hline A_24_P234196 & RRM2 & ribonucleotide reductase $\mathrm{M} 2$ polypeptide & 2,569 & $1,68 \mathrm{E}-05$ \\
\hline A_23_P42718 & NFE2L3 & nuclear factor (erythroid-derived 2)-like 3 & 2,029 & $1,78 \mathrm{E}-05$ \\
\hline A_24_P302172 & PTGFR & prostaglandin F receptor (FP) & 2,273 & $1,93 \mathrm{E}-05$ \\
\hline A_24_P360269 & RNASET2 & ribonuclease $\mathrm{T} 2$ & 2,410 & $2,23 \mathrm{E}-05$ \\
\hline A_24_P20630 & LEF1 & lymphoid enhancer-binding factor 1 & 2,377 & $2,29 \mathrm{E}-05$ \\
\hline A_23_P432947 & GREM1 & $\begin{array}{l}\text { gremlin 1, cysteine knot superfamily, homolog } \\
\text { (Xenopus laevis) }\end{array}$ & 3,065 & $2,93 \mathrm{E}-05$ \\
\hline
\end{tabular}




\begin{tabular}{|c|c|c|c|c|}
\hline AgilentID & Symbol & Genname & $\operatorname{logFC} Z K 2-B K 2$ & FDR ZK2-BK2 \\
\hline A_23_P252449 & HNRNPAO & heterogeneous nuclear ribonucleoprotein $\mathrm{AO}$ & 2,070 & $3,12 \mathrm{E}-05$ \\
\hline A_23_P204133 & GALNT6 & $\begin{array}{l}\text { UDP-N-acetyl-alpha-D-galactosamine:polypeptide N- } \\
\text { acetylgalactosaminyltransferase } 6 \text { (GalNAc-T6) }\end{array}$ & 2,146 & $3,20 \mathrm{E}-05$ \\
\hline A_23_P76364 & $\mathrm{CD} 9$ & CD9 molecule & 2,025 & $3,45 \mathrm{E}-05$ \\
\hline A_23_P66017 & PRRT2 & proline-rich transmembrane protein 2 & 2,151 & $3,96 \mathrm{E}-05$ \\
\hline A_32_P108277 & SLC8A1 & $\begin{array}{l}\text { solute carrier family } 8 \text { (sodium/calcium exchanger), } \\
\text { member } 1\end{array}$ & 2,150 & $8,02 \mathrm{E}-05$ \\
\hline A_23_P433016 & FBLN1 & fibulin 1 & 2,095 & $9,38 \mathrm{E}-05$ \\
\hline A_24_P401855 & FGF5 & fibroblast growth factor 5 & 2,750 & $1,02 \mathrm{E}-04$ \\
\hline A_24_P53976 & GLUL & glutamate-ammonia ligase (glutamine synthetase) & 2,270 & $1,13 \mathrm{E}-04$ \\
\hline A_32_P62997 & PBK & PDZ binding kinase & 2,524 & $1,46 \mathrm{E}-04$ \\
\hline A_24_P918317 & DKK3 & dickkopf homolog 3 (Xenopus laevis) & 2,241 & $1,77 \mathrm{E}-04$ \\
\hline A_24_P350589 & RNF150 & ring finger protein 150 & 2,029 & $2,36 \mathrm{E}-04$ \\
\hline A_23_P75002 & MKX & mohawk homeobox & 2,330 & $3,13 \mathrm{E}-04$ \\
\hline A_23_P118834 & TOP2A & topoisomerase (DNA) II alpha 170kDa & 2,077 & $5,25 \mathrm{E}-04$ \\
\hline A_23_P76450 & PHLDA1 & pleckstrin homology-like domain, family A, member 1 & 2,224 & $5,32 \mathrm{E}-04$ \\
\hline A_24_P187218 & PCDH9 & protocadherin 9 & 2,068 & $6,94 \mathrm{E}-04$ \\
\hline A_23_P132619 & OXTR & oxytocin receptor & 2,418 & $7,99 \mathrm{E}-04$ \\
\hline A_32_P138348 & LY6K & lymphocyte antigen 6 complex, locus $\mathrm{K}$ & 2,146 & $8,99 \mathrm{E}-04$ \\
\hline A_24_P261417 & DKK3 & dickkopf homolog 3 (Xenopus laevis) & 2,235 & $2,70 \mathrm{E}-03$ \\
\hline A_24_P914434 & GSTM3 & glutathione S-transferase mu 3 (brain) & 2,012 & $4,04 \mathrm{E}-03$ \\
\hline A_23_P94255 & TRPA1 & $\begin{array}{l}\text { transient receptor potential cation channel, subfamily } \\
\text { A, member } 1\end{array}$ & 2,045 & $9,22 \mathrm{E}-03$ \\
\hline A_23_P361085 & SNHG5 & small nucleolar RNA host gene 5 (non-protein coding) & 2,335 & $9,33 \mathrm{E}-03$ \\
\hline
\end{tabular}

Tabelle A-19: Die 266 Gene der Stro- $1^{+}$-Beckenkammzellen, die gegenüber den Stro- $1^{+}-$ Zahnkeimzellen im ODM hochreguliert sind. Die Gene sind nach der Höhe der FDR aufsteigend sortiert. Die Auswahlkriterien waren $|\log F C|>2$ und FDR $\leq 0,01$.

\begin{tabular}{|l|l|l|c|c|}
\hline AgilentID & Symbol & Genname & logFC ZK2-BK2 & FDR ZK2-BK2 \\
\hline A_23_P324384 & RPS4Y2 & ribosomal protein S4, Y-linked 2 & $-8,315$ & $5,50 \mathrm{E}-14$ \\
A_24_P264943 & COMP & cartilage oligomeric matrix protein & $-7,208$ & $2,25 \mathrm{E}-12$ \\
A_23_P307310 & ACAN & aggrecan & $-8,333$ & $6,58 \mathrm{E}-12$ \\
A_23_P25150 & HOXC9 & homeobox C9 & $-6,222$ & $6,58 \mathrm{E}-12$ \\
A_23_P10902 & FRZB & frizzled-related protein & $-3,923$ & $1,46 \mathrm{E}-11$ \\
A_23_P259314 & RPS4Y1 & ribosomal protein S4, Y-linked 1 & $-8,323$ & $2,61 \mathrm{E}-11$ \\
A_23_P64617 & FZD4 & frizzled homolog 4 (Drosophila) & $-4,151$ & $2,61 \mathrm{E}-11$ \\
A_23_P128084 & ITGA7 & integrin, alpha 7 & $-4,812$ & $3,47 \mathrm{E}-11$ \\
A_23_P40574 & CRYBB2 & crystallin, beta B2 & $-3,835$ & $5,35 \mathrm{E}-11$ \\
A_23_P406025 & PRUNE2 & prune homolog 2 (Drosophila) & $-3,643$ & $5,35 \mathrm{E}-11$ \\
A_24_P892472 & EMX2OS & EMX2 opposite strand (non-protein coding) & $-4,620$ & $6,64 \mathrm{E}-11$ \\
A_23_P119943 & IGFBP2 & insulin-like growth factor binding protein 2,36kDa & $-4,077$ & $7,13 \mathrm{E}-11$ \\
A_23_P215060 & PODXL & podocalyxin-like & $-4,674$ & $8,67 \mathrm{E}-11$ \\
A_23_P44264 & EMX2 & empty spiracles homeobox 2 & $-3,890$ & $8,67 \mathrm{E}-11$ \\
A_23_P167367 & PITX2 & paired-like homeodomain 2 & $-4,167$ & $1,13 \mathrm{E}-10$ \\
A_23_P90436 & COMP & cartilage oligomeric matrix protein & $-6,911$ & $1,21 \mathrm{E}-10$ \\
A_24_P335092 & SAA1 & serum amyloid A1 & $-4,345$ & $1,43 \mathrm{E}-10$ \\
A_23_P27400 & HAS1 & hyaluronan synthase 1 & $-5,860$ & $1,52 \mathrm{E}-10$ \\
\hline
\end{tabular}




\begin{tabular}{|c|c|c|c|c|}
\hline AgilentID & Symbol & Genname & $\operatorname{logFC} Z K 2-B K 2$ & FDR ZK2-BK2 \\
\hline A_24_P652609 & RP11-138L21.1 & similar to cell recognition molecule CASPR3 & $-3,765$ & $2,92 \mathrm{E}-10$ \\
\hline A_24_P128442 & TBX15 & T-box 15 & $-4,878$ & $3,10 \mathrm{E}-10$ \\
\hline A_24_P206776 & CRYAB & crystallin, alpha B & $-5,444$ & $3,11 \mathrm{E}-10$ \\
\hline A_23_P87700 & MFAP5 & microfibrillar associated protein 5 & $-4,891$ & $3,68 \mathrm{E}-10$ \\
\hline A_23_P66682 & HOXB6 & homeobox B6 & $-4,073$ & $3,82 \mathrm{E}-10$ \\
\hline A_32_P117354 & LIMCH1 & LIM and calponin homology domains 1 & $-4,707$ & $3,98 \mathrm{E}-10$ \\
\hline A_23_P55356 & VMO1 & vitelline membrane outer layer 1 homolog (chicken) & $-3,548$ & $4,20 \mathrm{E}-10$ \\
\hline A_23_P211207 & ADARB1 & $\begin{array}{l}\text { adenosine deaminase, RNA-specific, B1 (RED1 homolog } \\
\text { rat) }\end{array}$ & $-4,927$ & $5,45 \mathrm{E}-10$ \\
\hline A_23_P217797 & DDX3Y & DEAD (Asp-Glu-Ala-Asp) box polypeptide 3, Y-linked & $-4,481$ & $5,45 \mathrm{E}-10$ \\
\hline A_23_P50081 & IMPA2 & inositol(myo)-1(or 4)-monophosphatase 2 & $-3,591$ & $7,16 \mathrm{E}-10$ \\
\hline A_23_P3312 & ISLR & $\begin{array}{l}\text { immunoglobulin superfamily containing leucine-rich } \\
\text { repeat }\end{array}$ & $-3,489$ & $7,37 \mathrm{E}-10$ \\
\hline A_23_P363778 & FRZB & frizzled-related protein & $-3,796$ & $9,02 \mathrm{E}-10$ \\
\hline A_23_P137665 & CHI3L1 & chitinase 3-like 1 (cartilage glycoprotein-39) & $-4,818$ & 1,09E-09 \\
\hline A_23_P6771 & LMCD1 & LIM and cysteine-rich domains 1 & $-3,661$ & 1,15E-09 \\
\hline A_23_P75283 & RBP4 & retinol binding protein 4 , plasma & $-5,730$ & 1,18E-09 \\
\hline A_24_P296772 & PPP1R14A & $\begin{array}{l}\text { protein phosphatase } 1 \text {, regulatory (inhibitor) subunit } \\
14 \mathrm{~A}\end{array}$ & $-4,525$ & 1,18E-09 \\
\hline A_23_P167129 & HHIP & hedgehog interacting protein & $-2,944$ & 1,18E-09 \\
\hline A_32_P154911 & PRR15 & proline rich 15 & $-4,526$ & $1,25 \mathrm{E}-09$ \\
\hline A_23_P150281 & TP53111 & tumor protein p53 inducible protein 11 & $-3,112$ & $1,34 \mathrm{E}-09$ \\
\hline A_32_P169406 & LOC400043 & hypothetical LOC400043 & $-3,689$ & $1,43 E-09$ \\
\hline A_23_P19624 & BMP6 & bone morphogenetic protein 6 & $-3,098$ & 2,13E-09 \\
\hline A_23_P349966 & TMEM130 & transmembrane protein 130 & $-3,477$ & $2,40 \mathrm{E}-09$ \\
\hline A_23_P27734 & NPAS1 & neuronal PAS domain protein 1 & $-3,008$ & 2,61E-09 \\
\hline A_23_P256033 & EEF1A2 & eukaryotic translation elongation factor 1 alpha 2 & $-2,678$ & 2,61E-09 \\
\hline A_23_P153745 & IFI30 & interferon, gamma-inducible protein 30 & $-2,964$ & $2,76 \mathrm{E}-09$ \\
\hline A_23_P103703 & HSPB7 & $\begin{array}{l}\text { heat shock } 27 \mathrm{kDa} \text { protein family, member } 7 \text { (cardiovas- } \\
\text { cular) }\end{array}$ & $-4,242$ & $2,77 \mathrm{E}-09$ \\
\hline A_23_P368028 & TP53111 & tumor protein p53 inducible protein 11 & $-3,352$ & 2,77E-09 \\
\hline A_23_P76731 & RAGE & renal tumor antigen & $-2,804$ & 2,77E-09 \\
\hline A_23_P255104 & LHFPL2 & lipoma HMGIC fusion partner-like 2 & $-2,415$ & $2,77 E-09$ \\
\hline A_23_P390504 & FOXC1 & forkhead box C1 & $-3,101$ & $3,28 \mathrm{E}-09$ \\
\hline A_24_P297182 & GGT5 & gamma-glutamyltransferase 5 & $-4,096$ & $3,36 \mathrm{E}-09$ \\
\hline A_32_P140489 & GDF6 & growth differentiation factor 6 & $-3,608$ & $4,22 \mathrm{E}-09$ \\
\hline A_23_P99515 & C13orf33 & chromosome 13 open reading frame 33 & $-4,718$ & $5,05 \mathrm{E}-09$ \\
\hline A_23_P206022 & ITGA11 & integrin, alpha 11 & $-3,759$ & $5,05 \mathrm{E}-09$ \\
\hline A_23_P166376 & GGT5 & gamma-glutamyltransferase 5 & $-3,084$ & $5,40 \mathrm{E}-09$ \\
\hline A_23_P218928 & C4orf18 & chromosome 4 open reading frame 18 & $-3,722$ & $5,48 \mathrm{E}-09$ \\
\hline A_23_P403445 & CGREF1 & cell growth regulator with EF-hand domain 1 & $-3,096$ & $5,80 \mathrm{E}-09$ \\
\hline A_23_P66798 & KRT19 & keratin 19 & $-3,093$ & $5,80 \mathrm{E}-09$ \\
\hline A_23_P91230 & SLPI & secretory leukocyte peptidase inhibitor & $-3,130$ & $5,86 \mathrm{E}-09$ \\
\hline A_24_P50228 & C11orf87 & chromosome 11 open reading frame 87 & $-3,278$ & $6,16 \mathrm{E}-09$ \\
\hline A_23_P56197 & CRLF1 & cytokine receptor-like factor 1 & $-5,473$ & $7,28 \mathrm{E}-09$ \\
\hline A_23_P151075 & ARHGDIB & Rho GDP dissociation inhibitor (GDI) beta & $-2,754$ & $7,28 \mathrm{E}-09$ \\
\hline A_23_P156708 & TNXB & tenascin XB & $-2,723$ & $7,28 \mathrm{E}-09$ \\
\hline A_23_P24077 & C10orf54 & chromosome 10 open reading frame 54 & $-2,257$ & 7,39E-09 \\
\hline A_24_P86537 & HSPB1 & heat shock $27 \mathrm{kDa}$ protein 1 & $-2,479$ & $8,86 \mathrm{E}-09$ \\
\hline A_23_P144911 & EGFLAM & EGF-like, fibronectin type III and laminin G domains & $-3,234$ & $9,15 \mathrm{E}-09$ \\
\hline A_24_P919150 & ACAN & aggrecan & $-2,880$ & $9,28 \mathrm{E}-09$ \\
\hline
\end{tabular}




\begin{tabular}{|c|c|c|c|c|}
\hline AgilentID & Symbol & Genname & $\operatorname{logFC} Z K 2-B K 2$ & FDR ZK2-BK2 \\
\hline A_23_P27795 & SPINT2 & serine peptidase inhibitor, Kunitz type, 2 & $-2,943$ & $9,74 \mathrm{E}-09$ \\
\hline A_23_P112798 & CRIP2 & cysteine-rich protein 2 & $-3,160$ & $9,76 \mathrm{E}-09$ \\
\hline A_23_P397999 & FZD5 & frizzled homolog 5 (Drosophila) & $-2,687$ & $1,19 \mathrm{E}-08$ \\
\hline A_23_P142796 & LIMS2 & LIM and senescent cell antigen-like domains 2 & $-2,784$ & $1,22 \mathrm{E}-08$ \\
\hline A_23_P215454 & ELN & elastin & $-3,292$ & $1,43 \mathrm{E}-08$ \\
\hline A_23_P146554 & PTGDS & prostaglandin D2 synthase 21kDa (brain) & $-3,132$ & $1,52 \mathrm{E}-08$ \\
\hline A_23_P500998 & HOXA9 & homeobox A9 & $-3,793$ & $1,54 \mathrm{E}-08$ \\
\hline A_23_P200737 & RGS4 & regulator of G-protein signaling 4 & $-3,064$ & $1,58 \mathrm{E}-08$ \\
\hline A_23_P215459 & ELN & elastin & $-4,358$ & $1,61 \mathrm{E}-08$ \\
\hline A_23_P119562 & CFD & complement factor D (adipsin) & $-2,542$ & $1,77 \mathrm{E}-08$ \\
\hline A_24_P397817 & LEP & leptin & $-2,910$ & $1,85 \mathrm{E}-08$ \\
\hline A_24_P926960 & MEGF6 & multiple EGF-like-domains 6 & $-3,186$ & $2,11 \mathrm{E}-08$ \\
\hline A_23_P253692 & GPR64 & G protein-coupled receptor 64 & $-2,366$ & $2,31 \mathrm{E}-08$ \\
\hline A_23_P35414 & PPP1R3C & protein phosphatase 1 , regulatory (inhibitor) subunit $3 \mathrm{C}$ & $-3,522$ & $2,31 \mathrm{E}-08$ \\
\hline A_23_P407840 & FNDC1 & fibronectin type III domain containing 1 & $-2,737$ & $2,32 \mathrm{E}-08$ \\
\hline A_23_P87011 & TAGLN & transgelin & $-2,308$ & $2,33 \mathrm{E}-08$ \\
\hline A_23_P28434 & VAMP8 & vesicle-associated membrane protein 8 (endobrevin) & $-2,641$ & $2,63 \mathrm{E}-08$ \\
\hline A_23_P65518 & DACT1 & $\begin{array}{l}\text { dapper, antagonist of beta-catenin, homolog } 1 \\
\text { (Xenopus laevis) }\end{array}$ & $-2,738$ & $2,78 \mathrm{E}-08$ \\
\hline A_23_P256158 & ADRA2C & adrenergic, alpha-2C-, receptor & $-3,471$ & $3,05 \mathrm{E}-08$ \\
\hline A_24_P389916 & LRRC32 & leucine rich repeat containing 32 & $-3,318$ & $3,07 E-08$ \\
\hline A_24_P329795 & C10orf10 & chromosome 10 open reading frame 10 & $-3,862$ & $3,07 E-08$ \\
\hline A_23_P87013 & TAGLN & transgelin & $-2,621$ & $3,10 \mathrm{E}-08$ \\
\hline A_23_P381261 & ADCY4 & adenylate cyclase 4 & $-2,914$ & $3,15 \mathrm{E}-08$ \\
\hline A_23_P161837 & MRVI1 & murine retrovirus integration site 1 homolog & $-2,229$ & $3,34 \mathrm{E}-08$ \\
\hline A_23_P306105 & GALNT1 & $\begin{array}{l}\text { UDP-N-acetyl-alpha-D-galactosamine:polypeptide N- } \\
\text { acetylgalactosaminyltransferase } 1 \text { (GalNAc-T1) }\end{array}$ & $-2,895$ & $3,61 \mathrm{E}-08$ \\
\hline A_23_P257704 & HSPB1 & heat shock $27 \mathrm{kDa}$ protein 1 & $-2,526$ & $4,06 \mathrm{E}-08$ \\
\hline A_23_P398854 & DOK7 & docking protein 7 & $-3,005$ & $4,10 \mathrm{E}-08$ \\
\hline A_23_P208991 & PALM & paralemmin & $-2,447$ & $4,46 \mathrm{E}-08$ \\
\hline A_23_P363769 & KRT86 & keratin 86 & $-2,188$ & $4,60 \mathrm{E}-08$ \\
\hline A_23_P107283 & НОХВ2 & homeobox B2 & $-4,878$ & $4,90 \mathrm{E}-08$ \\
\hline A_24_P178444 & LOC341230 & similar to argininosuccinate synthase & $-2,296$ & $4,90 \mathrm{E}-08$ \\
\hline A_23_P215634 & IGFBP3 & insulin-like growth factor binding protein 3 & $-3,184$ & $4,90 \mathrm{E}-08$ \\
\hline A_23_P378416 & GPM6B & glycoprotein M6B & $-3,195$ & $5,51 \mathrm{E}-08$ \\
\hline A_23_P106389 & SEMA7A & $\begin{array}{l}\text { semaphorin 7A, GPI membrane anchor (John Milton } \\
\text { Hagen blood group) }\end{array}$ & $-3,170$ & $5,58 \mathrm{E}-08$ \\
\hline A_23_P201808 & PPAP2B & phosphatidic acid phosphatase type $2 B$ & $-2,357$ & $5,58 \mathrm{E}-08$ \\
\hline A_24_P77904 & HOXA10 & homeobox A10 & $-2,595$ & $5,73 E-08$ \\
\hline A_23_P435407 & GPC4 & glypican 4 & $-2,627$ & $5,75 \mathrm{E}-08$ \\
\hline A_23_P128230 & NR4A1 & nuclear receptor subfamily 4 , group $A$, member 1 & $-2,954$ & $5,84 \mathrm{E}-08$ \\
\hline A_23_P46470 & ERRFI1 & ERBB receptor feedback inhibitor 1 & $-2,800$ & $5,93 \mathrm{E}-08$ \\
\hline A_23_P64743 & STK38L & serine/threonine kinase 38 like & $-3,303$ & $6,59 \mathrm{E}-08$ \\
\hline A_24_P220485 & OLFML2A & olfactomedin-like $2 \mathrm{~A}$ & $-3,452$ & $7,02 \mathrm{E}-08$ \\
\hline A_23_P62021 & THBS2 & thrombospondin 2 & $-3,164$ & $7,17 \mathrm{E}-08$ \\
\hline A_32_P108254 & FAM20A & family with sequence similarity 20 , member $\mathrm{A}$ & $-3,478$ & $7,44 \mathrm{E}-08$ \\
\hline A_24_P399220 & НОХВ3 & homeobox B3 & $-3,325$ & $7,44 \mathrm{E}-08$ \\
\hline A_32_P157945 & DSP & desmoplakin & $-2,836$ & $7,44 \mathrm{E}-08$ \\
\hline A_23_P4335 & KRT14 & keratin 14 & $-2,776$ & $7,44 \mathrm{E}-08$ \\
\hline A_23_P352402 & C10orf47 & chromosome 10 open reading frame 47 & $-2,394$ & $7,44 \mathrm{E}-08$ \\
\hline
\end{tabular}




\begin{tabular}{|c|c|c|c|c|}
\hline AgilentID & Symbol & Genname & $\log \mathrm{FC} Z \mathrm{ZK} 2-\mathrm{BK} 2$ & FDR ZK2-BK2 \\
\hline A_23_P309619 & LOC100131004 & hypothetical protein LOC100131004 & $-2,202$ & $7,89 \mathrm{E}-08$ \\
\hline A_23_P204286 & MGP & matrix Gla protein & $-2,977$ & $8,02 \mathrm{E}-08$ \\
\hline A_32_P42574 & C1orf198 & chromosome 1 open reading frame 198 & $-3,087$ & $8,18 \mathrm{E}-08$ \\
\hline A_32_P66881 & TLR4 & toll-like receptor 4 & $-2,952$ & $8,41 \mathrm{E}-08$ \\
\hline A_23_P399001 & CXXC5 & CXXC finger 5 & $-2,789$ & $1,13 \mathrm{E}-07$ \\
\hline A_23_P306203 & SAA2 & serum amyloid A2 & $-4,078$ & $1,14 \mathrm{E}-07$ \\
\hline A_32_P201261 & C11orf87 & chromosome 11 open reading frame 87 & $-2,779$ & $1,16 \mathrm{E}-07$ \\
\hline A_23_P121795 & SORBS2 & sorbin and $\mathrm{SH} 3$ domain containing 2 & $-3,615$ & $1,16 \mathrm{E}-07$ \\
\hline A_24_P218814 & RDH5 & retinol dehydrogenase 5 (11-cis/9-cis) & $-3,045$ & $1,21 \mathrm{E}-07$ \\
\hline A_23_P341223 & KLHL21 & kelch-like 21 (Drosophila) & $-2,102$ & $1,21 \mathrm{E}-07$ \\
\hline A_23_P36562 & ITGA5 & $\begin{array}{l}\text { integrin, alpha } 5 \text { (fibronectin receptor, alpha polypep- } \\
\text { tide) }\end{array}$ & $-3,222$ & $1,31 \mathrm{E}-07$ \\
\hline A_24_P237511 & EIF1AY & eukaryotic translation initiation factor $1 \mathrm{~A}, \mathrm{Y}$-linked & $-2,827$ & $1,39 \mathrm{E}-07$ \\
\hline A_23_P31143 & TPD52L1 & tumor protein D52-like 1 & $-2,929$ & $1,52 \mathrm{E}-07$ \\
\hline A_23_P13382 & LSP1 & lymphocyte-specific protein 1 & $-3,307$ & $1,59 \mathrm{E}-07$ \\
\hline A_23_P254741 & SOD3 & superoxide dismutase 3 , extracellular & $-2,751$ & $1,99 \mathrm{E}-07$ \\
\hline A_23_P216556 & EPB41L4B & erythrocyte membrane protein band 4.1 like $4 B$ & $-2,308$ & $2,09 \mathrm{E}-07$ \\
\hline A_23_P156970 & MEST & mesoderm specific transcript homolog (mouse) & $-2,857$ & $2,19 \mathrm{E}-07$ \\
\hline A_23_P101054 & KRT34 & keratin 34 & $-3,189$ & $2,32 \mathrm{E}-07$ \\
\hline A_23_P315320 & IL27 & interleukin 27 & $-2,247$ & $2,49 \mathrm{E}-07$ \\
\hline A_23_P205894 & ACTC1 & actin, alpha, cardiac muscle 1 & $-2,494$ & $2,72 \mathrm{E}-07$ \\
\hline A_32_P200697 & FAM101A & family with sequence similarity 101 , member $A$ & $-3,683$ & $2,85 \mathrm{E}-07$ \\
\hline A_23_P329573 & ITGB2 & $\begin{array}{l}\text { integrin, beta } 2 \text { (complement component } 3 \text { receptor } 3 \\
\text { and } 4 \text { subunit) }\end{array}$ & $-2,155$ & $3,08 \mathrm{E}-07$ \\
\hline A_24_P406754 & LOXL4 & lysyl oxidase-like 4 & $-2,676$ & $3,18 \mathrm{E}-07$ \\
\hline A_23_P36658 & MGST1 & microsomal glutathione S-transferase 1 & $-2,385$ & $3,46 \mathrm{E}-07$ \\
\hline A_23_P43164 & SULF1 & sulfatase 1 & $-2,396$ & $3,90 \mathrm{E}-07$ \\
\hline A_23_P70968 & HOXA7 & homeobox A7 & $-3,644$ & $3,96 \mathrm{E}-07$ \\
\hline A_23_P167159 & SCRG1 & scrapie responsive protein 1 & $-2,334$ & $4,11 \mathrm{E}-07$ \\
\hline A_23_P114740 & $\mathrm{CFH}$ & complement factor $\mathrm{H}$ & $-3,109$ & $4,40 \mathrm{E}-07$ \\
\hline A_23_P72157 & MFSD7 & major facilitator superfamily domain containing 7 & $-2,458$ & $4,72 \mathrm{E}-07$ \\
\hline A_23_P365685 & LIMS3 & LIM and senescent cell antigen-like domains 3 & $-2,123$ & $5,04 \mathrm{E}-07$ \\
\hline A_23_P114883 & FMOD & fibromodulin & $-3,006$ & $5,57 \mathrm{E}-07$ \\
\hline A_23_P324340 & DISP2 & dispatched homolog 2 (Drosophila) & $-2,507$ & $6,02 \mathrm{E}-07$ \\
\hline A_23_P125233 & CNN1 & calponin 1, basic, smooth muscle & $-2,154$ & $6,28 \mathrm{E}-07$ \\
\hline A_23_P83403 & LIMCH1 & LIM and calponin homology domains 1 & $-2,474$ & $6,92 \mathrm{E}-07$ \\
\hline A_24_P80204 & MALL & mal, T-cell differentiation protein-like & $-3,514$ & $7,24 \mathrm{E}-07$ \\
\hline A_23_P41854 & CARD6 & caspase recruitment domain family, member 6 & $-2,569$ & $8,22 \mathrm{E}-07$ \\
\hline A_23_P253982 & HOXA4 & homeobox A4 & $-2,515$ & $8,22 \mathrm{E}-07$ \\
\hline A_23_P210708 & SIRPA & signal-regulatory protein alpha & $-2,740$ & $8,25 \mathrm{E}-07$ \\
\hline A_32_P334340 & C6orf124 & chromosome 6 open reading frame 124 & $-2,184$ & $8,92 \mathrm{E}-07$ \\
\hline A_24_P605612 & THBS2 & thrombospondin 2 & $-2,116$ & $9,78 \mathrm{E}-07$ \\
\hline A_23_P57709 & PCOLCE2 & procollagen C-endopeptidase enhancer 2 & $-3,673$ & $1,01 \mathrm{E}-06$ \\
\hline A_24_P372625 & RNF141 & ring finger protein 141 & $-2,104$ & $1,01 \mathrm{E}-06$ \\
\hline A_23_P65240 & COL4A1 & collagen, type IV, alpha 1 & $-2,784$ & $1,06 \mathrm{E}-06$ \\
\hline A_23_P361336 & ADARB1 & $\begin{array}{l}\text { adenosine deaminase, RNA-specific, B1 (RED1 homolog } \\
\text { rat) }\end{array}$ & $-2,405$ & $1,06 \mathrm{E}-06$ \\
\hline A_23_P69497 & CLEC3B & C-type lectin domain family 3 , member B & $-2,792$ & $1,14 \mathrm{E}-06$ \\
\hline A_23_P112634 & C4orf34 & chromosome 4 open reading frame 34 & $-2,185$ & $1,22 \mathrm{E}-06$ \\
\hline A_24_P124558 & $\mathrm{HOXC8}$ & homeobox C8 & $-3,354$ & $1,23 \mathrm{E}-06$ \\
\hline
\end{tabular}




\begin{tabular}{|c|c|c|c|c|}
\hline AgilentID & Symbol & Genname & $\log \mathrm{FC} Z \mathrm{ZK} 2-\mathrm{BK} 2$ & FDR ZK2-BK2 \\
\hline A_32_P76247 & HSPB1 & heat shock $27 \mathrm{kDa}$ protein 1 & $-2,130$ & $1,26 \mathrm{E}-06$ \\
\hline A_23_P422851 & CABLES1 & Cdk5 and Abl enzyme substrate 1 & $-2,058$ & $1,30 \mathrm{E}-06$ \\
\hline A_24_P17490 & CNTN3 & contactin 3 (plasmacytoma associated) & $-2,106$ & 1,37E-06 \\
\hline A_24_P48723 & PTGIS & prostaglandin 12 (prostacyclin) synthase & $-2,988$ & $1,46 \mathrm{E}-06$ \\
\hline A_23_P74609 & GOS2 & G0/G1switch 2 & $-2,102$ & $1,49 \mathrm{E}-06$ \\
\hline A_23_P62583 & MEGF6 & multiple EGF-like-domains 6 & $-2,574$ & $1,50 \mathrm{E}-06$ \\
\hline A_23_P254654 & CLIC3 & chloride intracellular channel 3 & $-2,747$ & $1,59 \mathrm{E}-06$ \\
\hline A_23_P426021 & KIAA0746 & KIAA0746 protein & $-2,832$ & $1,76 \mathrm{E}-06$ \\
\hline A_24_P218805 & HOXC10 & homeobox C10 & $-2,359$ & $1,81 \mathrm{E}-06$ \\
\hline A_23_P61688 & SLC12A7 & $\begin{array}{l}\text { solute carrier family } 12 \text { (potassium/chloride transport- } \\
\text { ers), member } 7\end{array}$ & $-2,130$ & $1,88 \mathrm{E}-06$ \\
\hline A_24_P262543 & KCNK6 & potassium channel, subfamily K, member 6 & $-2,146$ & 1,97E-06 \\
\hline A_23_P257971 & AKR1C1 & $\begin{array}{l}\text { aldo-keto reductase family 1, member C1 (dihydrodiol } \\
\text { dehydrogenase 1; 20-alpha (3-alpha)-hydroxysteroid } \\
\text { dehydrogenase) }\end{array}$ & $-2,612$ & $2,13 \mathrm{E}-06$ \\
\hline A_23_P421423 & TNFAIP2 & tumor necrosis factor, alpha-induced protein 2 & $-2,629$ & 2,17E-06 \\
\hline A_23_P399255 & RNF182 & ring finger protein 182 & $-2,576$ & $2,26 \mathrm{E}-06$ \\
\hline A_23_P369994 & DCLK1 & doublecortin-like kinase 1 & $-2,222$ & 2,27E-06 \\
\hline A_24_P766716 & CMKLR1 & chemokine-like receptor 1 & $-2,817$ & $2,28 \mathrm{E}-06$ \\
\hline A_23_P122216 & LOX & lysyl oxidase & $-2,192$ & $2,28 \mathrm{E}-06$ \\
\hline A_24_P133584 & MFGE8 & milk fat globule-EGF factor 8 protein & $-3,079$ & $2,40 \mathrm{E}-06$ \\
\hline A_23_P82420 & STX1A & syntaxin $1 \mathrm{~A}$ (brain) & $-2,251$ & $2,48 \mathrm{E}-06$ \\
\hline A_23_P417942 & FNBP1L & formin binding protein 1-like & $-2,248$ & $2,50 \mathrm{E}-06$ \\
\hline A_23_P138541 & AKR1C3 & $\begin{array}{l}\text { aldo-keto reductase family } 1 \text {, member C3 (3-alpha } \\
\text { hydroxysteroid dehydrogenase, type II) }\end{array}$ & $-3,582$ & 2,89E-06 \\
\hline A_24_P943894 & SCUBE3 & signal peptide, CUB domain, EGF-like 3 & $-2,791$ & 2,93E-06 \\
\hline A_24_P924862 & RAPH1 & $\begin{array}{l}\text { Ras association (RalGDS/AF-6) and pleckstrin homology } \\
\text { domains } 1\end{array}$ & $-2,220$ & $3,09 \mathrm{E}-06$ \\
\hline A_23_P38795 & FPR1 & formyl peptide receptor 1 & $-2,377$ & $3,24 \mathrm{E}-06$ \\
\hline A_24_P158946 & FGD4 & FYVE, RhoGEF and PH domain containing 4 & $-3,041$ & $3,38 \mathrm{E}-06$ \\
\hline A_24_P231104 & LEPR & leptin receptor & $-2,235$ & $3,51 \mathrm{E}-06$ \\
\hline A_24_P31627 & KCNB1 & $\begin{array}{l}\text { potassium voltage-gated channel, Shab-related subfam- } \\
\text { ily, member } 1\end{array}$ & $-2,065$ & $3,61 \mathrm{E}-06$ \\
\hline A_23_P162171 & MCAM & melanoma cell adhesion molecule & $-2,437$ & $3,71 \mathrm{E}-06$ \\
\hline A_32_P205110 & FOXC1 & forkhead box C1 & $-2,202$ & $3,76 \mathrm{E}-06$ \\
\hline A_23_P170233 & CSTA & cystatin A (stefin A) & $-2,412$ & $3,94 \mathrm{E}-06$ \\
\hline A_23_P161218 & ANKRD1 & ankyrin repeat domain 1 (cardiac muscle) & $-2,139$ & $4,00 E-06$ \\
\hline A_23_P363255 & CCDC68 & coiled-coil domain containing 68 & $-2,227$ & $4,04 \mathrm{E}-06$ \\
\hline A_23_P339818 & ARRDC4 & arrestin domain containing 4 & $-2,794$ & $4,22 \mathrm{E}-06$ \\
\hline A_32_P11372 & KGFLP1 & keratinocyte growth factor-like protein 1 & $-2,798$ & 4,77E-06 \\
\hline A_23_P161727 & HSPB2 & heat shock $27 \mathrm{kDa}$ protein 2 & $-2,436$ & $4,96 \mathrm{E}-06$ \\
\hline A_24_P150466 & SMOC1 & SPARC related modular calcium binding 1 & $-2,301$ & $4,98 \mathrm{E}-06$ \\
\hline A_23_P357207 & MRAP2 & melanocortin 2 receptor accessory protein 2 & $-2,231$ & $5,22 \mathrm{E}-06$ \\
\hline A_32_P37867 & KIAA1644 & KIAA1644 & $-2,232$ & $5,42 \mathrm{E}-06$ \\
\hline A_24_P176079 & WASF3 & WAS protein family, member 3 & $-3,254$ & $5,62 \mathrm{E}-06$ \\
\hline A_24_P354689 & SPOCK1 & $\begin{array}{l}\text { sparc/osteonectin, cwcv and kazal-like domains prote- } \\
\text { oglycan (testican) } 1\end{array}$ & $-2,299$ & $5,80 \mathrm{E}-06$ \\
\hline A_23_P254944 & GSTT1 & glutathione S-transferase theta 1 & $-2,086$ & $5,85 E-06$ \\
\hline A_23_P253542 & SMPX & small muscle protein, $\mathrm{X}$-linked & $-2,020$ & $6,15 \mathrm{E}-06$ \\
\hline A_23_P116898 & $\mathrm{A} 2 \mathrm{M}$ & alpha-2-macroglobulin & $-2,407$ & $6,36 \mathrm{E}-06$ \\
\hline A_23_P217326 & FHL1 & four and a half LIM domains 1 & $-2,562$ & $6,38 \mathrm{E}-06$ \\
\hline A_23_P86653 & SRGN & serglycin & $-2,814$ & $6,60 \mathrm{E}-06$ \\
\hline
\end{tabular}




\begin{tabular}{|c|c|c|c|c|}
\hline AgilentID & Symbol & Genname & $\operatorname{logFC~ZK2-BK2~}$ & FDR ZK2-BK2 \\
\hline A_24_P403417 & PTGES & prostaglandin E synthase & $-2,608$ & $7,50 \mathrm{E}-06$ \\
\hline A_23_P141624 & KRTAP1-1 & keratin associated protein 1-1 & $-2,077$ & $7,80 \mathrm{E}-06$ \\
\hline A_23_P120227 & LBH & limb bud and heart development homolog (mouse) & $-2,470$ & $8,61 \mathrm{E}-06$ \\
\hline A_24_P412734 & PRSS36 & protease, serine, 36 & $-2,392$ & $8,78 \mathrm{E}-06$ \\
\hline A_23_P118203 & LOC124220 & similar to common salivary protein 1 & $-2,288$ & $8,91 \mathrm{E}-06$ \\
\hline A_23_P428129 & CDKN1C & cyclin-dependent kinase inhibitor $1 \mathrm{C}$ (p57, Kip2) & $-2,026$ & $8,98 \mathrm{E}-06$ \\
\hline A_23_P106405 & NDN & necdin homolog (mouse) & $-2,185$ & $9,03 E-06$ \\
\hline A_23_P58082 & CCDC80 & coiled-coil domain containing 80 & $-2,267$ & $9,78 \mathrm{E}-06$ \\
\hline A_23_P31921 & ASS1 & argininosuccinate synthetase 1 & $-2,030$ & 9,87E-06 \\
\hline A_24_P348861 & TTTY15 & testis-specific transcript, Y-linked 15 & $-2,427$ & 1,17E-05 \\
\hline A_23_P205031 & COL4A2 & collagen, type IV, alpha 2 & $-2,206$ & $1,22 \mathrm{E}-05$ \\
\hline A_24_P140475 & SORBS2 & sorbin and $\mathrm{SH} 3$ domain containing 2 & $-2,987$ & $1,37 \mathrm{E}-05$ \\
\hline A_23_P73848 & CYorf14 & chromosome $\mathrm{Y}$ open reading frame 14 & $-2,790$ & $1,38 \mathrm{E}-05$ \\
\hline A_23_P116414 & PLA2G16 & phospholipase $\mathrm{A} 2$, group XVI & $-2,585$ & $1,63 \mathrm{E}-05$ \\
\hline A_23_P14612 & FGF7 & fibroblast growth factor 7 (keratinocyte growth factor) & $-2,598$ & $1,68 \mathrm{E}-05$ \\
\hline A_24_P892612 & LOC100128164 & hypothetical LOC100128164 & $-2,413$ & $1,73 \mathrm{E}-05$ \\
\hline A_24_P220947 & AKR1C1 & $\begin{array}{l}\text { aldo-keto reductase family 1, member C1 (dihydrodiol } \\
\text { dehydrogenase 1; 20-alpha (3-alpha)-hydroxysteroid } \\
\text { dehydrogenase) }\end{array}$ & $-2,772$ & 2,29E-05 \\
\hline A_23_P151426 & FOXO1 & forkhead box $\mathrm{O} 1$ & $-2,871$ & $2,70 \mathrm{E}-05$ \\
\hline A_24_P416370 & HOXB4 & homeobox B4 & $-2,263$ & $2,73 \mathrm{E}-05$ \\
\hline A_32_P42895 & NOTCH3 & Notch homolog 3 (Drosophila) & $-2,025$ & $3,25 \mathrm{E}-05$ \\
\hline A_23_P392575 & KCNE4 & $\begin{array}{l}\text { potassium voltage-gated channel, Isk-related family, } \\
\text { member } 4\end{array}$ & $-2,906$ & $3,36 \mathrm{E}-05$ \\
\hline A_32_P78816 & PSPH & phosphoserine phosphatase & $-2,345$ & $3,45 \mathrm{E}-05$ \\
\hline A_23_P50919 & SERPINE2 & $\begin{array}{l}\text { serpin peptidase inhibitor, clade } E \text { (nexin, plasminogen } \\
\text { activator inhibitor type 1), member } 2\end{array}$ & $-2,787$ & $3,48 \mathrm{E}-05$ \\
\hline A_23_P19142 & KCNMB1 & $\begin{array}{l}\text { potassium large conductance calcium-activated chan- } \\
\text { nel, subfamily M, beta member } 1\end{array}$ & $-2,350$ & 3,63E-05 \\
\hline A_23_P381945 & KRT7 & keratin 7 & $-2,222$ & $5,02 \mathrm{E}-05$ \\
\hline A_24_P14584 & BACE2 & beta-site APP-cleaving enzyme 2 & $-2,106$ & $5,20 \mathrm{E}-05$ \\
\hline A_23_P398476 & HOXC8 & homeobox C8 & $-2,671$ & $5,35 \mathrm{E}-05$ \\
\hline A_23_P202327 & ADAM12 & ADAM metallopeptidase domain 12 & $-2,441$ & $5,84 \mathrm{E}-05$ \\
\hline A_24_P6370 & C1orf110 & chromosome 1 open reading frame 110 & $-2,049$ & $5,97 \mathrm{E}-05$ \\
\hline A_24_P370372 & CBX6 & chromobox homolog 6 & $-2,114$ & $6,82 \mathrm{E}-05$ \\
\hline A_23_P374695 & TEK & TEK tyrosine kinase, endothelial & $-2,509$ & $8,16 \mathrm{E}-05$ \\
\hline A_24_P326660 & MCAM & melanoma cell adhesion molecule & $-2,001$ & $8,67 \mathrm{E}-05$ \\
\hline A_23_P94517 & DBC1 & deleted in bladder cancer 1 & $-2,290$ & $8,75 \mathrm{E}-05$ \\
\hline A_23_P371284 & LCE2D & late cornified envelope 2D & $-2,551$ & $9,17 E-05$ \\
\hline A_23_P156445 & DDX43 & DEAD (Asp-Glu-Ala-Asp) box polypeptide 43 & $-2,524$ & $9,90 \mathrm{E}-05$ \\
\hline A_23_P501007 & EFEMP1 & $\begin{array}{l}\text { EGF-containing fibulin-like extracellular matrix protein } \\
1\end{array}$ & $-2,500$ & $1,47 E-04$ \\
\hline A_23_P58676 & C5orf23 & chromosome 5 open reading frame 23 & $-2,037$ & $1,56 \mathrm{E}-04$ \\
\hline A_24_P274111 & CHI3L1 & chitinase 3-like 1 (cartilage glycoprotein-39) & $-2,158$ & $1,57 \mathrm{E}-04$ \\
\hline A_23_P78158 & RABEP1 & rabaptin, RAB GTPase binding effector protein 1 & $-2,262$ & $1,82 \mathrm{E}-04$ \\
\hline A_24_P382187 & IGFBP4 & insulin-like growth factor binding protein 4 & $-2,841$ & $1,92 \mathrm{E}-04$ \\
\hline A_23_P146572 & NPDC1 & neural proliferation, differentiation and control, 1 & $-2,057$ & $1,95 \mathrm{E}-04$ \\
\hline A_24_P498854 & LOC284998 & hypothetical protein LOC284998 & $-2,044$ & 1,97E-04 \\
\hline A_23_P170649 & C8orf84 & chromosome 8 open reading frame 84 & $-2,051$ & $1,99 \mathrm{E}-04$ \\
\hline A_23_P97700 & TXNIP & thioredoxin interacting protein & $-2,154$ & $2,06 \mathrm{E}-04$ \\
\hline A_23_P110686 & STC2 & stanniocalcin 2 & $-2,041$ & $2,44 \mathrm{E}-04$ \\
\hline A_23_P127584 & NNMT & nicotinamide $\mathrm{N}$-methyltransferase & $-2,267$ & 2,57E-04 \\
\hline
\end{tabular}




\begin{tabular}{|c|c|c|c|c|}
\hline AgilentID & Symbol & Genname & $\operatorname{logFC} Z K 2-B K 2$ & FDR ZK2-BK2 \\
\hline A_24_P270728 & NUPR1 & nuclear protein 1 & $-2,265$ & $3,33 \mathrm{E}-04$ \\
\hline A_32_P62963 & MGC102966 & $\begin{array}{l}\text { similar to Keratin, type I cytoskeletal } 16 \text { (Cytokeratin- } \\
\text { 16) (CK-16) (Keratin-16) (K16) }\end{array}$ & $-2,762$ & $3,93 \mathrm{E}-04$ \\
\hline A_23_P36546 & HOXC10 & homeobox C10 & $-2,801$ & $4,70 \mathrm{E}-04$ \\
\hline A_32_P114003 & LOC100192378 & hypothetical LOC100192378 & $-2,484$ & $5,17 \mathrm{E}-04$ \\
\hline A_23_P119353 & RASIP1 & Ras interacting protein 1 & $-2,445$ & $7,35 \mathrm{E}-04$ \\
\hline A_32_P24832 & OLFML3 & olfactomedin-like 3 & $-2,553$ & $7,68 \mathrm{E}-04$ \\
\hline A_23_P48951 & MFGE8 & milk fat globule-EGF factor 8 protein & $-2,886$ & $8,05 \mathrm{E}-04$ \\
\hline A_23_P314101 & SUSD2 & sushi domain containing 2 & $-2,330$ & $8,05 \mathrm{E}-04$ \\
\hline A_23_P209625 & CYP1B1 & cytochrome P450, family 1 , subfamily B, polypeptide 1 & $-2,097$ & $9,00 \mathrm{E}-04$ \\
\hline A_23_P119196 & KLF2 & Kruppel-like factor 2 (lung) & $-3,402$ & $9,30 \mathrm{E}-04$ \\
\hline A_24_P258473 & SMOC1 & SPARC related modular calcium binding 1 & $-2,306$ & $1,12 \mathrm{E}-03$ \\
\hline A_23_P83328 & ENG & endoglin & $-2,245$ & $2,34 \mathrm{E}-03$ \\
\hline A_23_P154338 & EFHD1 & EF-hand domain family, member D1 & $-2,060$ & $3,21 \mathrm{E}-03$ \\
\hline A_24_P265346 & KRT14 & keratin 14 & $-2,412$ & $4,36 \mathrm{E}-03$ \\
\hline A_24_P887857 & KRT17P3 & keratin 17 pseudogene 3 & $-2,450$ & $5,67 E-03$ \\
\hline A_32_P232214 & LOC388630 & UPF0632 protein A & $-2,130$ & $5,68 \mathrm{E}-03$ \\
\hline
\end{tabular}




\section{Literaturverzeichnis}

Amin S, Riggs BL, Atkinson EJ, Oberg AL, Melton LJ 3rd, Khosla S (2004): A potentially deleterious role of IGFBP-2 on bone density in aging men and women. J Bone Miner Res $\underline{19}$, 1075-1083

Amin S, Riggs BL, Melton LJ 3rd, Achenbach SJ, Atkinson EJ, Khosla S (2007): High serum IGFBP-2 is predictive of increased bone turnover in aging men and women. J Bone Miner Res 22 , 799-807

Arai R, Ito K, Ohnishi T, Ohba H, Akasaka R, Bessho Y, Hanawa-Suetsugu K, Yoshikawa T, Shirouzu M, Yokoyama S (2007): Crystal structure of human myo-inositol monophosphatase 2, the product of the putative susceptibility gene for bipolar disorder, schizophrenia, and febrile seizures. Proteins $\underline{67}, 732-742$

Ashburner M, Ball CA, Blake JA, Botstein D, Butler H, Cherry JM, Davis AP, Dolinski K, Dwight SS, Eppig JT et al. (2000): Gene ontology: tool for the unification of biology. The Gene Ontology Consortium. Nat Genet 25, 25-29

Atkins GJ, Kostakis P, Pan B, Farrugia A, Gronthos S, Evdokiou A, Harrison K, Findlay DM, Zannettino AC (2003): RANKL expression is related to the differentiation state of human osteoblasts. J Bone Miner Res $\underline{18}, 1088-1098$

Bao L, Liu H, You B, Gu M, Shi S, Shan Y, Li L, Chen J, You Y (2016): Overexpression of IGFBP3 is associated with poor prognosis and tumor metastasis in nasopharyngeal carcinoma. Tumour Biol 37, 15043-15052

Barroca V, Lewandowski D, Jaracz-Ros A, Hardouin SN (2017): Paternal Insulin-like Growth Factor 2 (Igf2) Regulates Stem Cell Activity During Adulthood. EBioMedicine 15, 150-162

Baruah P, Dumitriu IE, Peri G, Russo V, Mantovani A, Manfredi AA, Rovere-Querini P (2006): The tissue pentraxin PTX3 limits C1q-mediated complement activation and phagocytosis of apoptotic cells by dendritic cells. J Leukoc Biol $\underline{80}, 87-95$

Batouli S, Miura M, Brahim J, Tsutsui TW, Fisher LW, Gronthos S, Robey PG, Shi S (2003): Comparison of stem-cell-mediated osteogenesis and dentinogenesis. J Dent Res $\underline{82,976-981}$

Baughman G, Wiederrecht GJ, Campbell NF, Martin MM, Bourgeois S (1995): FKBP51, a novel T-cell-specific immunophilin capable of calcineurin inhibition. Mol Cell Biol 15, 4395-4402

Becker AJ, McCulloch EA, Till JE (1963): Cytological demonstration of the clonal nature of spleen colonies derived from transplanted mouse marrow cells. Nature $\underline{197}, 452-454$

Beissbarth T, Speed TP (2004): GOstat: find statistically overrepresented Gene Ontologies within a group of genes. Bioinformatics $\underline{20}, 1464-1465$

Benjamini Y, Hochberg Y (1995): Controlling the false discovery rate: A practical and powerful approach to multiple testing. J R Stat Soc Series B Stat Methodol 57, 289-300 
Benjamini Y, Drai D, Elmer G, Kafkafi N, Golani I (2001): Controlling the false discovery rate in behavior genetics research. Behav Brain Res 125, 279-284

Bennett JH, Joyner CJ, Triffitt JT, Owen ME (1991): Adipocytic cells cultured from marrow have osteogenic potential. J Cell Sci $\underline{99}, 131-139$

Bergman D, Halje M, Nordin M, Engström W (2013): Insulin-like growth factor 2 in development and disease: a mini-review. Gerontology 59, 240-249

Brafman A, Mett I, Shafir M, Gottlieb H, Damari G, Gozlan-Kelner S, Vishnevskia-Dai V, Skaliter R, Einat P, Faerman A et al. (2004): Inhibition of oxygen-induced retinopathy in RTP801-deficient mice. Invest Ophthalmol Vis Sci $\underline{45}, 3796-3805$

Brew K, Nagase H (2010): The tissue inhibitors of metalloproteinases (TIMPs): an ancient family with structural and functional diversity. Biochim Biophys Acta 1803, 55-71

Brunner HG, Nelen MR, van Zandvoort P, Abeling NG, van Gennip AH, Wolters EC, Kuiper MA, Ropers HH, van Oost BA (1993): X-linked borderline mental retardation with prominent behavioral disturbance: phenotype, genetic localization, and evidence for disturbed monoamine metabolism. Am J Hum Genet 52, 1032-1039

Buraschi S, Neill T, Goyal A, Poluzzi C, Smythies J, Owens RT, Schaefer L, Torres A, Iozzo RV (2013): Decorin causes autophagy in endothelial cells via Peg3. Proc Natl Acad Sci U S A $\underline{110}$, E2582-91

Byers RJ, Brown J, Brandwood C, Wood P, Staley W, Hainey L, Freemont AJ, Hoyland JA (1999): Osteoblastic differentiation and mRNA analysis of STRO-1-positive human bone marrow stromal cells using primary in vitro culture and poly (A) PCR. J Pathol 187, 374-381

Cabanillas B, Novak N (2016): Atopic dermatitis and filaggrin. Curr Opin Immunol $\underline{42}, 1-8$

Christophersen NS, Helin K (2010): Epigenetic control of embryonic stem cell fate. J Exp Med 207, 2287-2295

Cohnheim J (1867): Ueber Entzündung und Eiterung. Virchows Arch Pathol Anat Physiol Klin Med $\underline{40}, 1-79$

Conover CA, Johnstone EW, Turner RT, Evans GL, John Ballard FJ, Doran PM, Khosla S (2002): Subcutaneous administration of insulin-like growth factor (IGF)-II/IGF binding protein-2 complex stimulates bone formation and prevents loss of bone mineral density in a rat model of disuse osteoporosis. Growth Horm IGF Res $\underline{12}, 178-183$

D’Aquino R, Graziano A, Sampaolesi M, Laino G, Pirozzi G, De Rosa A, Papaccio G (2007): Human postnatal dental pulp cells co-differentiate into osteoblasts and endotheliocytes: a pivotal synergy leading to adult bone tissue formation. Cell Death Differ $\underline{14}, 1162-1171$

Da Silva M, Dombre C, Brionne A, Monget P, Chessé M, De Pauw M, Mills M, Combes-Soia L, Labas V, Guyot N et al. (2019): The Unique Features of Proteins Depicting the Chicken Amniotic Fluid. Mol Cell Proteomics $\underline{18}, 174-190$ 
Dalman MR, Deeter A, Nimishakavi G, Duan ZH (2012): Fold change and p-value cutoffs significantly alter microarray interpretations. BMC Bioinformatics $\underline{13}, 11$

De Buck M, Gouwy M, Wang JM, Van Snick J, Opdenakker G, Struyf S, Van Damme J (2016): Structure and Expression of Different Serum Amyloid A (SAA) Variants and their ConcentrationDependent Functions During Host Insults. Curr Med Chem 23, 1725-1755

De Buck M, Gouwy M, Berghmans N, Opdenakker G, Proost P, Struyf S, Van Damme J (2018): COOH-terminal SAA1 peptides fail to induce chemokines but synergize with CXCL8 and CCL3 to recruit leukocytes via FPR2. Blood 131, 439-449

Deutsch E (1992): Fetus in Germany: the Fetus Protection Law of 12.13.1990. J Int Bioethique $\underline{3}$, 85-93

Dittrich R, Beckmann MW, Würfel W (2015): Non-embryo-destructive Extraction of Pluripotent Embryonic Stem Cells: Implications for Regenerative Medicine and Reproductive Medicine. Geburtshilfe Frauenheilkd 포, 1239-1242

Doyonnas R, Kershaw DB, Duhme C, Merkens H, Chelliah S, Graf T, McNagny KM (2001): Anuria, omphalocele, and perinatal lethality in mice lacking the $\mathrm{CD} 34$-related protein podocalyxin. $\mathrm{J}$ Exp Med 194, 13-27

Echeverria C, Diaz A, Suarez B, Bevilacqua JA, Bonnemann C, Bertini E, Castiglioni C (2017): Keloids, Spontaneous or After Minor Skin Injury: Importance of Not Missing Bethlem Myopathy. Acta Derm Venereol 97, 297-298

Ellisen LW (2005): Growth control under stress: mTOR regulation through the REDD1-TSC pathway. Cell Cycle 4 , 1500-1502

Elmose C, Thomsen SF (2015): Twin Studies of Atopic Dermatitis: Interpretations and Applications in the Filaggrin Era. J Allergy (Cairo) 2015, 902359

Emons JAM, Gerth van Wijk R (2018): Food Allergy and Asthma: Is There a Link? Curr Treat Options Allergy $\underline{5}, 436-444$

Endicott J, Holden P, Fitzgerald J (2017): Authentication of collagen VI antibodies. BMC Res Notes $\underline{10}, 358$

Enomoto-Iwamoto M, Kitagaki J, Koyama E, Tamamura Y, Wu C, Kanatani N, Koike T, Okada H, Komori T, Yoneda T et al. (2002): The Wnt antagonist Frzb-1 regulates chondrocyte maturation and long bone development during limb skeletogenesis. Dev Biol 251, 142-156

Erlandsen H, Ames JE, Tamkenath A, Mamaeva O, Stidham K, Wilson ME, Perez-Pinera P, Deuel TF, Macdougall M (2012): Pleiotrophin expression during odontogenesis. J Histochem Cytochem $\underline{60}, 366-375$

Erreni M, Manfredi AA, Garlanda C, Mantovani A, Rovere-Querini P (2017): The long pentraxin PTX3: A prototypical sensor of tissue injury and a regulator of homeostasis. Immunol Rev $\underline{280}$, $112-125$ 
Eyckmans J, Luyten FP (2006): Species specificity of ectopic bone formation using periosteumderived mesenchymal progenitor cells. Tissue Eng 12, 2203-2213

Faltus T, Storz U (2016): Response to: Dittrich et al.: Non-Embryo-Destructive Extraction of Pluripotent Embryonic Stem Cells - Overlooked Legal Prohibitions, Professional Legal Consequences and Inconsistencies in Patent Law. Geburtshilfe Frauenheilkd 76, 1302-1307

Ferguson CA, Tucker AS, Christensen L, Lau AL, Matzuk MM, Sharpe PT (1998): Activin is an essential early mesenchymal signal in tooth development that is required for patterning of the murine dentition. Genes Dev 12, 2636-2649

Ferreira E, Porter RM, Wehling N, O'Sullivan RP, Liu F, Boskey A, Estok DM, Harris MB, Vrahas MS, Evans CH et al. (2013): Inflammatory cytokines induce a unique mineralizing phenotype in mesenchymal stem cells derived from human bone marrow. J Biol Chem $\underline{288}$, 29494-29505

Frasca F, Pandini G, Scalia P, Sciacca L, Mineo R, Costantino A, Goldfine ID, Belfiore A, Vigneri $R$ (1999): Insulin receptor isoform A, a newly recognized, high-affinity insulin-like growth factor II receptor in fetal and cancer cells. Mol Cell Biol $\underline{19}, 3278-3288$

Galotto M, Campanile G, Robino G, Cancedda FD, Bianco P, Cancedda R (1994): Hypertrophic chondrocytes undergo further differentiation to osteoblast-like cells and participate in the initial bone formation in developing chick embryo. J Bone Miner Res $\underline{9}, 1239-1249$

Gazzerro E, Pereira RC, Jorgetti V, Olson S, Economides AN, Canalis E (2005): Skeletal overexpression of gremlin impairs bone formation and causes osteopenia. Endocrinology 146, 655-665

Gerton GL, Hedrick JL (1986): The vitelline envelope to fertilization envelope conversion in eggs of Xenopus laevis. Dev Biol 116, 1-7

Gharibi B, Ghuman M, Hughes FJ (2016): DDIT4 regulates mesenchymal stem cell fate by mediating between HIF1 $\alpha$ and mTOR signalling. Sci Rep $\underline{6}, 36889$

Gronthos S, Graves SE, Ohta S, Simmons PJ (1994): The STRO-1+ fraction of adult human bone marrow contains the osteogenic precursors. Blood $\underline{84}, 4164-4173$

Gronthos S, Mankani M, Brahim J, Robey PG, Shi S (2000): Postnatal human dental pulp stem cells (DPSCs) in vitro and in vivo. Proc Natl Acad Sci U S A 97, 13625-13630

Gronthos S, Franklin DM, Leddy HA, Robey PG, Storms RW, Gimble JM (2001): Surface protein characterization of human adipose tissue-derived stromal cells. J Cell Physiol 189, 54-63

Gronthos S, Brahim J, Li W, Fisher LW, Cherman N, Boyde A, DenBesten P, Robey PG, Shi S (2002): Stem cell properties of human dental pulp stem cells. J Dent Res $\underline{81}, 531-535$

Gronthos S, Zannettino AC, Hay SJ, Shi S, Graves SE, Kortesidis A, Simmons PJ (2003): Molecular and cellular characterisation of highly purified stromal stem cells derived from human bone marrow. J Cell Sci 116, 1827-1835

Gubbiotti MA, Vallet SD, Ricard-Blum S, Iozzo RV (2016): Decorin interacting network: A comprehensive analysis of decorin-binding partners and their versatile functions. Matrix Biol 55, 7-21 
Gümmer AM: Proliferations- und Differenzierungsverhalten humaner Zahnkeimzellen der Pulpa. Zahnmed. Diss. Göttingen 2011

Guyot N, Labas V, Harichaux G, Chessé M, Poirier JC, Nys Y, Réhault-Godbert S (2016): Proteomic analysis of egg white heparin-binding proteins: towards the identification of natural antibacterial molecules. Sci Rep $\underline{6}, 27974$

Halper J, Kjaer M (2014): Basic components of connective tissues and extracellular matrix: elastin, fibrillin, fibulins, fibrinogen, fibronectin, laminin, tenascins and thrombospondins. Adv Exp Med Biol $\underline{802}, 31-47$

Hansen NU, Willumsen N, Sand JM, Larsen L, Karsdal MA, Leeming DJ (2016): Type VIII collagen is elevated in diseases associated with angiogenesis and vascular remodeling. Clin Biochem $\underline{49}$, 903-908

Hepp H, Haller U, Winter R (2003): Science and law in assisted reproductive medicine - two sides of the same token. Gynakol Geburtshilfliche Rundsch $\underline{43}, 1-5$

Hildebrand A, Romarís M, Rasmussen LM, Heinegard D, Twardzik DR, Border WA, Ruoslahti E (1994): Interaction of the small interstitial proteoglycans biglycan, decorin and fibromodulin with transforming growth factor beta. Biochem $\mathrm{J} \underline{302}, 527-534$

Hoang B, Moos M Jr, Vukicevic S, Luyten FP (1996): Primary structure and tissue distribution of FRZB, a novel protein related to Drosophila frizzled, suggest a role in skeletal morphogenesis. J Biol Chem 271, 26131-26137

Hong S, Kim MM (2018): IGFBP-3 plays an important role in senescence as an aging marker. Environ Toxicol Pharmacol 59, 138-145

Hu YY, Liu JC, Xing AY, You Y, Wang XD (2012): REDD1 expression in placenta during human gestation. Reprod Sci 19, 995-1000

Huang DW, Sherman BT, Tan Q, Kir J, Liu D, Bryant D, Guo Y, Stephens R, Baseler MW, Lane HC et al. (2007): DAVID Bioinformatics Resources: expanded annotation database and novel algorithms to better extract biology from large gene lists. Nucleic Acids Res 35, W169-75

Huang J, Hu W, Lin X, Wang X, Jin K (2015): FRZB up-regulated in hepatocellular carcinoma bone metastasis. Int J Clin Exp Pathol $\underline{8}, 13353-13359$

Ikeda E, Morita R, Nakao K, Ishida K, Nakamura T, Takano-Yamamoto T, Ogawa M, Mizuno M, Kasugai S, Tsuji T (2009): Fully functional bioengineered tooth replacement as an organ replacement therapy. Proc Natl Acad Sci U S A 106, 13475-13480

Inada M, Takita M, Yokoyama S, Watanabe K, Tominari T, Matsumoto C, Hirata M, Maru Y, Maruyama T, Sugimoto Y et al. (2015): Direct Melanoma Cell Contact Induces Stromal Cell Autocrine Prostaglandin E2-EP4 Receptor Signaling That Drives Tumor Growth, Angiogenesis, and Metastasis. J Biol Chem 290, 29781-29793

Irizarry RA, Hobbs B, Collin F, Beazer-Barclay YD, Antonellis KJ, Scherf U, Speed TP (2003): Exploration, normalization, and summaries of high density oligonucleotide array probe level data. Biostatistics 4, 249-264 
Järveläinen H, Sainio A, Wight TN (2015): Pivotal role for decorin in angiogenesis. Matrix Biol $\underline{43}, 15-26$

Jiang Y, Jahagirdar BN, Reinhardt RL, Schwartz RE, Keene CD, Ortiz-Gonzalez XR, Reyes M, Lenvik T, Lund T, Blackstad M et al. (2002): Pluripotency of mesenchymal stem cells derived from adult marrow. Nature $418,41-49$

Justus CR, Dong L, Yang LV (2013): Acidic tumor microenvironment and pH-sensing G proteincoupled receptors. Front Physiol 4, 354

Kang HG, Lee M, Lee KB, Hughes M, Kwon BS, Lee S, McNagny KM, Ahn YH, Ko JM, Ha IS et al. (2017): Loss of podocalyxin causes a novel syndromic type of congenital nephrotic syndrome. Exp Mol Med 49, e414

Kato T (2007): Molecular genetics of bipolar disorder and depression. Psychiatry Clin Neurosci $\underline{61}$, 3-19

Kemp KC, Hows J, Donaldson C (2005): Bone marrow-derived mesenchymal stem cells. Leuk Lymphoma $\underline{46}, 1531-1544$

Kezic S, Jakasa I (2016): Filaggrin and Skin Barrier Function. Curr Probl Dermatol 49, 1-7

Kido S, Doi Y, Kim F, Morishita E, Narita H, Kanaya S, Ohkubo T, Nishikawa K, Yao T, Ooi T (1995): Characterization of vitelline membrane outer layer protein I, VMO-I: amino acid sequence and structural stability. J Biochem $\underline{117}, 1183-1191$

Kim JR, Lee SR, Chung HJ, Kim S, Baek SH, Kim JH, Kim YS (2003): Identification of amyloid beta-peptide responsive genes by cDNA microarray technology: involvement of RTP801 in amyloid beta-peptide toxicity. Exp Mol Med 35, 403-411

Kimmelman AC (2011): The dynamic nature of autophagy in cancer. Genes Dev 25, 1999-2010

Kurosaki M, Bolis M, Fratelli M, Barzago MM, Pattini L, Perretta G, Terao M, Garattini E (2013): Structure and evolution of vertebrate aldehyde oxidases: from gene duplication to gene suppression. Cell Mol Life Sci $\underline{70}$, 1807-1830

Lee NH, Saeed AI (2007): Microarrays: an overview. Methods Mol Biol 353, 265-300

Lei M, Li K, Li B, Gao LN, Chen FM, Jin Y (2014): Mesenchymal stem cell characteristics of dental pulp and periodontal ligament stem cells after in vivo transplantation. Biomaterials $\underline{35}$, 6332-6343

Lodewyckx L, Cailotto F, Thysen S, Luyten FP, Lories RJ (2012): Tight regulation of winglesstype signaling in the articular cartilage - subchondral bone biomechanical unit: transcriptomics in Frzb-knockout mice. Arthritis Res Ther 14, R16

Lowell CA, Stearman RS, Morrow JF (1986): Transcriptional regulation of serum amyloid A gene expression. J Biol Chem 261, 8453-8461 
Lysiak JJ, Hunt J, Pringle GA, Lala PK (1995): Localization of transforming growth factor beta and its natural inhibitor decorin in the human placenta and decidua throughout gestation. Placenta $\underline{16}, 221-231$

Maeshima Y, Colorado PC, Torre A, Holthaus KA, Grunkemeyer JA, Ericksen MB, Hopfer H, Xiao Y, Stillman IE, Kalluri R (2000): Distinct antitumor properties of a type IV collagen domain derived from basement membrane. J Biol Chem 275, 21340-21348

Mahmoud LH, el-Alfy NM (2003): Electron miscroscopy and histochemical studies on four Egyptian helminthes eggs of medical importance. J Egypt Soc Parasitol 33, 229-243

Malagelada C, Lopez-Toledano MA, Willett RT, Jin ZH, Shelanski ML, Greene LA (2011): RTP801/REDD1 regulates the timing of cortical neurogenesis and neuron migration. J Neurosci 31 , 3186-3196

Marino G, Niso-Santano M, Baehrecke EH, Kroemer G (2014a): Self-consumption: the interplay of autophagy and apoptosis. Nat Rev Mol Cell Biol 15, 81-94

Marino G, Pietrocola F, Madeo F, Kroemer G (2014b): Caloric restriction mimetics: natural/physiological pharmacological autophagy inducers. Autophagy $\underline{10}, 1879-1882$

Marneros AG, Olsen BR (2005): Physiological role of collagen XVIII and endostatin. FASEB J 19 , $716-728$

McKinnon CM, Mellor H (2017): The tumor suppressor RhoBTB1 controls Golgi integrity and breast cancer cell invasion through METTL7B. BMC Cancer 17, 145

Miller LD, Long PM, Wong L, Mukherjee S, McShane LM, Liu ET (2002): Optimal gene expression analysis by microarrays. Cancer Cell $\underline{2}, 353-361$

Mimeault M, Batra SK (2011): Frequent Gene Products and Molecular Pathways Altered in Prostate Cancer- and Metastasis-Initiating Cells and Their Progenies and Novel Promising Multitargeted Therapies. Mol Med 17, 949-964

Mitsiadis TA, Salmivirta M, Muramatsu T, Muramatsu H, Rauvala H, Lehtonen E, Jalkanen M, Thesleff I (1995): Expression of the heparin-binding cytokines, midkine (MK) and HB-GAM (pleiotrophin) is associated with epithelial-mesenchymal interactions during fetal development and organogenesis. Development 121, 37-51

Miura M, Gronthos S, Zhao M, Lu B, Fisher LW, Robey PG, Shi S (2003): SHED: stem cells from human exfoliated deciduous teeth. Proc Natl Acad Sci U S A $\underline{100}$, 5807-5812

Miura M, Chen XD, Allen MR, Bi Y, Gronthos S, Seo BM, Lakhani S, Flavell RA, Feng XH, Robey PG et al. (2004): A crucial role of caspase-3 in osteogenic differentiation of bone marrow stromal stem cells. J Clin Invest $\underline{114}, 1704-1713$

Miyachi K, Yamada T, Kawagishi-Hotta M, Hasebe Y, Date Y, Hasegawa S, Arima M, Iwata Y, Kobayashi T, Numata $\mathrm{S}$ et al. (2018): Extracellular proteoglycan decorin maintains human hair follicle stem cells. J Dermatol $\underline{45}, 1403-1410$ 
Mödder UI, Roforth MM, Nicks KM, Peterson JM, McCready LK, Monroe DG, Khosla S (2012): Characterization of mesenchymal progenitor cells isolated from human bone marrow by negative selection. Bone 50, 804-810

Morsczeck C, Götz W, Schierholz J, Zeilhofer F, Kühn U, Möhl C, Sippel C, Hoffmann KH (2005): Isolation of precursor cells (PCs) from human dental follicle of wisdom teeth. Matrix Biol $\underline{24}, 155-165$

Musina RA, Bekchanova ES, Belyavskii AV, Sukhikh GT (2006): Differentiation potential of mesenchymal stem cells of different origin. Bull Exp Biol Med 141, 147-151

Nagatomo KJ, Tompkins KA, Fong H, Zhang H, Foster BL, Chu EY, Murakami A, Stadmeyer L, Canalis E, Somerman MJ (2008): Transgenic overexpression of gremlin results in developmental defects in enamel and dentin in mice. Connect Tissue Res 49, 391-400

Nagatsu T (2004): Progress in monoamine oxidase (MAO) research in relation to genetic engineering. Neurotoxicology $\underline{25}, 11-20$

Nakajima J, Okamoto N, Tohyama J, Kato M, Arai H, Funahashi O, Tsurusaki Y, Nakashima M, Kawashima H, Saitsu H et al. (2015): De novo EEF1A2 mutations in patients with characteristic facial features, intellectual disability, autistic behaviors and epilepsy. Clin Genet $\underline{87}$, 356-361

Neill T, Torres A, Buraschi S, Iozzo RV (2013): Decorin has an appetite for endothelial cell autophagy. Autophagy $\underline{9}, 1626-1628$

Newbery HJ, Loh DH, O'Donoghue JE, Tomlinson VAL, Chau YY, Boyd JA, Bergmann JH, Brownstein D, Abbott CM (2007): Translation elongation factor eEF1A2 is essential for postweaning survival in mice. J Biol Chem 282, 28951-28959

Oellerich DC: Analyse der differentiellen Genexpression von humanen Stro1-positiven Zellen aus pulpalem Zahnkeimgewebe und Beckenkammspongiosa. Zahnmed. Diss. Göttingen 2016

Onyia JE, Helvering LM, Gelbert L, Wei T, Huang S, Chen P, Dow ER, Maran A, Zhang M, Lotinun $S$ et al. (2005): Molecular profile of catabolic versus anabolic treatment regimens of parathyroid hormone (PTH) in rat bone: an analysis by DNA microarray. J Cell Biochem 95, 403-418

Opitz L, Salinas-Riester G, Grade M, Jung K, Jo P, Emons G, Ghadimi BM, Beissbarth T, Gaedcke J (2010): Impact of RNA degradation on gene expression profiling. BMC Med Genomics $\underline{3}, 36$

Oshima M, Mizuno M, Imamura A, Ogawa M, Yasukawa M, Yamazaki H, Morita R, Ikeda E, Nakao K, Takano-Yamamoto T et al. (2011): Functional tooth regeneration using a bioengineered tooth unit as a mature organ replacement regenerative therapy. PLoS One $\underline{6}$, e21531

Parry DA, Smith CE, El-Sayed W, Poulter JA, Shore RC, Logan CV, Mogi C, Sato K, Okajima F, Harada A et al. (2016): Mutations in the pH-Sensing G-protein-Coupled Receptor GPR68 Cause Amelogenesis Imperfecta. Am J Hum Genet 99, 984-990

Pittenger MF, Mackay AM, Beck SC, Jaiswal RK, Douglas R, Mosca JD, Moorman MA, Simonetti DW, Craig S, Marshak DR (1999): Multilineage potential of adult human mesenchymal stem cells. Science 284, 143-147 
Pozzi A, Yurchenco PD, Iozzo RV (2017): The nature and biology of basement membranes. Matrix Biol 57-58, 1-11

Presta M, Camozzi M, Salvatori G, Rusnati M (2007): Role of the soluble pattern recognition receptor PTX3 in vascular biology. J Cell Mol Med 11, 723-738

Proksch E (2018): pH in nature, humans and skin. J Dermatol 45, 1044-1052

Przygrodzka E, Kaczmarek MM, Kaczynski P, Ziecik AJ (2016): Steroid hormones, prostanoids, and angiogenic systems during rescue of the corpus luteum in pigs. Reproduction 151, 135-147

Pufe T, Petersen WJ, Miosge N, Goldring MB, Mentlein R, Varoga DJ, Tillmann BN (2004): Endostatin/collagen XVIII - an inhibitor of angiogenesis - is expressed in cartilage and fibrocartilage. Matrix Biol 23, 267-276

Ravaglia MA, Maggese MC (2003): Ovarian follicle ultrastructure in the teleost Synbranchus marmoratus (Bloch, 1795), with special reference to the vitelline envelope development. Tissue Cell $\underline{35}, 9-17$

Riederer P, Konradi C, Schay V, Kienzl E, Birkmayer G, Danielczyk W, Sofic E, Youdim MB (1987): Localization of MAO-A and MAO-B in human brain: a step in understanding the therapeutic action of L-deprenyl. Adv Neurol 45, 111-118

Rodríguez D, Morrison CJ, Overall CM (2010): Matrix metalloproteinases: what do they not do? New substrates and biological roles identified by murine models and proteomics. Biochim Biophys Acta $\underline{1803}, 39-54$

Rolf HJ, Kierdorf U, Kierdorf H, Schulz J, Seymour N, Schliephake H, Napp J, Niebert S, Wölfel H, Wiese KG (2008): Localization and characterization of STRO-1 cells in the deer pedicle and regenerating antler. PLoS One $\underline{3}$, e2064

Rolf HJ, Niebert S, Niebert M, Gaus L, Schliephake H, Wiese KG (2012): Intercellular transport of Oct4 in mammalian cells: a basic principle to expand a stem cell niche? PLoS One $\underline{7}$, e32287

Sarkar L, Sharpe PT (1999): Expression of Wnt signalling pathway genes during tooth development. Mech Dev $\underline{85}, 197-200$

Schena M, Shalon D, Davis RW, Brown PO (1995): Quantitative monitoring of gene expression patterns with a complementary DNA microarray. Science 270, 467-470

Schiebler TH, Korf HW: Anatomie: Histologie, Entwicklungsgeschichte, makroskopische und mikroskopische Anatomie, Topographie. 10. Auflage; Steinkopff-Verlag, Darmstadt 2007

Schöne-Seifert B (2009): Induzierte pluripotente Stammzellen: Ruhe an der Ethikfront? Ethik Med $\underline{21}, 271-273$

Schönherr E, Broszat M, Brandan E, Bruckner P, Kresse H (1998): Decorin core protein fragment Leu155-Val260 interacts with TGF-beta but does not compete for decorin binding to type I collagen. Arch Biochem Biophys 355, 241-248 
Seo BM, Miura M, Gronthos S, Bartold PM, Batouli S, Brahim J, Young M, Robey PG, Wang CY, Shi S (2004): Investigation of multipotent postnatal stem cells from human periodontal ligament. Lancet 364, 149-155

Seo BM, Sonoyama W, Yamaza T, Coppe C, Kikuiri T, Akiyama K, Lee JS, Shi S (2008): SHED repair critical-size calvarial defects in mice. Oral Dis $14,428-434$

Sertié AL, Sossi V, Camargo AA, Zatz M, Brahe C, Passos-Bueno MR (2000): Collagen XVIII, containing an endogenous inhibitor of angiogenesis and tumor growth, plays a critical role in the maintenance of retinal structure and in neural tube closure (Knobloch syndrome). Hum Mol Genet $\underline{9}, 2051-2058$

Shamsi FA, Chen Z, Liang J, Li K, Al-Rajhi AA, Chaudhry IA, Li M, Wu K (2011): Analysis and comparison of proteomic profiles of tear fluid from human, cow, sheep, and camel eyes. Invest Ophthalmol Vis Sci $\underline{52}, 9156-9165$

Shi S, Gronthos S (2003): Perivascular niche of postnatal mesenchymal stem cells in human bone marrow and dental pulp. J Bone Miner Res $\underline{18}$, 696-704

Shi S, Robey PG, Gronthos S (2001): Comparison of human dental pulp and bone marrow stromal stem cells by cDNA microarray analysis. Bone $\underline{29}, 532-539$

Shih JC, Chen K, Ridd MJ (1999): Role of MAO A and B in neurotransmitter metabolism and behavior. Pol J Pharmacol 51, 25-29

Shinn SE, Liyanage R, Lay JO Jr, Proctor A (2016): Isolation and Characterization of Chicken Yolk Vitelline Membrane Lipids Using Eggs Enriched With Conjugated Linoleic Acid. Lipids $\underline{51}$, 769-779

Simic P, Culej JB, Orlic I, Grgurevic L, Draca N, Spaventi R, Vukicevic S (2006): Systemically administered bone morphogenetic protein- 6 restores bone in aged ovariectomized rats by increasing bone formation and suppressing bone resorption. J Biol Chem $\underline{281}$, 25509-25521

Siminovitch L, McCulloch EA, Till JE (1963): The Distribution of Colony-forming Cells among Spleen colonies. J Cell Comp Physiol 62, 327-336

Simmons PJ, Torok-Storb B (1991): Identification of stromal cell precursors in human bone marrow by a novel monoclonal antibody, STRO-1. Blood $\underline{78}, 55-62$

Smyth GK (2004): Linear models and empirical bayes methods for assessing differential expression in microarray experiments. Stat Appl Genet Mol Biol $\underline{3}, 3$

Sneddon JB, Zhen HH, Montgomery K, van de Rijn M, Tward AD, West R, Gladstone H, Chang HY, Morganroth GS, Oro AE et al. (2006): Bone morphogenetic protein antagonist gremlin 1 is widely expressed by cancer-associated stromal cells and can promote tumor cell proliferation. Proc Natl Acad Sci U S A 103 , 14842-14847

Sonoyama W, Liu Y, Yamaza T, Tuan RS, Wang S, Shi S, Huang GT (2008): Characterization of the apical papilla and its residing stem cells from human immature permanent teeth: a pilot study. $\mathrm{J}$ Endod $\underline{34}, 166-171$ 
Stewart K, Monk P, Walsh S, Jefferiss CM, Letchford J, Beresford JN (2003): STRO-1, HOP-26 (CD63), CD49a and SB-10 (CD166) as markers of primitive human marrow stromal cells and their more differentiated progeny: a comparative investigation in vitro. Cell Tissue Res 313, 281-290

Stidham K, Macdougall M, Perez-Pinera P, Deuel TF, Erlandsen H (2009): Critical Role for Pleiotrophin during Tooth Development. J Dent Res $\underline{88}, 3089$

Stoeckert, CJ Jr, Causton HC, Ball CA (2002): Microarray databases: standards and ontologies. Nat Genet $\underline{32}$, 469-473

Su Q, Weindl G (2018): Glucocorticoids and Toll-like receptor 2 cooperatively induce acute-phase serum amyloid A. Pharmacol Res $\underline{128}, 145-152$

Takahashi K, Yamanaka S (2006): Induction of pluripotent stem cells from mouse embryonic and adult fibroblast cultures by defined factors. Cell 126, 663-676

Takeda T, Tezuka Y, Horiuchi M, Hosono K, Iida K, Hatakeyama D, Miyaki S, Kunisada T, Shibata T, Tezuka K (2008): Characterization of dental pulp stem cells of human tooth germs. J Dent Res $\underline{87}, 676-681$

Taylor CF, Field D, Sansone SA, Aerts J, Apweiler R, Ashburner M, Ball CA, Binz PA, Bogue M, Booth $\mathrm{T}$ et al. (2008): Promoting coherent minimum reporting guidelines for biological and biomedical investigations: the MIBBI project. Nat Biotechnol 26, 889-896

Thierry L, Geiser AS, Hansen A, Tesche F, Herken R, Miosge N (2004): Collagen types XII and XIV are present in basement membrane zones during human embryonic development. J Mol Histol $\underline{35}, 803-810$

Thomson M, Liu SJ, Zou LN, Smith Z, Meissner A, Ramanathan S (2011): Pluripotency factors in embryonic stem cells regulate differentiation into germ layers. Cell 145, 875-889

Tomioka Y, Jiménez E, Salagre E, Arias B, Mitjans M, Ruiz V, Sáiz P, García-Portilla MP, de la Fuente L, Gomes-da-Costa SP et al. (2018): Association between genetic variation in the myoinositol monophosphatase 2 (IMPA2) gene and age at onset of bipolar disorder. J Affect Disord $232,229-236$

Tuli R, Tuli S, Nandi S, Wang ML, Alexander PG, Haleem-Smith H, Hozack WJ, Manner PA, Danielson KG, Tuan RS (2003): Characterization of multipotential mesenchymal progenitor cells derived from human trabecular bone. Stem Cells $\underline{21}, 681-693$

Tusher VG, Tibshirani R, Chu G (2001): Significance analysis of microarrays applied to the ionizing radiation response. Proc Natl Acad Sci U S A 98, 5116-5121

Van Doren SR (2015): Matrix metalloproteinase interactions with collagen and elastin. Matrix Biol 44-46, 224-231

Wadhwa S, Bi Y, Ortiz AT, Embree MC, Kilts T, Iozzo R, Opperman LA, Young MF (2007): Impaired posterior frontal sutural fusion in the biglycan/decorin double deficient mice. Bone $\underline{40}, 861-$ 866 
Wang W, Wu W, Desai T, Ward DC, Kaufman SJ (1995): Localization of the alpha 7 integrin gene (ITGA7) on human chromosome 12q13: clustering of integrin and Hox genes implies parallel evolution of these gene families. Genomics $26,568-570$

Wang XP, Suomalainen M, Jorgez CJ, Matzuk MM, Wankell M, Werner S, Thesleff I (2004): Modulation of activin/bone morphogenetic protein signaling by follistatin is required for the morphogenesis of mouse molar teeth. Dev Dyn 231, 98-108

Weigert J, Neumeier M, Bauer S, Mages W, Schnitzbauer AA, Obed A, Gröschl B, Hartmann A, Schäffler A, Aslanidis C et al. (2008): Small-interference RNA-mediated knock-down of aldehyde oxidase 1 in 3T3-L1 cells impairs adipogenesis and adiponectin release. FEBS Lett $\underline{582}$, 29652972

Weiß KT, Fante M, Köhl G, Schreml J, Haubner F, Kreutz M, Haverkampf S, Berneburg M, Schreml S (2017): Proton-sensing G protein-coupled receptors as regulators of cell proliferation and migration during tumor growth and wound healing. Exp Dermatol 26, 127-132

Whibley A, Urquhart J, Dore J, Willatt L, Parkin G, Gaunt L, Black G, Donnai D, Raymond FL (2010): Deletion of MAOA and MAOB in a male patient causes severe developmental delay, intermittent hypotonia and stereotypical hand movements. Eur J Hum Genet 18, 1095-1099

Wiley SZ, Sriram K, Salmerón C, Insel PA (2019): GPR68: An Emerging Drug Target in Cancer. Int J Mol Sci $\underline{20}, 559$

Worst TS, Waldbillig F, Abdelhadi A, Weis CA, Gottschalt M, Steidler A, von Hardenberg J, Michel MS, Erben P (2017): The EEF1A2 gene expression as risk predictor in localized prostate cancer. BMC Urol $\underline{17}, 86$

Yamada Y, Ando F, Shimokata H (2008): Association of genetic variants of MAOA and SH2B1 with bone mineral density in community-dwelling Japanese women. Mol Med Rep 1, 269-274

Yao S, He H, Gutierrez DL, Rad MR, Liu D, Li C, Flanagan M, Wise GE (2013): Expression of bone morphogenetic protein- 6 in dental follicle stem cells and its effect on osteogenic differentiation. Cells Tissues Organs $\underline{198}, 438-447$

Zhou S, Shen Y, Zheng M, Wang L, Che R, Hu W, Li P (2017): DNA methylation of METTL7A gene body regulates its transcriptional level in thyroid cancer. Oncotarget $\underline{8}, 34652-34660$

Zoncu R, Efeyan A, Sabatini DM (2011): mTOR: from growth signal integration to cancer, diabetes and ageing. Nat Rev Mol Cell Biol 12, 21-35

Zorn AM (1997): Cell-cell signalling: frog frizbees. Curr Biol 7, R501-504 


\section{Danksagung}

Allen voran möchte ich mich besonders bei meinem Doktorvater Herrn Prof. Dr. med. Dr. med. dent. K. G. Wiese für die freundliche Überlassung des Themas und die hervorragende Betreuung dieser Dissertation bedanken. Mein Dank gilt ferner Herrn Dipl.-Biol. Dr. rer. nat. Hans J. Rolf und Frau Dr. rer. nat. Sabine Niebert für die Durchführung der Zellkulturexperimente sowie Frau Dr. rer. nat. G. Salinas-Riester und Herrn Dr. rer. nat. T. Linger des Transkriptomanalyselabors der Universitätsmedizin Göttingen. Des Weiteren möchte ich dem gesamten Laborteam der Abteilung für Mund-, Kiefer- und Gesichtschirurgie unter der Leitung von Prof. Dr. med. Dr. med. dent. H. Schliephake meinen herzlichen Dank für die tatkräftige Unterstützung aussprechen, namentlich Frau C. Schäfer für die Unterstützung bei der Anfertigung der histologischen Präparate. Abschließend danke ich der Georg-August-Universität Göttingen für die Bereitstellung und Nutzungsmöglichkeit der räumlichen und technischen Einrichtungen. 